\title{
BIOREDUCTIVE METABOLISM OF SMALL MOLECULE NITROAROMATICS AND N-OXIDES IN HYPOXIA
}

\author{
A Dissertation \\ Presented to \\ The Faculty of the Graduate School \\ University of Missouri-Columbia \\ In partial Fulfillment \\ Of the Requirement of the Degree \\ Doctor of Philosophy \\ By \\ ANURUDDHA RAJAPAKSE \\ Prof. Kent S. Gates, Dissertation Supervisor \\ December 2012
}


(C) Copyright by Anuruddha Rajapakse 2012

All Rights Reserved 
The undersigned, appointed by the Dean of the Graduate School, have examined the dissertation entitled

BIOREDUCTIVE METABOLISM OF SMALL MOLECULE NITROAROMATICS AND N-OXIDES IN HYPOXIA

\section{Presented by Anuruddha Rajapakse}

A candidate for the degree of Doctor of Philosophy

and hereby certify that in their opinion it is worthy of acceptance

Professor Kent S. Gates

Professor Timothy Glass

Professor Paul S. Sharp

Professor Frank Schmidt 


\section{ACKNOWLEGEMENTS}

I would like to take this opportunity to thank everyone who helped me during my graduate studies at MU. First, I thank Professor Kent S. Gates, my advisor, for his dedicated guidance, encouragement and support. From the early stages and throughout my study, his availability to talk and motivation to instruct made my interest in bioorganic research grow immensely. Dr. Gates' outstanding knowledge on fundamentals of chemistry and his research experience have shaped my scientific career. I also want to thank my committee members Prof. Timothy Glass, Professor Paul Sharp and Professor Frank Schmidt for their comments and help along the way of my graduate study.

I would like to thank my parents, especially my mother for her support and my father for his dedicated guidance and I thank also my brothers.

In my graduate studies I have worked with many people from different backgrounds. Specially, I would like to thank all past and current Gates' group members for their intelligence and work ethics that we have shared and passed along. I am grateful to all students and staff members of the scientific community at MU that I have interacted with over the years.

Again I would like to restate my sincerer appreciation and gratitude for Dr. Gates. I would not have reached the current stage without his help. 


\section{TABLE OF CONTENT}

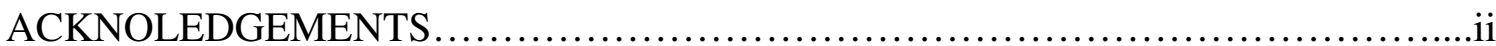

LIST OF SCHEMES....................................................................................vii

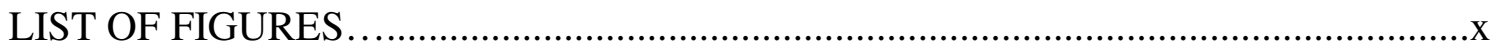

LIST OF TABLES ..........................................................................................

TABLE OF COMPOUND STRUCTURE AND NUMBER .........................xiv

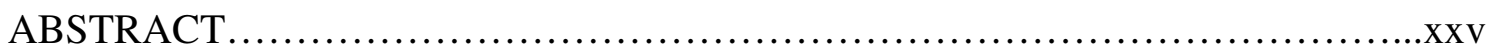

\section{Chapter 1:Nitroaromatics and $N$-oxide compounds as radiosensitizers,} oxygen sensors and cytotoxic agents in tumor therapy

1.1. Hypoxia.............................................................

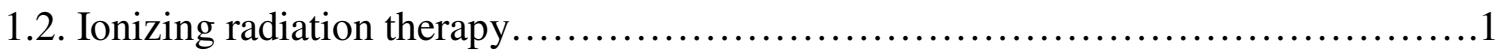

1.3. Radio sensitizing oxygen mimetic agents.................................

1.3.1. Nitro aromatic reduction in hypoxic cells................................6

1.3.2. Elimination of active agent through nitroaromatic reduction....................

1.4. $\mathrm{N}$-oxides............................................................ 11

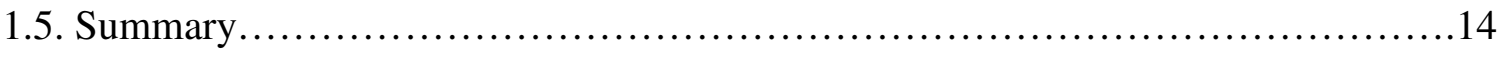

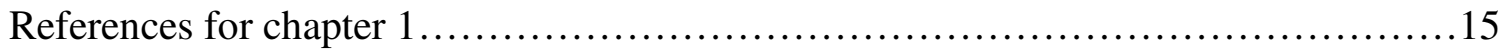




\section{Chapter 2: Hypoxia-selective, enzymatic conversion of 6-nitroquinoline into a fluorescent helicene: pyrido[3,2-f]quinolino[6,5-c]cinnoline 3- oxide}

2.1. Hypoxia as a parameter to be determined qualitatively and quantitatively..........23

2.2. Fluorescent probes to detect hypoxia.......................................... 24

2.3. Reduction of $\mathbf{4 2}$ to Obtain $\mathbf{4 3}$ under anaerobic conditions.......................24

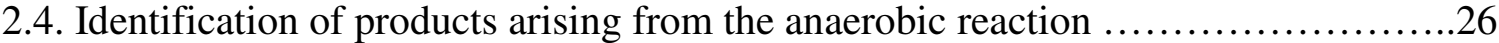

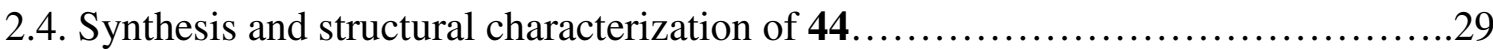

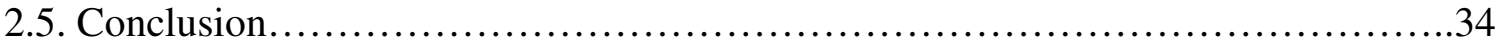

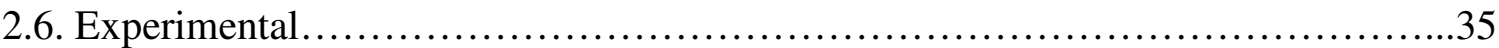

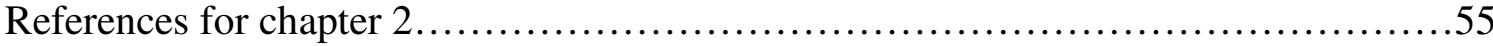

Chapter 3: Hypoxia-selective enzymatic conversion of 6-nitroquinoline to the fluorescent product, 6-aminoquinoline

3.1. Hypoxia is an attractive target to develop fluorescent probes 59

3.2. Fluorescent Probes to Detect Hypoxia... .59

3.3. LC/MS analysis of the reaction mixtures generated by hypoxic metabolism of $\mathbf{4 2}$ by xanthine/xanthine oxidase

3.4. LC/MS analysis of the reaction mixtures generated by aerobic metabolism of $\mathbf{4 2}$ by xanthine/xanthine oxidase.

3.5. Xanthine oxidase oxidizes aryl carbon, bonded to heteroatom of $\mathbf{4 2}$ to produce 6nitroquinolone $\mathbf{5 1}$ 
3.6. Hypoxia-selective conversion of hydroxylamine $\mathbf{5 0}$ to amine $\mathbf{4 3}$

3.7. Hypoxia-selective conversion of 6-nitroquinolone $\mathbf{5 1}$ to 6 -aminoquinolone $\mathbf{5 4} \ldots . .72$

3.8. Enzymatic conversion of $\mathbf{4 2}$ to 6-nitroquinolone $\mathbf{5 1}$ followed by hypoxia-selective

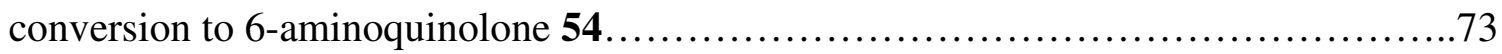

3.9. Conclusions...................................................... 74

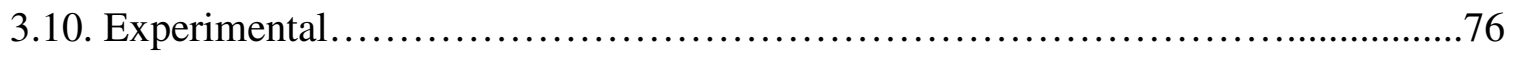

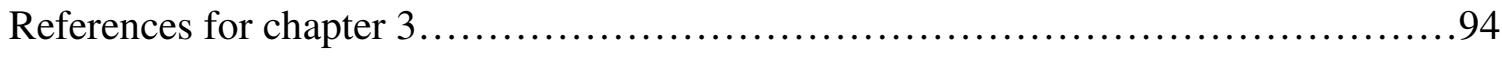

\section{Chapter 4: Mechanistic Aanalysis Related to the Oxidative DNA}

\section{Damage Caused by 1,2,4-Benzotraizine Dioxide}

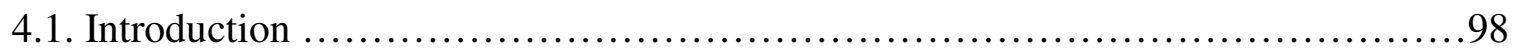

4.2. Mechanistic evidence for the oxidizing radical formation by TPZ ...............99

4.3. Hypothesis and design of experiments................................... 100

4.4. Examine the dehydration mechanism in relation to the release of oxidizing species

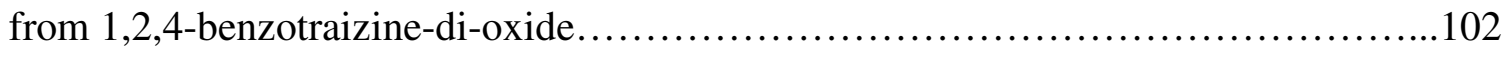

4.5. Chemical Synthesis of 1,2,4-benzotraizine 1,4-dioxide..........................103

4.6. DNA-damaging properties of TPZ and TPZ analogs....................... 103

4.6.1. TPZ analogs perform concentration dependent DNA damage.................103

4.6.2. DNA damage is decreased by radical scavengers.......................... 106

4.7. Examining chemical mechanism of bio-reductive metabolism of $\mathbf{5 5}$ and $\mathbf{6 0} \ldots \ldots . .111$

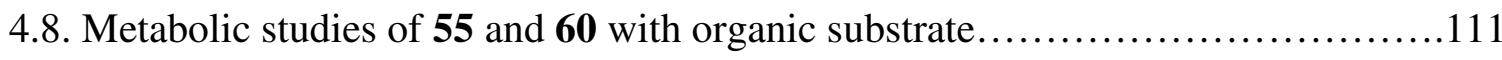

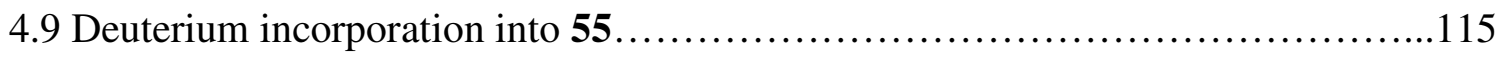

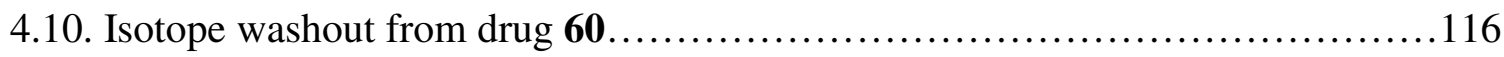


4.11. Isotope replacement analysis and dehydration mechanism

4.12. Conclusion...................................................... 118

4.13. Experimental.....................................................119

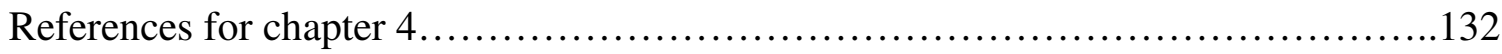

\section{Chapter 5: Synthesis of bioreductivly-activated nitroaromatic triggers}

5.1. Qualitative and quantitative determination of hypoxia....

5.2. Goal: Constructing suitable nitroaromatic fluorescent probes for hypoxia..........140

5.3. Synthesis of 5-nitrothienyl moeity, 2-(5-Nitrothien-2-yl) propan-2-ol 73.........141

5.4. Synthesis of 1-methyl-2-nitro-5-hydroxymethyl imidazole 79................142

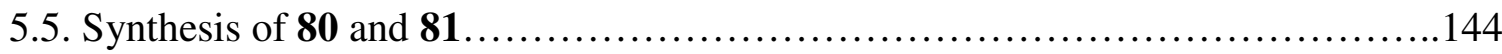

5.6. Synthesis of 3-acetylquinoline-1,2,4-benzotraizine 1,4-dioxide 84.............144

5.7. Experimental...................................................... 145

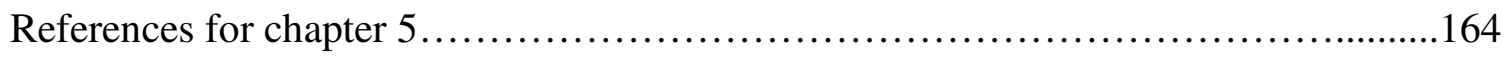

VITA.................................................................. 167 


\section{LIST OF SCHEMES}

\section{Chapter 1}

Scheme 1.1 Gamma radiolysis generates radical species.............................

Scheme 1.2 Hydroxyl radical abstract hydrogen from DNA...........................1

Scheme 1.3 DNA radical on C4' is fixed by oxygen.................................

Scheme 1.4 Formation of ribonolactone................................................

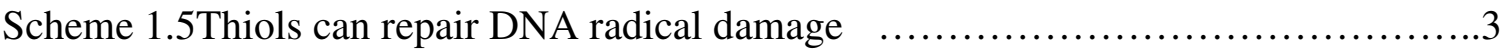

Scheme 1.6 Radiolysis induced nitro-reduction and DNA radical formation..............4

Scheme 1.7 Oxygen of nitro group is donated to DNA...............................

Scheme 1.8 Enzyme mediated-Nitro reduction undergo in hypoxia.....................5

Scheme 1.9 Hydroxylamine produces glyoxal-dialdehyde alkylator.....................5

Scheme 1.10 Nitroaromatics reduction in hypoxia produces the active drug .............7

Scheme 1.11 Nitrophenyl-mustard alkylating agents..............................

Scheme 1.12 Nitrophenyl-mustard alkylating agents.................................

Scheme 1.13 Hydroxylamine release the active drug................................

Scheme 1.14 Phosphoramidate forms azide upon elimination of leaving group...........9

Scheme 1.15 Cyclophophoramide (18) metabolism by $\mathrm{CYP}_{450} \ldots \ldots \ldots \ldots \ldots \ldots \ldots \ldots \ldots$

Scheme 1.16 Nitroquinoline phosphoramide prodrug release..........................10

Scheme 1.17 Nitrophenyl, nitrofuryl and nitrothienyl phosphoramide conjugates .......10

Scheme 1.18 Nitrothienyl and nitrophenyl dimethyl pro-drugs.......................11

Scheme $1.19 \mathrm{~N}$-oxide radiosentising agents..................................... 12

Scheme 1.20 Enzyme mediated reduction of $\mathbf{3 3}$ in hypoxia...........................12 
Scheme 1.21. Enzyme-mediated reduction of $\mathbf{3 3}$ in hypoxia abstract proton from DNA, followed by dehydration releases $\mathbf{3 5}$ as the major metabolite.........................13

Scheme 1.22. The enzyme-mediated reduction of $\mathbf{3 3}$ in hypoxia may produce hydroxyl radical or benzotrazine radicals $\mathbf{3 9}, \mathbf{4 0}$ or $\mathbf{4 1}$ as the oxidizing species................13

\section{Chapter 2}

Scheme 2.1. Enzymatic reduction profile of nitroaromatic compound.................24

Scheme 2.2. Hypoxic metabolism of $\mathbf{4 2}$ is expected to form fluorescent $\mathbf{4 3} \ldots \ldots \ldots \ldots .25$

Scheme 2.3. Metabolites formed by the reduction of $\mathbf{4 2}$ with NADPH/CYP450R......29

Scheme 2.4. Mechanism for the formation of $\mathbf{4 4}$ under anaerobic conditions.............34

\section{Chapter 3}

Scheme 3.1. Enzymatic reduction steps of a typical nitroaromatic compound...........60

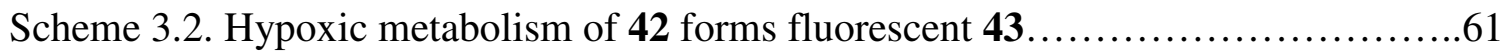

Scheme 3.3. CYP450R mediates conversion of $\mathbf{4 2}$ into fluorescent metabolites.........61

Scheme 3.4 Hypoxic metabolism of $\mathbf{4 2}$ by xanthine and xanthine oxidase.............64

Scheme 3.5 Enzymatic generation of $\mathbf{5 1}$ by xanthine and xanthine oxidase.............68

Scheme 3.6 Enzymatic generation of $\mathbf{4 3}$ by xanthine and xanthine oxidase............69

Scheme 3.7 Enzymatic generation of $\mathbf{5 4}$ from $\mathbf{5 1}$ by xanthine and xanthine oxidase is

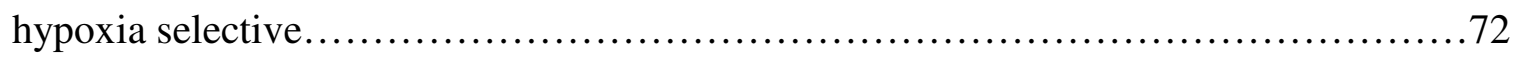

Scheme 3.8 Enzymatic generation of $\mathbf{5 1}$ from $\mathbf{4 2}$ and production of $\mathbf{5 4}$ from $\mathbf{5 1} \ldots . . . . .73$ 


\section{Chapter 4}

Scheme 4.1 Enzymatic reduction of $\mathbf{3 3}$ produces DNA damaging radicals and oxidative stress...................................................................... 99

Scheme 4.2 Different mechanisms are proposed to explain enzymatic metabolism of $\mathbf{3 3}$

Scheme 4.3 Enzymatic reduction of $\mathbf{5 5}$ under low oxygen concentrations forms major

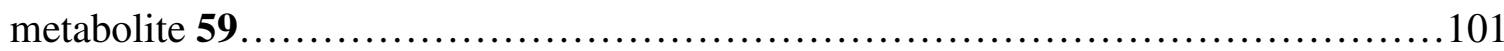

Scheme 4.4 Isotopic content of major metabolite of $\mathbf{5 5 / 6 0}$ determines mechanism......102

\section{Chapter 5}

Scheme 5.1. Bio-reducible moieties can be used as oxygen sensors.................139

Scheme 5.2. Nitro phenyl benzyl phosphoramadite prodrugs......................140

Scheme 5.3. 1,6-elimination of active drug species.............................140

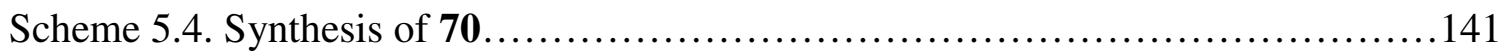

Scheme 5.5. Synthesis of 2-(5-nitrothien-2-yl) propan-2-ol $73 \ldots \ldots \ldots \ldots \ldots \ldots \ldots \ldots \ldots \ldots \ldots \ldots \ldots \ldots \ldots$

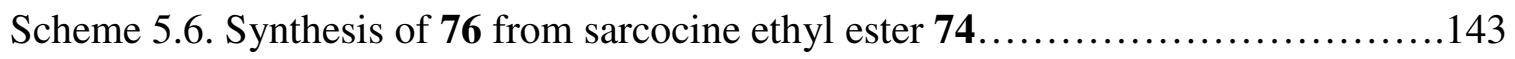

Scheme 5.7. Synthesis of 1-methyl-2-nitro-5hydroxymethyl imidazole 79...........143

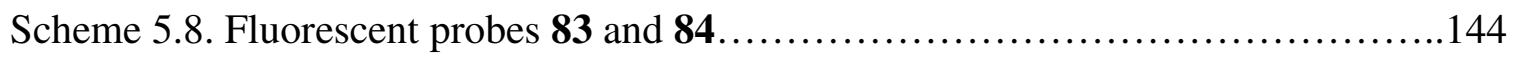

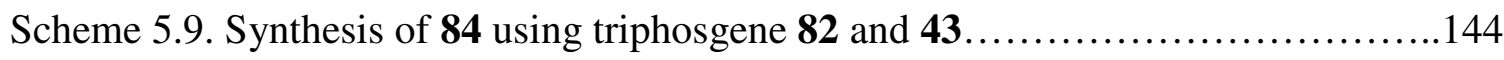




\section{LIST OF FIGURES}

\section{Chapter 2}

Figure 2.1. Enzymatic conversion of $\mathbf{4 2}$ into a fluorescent product under hypoxic

conditions. .26

Figure 2.2. LC/MS analysis of the reaction mixture generated by anaerobic metabolism of $42(0.8 \mathrm{mM})$ by cytochrome p450 reductase $(1.1 \mathrm{U} / \mathrm{mL})$ and NADPH $(6.4 \mathrm{mM})$. .28

Figure 2.3. In 44, the 4 and 4'-hydrogens (see numbering system in Scheme 2.2) are close in space.

Figure 2.4. Fluorescence spectrum of authentic $44(50 \mu \mathrm{M}, \lambda$ ex $307 \mathrm{~nm})$ in sodium phosphate buffer. .33

\section{Chapter 3}

Figure 3.1. Enzymatic conversions of $\mathbf{4 2}$ to a fluorescent product selectively under

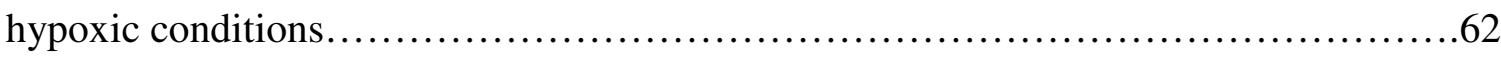

Figure 3.2. LC/MS analysis of the reaction mixture generated by anaerobic metabolism of $42(0.8 \mathrm{mM})$ .65

Figure 3.3. LC/MS analysis of authentic

compounds .66

Figure 3.4. LC/MS analysis of the reaction mixture generated by aerobic metabolism of $42(0.8 \mathrm{mM})$ .67

Figure 3.5. ORTEP diagram of $\mathbf{5 1}$ 68 
Figure 3.6. Enzymatic conversion of $\mathbf{5 0}$ into a fluorescent $\mathbf{4 3}$ under hypoxic conditions. 70

Figure 3.7. LC/MS analysis of the reaction mixture generated by anaerobic metabolism of $50(0.8 \mathrm{mM})$

Figure 3.8 Enzymatic conversions of $\mathbf{5 1}$ to $\mathbf{5 4}$ under hypoxic conditions. .72

Figure 3.9 Enzymatic conversion of $\mathbf{4 2}$ to $\mathbf{5 1}$ and reduction to $\mathbf{5 4}$ in hypoxia. .74

Figure 3.10 Fluorescence spectra of control reactions .77

\section{Chapter 4}

Figure 4.1. Cleavage of supercoiled plasmid DNA by $33(50-250 \mu \mathrm{M})$ in the presence of NADPH:cytochrome $\mathrm{P} 450$ reductase as an activating system 104

Figure 4.2. Cleavage of supercoiled plasmid DNA by $55(50-250 \mu \mathrm{M})$ in the presence of NADPH:cytochrome $\mathrm{P} 450$ reductase as an activating system

Figure 4.3. Cleavage of supercoiled plasmid DNA by $60(50-250 \mu \mathrm{M})$ in the presence of NADPH:cytochrome $\mathrm{P} 450$ reductase as an activating system 105

Figure 4.4. Comparison of DNA cleavage by reductively activated 33, 55 and $\mathbf{6 0}$ under anaerobic conditions 106

Figure 4.5. Cleavage of supercoiled plasmid DNA by $33(25 \mu \mathrm{M})$ in the presence of NADPH:cytochrome P450 reductase as an activating system is reduced by radical scavengers 
Figure 4.6. Cleavage of supercoiled plasmid DNA by $55(50 \mu \mathrm{M})$ in the presence of NADPH:cytochrome P450 reductase as an activating system is reduced by radical scavengers

Figure 4.7. Cleavage of supercoiled plasmid DNA by $\mathbf{6 0}(50 \mu \mathrm{M})$ in the presence of NADPH:cytochrome P450 reductase as an activating system is reduced by radical scavengers

Figure 4.8. Comparison of DNA cleavage by reductively activated $\mathbf{3 3}, \mathbf{5 5}$ or $\mathbf{6 0}$ under anaerobic conditions and DNA cleavage is reduced by radical scavengers

Figure 4.9. LC/MS analysis of anaerobic metabolism of $\mathbf{5 5}$ and $\mathbf{6 0}(0.5 \mathrm{mM})$ by

cytochrome $\mathrm{p} 450$ reductase $(0.4 \mathrm{U} / \mathrm{mL}) / \mathrm{NADPH}(0.5 \mathrm{mM})$ 113

Figure 4.10. LC/MS analysis of authentic 60, 63, 55 and 59

Figure 4.11. HRMS of the major metabolite 1-N-oxide $\mathbf{5 9}$ arising from metabolism of $\mathbf{6 0}$ under reductively activated conditions in hypoxia

Figure 4.12. HRMS of the major metabolite 1-N-oxide $\mathbf{6 3}$ arising from metabolism of $\mathbf{6 0}$ under reductively activated conditions in hypoxia 


\section{LIST OF TABLES}

\section{Chapter 2}

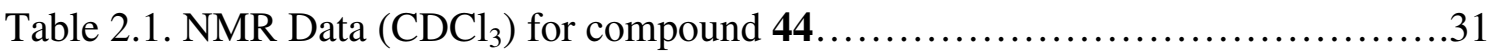

\section{Chapter 4}

Table 4.1. Cleavage of plasmid DNA in control reactions.........................107 
TABLE OF COMPOUND STRUCTURE AND NUMBER

\begin{tabular}{|l|l|}
\hline & Number \\
\hline & 1 \\
\hline
\end{tabular}


TABLE OF COMPOUND STRUCTURE AND NUMBER CONT'D.

\begin{tabular}{|l|l|}
\hline & Number \\
\hline
\end{tabular}


TABLE OF COMPOUND STRUCTURE AND NUMBER CONT'D.

\begin{tabular}{|l|l|}
\hline & Number \\
\hline & 16 \\
\hline & \\
\hline
\end{tabular}


TABLE OF COMPOUND STRUCTURE AND NUMBER CONT'D.

\begin{tabular}{|l|l|l|}
\hline & Number \\
\hline & \\
\hline
\end{tabular}


TABLE OF COMPOUND STRUCTURE AND NUMBER CONT'D.

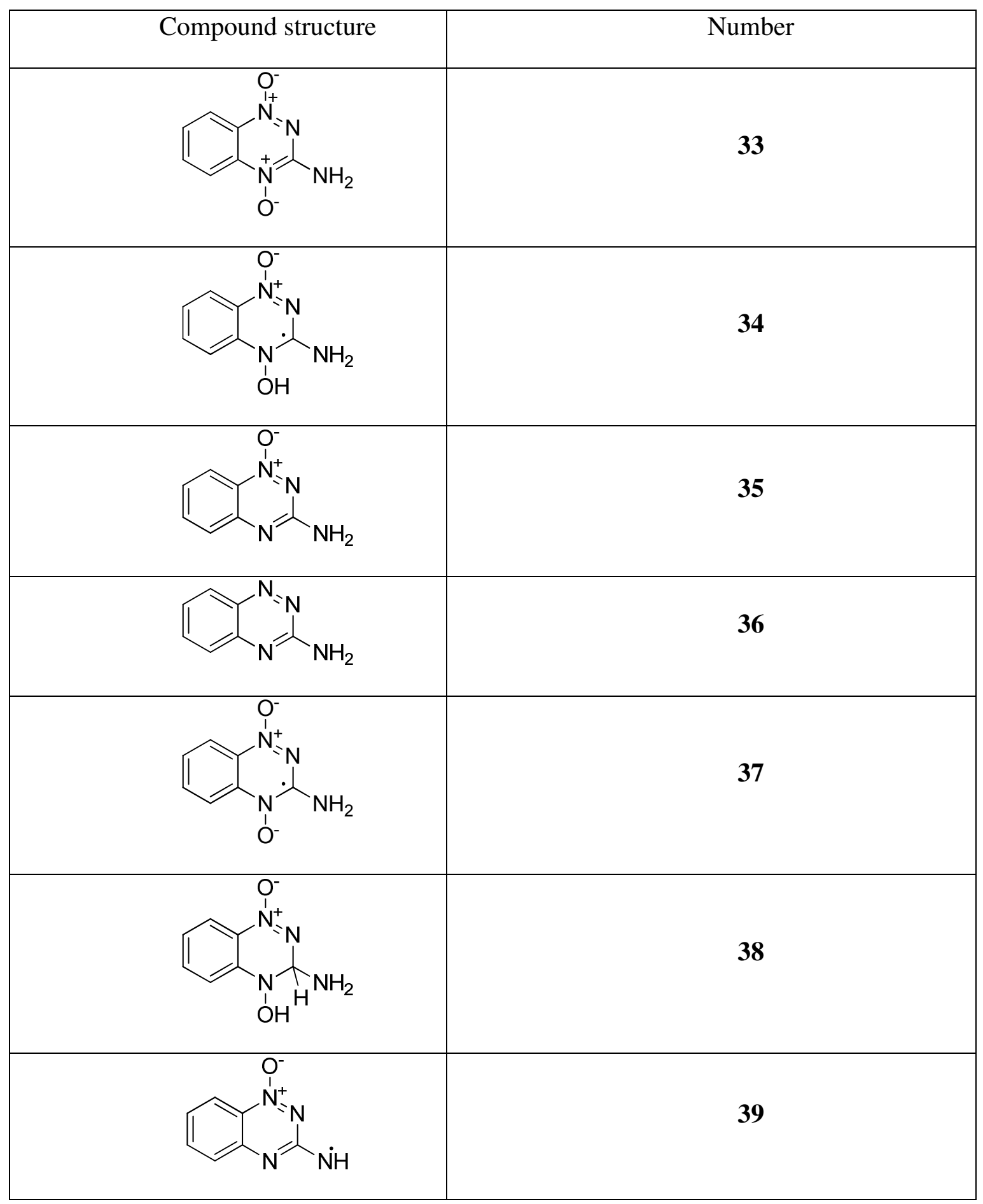


TABLE OF COMPOUND STRUCTURE AND NUMBER CONT'D.

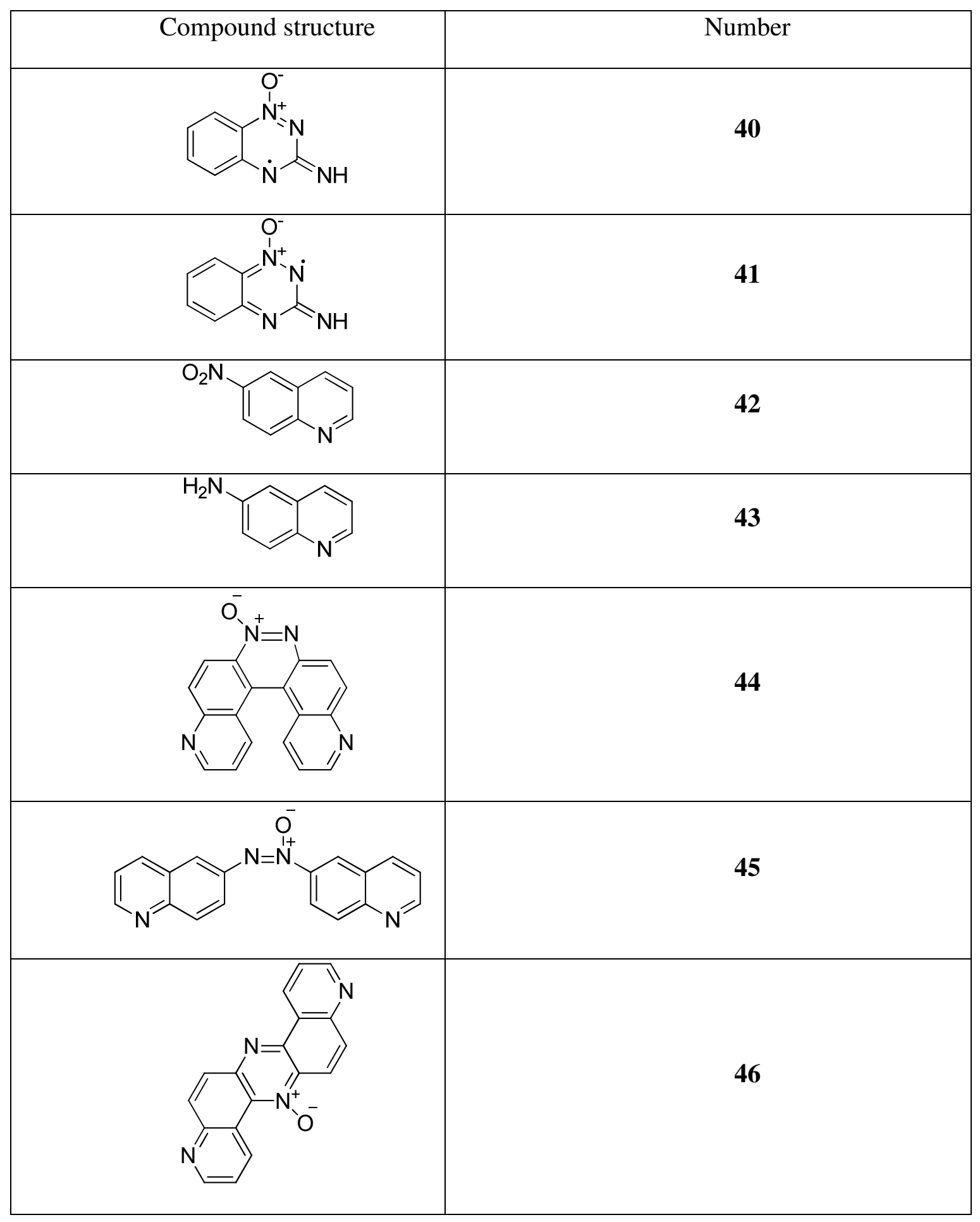


TABLE OF COMPOUND STRUCTURE AND NUMBER CONT'D.

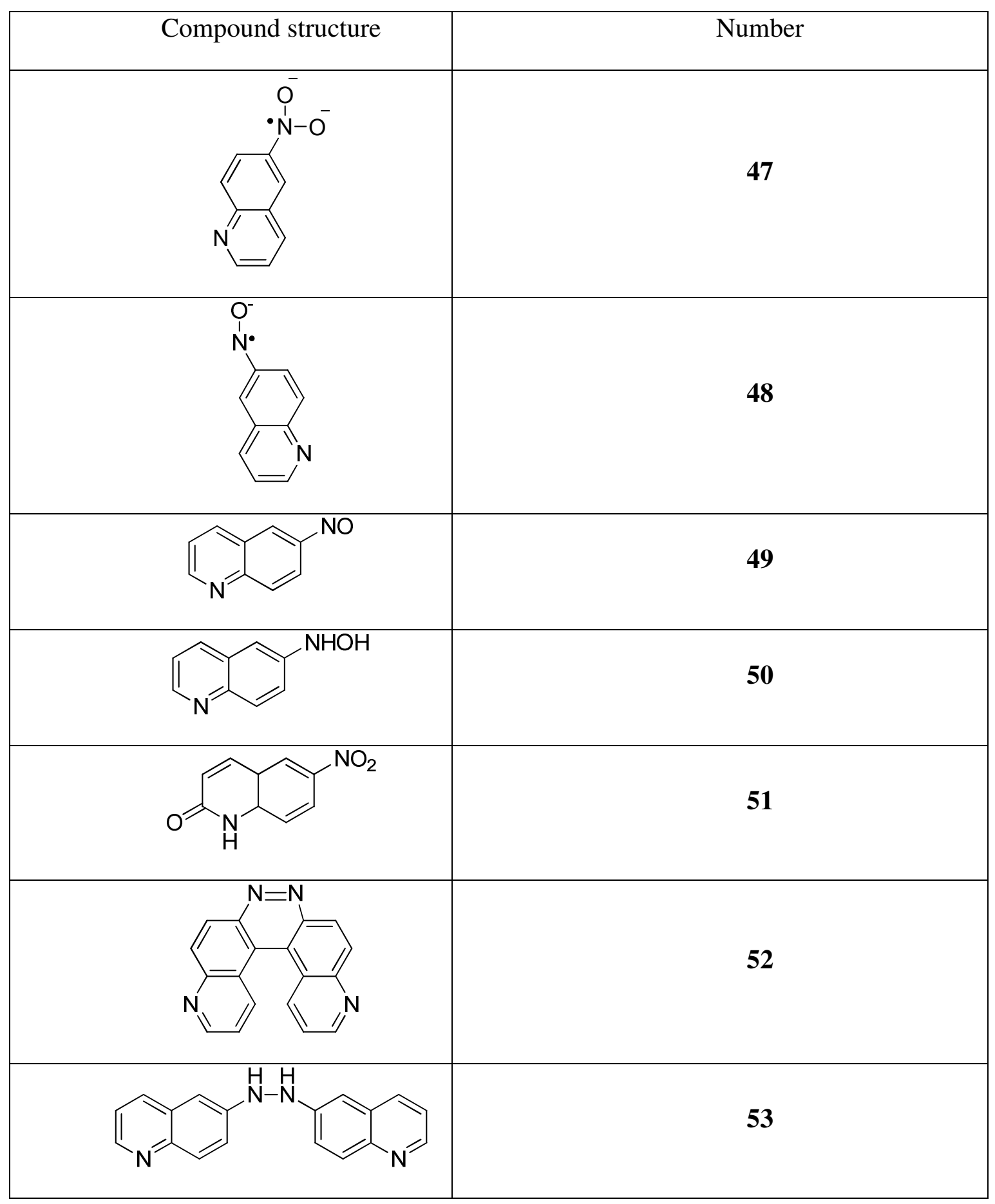


TABLE OF COMPOUND STRUCTURE AND NUMBER CONT'D.

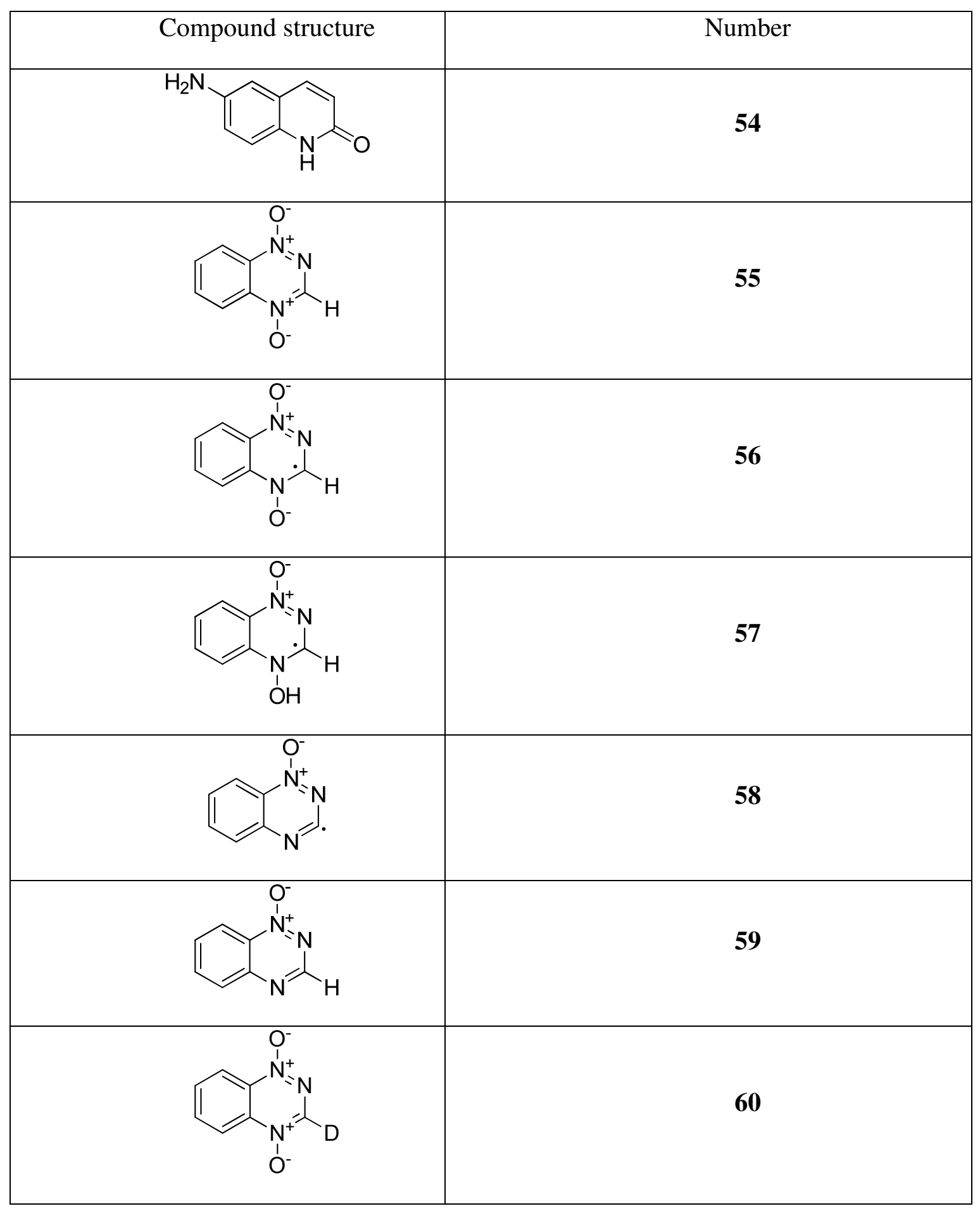


TABLE OF COMPOUND STRUCTURE AND NUMBER CONT'D.

\begin{tabular}{|l|l|}
\hline & Number \\
\hline & 61 \\
\hline & \\
\hline
\end{tabular}


TABLE OF COMPOUND STRUCTURE AND NUMBER CONT'D.

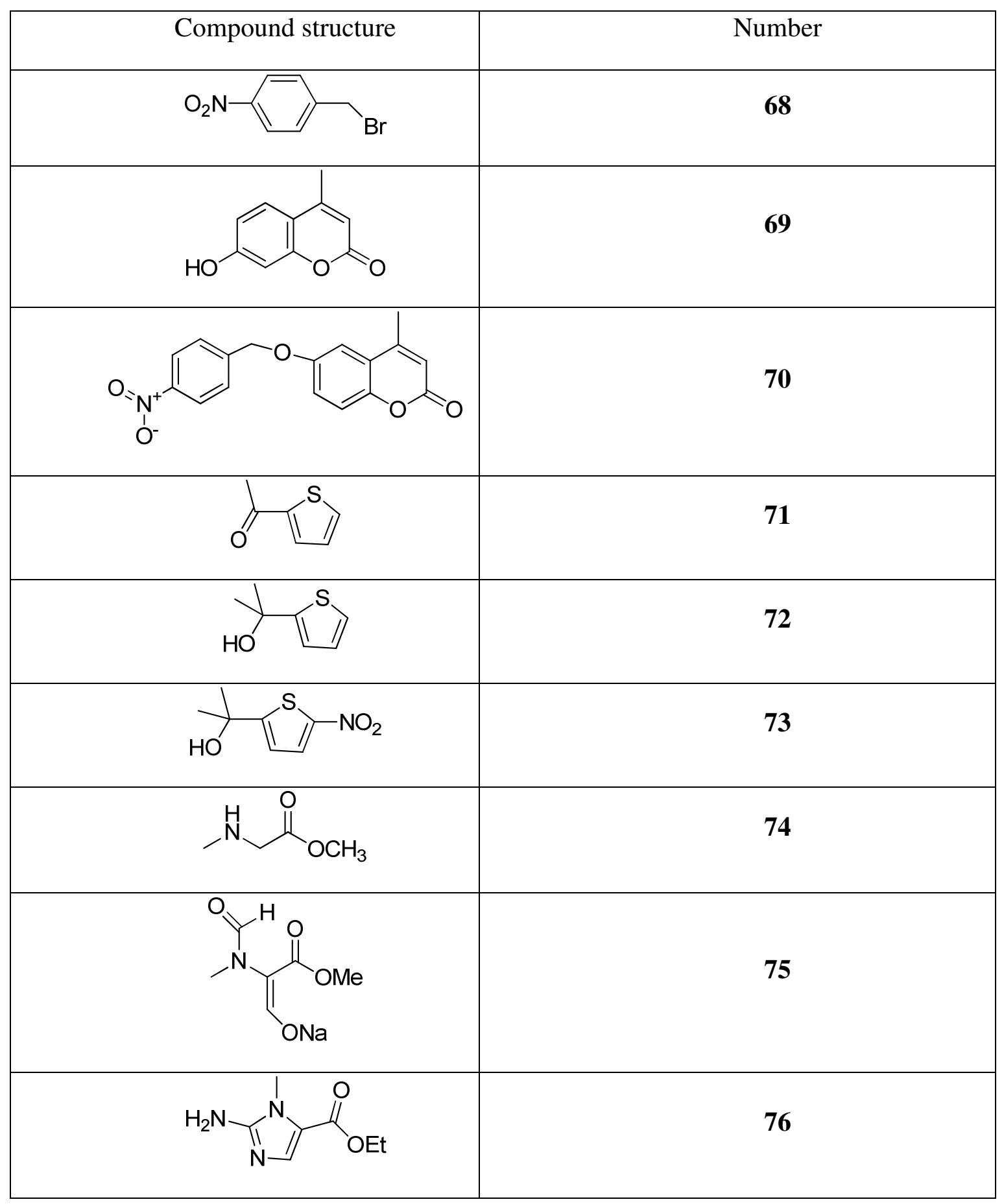


TABLE OF COMPOUND STRUCTURE AND NUMBER CONT'D.

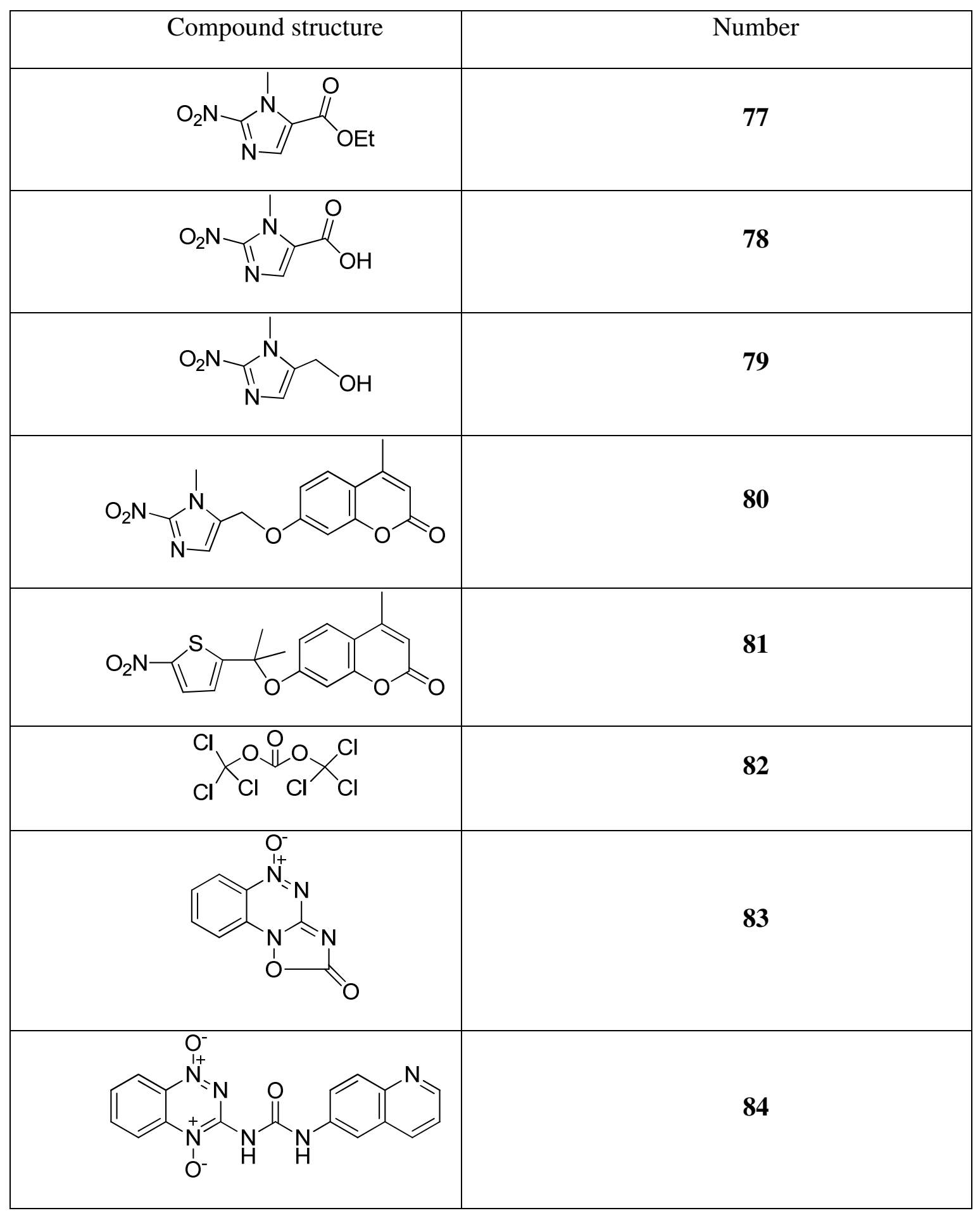




\begin{abstract}
Hypoxia in tumors causes adverse effects to therapy and negatively impacts on patient prognosis. Identification and quantification of hypoxia is considered to have a strong impact on treatments in tumor therapy. Fluorescent-based detection to mark hypoxia may be vital to be used along with available methods such as radiochemical and immunohistochemical staining.

In this work, the non-fluorescent 6-nitroquinoline (42) was used to investigate the production of a fluorescent 6-aminoquinoline (43) and other metabolites under bioreducing hypoxic conditions. In the presence of the enzymatic reducing system NADPH:cytochrome P450 reductase/NADPH, 6-nitroquinoline (42) produced the fluorescent helicene (44), along with the non-florescent azo (45). An authentic sample of (44) was chemically synthesized and characterized and used to confirm the production of this molecule in the enzymatic process. Interestingly, the expected fluorophore (43) is not produced by NADPH:cytochrome P450 reductase/NADPH.

In another study, the enzymatic reducing system xanthine/xanthine oxidase was used to reduce (42) under hypoxia to obtain (43). In these experiments $(\mathbf{4 3})$ was produced and the yield is increased with xanthine concentration. Metabolic identification revealed that intermediates of typical nitro reduction pathway are present along with 6nitroquinolone (51). which is formed by xanthine oxidase mediated oxidation of (42). The absence of (44) as a metabolite with xanthine/xanthine oxidase system highlights the complexity of bio-reduction of nitroaromatics under hypoxia.
\end{abstract}


In our laboratory, bio-activation of di- $\mathrm{N}$-oxides such as tirapazamine (TPZ, 42) has been studied. TPZ undergoes one-electron bio-reduction to produce oxidizing radical, which causes DNA damage under hypoxia. In our laboratory, the mechanism by which TPZ mediated DNA damage has been investigated using TPZ and its analogs.

Our evidence suggests that upon undergoing bio-reduction, TPZ produces hydroxyl radical as the DNA damaging radical species. Others have suggested another mechanism, which proposes the formation benzotriazine radical (38) upon dehydration process over the bioreduction step. In the current work, TPZ analog 1,2,4-benzotraizine1,4-dioxide (55) and deuterated (60) were used to test the dehydration mechanism. Isotopic content analysis of metabolites, derived from bio-reducing metabolism of (55) and its deuterated analog (60), using HRMS show evidence against the dehydration mechanism. 


\section{Chapter 1}

\section{Nitroaromatics and $N$-oxide compounds as radiosensitizers, oxygen sensors and cytotoxic agents in tumor therapy}

\subsection{Hypoxia.}

Low oxygen levels (hypoxia) is considered as an important physiological factor in tumor biology. ${ }^{1}$ The oxygen concentration, found in a normal tissue falls within a range of $20 \mu \mathrm{M}$ to $90 \mu \mathrm{M}^{2}$ It is well established that solid tumors contain cell populations having low oxygen concentrations. ${ }^{3}$ Hypoxia is the end physiological result, caused by the presence of irregular vasculature in tumors. ${ }^{4}$ The inconsistent blood flow in tumors may produce acute or chronic hypoxia. ${ }^{1}$ Hypoxic conditions can diminish effects of ionizing radiation mediated tumor therapy. ${ }^{5}$ Ionizing radiation is a key method in tumor therapy and hypoxia has drawn attention as a challenge which should be addressed to achieve clinical success. ${ }^{6}$

\subsection{Ionizing radiation therapy}

In the presence of ionizing radiation water molecules break down to form highly reactive, oxidizing hydroxyl radicals (Scheme 1.1$){ }^{7}$

$$
\mathrm{H}_{2} \mathrm{O} \stackrel{\text { radiolysis }}{\longrightarrow} \mathrm{e}_{\text {aq }}^{-}+\mathrm{OH}+\mathrm{H}+\mathrm{H}_{2}+\mathrm{H}_{2} \mathrm{O}_{2}
$$

Scheme 1.1. Gamma radiolysis generates radical species

The hydroxyl radical is able to abstract hydrogen from organic substrates such as DNA, which can cause cell death (Scheme 1.2). ${ }^{8}$ 


$$
\mathrm{OH}+\mathrm{DNA}-\mathrm{H} \longrightarrow \mathrm{H}_{2} \mathrm{O}+\text { DNA } \text {. }
$$

Scheme 1.2. Hydroxyl radical abstract hydrogen from DNA

The oxidative abstraction of hydrogen atoms from DNA produces DNA radicals. ${ }^{9}$ DNA radicals can be created on the DNA bases or on sugar phosphate backbone. DNA radicals, formed on thymidine or guanine DNA bases would develop into strand breaks. ${ }^{10}$ The hydrogen atom abstraction, which occurs on the sugar phosphate backbone produces carbon centered radicals on $\mathrm{C}^{\prime}$ ', C2', C3', C4' and $\mathrm{C} 5$ ' corbons and oxygen is required to make the radical damage permanent and induce strand breaks. ${ }^{9}$ The radical fixation, which is mediated by oxygen on DNA backbone carbon radicals, produces characteristic DNA lesions. ${ }^{11}$ The damage, on C4' and C5'carbons, produces 3'-phosphoglycolate and strand breaks (Scheme 1.3). ${ }^{12}$

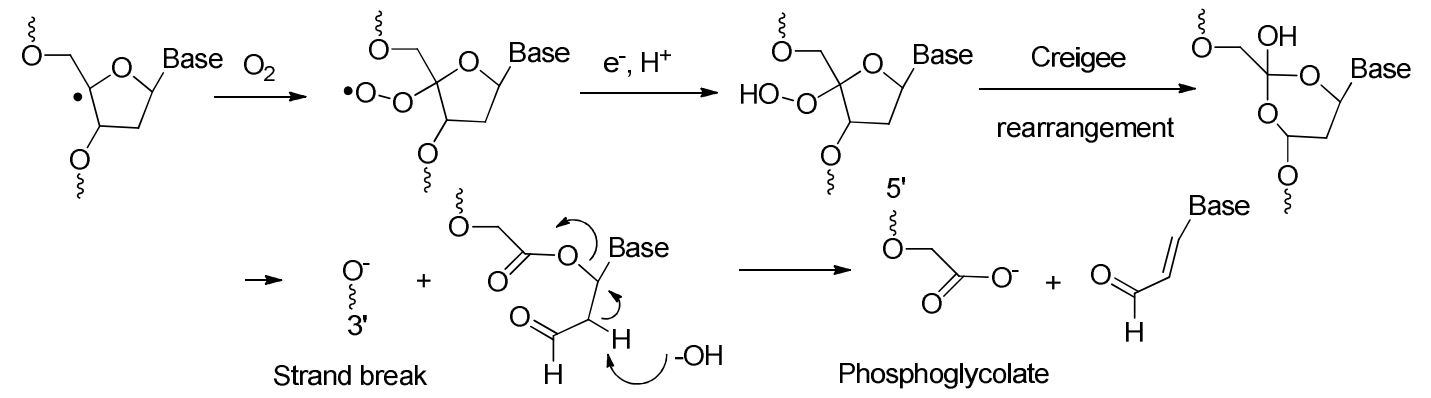

Scheme 1.3. DNA radical on C4' is fixed by oxygen

Formation of a ribonolactone occurs when oxygen fixes a C1' DNA radical. ${ }^{13}$ Under basic conditions 1, ribonolactone undergo elimination to yield strand breaks. (Scheme 1.4). ${ }^{8}$ 


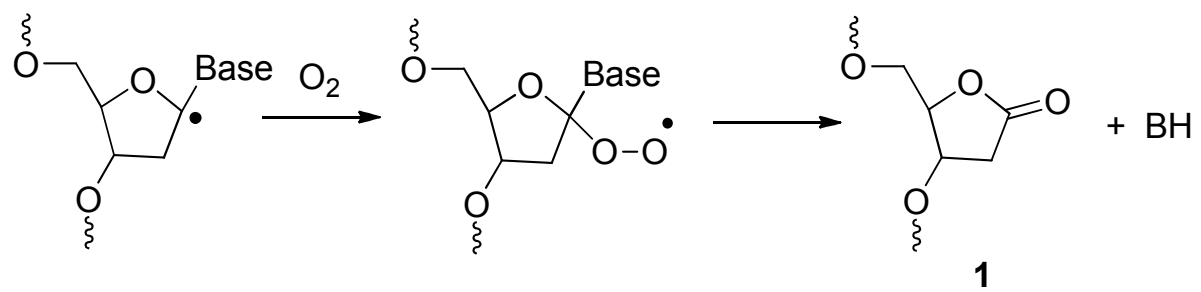

Scheme 1.4. Formation of ribonolactone

Once the DNA damage, either on backbone or DNA base, is made permanent by producing stand breaks, a cascade of cellular events triggers cell death. ${ }^{14}$

Under hypoxic conditions, the low oxygen levels diminish DNA radical fixation. ${ }^{3}$ Hence DNA radical-mediated cell death might not occur in solid tumors. ${ }^{15}$ It is noted that the DNA radicals created by ionizing radiation would be trapped by cellular thiols such as glutathione. ${ }^{7} 16$ The chemical repair of DNA damage by thiols under low oxygen levels may cause the tumor cell resistance to radiation therapy. ${ }^{13}$ The cellular glutathione levels are present in millimolar levels under physiological conditions (Scheme 1.5). ${ }^{7}$

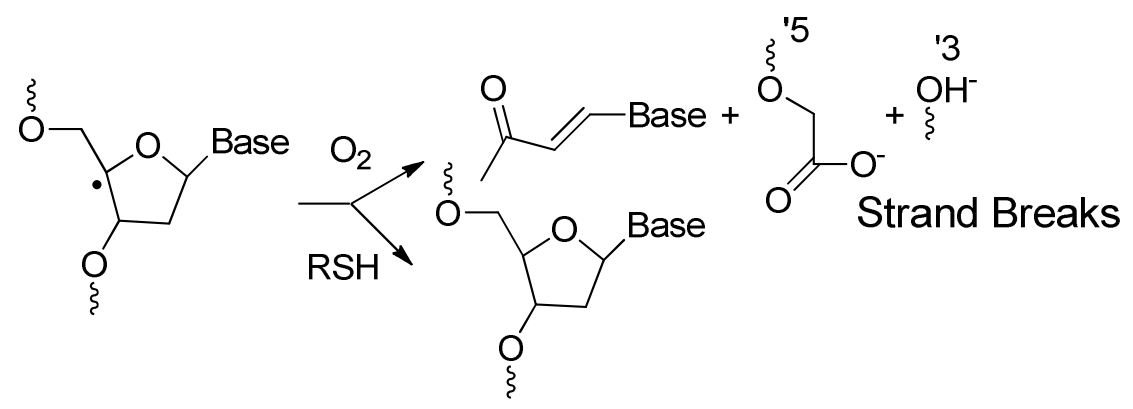

Scheme 1.5. Thiols can repair DNA radical damage

Accordingly, the fate of DNA radicals in tumors depends on the oxygen concentration of the cell. ${ }^{8}$ The lack of oxygen causes tumor cell to resist radiation therapy. ${ }^{3}$ Thus there was a need for alternative agents that can fix DNA radicals under low oxygen concentrations to potentiate radiation therapy. 


\subsection{Radiosensitizing oxygen mimetic agents}

In an effort to reduce tumor cell resistance to radiation therapy, investigations have been carried out to find agents that can mimic the behavior of oxygen in radiotherapy. ${ }^{17}$ As a part of the search nitro aromatic and $N$-oxide drugs have been tested as radiosensitizing agents to accompany radiotherapy in treatments. ${ }^{17 \mathrm{~b}}$

Potential agents such as TEMPO and misonidazole, $\mathbf{2}$ were tested in cytotoxicity assays with radiation. ${ }^{18}$ Nitroaromatics became the leading candidates in the search for radiation sensitizing agent. ${ }^{17 a}$ The sensitizing capacity of nitroaromatics can be radical fixation which can occur through oxygen mimetic ability of nitro group. Or the ability of nitro group to undergo reduction to form amine can be contribute for the radiation sensitivity. ${ }^{17 a}$ The higher electron affinity of nitroaromatic compounds can facilitate oxidation of DNA from which the charge distribution has been altered by radiolysis. ${ }^{19}$ This can produce DNA radical cations and oxygen sensitive nitroradicals which oxidize back to parent nitro group in the presence of oxygen (Scheme 1.6). ${ }^{10}$

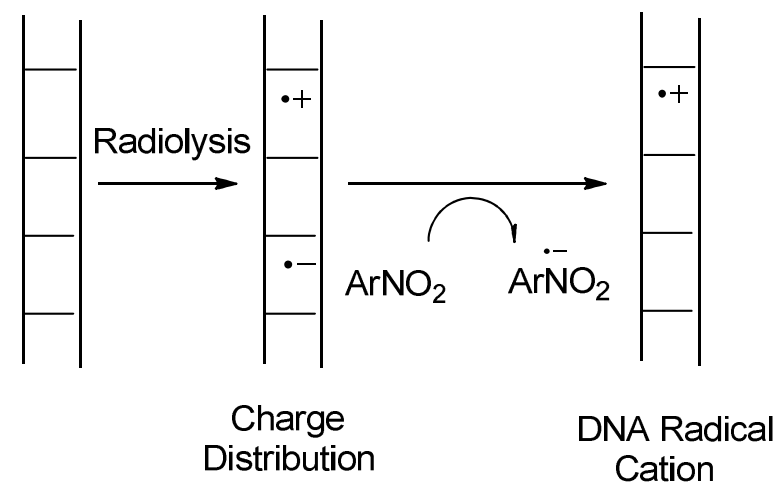

Scheme 1.6. Radiolysis induced nitro-reduction and DNA radical formation

There is evidence for donation of an oxygen atom from a nitro group to a DNA radical. ${ }^{20}$ Goldberg and researchers used an ${ }^{18}$ O-labeled nitro group containing 
misonidazole 2 and DNA radical precursors in his ${ }^{18} \mathrm{O}$-incorporation experiments. When misonidazole interacts with C5' DNA radical, nitroxide intermediate forms, followed by fragmentation caused strand breaks (Scheme 1.7). ${ }^{21}$

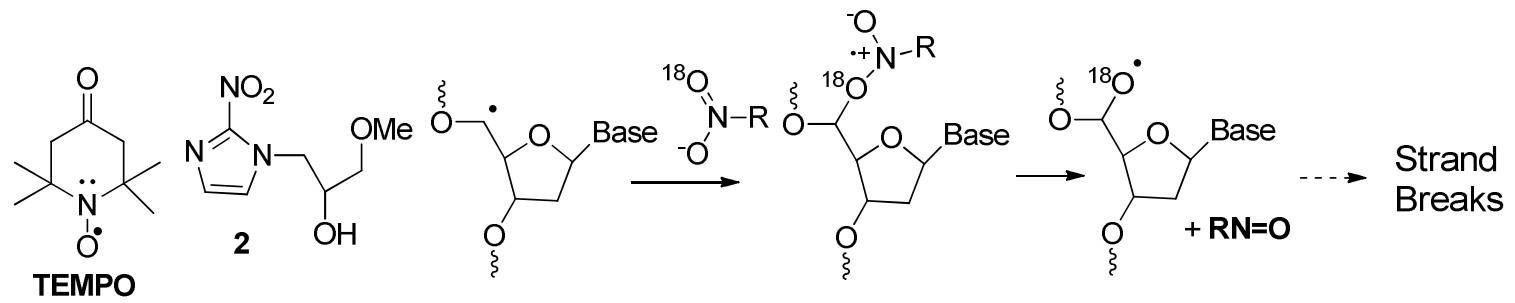

Scheme 1.7. Oxygen of nitro group is donated to DNA

Further studies on misonidazole-mediated radionsensitization revealed that $\mathbf{2}$ causes toxicity without ionizing radiation. ${ }^{22}$ The higher electron affinity of nitroaromatic compounds makes them substrate for cellular reductases. ${ }^{23}$ It was suggested that cellular reducing systems such as NADPH cytochrome P450 reductase may reduce nitro group to hydroxylamine and to amine groups via six consecutive $\mathrm{e}^{-}$reduction steps under hypoxic conditions (Scheme 1.8). ${ }^{24}$

$$
\mathrm{Ar}-\mathrm{NO}_{2} \stackrel{\mathrm{e}^{-}}{\rightarrow} \mathrm{Ar}-\mathrm{NO}_{2} \stackrel{\stackrel{\mathrm{e}}{-}^{-}}{\rightarrow} \mathrm{Ar}-\mathrm{NO} \underset{+\mathrm{H}^{+}}{\stackrel{\mathrm{e}^{-}}{\longrightarrow}} \mathrm{Ar}-\mathrm{NOH} \underset{+\mathrm{H}^{+}}{\stackrel{\mathrm{e}^{-}}{\rightarrow}} \mathrm{Ar}-\stackrel{\mathrm{N}}{\mathrm{N}}-\mathrm{OH} \stackrel{\mathrm{e}^{-}}{\rightarrow}[\mathrm{Ar}-\stackrel{\mathrm{N}-\mathrm{O}}{\bullet}] \stackrel{-}{\stackrel{\mathrm{e}^{-}}{\rightarrow}} \mathrm{Ar}-\mathrm{NH}_{2}
$$

Scheme 1.8. Enzyme mediated Nitro reduction undergo in hypoxia

The hydroxylamine intermediate may cause cytotoxicity by forming reactive intermediates. ${ }^{25}$ The reduction of 2-nitro-5-alkyl-nitroimidazole $\mathbf{3}$ would produce the hydroxylamine and then converts to the glyoxal-dialdehyde $\mathbf{4}$ form which may alkylate nucleophilic sites on DNA (Scheme 1.9). ${ }^{26}$ 


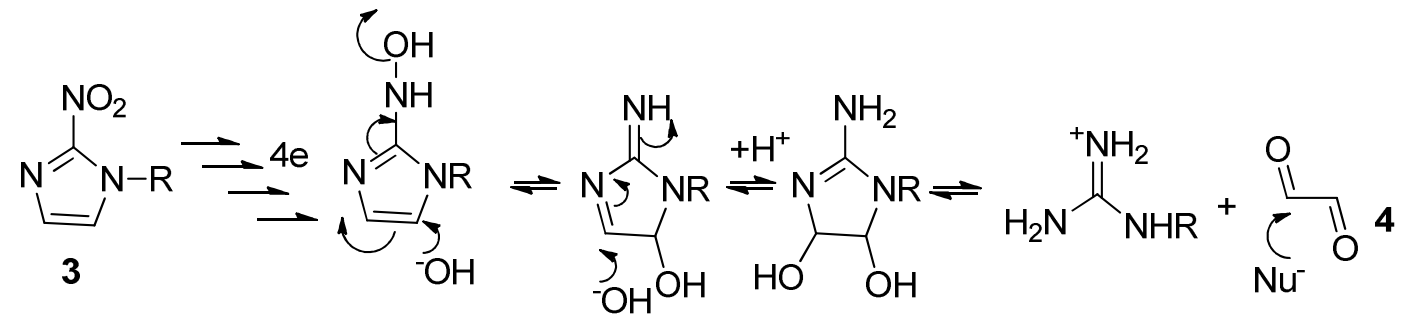

Scheme 1.9. Hydroxylamine produces glyoxal-dialdehyde alkylator 4

The clinical test, carried out using $\mathbf{2}$ produced neurotoxicity among patients. The observed toxicity may have arisen due to the formation of hydroxylamine intermediate.

\subsubsection{Nitroaromatic reduction in hypoxic cells}

Studies on reduction of nitroaromatic-radiosensitizing drugs established nitro reduction mechanism which may occur in cells. ${ }^{17 a}$, 27 The stepwise electron addition would produce the hydroxylamine intermediate. Further reduction produces the amino product. ${ }^{28}$ The nitro group reduction is mediated by cellular enzymes such as NADPH cytochrome P450 reductase, xanthine oxidase, nitroreductases and DT diaphorase. ${ }^{17 a}$, 24 These enzymes can be overexpressed or already abundant in tumor environment. ${ }^{27,29}$ The hypoxic conditions in tumors would permit sequential e- reduction to occur and produce reduced metabolites such as hydroxylamine and amine. ${ }^{30}$ The enzyme-mediated functional group transition from nitro to hydroxylamine has been considered as an electronic switch. ${ }^{27}$ The electron poor nitro group is converted to an electron rich hydroxylamine, and further reduction produces the amine moiety. ${ }^{31}$ For some drug candidates electron rich hydroxylamine represents the active form of the drug to be effective in tumor cells. ${ }^{32}$ The first nitro imidazole aziridine containing agent RSU1069, 5, explored hypoxia selective, redox activated generation of an alkylating agent. ${ }^{33}$ Similar nitro-imidazole-containing mustards such as RB6145 $\mathbf{6}$ and $\mathbf{5}$ were tested in tumor cells. ${ }^{34}$ In addition to mustard-type alkylating agents, DNA intercalating moieties such as 
acridine $\mathbf{7}$ and quinoline $\mathbf{8}$ groups were used as bio reductively activated agents. Upon bio-reduction, the intercalating ability of amine compounds of $\mathbf{7}$ and $\mathbf{8}$ is enhanced to cause interferences during DNA replication (Scheme 1.10). ${ }^{35}$<smiles>O=[N+]([O-])c1nccn1CC(O)CN1CC1</smiles>

5<smiles>O=[N+]([O-])c1nccn1CC(O)CNCCBr</smiles>

6<smiles>CN(C)CCCNc1c2ccccc2nc2cccc([N+](=O)[O-])c12</smiles>

7<smiles>CNCCCNc1ccnc2cccc([N+](=O)[O-])c12</smiles>

8

Scheme 1.10. Nitro aromatics reduction in hypoxia produces the active drug

Mustard groups have been attached to nitrophenyl moiety, as a continuation of efforts to develop nitroaryl-aziridine conjugates. ${ }^{36}$ Nitrobenzene aziridines CB 1954, 9, SN 23862, 10, and PR 104, 11 explore nitro reduction as the mean of mustard activation in tumor cells (Scheme 1.11). ${ }^{37}$<smiles>NC(=O)c1cc(N2CC2)c([N+](=O)[O-])cc1[N+](=O)[O-]</smiles>

9<smiles>NC(=O)c1cc(N(CCCl)CCCl)c([N+](=O)[O-])cc1[N+](=O)[O-]</smiles>

10<smiles>COOCCN(CCBr)c1c(C(=O)NCCOP(=O)(O)O[Na])cc([N+](=O)[O-])cc1[N+](=O)[O-]</smiles>

Scheme 1.11. Nitrophenyl-mustard alkylating agents

The aziridine alkylating moiety would attain greater activity upon the reduction of nitro group to amine group under hypoxia. Specific enzymes such as E. coli nitroreductases has been used as the reducing enzyme under gene directed enzyme prodrug therapy GDEPT to test nitrobenzyl mustard $9 .{ }^{32}$ In addition, DT diaphorase has been used with nitrophenyl-aziridines and nitrogen mustards to test the enhanced selectivity toward hypoxia and improved cytotoxicity. ${ }^{38}$ In the mechanism, of which nitroarylmustards attain activity, nitro compound $\mathbf{1 1}$ undergoes reduction to produce amine $\mathbf{1 2}$. 
The increased electron density on $\mathbf{1 2}$ works toward the formation of alkylating aziridine 13 (Scheme 1.12). ${ }^{39}$

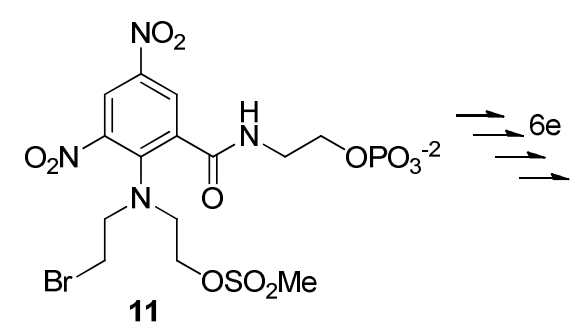<smiles>CO[R6](=O)(O[Na])OCCNC(=O)c1cc(N)cc([N+](=O)[O-])c1N(CCOC(C)=O)CC(C)Br</smiles>

Scheme 1.12. Nitrophenyl-mustard alkylating agents<smiles>COCCN1CC1c1cc(N)cc([N+](=O)[O-])c1C(=O)NCCOC(C)=O</smiles>

\subsubsection{Elimination of active agent through nitroaromatic reduction}

The electronic properties of a molecule can undergo a major shift when a pendent nitro group is reduced to the respective hydroxylamine and to the amine group in hypoxia mediated by cellular reductases. The increase of electron density on hydroxylamine nitrogen has been employed release an active agent. The active drug is attached to a suitable nitro aromatic group in its prodrug form. ${ }^{40}$ The activity of the agent is diminished or masked due to the ligation with the nitro aromatic group. The structural difference of conjugate $\mathbf{1 4}$, nitroimidazole-phosphoramidate to the active agent $\mathbf{1 7}$, a phosphoramidate, may cause the reduced effect of drug. ${ }^{41}$ Once the nitro group on $\mathbf{1 4}$ is reduced in hypoxia, to the hydroxylamine group bearing $\mathbf{1 5}$, the enhanced electron density on nitrogen of hydroxylamine will eject the active agent $\mathbf{1 7}$, which is a good leaving group. ${ }^{42}$ This electron movement will trigger covalent bond scission, which releases the active drug 17 from the pro-drug complex (Scheme 1.13) while forming imine methide $\mathbf{1 6}^{43}$<smiles>C=C1C(=C[PH2+])N(C)C(=N)[C@H]1NCCBr</smiles>

Scheme 1.13. Hydroxylamine releases the active drug 
The phosphoramidate $\mathbf{1 7}$ can form aziridine, which acts as an electrophile that can alkylate cellular nucleophiles (Scheme 1.14).

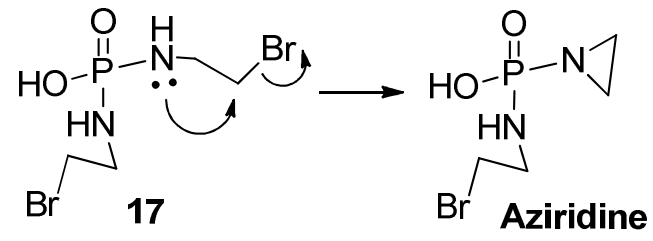

Scheme 1.14. Phosphoramidate forms azide upon elimination of leaving group

There are number of nitroaromatic-prodrugs designed to carry phosphoramide toxins, structurally and functionally similar to phosphoramidate, such as $\mathbf{1 8}$ to cells. The parent cyclophosphoramide drug $\mathbf{1 8}$ has been widely used anti-cancer agent with excellent toxicity toward various tumor types. ${ }^{44}$ Although the positive results were encouraging, the parent cyclophosphamide showed lethal side effect, occurred due to release of acrolein 21 along the $\mathrm{CYP}_{450}$-mediated metabolic pathway via forming intermediates 19 and 20 (Scheme 1.15). ${ }^{45}$

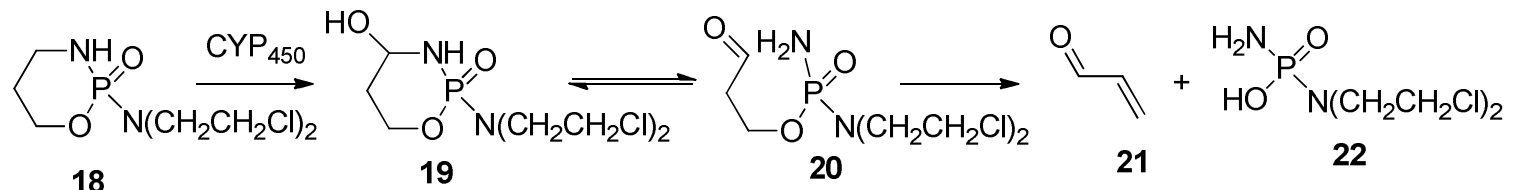

Scheme 1.15. Cyclophophoramide 18 metabolism by $\mathrm{CYP}_{450}$

Delivering phosphoramide, 22, selectively to tumor is considered important in order to avoid such toxicity reported with $18 .^{46}$ The nitroquinoline-phosphoramide mustard $\mathbf{2 3}$ was developed as a pro-drug to test the ejection of phosphoramide toxin $\mathbf{2 2}$. Upon the reduction of the nitro group on quinoline, the electron rich quinoline nitrogen on 24 triggers beta elimination of 22 leaving 25 as a metabolite. Tenfold increase of cytotoxicity was observed in hypoxia and evidence for alkylation occurred by 
phosphoramide confirmed the expected release of phosphoramide $\mathbf{2 2}$ upon nitro reduction (Scheme 1.16). ${ }^{40}$

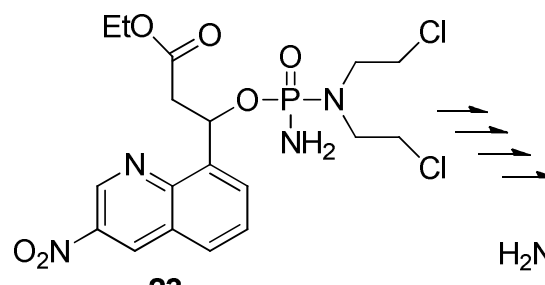

23<smiles>CCOC(=O)C(C)C(C)c1cccc2cc(N)cnc12</smiles>

24<smiles>CCOC(=O)/C=C/c1cccc2cc(N)c[nH+]c12</smiles>

25<smiles>NP(=O)(O)N(CCCl)CCCl</smiles>

22

Scheme 1.16. Nitroquinoline-phosphoramide prodrug release

Other nitro-aromatics nitrobenzyl, nitrofuryl and nitrothienyl have been used as bio-reducible triggers for conjugation with phosphoramides. These prodrugs, constructed from tagging phosphoramide with nitroaromatics have shown encouraging results; low cytotoxicity but enhanced tumor selectivity. Compound $\mathbf{2 4}$ generated DNA interstrand cross links in hypoxic HT-29 cells, with a selectivity ratio of $90 .^{47}$ Nitrophenyl 26, nitrofuryl 27 and nitrothienyl 28 derivatives show low toxicity in aerobic assays (Scheme $1.17) .^{48}$

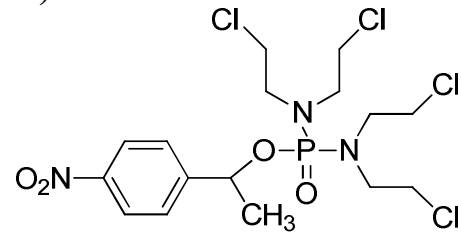

26

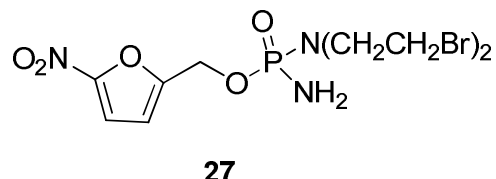

27

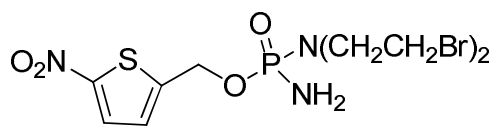

28

Scheme 1.17. Nitrophenyl, Nitrofuryl and nitrothienyl phosphoramide conjugates

In addition to the phosphoramide mustards, various anti-cancer agents are conjugated to nitroaromatics. Combrestatin, 29 and its nitrothienyl couple 30, and nitrophenyl-mercaptopurine prodrug 31 have shown effective release of agent upon bioreduction (Scheme 1.18). ${ }^{49}$ 
<smiles>COc1cccc(/C=C\c2cc(OC)c(OC)c(OC)c2)c1OC</smiles>

29

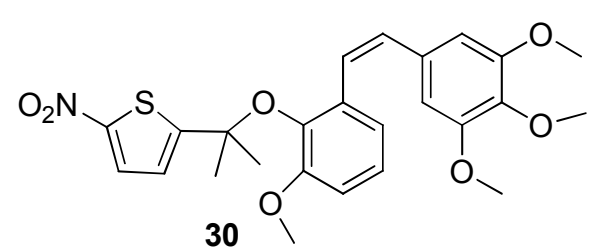

30

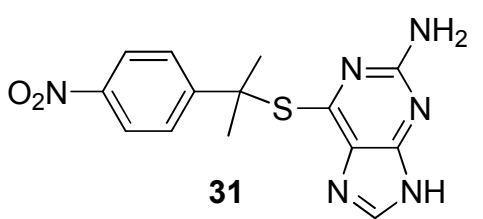

31

Scheme 1.18. Nitrothienyl and nitrophenyl dimethyl prodrugs

The importance of nitroaromatic reduction in tumor therapy and prodrug designing is well established in medicinal chemistry and bioorganic chemistry. In the coming chapters, interesting metabolic and fluorescence studies on 6-nitroquinoline reduction will be discussed. Moreover, the oxygen sensitivity of 6-nitroquinoline reduction, under two enzymatic reducing systems will be presented. Several novel findings related to the 6-nitroquinoline reduction will add complexity to enzyme mediated nitroaromatic reduction in hypoxia.

\section{4. $N$-oxides}

Investigations carried out to develop radio sensitizing agents tested nitroxyl radical TEMPO. It has been discovered that TEMPO connects with the DNA radical, which is formed by radiolysis under hypoxia to produce DNA adduct $32 .{ }^{18}$ In search for backups to $\mathrm{N}$-oxide radiosensitizing agents, Brown and coworkers tested tirapazamine (TPZ), $N$-oxide $\mathbf{3 3}$ as an oxygen mimetic agent in radiolysis of cells. They found that $\mathbf{3 3}$ was toxic as a single agent and the cytotoxicity was 200 fold higher for hypoxic cells. ${ }^{50}$ The anti-cancer properties shown by $\mathbf{3 3}$ in the absence of $\gamma$ radiation was stirred interest and the mechanism for the anti-tumor activity of $\mathbf{3 3}$ has been subjected further for research (Scheme 1.19). ${ }^{51}$ 


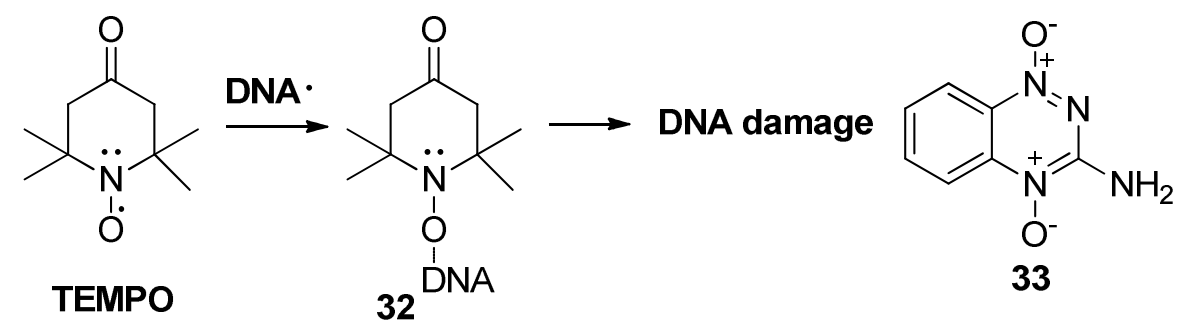

Scheme 1.19. $N$-oxide radiosensitizing agents

TPZ is believed to be activated by enzyme systems such as cytochrome P450 and cytochrome P450 reductase, xanthine and xanthine oxidase, aldehyde oxidase and nitric oxide synthase in cells. ${ }^{52}$ The activation produces a TPZ radical which back oxidizes to the parent TPZ by oxygen under aerobic conditions to produce superoxide radical. ${ }^{23,50,53}$ The superoxide radical disproportionate to yield hydrogen peroxide by super oxide dismutase (SOD) and hydrogen peroxide is converted to water and hydroxide ion by catalase (CAT) ${ }^{23}$ Unless the superoxide radical is handled consecutively by SOD and CAT, radical-mediated oxidative damage may occur to biomolecules. ${ }^{23}$ Under hypoxia, the TPZ radical 34 persists and produces an oxidizing radical which cause DNA damage. ${ }^{51,54}$ The in vivo enzymatic reduction process produces metabolites $\mathbf{3 5}$, the major metabolite and $\mathbf{3 6}$ (Scheme 1.20). ${ }^{55}$

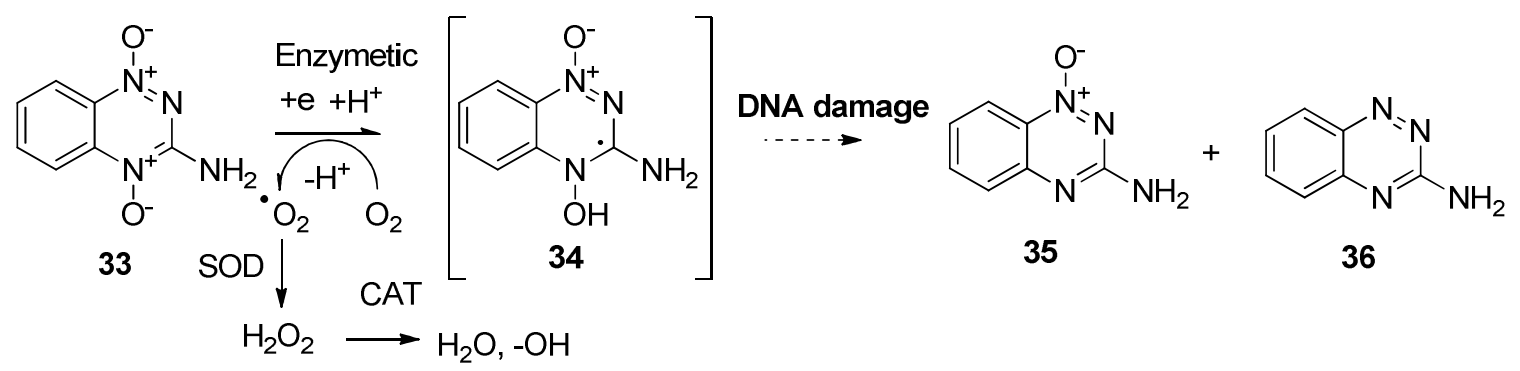

Scheme 1.20. Enzyme mediated reduction of 33 in hypoxia 
The DNA damage resulted by TPZ in hypoxia is believed to cause cytotoxicity in tumors. ${ }^{56}$ The mechanism of TPZ-mediated DNA damage is not properly understood. ${ }^{57}$ There are three mechanisms proposed to describe the nature of the DNA damaging species. $^{58}$

The neutral benzotriazine dioxide radical 34, formed from 37 upon enzymatic reduction of $\mathbf{3 3}$ has been proposed by Brown's group as the oxidizing species which causes the DNA damage. ${ }^{59}$ In this proposal, a proton on DNA is abstracted by $\mathbf{3 4}$ to form 38. A dehydration event proceeds via $\mathbf{3 8}$ to release water and $\mathbf{3 5}$ (Scheme 1.21). ${ }^{60}$

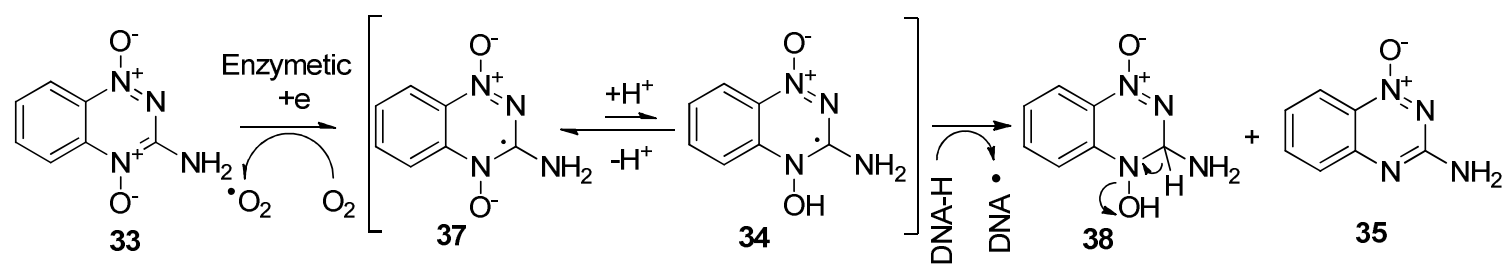

Scheme 1.21. Enzyme mediated reduction of $\mathbf{3 3}$ in hypoxia abstract proton from DNA, followed by dehydration releases $\mathbf{3 5}$ as the major metabolite

Alternatively, a homolytic bond scission of $\mathrm{N}-\mathrm{OH}$ bond in neutral benzotriazine dioxide radical $\mathbf{3 4}$ can form a hydroxyl radical and the major metabolite $\mathbf{3 5}$ (Scheme 1.22 upper arm). ${ }^{61}$ The hydroxyl radical, released from $\mathbf{3 4}$ is capable of performing oxidative damage on DNA. ${ }^{62}$ Oxidative DNA damage occurs in tumor cells can initiate a cascade of events which result in cytotoxicity. ${ }^{63}$ Denny and co-workers suggest a mechanism based on dehydration that might occur on the neutral benzotriazine di-oxide radical 34 forms a benzotriazinyl 1-oxide radical (structures 39, 40 and 41) which is responsible for the DNA damage (Scheme 1.22 lower arm). ${ }^{64}$ 


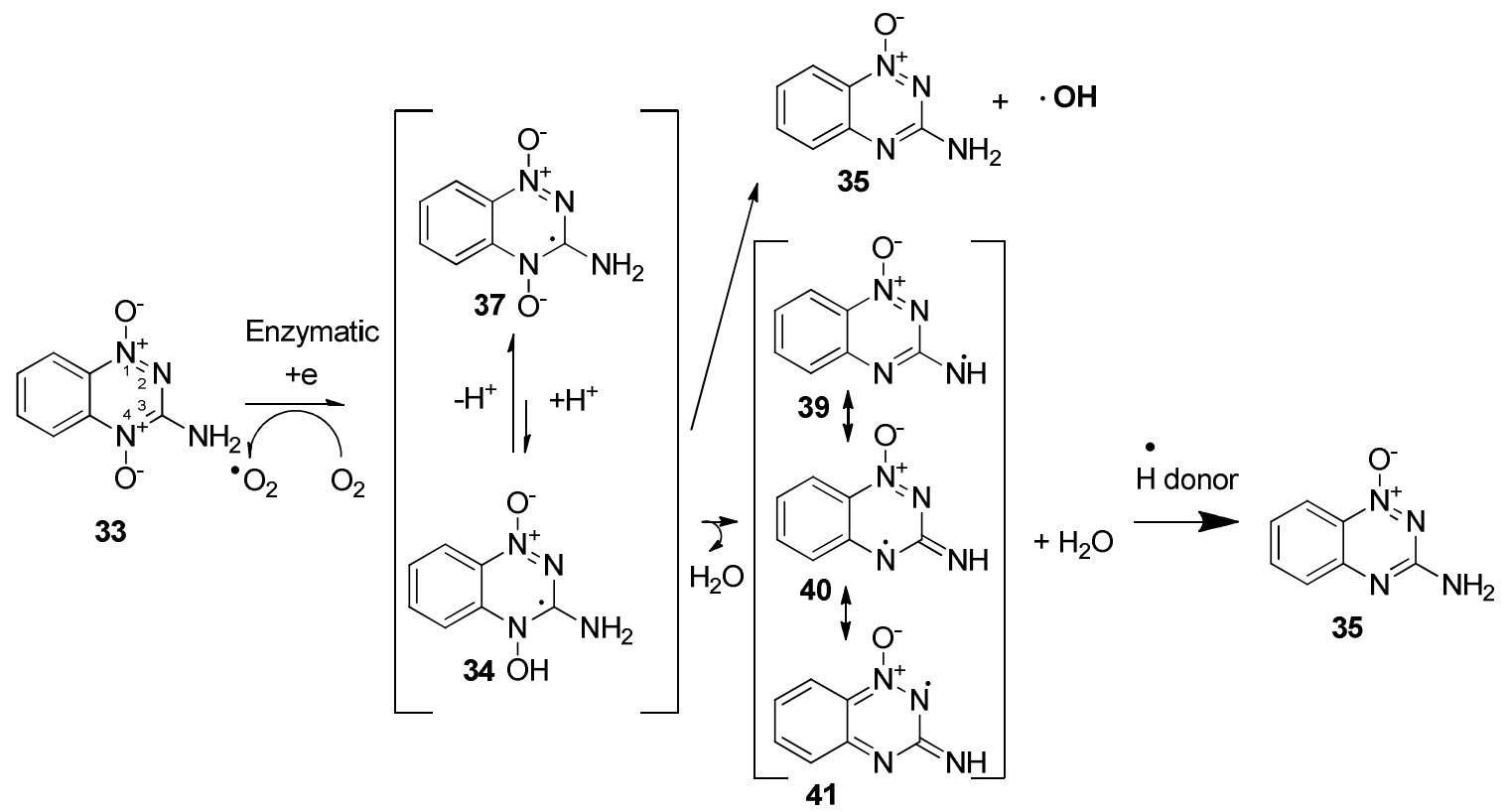

Scheme 1.22. The enzyme mediated reduction of $\mathbf{3 3}$ in hypoxia may produce hydroxyl radical or benzotriazine radicals $39, \mathbf{4 0}$ or $\mathbf{4 1}$ as the oxidizing species

Research carried out by our group support the mechanism involving hydroxyl radical mediated DNA damage. ${ }^{65}$

\subsection{Summary}

Nitroaromatic compounds have become a prominent drug class in medicinal chemistry research. ${ }^{66}$ The nitroaromatic reduction that occurs in low oxygen concentrations is mediated by reductive enzymes and has become an attractive concept in bioreductive prodrug therapy. ${ }^{58}$ Nitroaromatic reduction reactions are complex due to the presence of various intermediates and byproducts. ${ }^{67}$ The work presented in this thesis describes the use of small molecule 6-nitroquinoline as a fluorescent probe that can detect hypoxia. ${ }^{68}$ A rich metabolic study is accompanying the fluorescent results in coming chapters. In addition the lead $N$-oxide tirapazamine, which has been in phase trials I, II and III for clinical therapy over a decade and its analogs were used to study the DNA- 
damaging mechanism of $N$-oxides. ${ }^{69}$ The chemical basis for the DNA damage, caused by 33 depends on the reduction mechanism of these di-oxide. ${ }^{65}$ The chemical nature of the DNA-damaging species has become an interesting topic in research. In the current thesis, a mechanistic study is presented analyze the reduction mechanism and the chemical nature of the oxidizing species.

\section{References:}

1. Brown, J. M., The hypoxic cell: A target for selective cancer therapy. Cancer Res. 1999, 59, 5863-5870.

2. Patel, S. A.; Simon, M. C., Biology of hypoxia-inducible factor-2alpha in development and disease. Cell Death \& Diff 2008, 15 (4), 628-34.

3. Denny, W. A., The role of hypoxia-activated prodrugs in cancer therapy. The Lancet Oncol. 2000, 1, 25-29.

4. Harris, A. L., Hypoxia - a key regulatory factor in tumour growth. Nat. Rev. Cancer 2002, 2, 38-47.

5. Alper, T.; Howard-Flanders, P., Role of oxygen in modifying the radiosensitivity of E. coli B. Nature 1956, 178 (4540), 978-9.

6. Vaupel, P.; Kelleher, D. K.; Thews, O., Modulation of tumor oxygenation. Int. J. Radiat. Oncol. Biol. Phys. 1998, 42 (4), 843-848.

7. von Sonntag, C.; Hagen, U.; Schon-Bopp, A.; Schulte-Frohlinde, D., Radiationinduced strand breaks in DNA: chemical and enzymatic analysis of end groups and mechanistic aspects. Adv. Radiat. Biol. 1981, 9, 109-142.

8. Pogozelski, W. K.; Tullius, T. D., Oxidative strand scission of nucleic acids: routes initiated by hydrogen atom abstraction from the sugar moiety. Chem. Rev. 1998, 98, 1089-1107. 
9. Pogozelski, W. K.; McNeese, T. J.; Tullius, T. D., What species is responsible for strand scission in the reaction of [Fe(II)EDTA] ${ }^{2-}$ and $\mathrm{H}_{2} \mathrm{O}_{2}$ with DNA? J. Am. Chem. Soc. $1995,117,6428-6433$.

10. Burrows, C. J.; Muller, J. G., Oxidative nucleobase modifications leading to strand scission. Chem. Rev. 1998, 98, 1109-1151.

11. Murugesan, N.; Xu, C.; Ehrenfeld, G. M.; Sugiyama, H.; Kilkuskie, R. E.; Rodriguez, L. O.; Chang, L. H.; Hecht, S. M., Analysis of products formed during bleomycin-mediated DNA degradation. Biochemistry 1985, 24 (21), 5735-44.

12. Giese, B.; Beyrich-Graf, X.; Erdmann, P.; Petretta, M.; Schwitter, U., The chemistry of single-stranded 4'-DNA radicals: influence of the radical precursor on anaerobic and aerobic strand cleavage. Chem. Biol. 1995, 2, 367-375.

13. Greenberg, M. M., Investigating nucleic acid damage processes via independent generation of reactive intermediates. Chem. Res. Toxicol. 1998, 11 (11), 1235-1248.

14. Debatin, K., Activation of apoptosis pathways by anticancer treatment. Toxicol Lett 2000, 112-113, 41-8.

15. Hockel, M.; Vaupel, P., Biological consequences of tumor hypoxia. Semin Oncol 2001, 28, 36-41.

16. Bump, E. A.; Brown, J. M., Role of glutathione in the radiation response of mammalian cells in vitro and in vivo. Pharmac. Ther. 1990, 47, 117-136.

17. (a) Wilson, W. R., Tumour hypoxia: challenges for cancer chemotherapy. In The Search For New Anticancer Drugs, Waring, M. J.; Ponder, B. A. J., Eds. Kluwer Academic: Lancaster, 1992; (b) Brown, J. M., SR4233 (Tirapazamine): a new anticancer drug exploiting hypoxia in solid tumours. Br. J. Cancer 1993, 67, 1163-1170.

18. Hohman, W. F.; Palcic, B.; Skarsgard, L. D., The effect of nitroimidazole and nitroxyl radiosensitizers on the post-irradiation synthesis of DNA. Int. J. Radiat. Biol. Relat. Stud. Phys., Chem. Med. 1976, 30, 247-61.

19. Amphlett, C. B.; Adams, G. E.; Michael, B. D., Pulse radiolysis studies of deaerated aqueous salicylate solutions. Advan. Chem. Ser. 1968, 81, 231-50. 
20. Jagannadham, V.; Steenken, S., Reactivity of N1-heteroatom-substituted alkyl radicals with nitrobenzenes in aqueous solution: an entropy controlled electron transfer/addition mechanism. J. Am. Chem. Soc. 1988, 110, 2188-92.

21. Kappen, L. S.; Lee, T. R.; Yang, C.-c.; Goldberg, I. H. 1., Oxygen transfer from the nitro group of a nitroaromatic radiosensitizer to a DNA sugar damage product. Biochemistry 1989, 28, 4540-4542.

22. Hall, E. J.; Roizin-Towle, L.; Attix, F. H., Radiobiological studies with cyclotronproduced neutrons currently used for radiotherapy. Int J Radiat Oncol Biol Phys 1975, 1, 33-40.

23. Butler, J.; Hoey, B. M., DNA and Free Radicals. In Redox cycling drugs and DNA damage, Halliwell, B.; Aruoma, O. I., Eds. Ellis Horwood: New York, NY, 1993; pp 243-273.

24. Feller, D. R.; Morita, M.; Gillette, J. R., Reduction of heterocyclic nitro compounds in the rat liver. Proc. Soc. Exp. Biol. Med. 1971, 137, $433-7$.

25. (a) Miller, J. A., Carcinogenesis by chemicals: an overview--G. H. A. Clowes memorial lecture. Cancer Res 1970, 30 (Copyright (C) 2012 U.S. National Library of Medicine.), 559-76; (b) McClelland, R. A.; Fuller, J. R.; Seaman, N. E.; Rauth, A. M.; Battistella, R., 2-Hydroxylaminoimidazoles--unstable intermediates in the reduction of 2nitroimidazoles. Biochem Pharmacol 1984, 33, 303-9.

26. McClelland, R. A.; Panicucci, R.; Rauth, A. M., Products of the reductions of 2nitroimidazoles. J. Am. Chem. Soc. 1987, 109, 4308-4314.

27. Denny, W. A.; Wilson, W. R., Considerations for the design of nitrophenyl mustards as agents with selective toxicity for hypoxic tumor cells. J. Med. Chem. 1986, 29 (6), 879-887.

28. (a) Walton, M. I.; Wolf, C. R.; Workman, P., Molecular enzymology of the reductive bioactivation of hypoxic cell cytotoxins. Int. J. Radiat. Oncol. Biol. Phys. 1989, 16, 983-986; (b) Wilson, W. R.; Anderson, R. F.; Denny, W. A., Hypoxia-selective antitumor agents. 1. Relationships between structure, redox properties and hypoxiaselective cytotoxicity for 4-substituted derivatives of nitracrine. J. Med. Chem. 1989, 32, 23-30. 
29. (a) Gutierrez, P. L., The metabolism of quinone-containing alkylating agents: free radical production and measurement. Front Biosci 2000, 5, D629-38; (b) Belcourt, M. F.; Hodnick, W. F.; Rockwell, S.; Sartorelli, A. C., Exploring the mechanistic aspects of mitomycin antibiotic bioactivation in Chinese hamster ovary cells overexpressing NADPH:cytochrome C (P-450) reductase and DT-diaphorase. Adv Enzyme Regul 1998, 38, 111-33; (c) Volpato, M.; Abou-Zeid, N.; Tanner, R. W.; Glassbrook, L. T.; Taylor, J.; Stratford, I.; Loadman, P. M.; Jaffar, M.; Phillips, R. M., Chemical synthesis and biological evaluation of a $\mathrm{NAD}(\mathrm{P}) \mathrm{H}$ :quinone oxidoreductase-1-targeted tripartite quinone drug delivery system. Mol. Cancer Ther. 2007, 6, 3122-3130.

30. Sykes, B. M.; Atwell, G. J.; Hogg, A.; Wilson, W. R.; O'Connor, C. J.; Denny, W. A., N-Substituted 2-(2,6-Dinitrophenylamino)propanamides: Novel Prodrugs That Release a Primary Amine via Nitroreduction and Intramolecular Cyclization. J. Med. Chem. 1999, 42, 346-355.

31. Moselen, J. W.; Hay, M. P.; Denny, W. A.; Wilson, W. R., N-[2-(2-Methyl-5nitroimidazolyl)ethyl]-4-(2-nitroimidazolyl)butanamide (NSC 639862), a bisnitroimidazole with enhanced selectivity as a bioreductive drug. Cancer Res. 1995, 55, 574-80.

32. Knox, R. J.; Friedlos, F.; Marchbank, T.; Roberts, J. J., Bioactivation of CB 1954: reaction of the active 4-hydroxylamino derivative with thioesters to form the ultimate DNA-DNA interstrand crosslinking species. Biochem. Pharmacol. 1991, 42, 1691-7.

33. Stratford, I. J.; O'Neill, P.; Sheldon, P. W.; Silver, A. R. J.; Walling, J. M.; Adams, G. E., RSU 1069, a nitroimidazole containing an aziridine group. Bioreduction greatly increases cytotoxicity under hypoxic conditions. Biochem. Pharmacol. 1986, 35, 105-9.

34. Binger, M.; Workman, P., Pharmacokinetic contribution to the improved therapeutic selectivity of a novel bromoethylamino prodrug (RB 6145) of the mixedfunction hypoxic cell sensitizer/cytotoxin N1-(1-aziridinomethyl)-2-nitro-1H-imidazole1-ethanol (RSU 1069). Cancer Chemother. Pharmacol. 1991, 29, 37-47.

35. Wilson, W. R.; Denny, W. A.; Twigden, S. J.; Baguley, B. C.; Probert, J. C., Selective toxicity of nitracrine to hypoxic mammalian cells. Br. J. Cancer 1984, 49, 21523.

36. Knox, R. J.; Burke, P. J.; Chen, S.; Kerr, D. J., CB 1954: From the Walker tumor to NQO2 and VDEPT. Curr. Pharm. Des. 2003, 9, 2091-2104. 
37. (a) Helsby, N. A.; Wheeler, S. J.; Pruijn, F. B.; Palmer, B. D.; Yang, S.; Denny, W. A.; Wilson, W. R., Effect of Nitroreduction on the Alkylating Reactivity and Cytotoxicity of the 2,4-Dinitrobenzamide-5-aziridine CB 1954 and the Corresponding Nitrogen Mustard SN 23862: Distinct Mechanisms of Bioreductive Activation. Chem. Res. Toxicol. 2003, 16, 469-478; (b) Palmer, B. D.; Wilson, W. R.; Atwell, G. J.; Schultz, D.; Xu, X. Z.; Denny, W. A., Hypoxia-Selective Antitumor Agents. 9. Structure-Activity Relationships for Hypoxia-Selective Cytotoxicity among Analogs of 5-[N,N-Bis(2chloroethyl)amino]-2,4-dinitrobenzamide. J. Med. Chem. 1994, 37, 2175-84; (c) Palmer, B. D.; Wilson, W. R.; Anderson, R. F.; Boyd, M.; Denny, W. A., Hypoxia-Selective Antitumor Agents. 14. Synthesis and Hypoxic Cell Cytotoxicity of Regioisomers of the Hypoxia-Selective Cytotoxin 5-[N,N-Bis(2-chloroethyl)amino]-2,4-dinitrobenzamide. $J$. Med. Chem. 1996, 39, 2518-2528.

38. Helsby, N. A.; Ferry, D. M.; Patterson, A. V.; Pullen, S. M.; Wilson, W. R., 2Amino metabolites are key mediators of CB 1954 and SN 23862 bystander effects in nitroreductase GDEPT. Br. J. Cancer 2004, 90, 1084-1092.

39. Patterson, A. V.; Ferry, D. M.; Edmunds, S. J.; Gu, Y.; Singleton, R. S.; Patel, K. B.; Pullen, S. M.; Hicks, K. O.; Syddall, S. P.; Atwell, G. J.; Yang, S.; Denny, W. A.; Wilson, W. R., Mechanism of action and preclinical antitumor activity of the novel hypoxia-activated DNA cross-linking agent PR-104. Clin. Cancer Res. 2007, 13 (13), 3922-3932.

40. Firestone, A.; Mulcahy, R. T.; Borch, R. F., Nitro heterocycle reduction as a paradigm for intramolecular catalysis of drug delivery to hypoxic cells. J. Med. Chem. 1991, 34, 2933-5.

41. Duan, J.-X.; Jiao, H.; Kaizerman, J.; Stanton, T.; Evans, J. W.; Lan, L.; Lorente, G.; Banica, M.; Jung, D.; Wang, J.; Ma, H.; Li, X.; Yang, Z.; Hoffman, R. M.; Ammons, W. S.; Hart, C. P.; Matteucci, M., Potent and highly selective hypoxia-activated achiral phosphoramidate mustards as anticancer drugs. J. Med. Chem. 2008, 51, 2412-2420.

42. Hay, M. P.; Sykes, B. M.; Denny, W. A.; Wilson, W. R., A 2-nitroimidazole carbamate prodrug of 5-amino-1-(chloromethyl)-3-[(5,6,7-trimethoxyindol-2yl)carbonyl]-1,2-dihydro-3H-ben[E]indole (amino-seco-CBI-TMI) for use with ADEPT and GDEPT. Bioorg. Med. Chem. Lett. 1999, 9, 2237-2242.

43. Hay, M. P.; Wilson, W. R.; Denny, W. A., Design, synthesis and evaluation of imidazolylmethyl carbamate prodrugs of alkylating agents. Tetrahedron 2000, 56, 645657. 
44. Borch, R. F.; Canute, G. W., Synthesis and antitumor properties of activated cyclophosphamide analogs. J. Med. Chem. 1991, 34, 3044-52.

45. Li, F.; Patterson, A. D.; Hoefer, C. C.; Krausz, K. W.; Gonzalez, F. J.; Idle, J. R., Comparative metabolism of cyclophosphamide and ifosfamide in the mouse using UPLC-ESI-QTOFMS-based metabolomics. Biochem. Pharmacol. 2010, 80, 1063-1074.

46. Borch, R. F.; Liu, J.; Schmidt, J. P.; Marakovitz, J. T.; Joswig, C.; Gipp, J. J.; Mulcahy, R. T., Synthesis and evaluation of nitroheterocyclic phosphoramidates as hypoxia-selective alkylating agents. J. Med. Chem. 2000, 43, 2258-2265.

47. Mulcahy, R. T.; Gipp, J. J.; Schmidt, J. P.; Joswig, C.; Borch, R. F., Nitrobenzyl Phosphorodiamidates as Potential Hypoxia-Selective Alkylating Agents. J. Med. Chem. 1994, 37, 1610-15.

48. Borch, R. F.; Liu, J.; Joswig, C.; Baggs, R. B.; Dexter, D. L.; Mangold, G. L., Antitumor Activity and Toxicity of Novel Nitroheterocyclic Phosphoramidates. J. Med. Chem. 2001, 44, 74-77.

49. Thomson, P.; Naylor, M. A.; Stratford, M. R. L.; Lewis, G.; Hill, S.; Patel, K. B.; Wardman, P.; Davis, P. D., Hypoxia-driven elimination of thiopurines from their nitrobenzyl prodrugs. Bioorg. Med. Chem. Lett. 2007, 17, 4320-4322.

50. Zeman, E. M.; Brown, J. M.; Lemmon, M. J.; Hirst, V. K.; Lee, W. W., SR-4233: a new bioreductive agent with high selective toxicity for hypoxic mammalian cells. Int J Radiat Oncol Biol Phys 1986, 12, 1239-42.

51. Brown, J. M., SR 4233 (tirapazamine): a new anticancer drug exploiting hypoxia in solid tumors. Br. J. Cancer 1993, 67, 1163-70.

52. Denny, W. A., Prodrug strategies in cancer therapy. Eur. J. Med. Chem. 2001, 36, 577-595.

53. Fitzsimmons, S. A.; Lewis, A. D.; Riley, R. J.; Workman, P., Reduction of 3amino-1,2,4-benzotriazine-1,4,-di-N-oxide to a DNA-damaging species: a direct role for NADPH:cytochrome P450 oxidoreductase. Carcinogenesis 1994, 15 (8), 1503-1510. 
54. Lloyd, R. V.; Duling, D. R.; Rumyantseva, G. V.; Mason, R. P.; Bridson, P. K., Microsomal reduction of 3-amino-1,2,4,-benzotriazine 1,4-dioxide to a free radical. Mol. Pharmacol. 1991, 40, 440-445.

55. Costa, A. K.; Baker, M. A.; Brown, J. M.; Trudell, J. R., In vitro hepatotoxicity of SR 4233 (3-amino-1,2,4-benzotriazine-1,4-dioxide), a hypoxic cytotoxin and potential antitumor agent. Cancer Res 1989, 49, 925-9.

56. McKeown, S. R.; Cowen, R. L.; Williams, K. J., Bioreductive drugs: from concept to clinic. Clin Oncol (R Coll Radiol) 2007, 19, 427-42.

57. Von, P. J.; Von, R. R.; Gatzemeier, U.; Boyer, M.; Elisson, L. O.; Clark, P.; Talbot, D.; Rey, A.; Butler, T. W.; Hirsh, V.; Olver, I.; Bergman, B.; Ayoub, J.; Richardson, G.; Dunlop, D.; Arcenas, A.; Vescio, R.; Viallet, J.; Treat, J., Tirapazamine plus cisplatin versus cisplatin in advanced non-small-cell lung cancer: a report of the international CATAPULT I study group. J. Clin. Oncol. 2000, 18, 1351-1359.

58. Chen, Y.; Hu, L., Design of anticancer prodrugs for reductive activation. Med. Res. Rev. 2009, 29 (1), 29-64.

59. Baker, M. A.; Zeman, E. M.; Hirst, V. K.; Brown, J. M., Metabolism of SR 4233 by Chinese hamster ovary cells: basis of selective hypoxic cytotoxicity. Cancer Res. 1988, 48, 5947-52.

60. Laderoute, K. L.; Wardman, P.; Rauth, M., Molecular mechanisms for the hypoxia-dependent activation of 3-amino-1,2,4-benzotriazine 1,4-dioxide (SR4233). Biochem. Pharmacol. 1988, 37 (8), 1487-1495.

61. Daniels, J. S.; Gates, K. S., DNA Cleavage by the Antitumor Agent 3-Amino1,2,4-benzotriazine 1,4-Dioxide (SR4233): Evidence for Involvement of Hydroxyl Radical. J. Am. Chem. Soc. 1996, 118 (14), 3380-3385.

62. Daniels, J. S.; Gates, K. S.; Tronche, C.; Greenberg, M. M., Direct evidence for bimodal DNA damage induced by tirapazamine. Chem. Res. Toxicol. 1998, 11 (11), 1254-1257.

63. Chowdhury, G.; Junnutula, V.; Daniels, J. S.; Greenberg, M. M.; Gates, K. S., DNA strand damage analysis provides evidence that the tumor cell-specific cytotoxin 
tirapazamine produces hydroxyl radical and acts as a surrogate for O2. J. Am. Chem. Soc. 2007, 129, 12870-12877.

64. (a) Shinde, S. S.; Anderson, R. F.; Hay, M. P.; Gamage, S. A.; Denny, W. A., Oxidation of 2-Deoxyribose by Benzotriazinyl Radicals of Antitumor 3-Amino-1,2,4benzotriazine 1,4-Dioxides. J. Am. Chem. Soc. 2004, 126 (25), 7865-7874; (b) Anderson, R. F.; Shinde, S. S.; Hay, M. P.; Gamage, S. A.; Denny, W. A., Radical properties governing the hypoxia-selective cytotoxicity of antitumor 3-amino-1,2,4-benzotriazine 1,4-dioxides. Org. Biomol. Chem. 2005, 3 (11), 2167-2174.

65. Junnotula, V.; Sarkar, U.; Sinha, S.; Gates, K. S., Initiation of DNA strand cleavage by 1,2,4-benzotriazine 1,4-dioxides: mechanistic insight from studies of 3methyl-1,2,4-benzotriazine 1,4-dioxide. J. Am. Chem. Soc. 2009, 131, 1015-1024.

66. Boelsterli, U. A.; Ho, H. K.; Zhou, S.; Leow, K. Y., Bioactivation and hepatotoxicity of nitroaromatic drugs. Curr. Drug Metab. 2006, 7, 715-727.

67. (a) Rooseboom, M.; Commandeur, J. N. M.; Vermeulen, N. P. E., Enzymecatalyzed activation of anticancer prodrugs. Pharm. Rev. 2004, 56, 53-102; (b) Fitzsimmons, S. A.; Workman, P. A.; Grever, M.; Paull, K.; Camalier, R.; Lewis, A. D., Reductase enzyme expression across the National Cancer Institute tumor cell line panel: correlation with sensitivity to mitomycin C and E09. J. Natl. Cancer Inst. 1996, 88, 259269.

68. Rajapakse, A.; Gates, K. S., Hypoxia-Selective, Enzymatic Conversion of 6Nitroquinoline into a Fluorescent Helicene: Pyrido[3,2-f]quinolino[6,5-c]cinnoline 3Oxide. J. Org. Chem. 2012, 77, 3531-3537.

69. Hay, M. P.; Pchalek, K.; Pruijn, F. B.; Hicks, K. O.; Siim, B. G.; Anderson, M. M.; Shinde, S. S.; Denny, W. A.; Wilson, W. R., Hypoxia-selective 3-alkyl 1,2,4benzotriazine 1,4-dioxides: the influences of hydrogen bond donors on extravascular transport and antitumor activity. J. Med. Chem. 2007, 50 (26), 6654-6664. 


\section{Chapter 2}

\section{Hypoxia-selective, enzymatic conversion of 6-nitroquinoline into a}

fluorescent helicene: pyrido[3,2-f]quinolino[6,5-c]cinnoline 3-oxide

\subsection{Hypoxia as a parameter to be determined qualitatively and quantitatively.}

Hypoxia or low oxygen concentrations exist in disease conditions such as ischemia, stroke, inflammation and solid tumors, and in normal human physiology. ${ }^{1}$ Transient regions of hypoxia, reportedly present in stem tissues may have an effect on controlling cell division and differentiation during hematopoiesis and embryogenesis. ${ }^{2}$

Oxygen concentration in a normal healthy cell is within a range of 20 to $90 \mu \mathrm{M}$ (14-65 mm Hg). ${ }^{3}$ Any concentration below $20 \mu \mathrm{M}$ is considered hypoxia. ${ }^{4}$ Efforts were made to quantify hypoxia using an oxy probe, radiochemical imaging and immunohistochemical staining methods. ${ }^{5}$ Practical and technical difficulties limit accuracy and applicability of these techniques. ${ }^{6}$ Hence, there is a demand for a noninvasive tool which can qualitatively and quantitatively characterize tumor hypoxia in biological conditions. Fluorescent probes can be designed to light up inside the hypoxic tumor under physiological conditions, and the fluorescence outcome can be used as a parameter that can be measured and relate to the oxygen concentration of tumors. ${ }^{7}$ 


\subsection{Fluorescent probes to detect hypoxia}

Several approaches have been used to deliver a fluorescent agent into the tumor setting to mark hypoxic tissues. One method is to use nitro-aromatic non-fluorescent

compound which converts to a fluorescent amino metabolite under hypoxic conditions. ${ }^{7-8}$ Enzyme mediated cellular reduction of nitroaromatics, under low oxygen levels, has been reported and developed as a concept in biochemical research. The reduction process consists of consecutive addition of six electrons, in a stepwise manner to produce the final reduced product, the respective arylamine. ${ }^{9}$ The hypoxia selectivity arises within the first reduction step where the nitro radical anion back-oxidizes to the parent nitro compound in the presence of oxygen. ${ }^{9 \mathrm{~d}, \mathrm{e}, 10}$ The first electron addition step is oxygen sensitive and the remaining one electron addition steps may be oxygen sensitive. Niroso compound would next be converted to hydroxylamine intermediate by adding two electrons and in the final two electrons addition produces the amino product. (Scheme $2.1)^{11}$

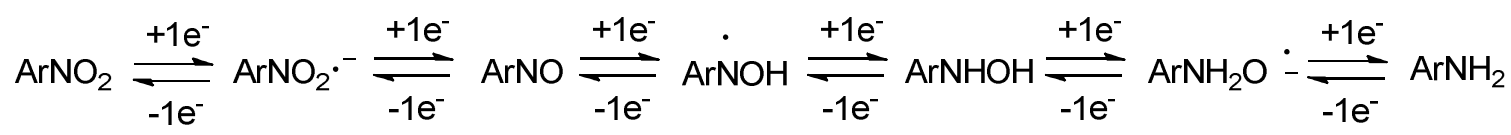

Scheme 2.1. Enzymatic reduction profile of nitroaromatic compound

\subsection{Reduction of 42 to obtain 43 under anaerobic conditions}

Non-fluorescent nitroaromatic compound 6-nitroquinoline $\mathbf{4 2}$ was used as a small molecule nitroaromatic probe to detect hypoxia. The compound $\mathbf{4 2}$ may be reduced under low oxygen levels and under bio-reductive conditions to produce fluorescent metabolite, 6-aminoquinoline (43, Scheme 2.2$)$ 


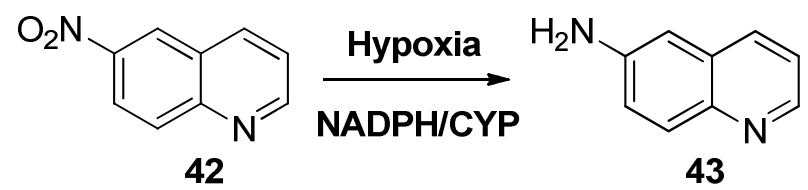

Scheme 2.2. Hypoxic metabolism of 42 is expected to form fluorescent 43

The amino compound $\mathbf{4 3}$ is a known fluorescent molecule and the reduction of $\mathbf{4 2}$ to $\mathbf{4 3}$ step yields a good Strokes shift of $205 \mathrm{~nm} .{ }^{12}$ The probe $\mathbf{4 2}$ is non-fluorescent in aqueous sodium phosphate buffer at $\mathrm{pH} 7.4$ (Figure 1A, column 1). ${ }^{11}$ The enzyme NADPH:cytochrome P450 reductase, a known reductase that reduces nitrocompounds in cells is used as the reducing enzyme with assistance of the substrate NADPH to reduce 42 under hypoxia. ${ }^{9 c, 13}$ The hypoxic reduction reaction forms fluorescence with an impressive 63 -fold increase at $445 \mathrm{~nm}$, indicating conversion of the non-fluorescent $\mathbf{4 2}$ to a fluorescent metabolite (Figure 1A, column 5). The enzymatic reduction of $\mathbf{4 2}$ under aerobic conditions produced no fluorescence (Figure 1A, column 4). Similarly, when non fluorescent electron acceptor benzotriazine 1,2,4-di-oxide was used in aerobic and anaerobic enzymatic reduction reactions, very low fluorescence was observed (Figure 1A, columns 2 and 3). Careful inspection of the shape of the fluorescent curve in Figure 1, column 5 showed that the fluorescence emission curve does not resemble the fluorescence curve of authentic $\mathbf{4 3}$. The fluorescence emission curve of $\mathbf{4 3}$ is broader at $445 \mathrm{~nm}$ and $530 \mathrm{~nm}$ regions (Figure 1B blue line) and, instead consists of a pair of emission maxima at 440 and $460 \mathrm{~nm}$. The unexpected fluorescence, yielded in the hypoxic metabolism of $\mathbf{4 2}$, was explored to identify and characterize the fluorescent metabolite. 

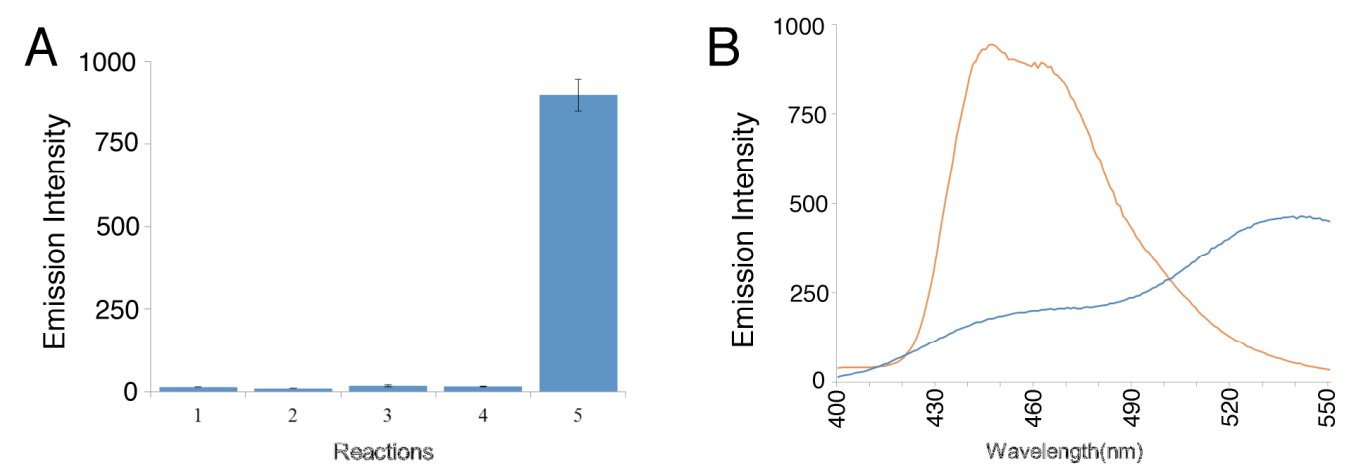

Figure 2.1. Enzymatic conversion of 42 into a fluorescent product under hypoxic conditions. A. Fluorescence emission at $445 \mathrm{~nm}(\lambda \mathrm{ex} 307 \mathrm{~nm})$ for: (1) a control sample of compound 42 alone $(0.8 \mathrm{mM})$, (2) a control reaction composed of NADPH:cytochrome P450 reductase $(1.1 \mathrm{U} / \mathrm{mL})$, NADPH $(2.4 \mathrm{mM})$, and a non-fluorescent electron acceptor 1,2,4-benzotriazine 1,4-dioxide (6.4 mM) under aerobic conditions, (3) a control reaction composed of NADPH:cytochrome P450 reductase, NADPH, and a non-fluorescent electron acceptor 1,2,4-benzotriazine 1,4-dioxide $(6.4 \mathrm{mM})$ under anaerobic conditions, (4) compound 42 $(0.8 \mathrm{mM})+\mathrm{NADPH}$ :cytochrome $\mathrm{P} 450$ reductase and NADPH under aerobic conditions, (5) compound 42 $(0.8 \mathrm{mM})+$ cytochrome $\mathrm{P} 450$ reductase and NADPH anaerobic. Reactions were incubated for $18 \mathrm{~h}$ in sodium phosphate buffer at $(12 \mathrm{mM}, \mathrm{pH} 7.4)$ at $24{ }^{\circ} \mathrm{C}$, then diluted with aerobic sodium phosphate buffer (12 mM, pH 7.4) and the fluorescence measured $\left(\lambda_{\mathrm{ex}} 307 \mathrm{~nm}, \lambda_{\mathrm{em}} 445 \mathrm{~nm}\right)$. It is important to note that NADPH exhibits fluorescence with an emission maximum at $445 \mathrm{~nm}$. However, control experiments showed that any NADPH left unconsumed at the end of the anaerobic reactions described here is ultimately converted to the non-fluorescent NADP+ product by enzyme-driven redox cycling of the electron accepting organic substrate upon opening the reaction vessel to air and dilution with aerobic buffer prior to fluorescence measurements. B. Fluorescence spectrum of the reaction mixture generated in the anaerobic metabolism of $\mathbf{4 2}$ by NADPH:cytochrome P450 reductase as described for reaction 5 above (orange line, with emission maxima at 440 and $450 \mathrm{~nm})$ and fluorescence spectrum of 6 -aminoquinoline $\left(43,50 \mu \mathrm{M}, \lambda_{\mathrm{ex}}\right.$ $340 \mathrm{~nm}$, in sodium phosphate buffer, $10 \mathrm{mM}, \mathrm{pH} 7.4){ }^{11}$

\subsection{Identification of products arising from the anaerobic reaction}

The anaerobic reaction mixture of metabolism of 42 , mediated by NADPH:cytochrome P450 reductase was analyzed using LC/MS. Two major products were identified in addition to the remaining starting material 42 (Figure $2.2 \mathrm{~A}$ ). Confirming the analysis of the fluorescence spectrum of the anaerobic reaction mixture, 43, the product expected by the original six electron reduction process was not observed in the LC/MS analysis. Under the same LC/MS conditions 43 appears at approximately $4.5 \mathrm{~min}$ (Figure $\mathrm{S} 1$ ). One of the products, eluting at $19.4 \mathrm{~min}$ in the UV trace has $\mathrm{m} / \mathrm{z}$ 
value of 301 (Figure 2.2 B). The $[\mathrm{M}+\mathrm{H}]^{+}$ion of 6,6'-azoxyquinoline would have a massto-charge ratio of $301(\mathbf{4 5}$, Scheme 2.2). Formation of $\mathbf{4 5}$ under relevant conditions is expected to be produced, based on precedents which suggest condensation of intermediates 6-nitrosoquinoline and 6-hydroxylaminoquinoline that are formed along the reduction path. ${ }^{14}$ An authentic sample of $\mathbf{4 5}$, synthesized from reducing $\mathbf{4 2}$ by hydrazine hydrate in the presence of Raney nickel gave similar LC/MS spectra with a peak at 19.4 min (Figures $2.2 \mathrm{E}$ and $\mathrm{F}$ ). ${ }^{15}$ Compound 45 is non-fluorescent under the applied conditions in the solution. Hence the fluorescence should arise from the product appearing at $15 \mathrm{~min}$ in the LC trace. There is evidence that complex dimmers such as $\mathbf{4 4}$ could be fluorescent. ${ }^{16}$ The mass-to-charge ratio of the new product was 299 (Figure 2.2 C). A simple, quinoline dimer such as azoxy or azo does not have a $\mathrm{m} / \mathrm{z}$ of 299 , rather a more complex quinoline-based bi aryl compound such as pyrido[3,2-f]quinolino[6,5c] cinnoline 3-oxide (44, Scheme 2.3) or dipyrido[3,2-a:3',2'-h]phenazine 7-oxide (46, Scheme 2.3) does have the observed $\mathrm{m} / \mathrm{z}$ value. 

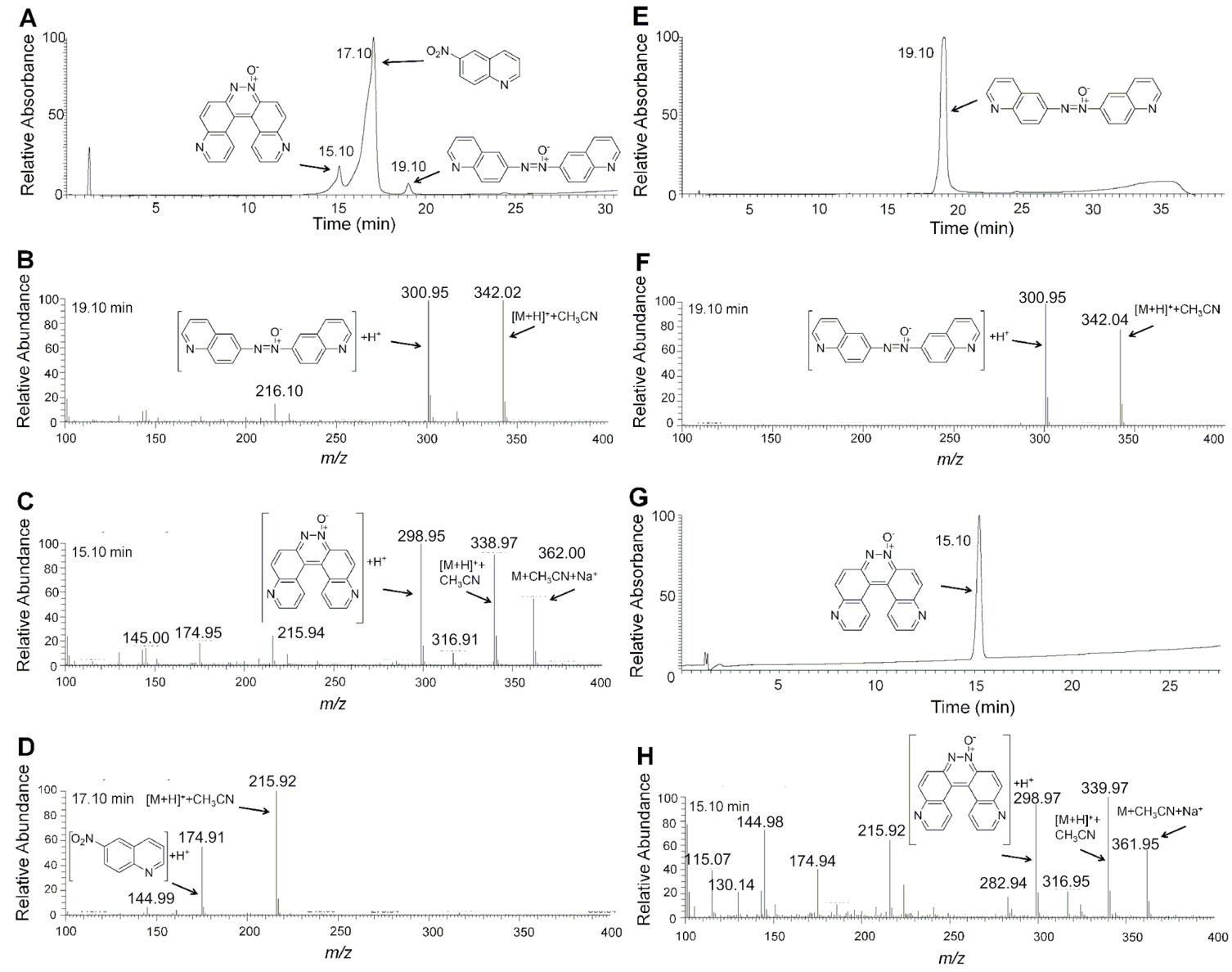

Figure 2.2. LC/MS analysis of the reaction mixture generated by anaerobic metabolism of $\mathbf{4 2}(0.8 \mathrm{mM})$ by cytochrome p450 reductase $(1.1 \mathrm{U} / \mathrm{mL})$ and NADPH $(6.4 \mathrm{mM})$. The enzymatic reduction of $\mathbf{4 2}$ was carried out as described in the experimental section and the legend of Figure 2.1. The reaction was dried and products dissolved in methanol. The mixture was eluted with a gradient of $99 \% \mathrm{~A}$ (water containing $0.1 \%$ acetic acid) and 1\% B (acetonitrile containing $0.1 \%$ acetic acid) followed by linear increase to $90 \% \mathrm{~B}$ over $30 \mathrm{~min}$. The elution was continued at $90 \% \mathrm{~B}$ for $3 \mathrm{~min}$ and then B was decreased to $1 \%$ over next $8 \mathrm{~min}$. A flow rate of $0.35 \mathrm{~mL} / \mathrm{min}$ was used and the metabolites were detected at $254 \mathrm{~nm}$. Mass spectra were obtained using electrospray ionization in the positive ion mode. Panel A: HPLC of the anaerobic reaction mixture monitoring absorbance at $254 \mathrm{~nm}$. Panel B: LC/MS spectrum of the product eluting at $19.1 \mathrm{~min}$. Panel C: LC/MS spectrum of the product eluting at $15.1 \mathrm{~min}$. Panel D: LC/MS spectrum for of the product eluting at $17.1 \mathrm{~min}$. Panel E: HPLC retention time of authentic $\mathbf{4 5}$ monitoring absorbance at $254 \mathrm{~nm}$. Panel F: LC/MS spectrum of authentic 45. Panel G: HPLC retention time of authentic $\mathbf{4 4}$ monitoring absorbance at $254 \mathrm{~nm}$. Panel H: LC/MS spectrum of authentic 44. 

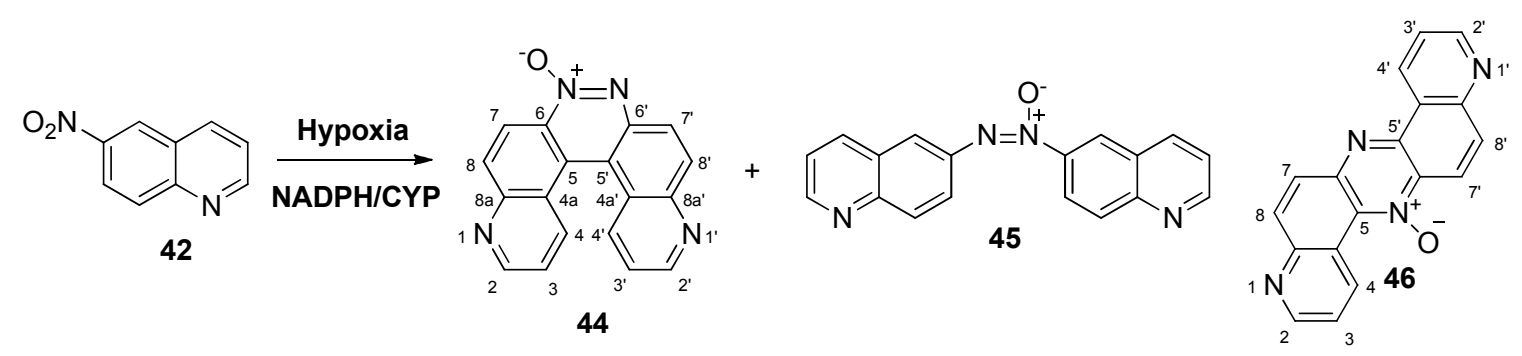

Scheme 2.3. Metabolites formed by the reduction of $\mathbf{4 2}$ with NADPH/CYP450R

According to precedents, helicenes are structurally similar to $\mathbf{4 4}$, and are fluorescent. ${ }^{16}$ Hence, the enzymatic reduction of $\mathbf{4 2}$, under above condition might be producing 44.The two structures $\mathbf{4 4}$ and $\mathbf{4 6}$ have same molecular formula. Huisgen proposed that compound $\mathbf{4 4}$ is formed in a reaction when $\mathbf{4 2}$ is reduced by sodium methoxide. ${ }^{17}$ Farrar claimed that Huisgen was obtaining compound 46, not $\mathbf{4 4} .{ }^{18}$ Moreover, Farrar carried out reduction of $\mathbf{4 2}$, with alkaline glucose as suggested by Galbraith et al to produce 45. Farrar claimed that alkaline glucose mediated reduction of $\mathbf{4 2}$ actually produces $\mathbf{4 4}$ not $\mathbf{4 5}{ }^{18}$

\subsection{Synthesis and structural characterization of 44}

Galbraith's alkaline glucose reduction of $\mathbf{4 2}$ has been successfully used as the chemical method to synthesize $44 .{ }^{19}$ The thin layer chromatographic (TLC) properties of the product of enzymatic reduction of $\mathbf{4 2}$ are compared with that of the product, obtained by the chemical synthesis. The blue fluorescent product showed similar migration with different solvent systems on TLC, suggesting two different reactions produce the same chemical product. Hence, we separated the suspected product from the chemical synthesis by preparative TLC and carried out full spectroscopic characterization (see materials and methods). The molecular formula obtained from a high-resolution mass 
spectrometric analysis of product, formed by alkaline glucose reduction of $\mathbf{4 2}$, matches with structures 44 or 46 . Presence of 18 different ${ }^{13} \mathrm{C}$ resonances suggested that the dimmer is not symmetric, but rather contains a complex asymmetric structure. The ${ }^{1} \mathrm{H}$ NMR analysis showed ten hydrogen resonances; aryl-aryl bridge between two quinoline molecules might be present in the structure. The 5 proton of $\mathbf{4 6}$ was expected to be downfielded to $\geq 9.3 \mathrm{ppm}$ due to its proximity to the $N$-oxide oxygen (We used a quinolone based numbering system in the section). ${ }^{20}$ In the product, a resonance at 9.3 ppm is absent. The fluorescence of enzymatic metabolite and NMR properties are supportive of $\mathbf{4 4}$ as the possible structure for the metabolite. Moreover, COSY and TOCSY spectra analysis allowed assigning resonances for 4 and 4' protons for structure 44. NOE experiment results showed a correlation between 4 and 4' protons that arises due to close proximity between two protons. The NOE correlation between 4 and 4'can be only present in $\mathbf{4 4}$. In $\mathbf{4 6}$, the protons 4 and 4' are unable to produce NOE resonance. Ultimately, the actual structure obtained from alkaline glucose reduction of $\mathbf{4 2}$ shows the distance between protons 4 and 4' is $2.5 \AA$ (Figure 4).

The NMR data obtained from the enzymatically synthesized $\mathbf{4 4}$ was compared with the NMRs of chemically synthesized $\mathbf{4 4}$. The ${ }^{1} \mathrm{H}$ NMR resonances and peak shifts obtained from the enzymatic reaction matched with that obtained from the glucose reduction. NOE spectrum of the enzymatic product shows a correlation between 4 and 4' protons, similar to the NOE result obtained from the glucose reduction. This observation confirms that product $\mathbf{4 4}$ is the metabolite produced in the anaerobic enzymatic reaction. The complete NMR analysis including TOCSY, COSY, HMQC, and HMBC data were consistent with the azoxy-helicene 44 (Table 1). 


\begin{tabular}{|c|c|c|c|c|c|c|}
\hline position & $\delta_{\mathrm{C}}$ & $\delta_{\mathrm{H}}(\mathrm{J}$ in $\mathrm{Hz})$ & COSY & TOCSY & $\mathrm{HMBC}^{\mathrm{a}}$ & NOE \\
\hline 2 & 153.4 & $\begin{array}{lll}9.15 & 1 \mathrm{H}, & \mathrm{d} \\
(4.5) & & \end{array}$ & 3 & $3^{\prime}, 4^{\prime}$ & $4^{\prime}, 8 a^{\prime}$ & $3^{\prime}$ \\
\hline 2 & 151.5 & $9.051 \mathrm{H}, \mathrm{m}$ & 3 & 3,4 & $4,8 \mathrm{a}$ & 3 \\
\hline 3 & 120.5 & $\begin{array}{l}7.46 \quad 1 \mathrm{H}, \quad \mathrm{dd} \\
(9.0,4.5)\end{array}$ & $2^{\prime}, 4^{\prime}$ & $2^{\prime}, 4^{\prime}$ & $4 a^{\prime}$ & $2^{\prime}, 4^{\prime}$ \\
\hline 3 & 120.7 & $\begin{array}{l}7.41 \quad 1 \mathrm{H}, \quad \mathrm{dd} \\
(9.0,4.5)\end{array}$ & 2,4 & 2,4 & $4 \mathrm{a}$ & 2,4 \\
\hline 4 & 136.0 & $\begin{array}{lll}8.87 & 1 \mathrm{H}, & \mathrm{d} \\
(9.0) & & \end{array}$ & $3^{\prime}$ & $3^{\prime}, 2^{\prime}$ & $2^{\prime}, 8 a^{\prime}$ & 4 \\
\hline 4 & 134.8 & $\begin{array}{lll}8.67 & 1 \mathrm{H}, & \mathrm{d} \\
(9.0) & & \end{array}$ & 3 & 3,2 & $2,8 \mathrm{a}$ & $4 '$ \\
\hline 5 & 128.0 & & & & & \\
\hline 5 & 114.2 & & & & & \\
\hline 4'a & 123.4 & & & & & \\
\hline $4 a$ & 123.5 & & & & & \\
\hline 7 & 121.8 & $9.051 \mathrm{H}, \mathrm{m}$ & $8^{\prime}$ & $8^{\prime}$ & $8 a^{\prime}, 5^{\prime}$ & $8^{\prime}$ \\
\hline 7 & 127.4 & $\begin{array}{lll}8.23 & 1 \mathrm{H}, & \mathrm{d} \\
(9.0) & & \end{array}$ & 8 & 8 & $8 \mathrm{a}, 5$ & 8 \\
\hline 8 & 133.4 & $\begin{array}{lll}8.43 & 1 \mathrm{H}, & \mathrm{d} \\
(9.0) & & \end{array}$ & $7^{\prime}$ & $7^{\prime}$ & $6^{\prime}, 4 a^{\prime}$ & $7^{\prime}$ \\
\hline 8 & 134.3 & $\begin{array}{lll}8.41 & 1 \mathrm{H}, & \mathrm{d} \\
(9.0) & & \end{array}$ & 7 & 7 & $6,4 a$ & 7 \\
\hline $6^{\prime}$ & 137.1 & & & & & \\
\hline 6 & 144.1 & & & & & \\
\hline 8 'a & 149.7 & & & & & \\
\hline $8 \mathrm{a}$ & 148.5 & & & & & \\
\hline
\end{tabular}

Table 1. NMR Data $\left(\mathrm{CDCl}_{3}\right)$ for compound $44^{\mathrm{a}} \mathrm{HMBC}$ correlations are from the proton to the stated carbon(s). 
The ultimate confirmation of the structure 44 was carried out by X-ray crystallographic analysis (Figure 2.3$){ }^{21}$

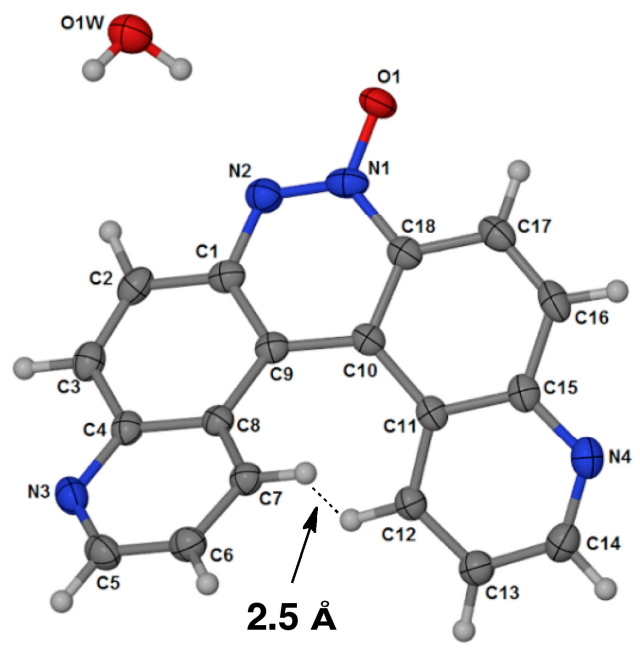

Figure 2.3. In 44, the 4 and 4'-hydrogens (see numbering system in Scheme 2.2) are close in space ${ }^{11}$

In summary, the spectroscopic and crystallographic characterization of $\mathbf{4 4}$ arising from the alkaline glucose reduction is consistent with Farrar's claim; $\mathbf{4 4}$ produced in the alkaline glucose reduction of $\mathbf{4 2}$. More importantly $\mathbf{4 4}$, produced by alkaline glucose method used as an authentic compound for comparison with the enzymatically produced 44. LC/MS properties of 44, produced under chemical and enzymatic methods showed matching retention times and $\mathrm{m} / \mathrm{z}$ results (Figure 2.2). The ${ }^{1} \mathrm{H}$ NMR analysis of the enzyme product resembles the authentic compound $\mathbf{4 4}$, made by the glucose reduction reaction. In addition, NOE experiment clearly shows the close distance between 4 and 4' protons of enzymatically-generated 44 . The fluorescence spectrum of $\mathbf{4 4}$, obtained from the glucose reduction (Figure 2.4) resembles the fluorescence spectrum obtained from the 
enzymatic reaction (Figure 2B). Close analysis of the spectra shows the similarity of emission maxima at 440 and $460 \mathrm{~nm}$ of both curves (Figure 2.1 and 2.4).

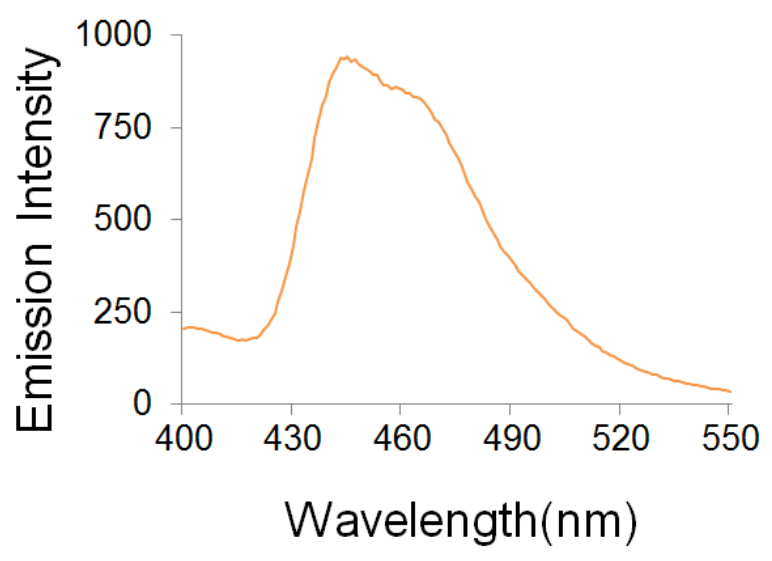

Figure 2.4. Fluorescence spectrum of authentic $45(50 \mu \mathrm{M}$, $\lambda$ ex $307 \mathrm{~nm})$ in sodium phosphate buffer (12 $\mathrm{mM}, \mathrm{pH}$ 7.4).

The azoxy functional group is known to be reduced to the corresponding azo group by NADPH:cytochrome P450 reductase. ${ }^{22}$ In this particular reaction compound $\mathbf{4 5}$ is not reduced to an azo product. 

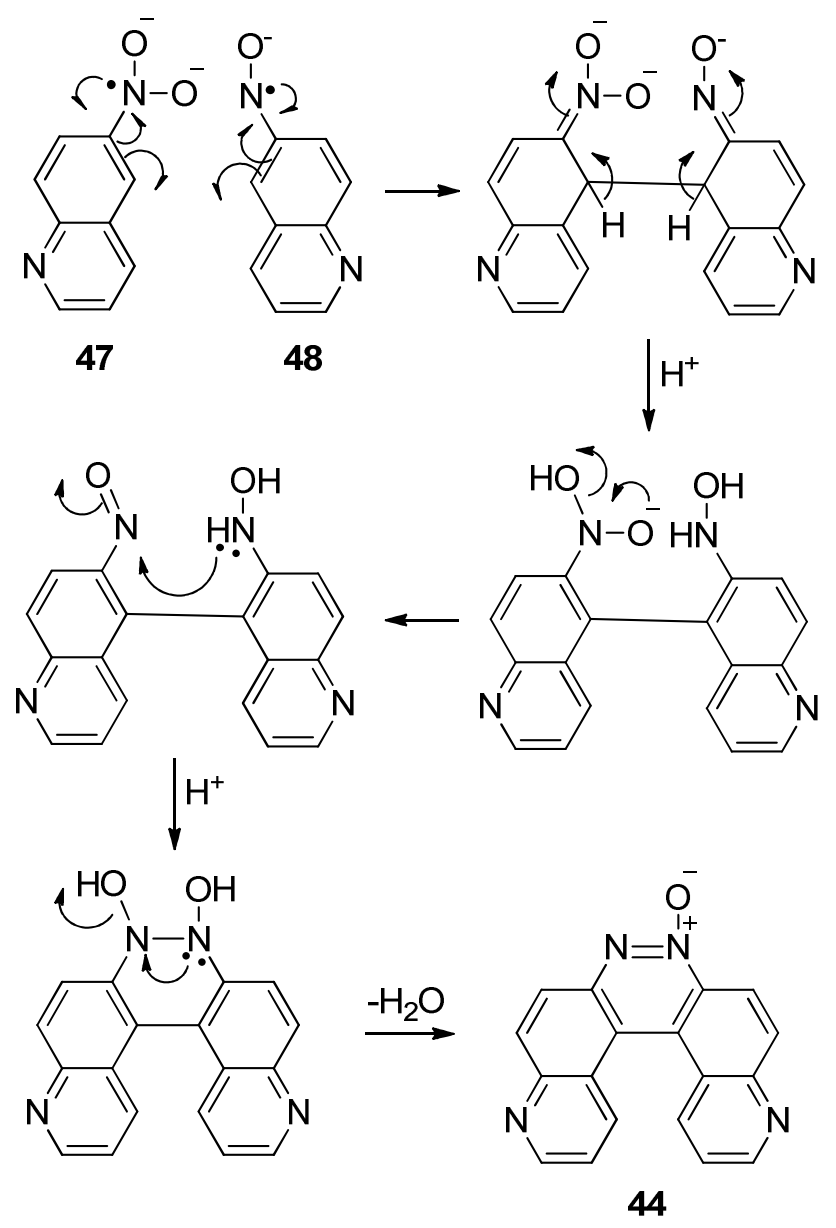

Scheme 2.4. Mechanism for the formation of 44 under anaerobic conditions

\subsection{Conclusion}

In conclusion, intermediate hydroxylamino or amino product were not observed in NADPH:cytochrome P450 reductase mediated reduction of $\mathbf{4 2}$ under hypoxic conditions. The azoxy compound 45 and the bi aryl bonded dimer 44 were formed under reductive conditions. The mechanism for the formation of $\mathbf{4 4}$ in the enzymatic reaction is 
complex. A possible pathway can be initiated when a nitroaryl radical 47 and a nitrosoaryl radical $\mathbf{4 8}$ are condensed to form a bi aryl bond to connect two quinolone groups and then tautomerization occurs toward an intramolecular condensation between hydroxylamine and nitroso moieties to produce 44 (Scheme 5).

Nitro aryl compounds are good candidates to selectively label hypoxic cells using

fluorescence under bio-reductive conditions. ${ }^{8 a, 23}$ Many probes have been synthesized but the products resulting from the bioreduction have not been characterized. ${ }^{7 \mathrm{a}, 23 \mathrm{a}, 24}$ Our work underlines the importance of characterization of complex metabolites that can arise in these reduction reactions of nitro-aromatic probes.

\subsection{Experimental}

Materials and methods. Materials were purchased from following sources: NADPH, cytochrome p450 reductase, sodium phosphate, DMF, glucose, Raney nickel slurry in water, silica gel (0.04-0.063 $\mathrm{mm}$ pore size) for column chromatography, and silica gel plates for thin layer chromatography from Sigma chemical company (St. Louis, MO); 6nitroquinoline, 6-aminoquinoline, and hydrazine hydrate from Alfa-Aesar (Ward Hill, MA); ethyl acetate, hexane, dichloromethane, methanol, ethanol, HPLC acetonitrile and HPLC water from Fischer; Deuterated NMR solvents were from Cambridge Isotope Laboratories (Andover, MA). The compound 1,2,4-benzotriazine-1,4-di-N-oxide was synthesized according literature methods. ${ }^{1}$ High resolution mass spectrometry (HRMS) analyses were performed at the mass spectroscopy facility of the University of Illinois Champaign-Urbana and low resolution mass spectroscopic analyses were carried out at 
the University of Missouri-Columbia. ${ }^{1} \mathrm{H}$ and ${ }^{13} \mathrm{C}$ NMR experiments and were done on a Bruker Avance DRX300 with 5 mm broadband probe and Bruker Avance DRX500 with CPTCI probe using deuterated NMR solvents methanol $\left(\mathrm{CD}_{3} \mathrm{OD}\right)$ and chloroform $\left(\mathrm{CDCl}_{3}\right)$ at the University of Missouri-Columbia. The reference peaks were set to $3.31 \mathrm{ppm}$ and $49.00 \mathrm{ppm}$ for deuterated methanol and $7.26 \mathrm{ppm}$ and $77.00 \mathrm{ppm}$ for deuterated chloroform from tetramethylsilane for the ${ }^{1} \mathrm{H}$ and ${ }^{13} \mathrm{C}$ spectra respectively. The fluorescence spectra were obtained on a Varian Cary Eclipse Fluorescence Spectrophotometer equipped with xenon flash lamp with instrumental slit width settings at $10 \mathrm{~nm}$ employing a $10 \mathrm{~mm}$ path length quartz cuvette.

\section{Procedure for hypoxic metabolism.}

In a typical enzymatic reaction, 42 ( $4 \mu \mathrm{L}$ from $50 \mathrm{mM}$ in DMF, final concentration 0.8 $\mathrm{mM}$ ) or non-fluorescent electron acceptor (24 $\mu \mathrm{L}$ from $50 \mathrm{mM}$ in $15 \%$ DMF water, final concentration $6.4 \mathrm{mM}$ ), was mixed with NADPH $(20-160 \mu \mathrm{L}$ of $10 \mathrm{mM}$, final concentration $0.8 \mathrm{mM}-6.4 \mathrm{mM})$, cytochrome p450 reductase $(2 \mu \mathrm{L}$ from $140 \mathrm{U} / \mathrm{mL}$, final concentration $1.1 \mathrm{U} / \mathrm{mL})$, sodium phosphate buffer $(6 \mu \mathrm{L}$ from $50 \mathrm{mM}$, final concentration $12 \mathrm{mM}, \mathrm{pH} 7.4)$ and HPLC water to obtain the final solution $(0.25 \mathrm{~mL}$, less than $2 \% \mathrm{DMF})$ at room temperature $\left(24^{0} \mathrm{C}\right)$. For anaerobic reactions, all reagents except NADPH and cytochrome p450 reductase were de-gassed in glass tubes by three freeze pump thaw cycles. The glass tubes were broke open inside an argon purged glove bag and bubbled with argon for five minutes. Solid NADPH was dissolved in HPLC water to make stock solution inside the glove bag and cytochrome p450 reductase was used as is from the original sample from the supplier. Upon mixing, the containers were wrapped with aluminum foil to prevent exposure to light. 


\section{Procedure for Fluorescence experiment}

Upon completion of incubation reaction solution was diluted up to $1 \mathrm{~mL}$ with sodium phosphate buffer $(50 \mathrm{mM}, \mathrm{pH} 7.4)$ in HPLC water, and then was added to the cuvette. In anaerobic experiments, upon completion the reaction mixtures were taken out of glove bag and kept $1 \mathrm{~h}$ under atmospheric conditions prior to the dilutions.

\section{Procedure for LC/MS analysis.}

In vitro enzymatic metabolism of $\mathbf{4 2}$ was carried out as described above, and the resulting products were extracted into ethyl acetate and dried using brine followed by roto vap evaporation of ethyl acetate. The solid was re-dissolved in methanol and analyzed by LC/MS in the positive ion mode. Separation of metabolites was carried using a C18 reverse phase Phenomenex Luna column (5 $\mu \mathrm{m}$ particle size, 100 A0 pore size, $150 \mathrm{~mm}$ length, $2.00 \mathrm{~mm}$ i.d.) and a ThermoSeparations liquid chromatograph (TSP4000), the metabolites were detected by their UV-absorbance at $254 \mathrm{~nm}$. The elution started with a gradient of $\mathrm{A}, 99 \%$ HPLC water $(0.1 \%$ acetic acid $)$ and $\mathrm{B}$ acetonitrile $(0.1 \%$ acetic acid $)$ followed by a linear increase to $90 \%$ B over the course of 30 min. The elution was continued at $90 \% \mathrm{~B}$ for $3 \mathrm{~min}$ and decreased to $1 \%$ over the next $8 \mathrm{~min}$. A flow rate of $0.35 \mathrm{~mL} / \mathrm{min}$ was used. The LC/ESI-MS analyses were carried out in the positive ion mode on a Finnigan TSQ 7000 triple quadrupole instrument using a $250 \mathrm{kV}$ needle voltage and at a capillary temperature of $250{ }^{\circ} \mathrm{C}$. 

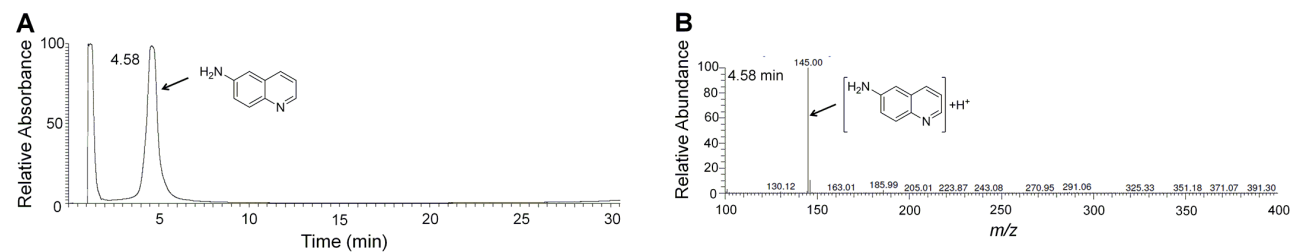

Figure S1. LC/MS analysis of 43. (A) UV chromatogram of 43, (B) LC/MS analysis of the product eluting at $4.6 \mathrm{~min}$ in the chromatogram.
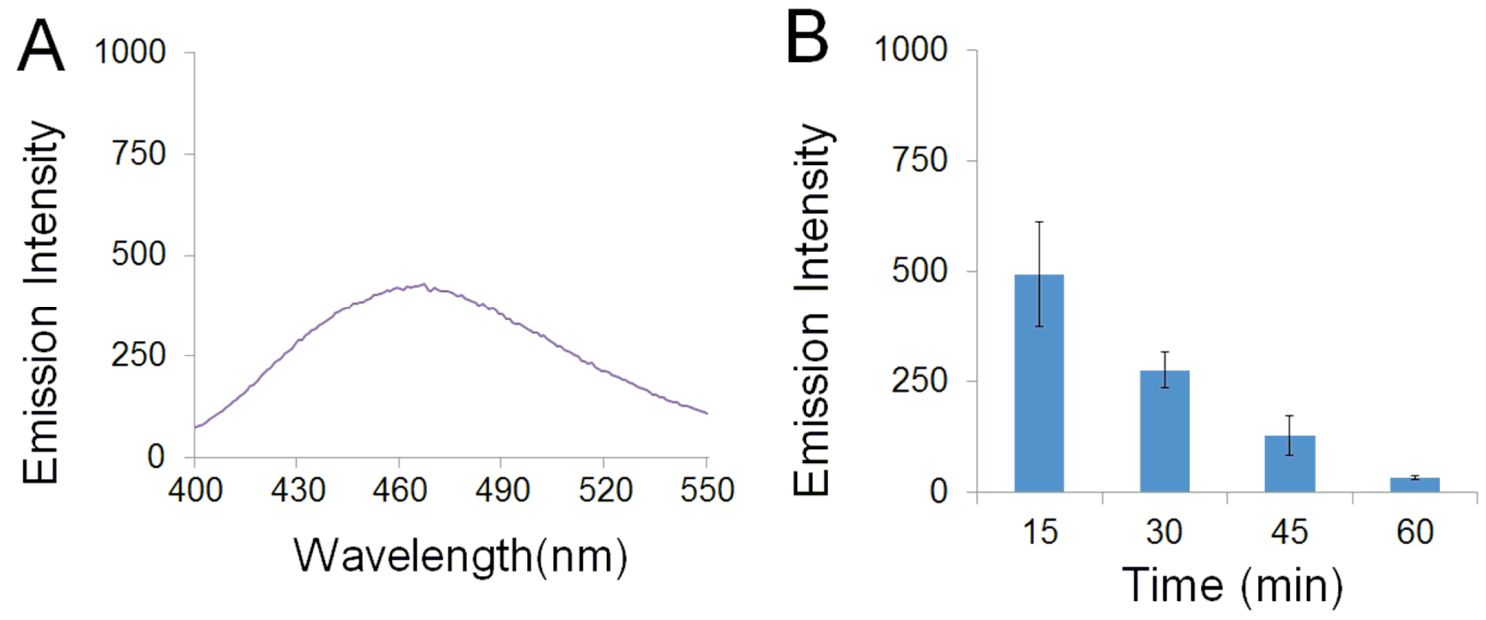

Figure S2. (A) Fluorescence spectrum of NADPH $\left(50 \mu \mathrm{M}, \lambda_{\text {ex }} 307 \mathrm{~nm}\right.$, in sodium phosphate buffer, 10 $\mathrm{mM}, \mathrm{pH}$ 7.4). It is noteworthy that the shape of the fluorescence emission peaks of NADPH and $\mathbf{4 4}$ are distinct. (B) NADPH fluorescence diminishes over the course of $1 \mathrm{~h}$ when the reactions are exposed to aerobic conditions. Reactions contained $42(0.8 \mathrm{mM})$, NADPH:cytochrome P450 reductase $(1.1 \mathrm{U} / \mathrm{mL})$, and NADPH ( $3 \mathrm{mM}$ ) in sodium phosphate buffer, $10 \mathrm{mM}$, pH $7.4\left(\lambda_{\mathrm{ex}} 307 \mathrm{~nm}, \lambda_{\mathrm{em}} 460 \mathrm{~nm}\right)$. Reactions described here were incubated quenched with aerobic buffer and incubated for approximately $1 \mathrm{~h}$ before fluorescence analysis. Thus, the control experiment provides evidence that fluorescence detected in the metabolism of $\mathbf{4 2}$ is not due to residual NADPH. 


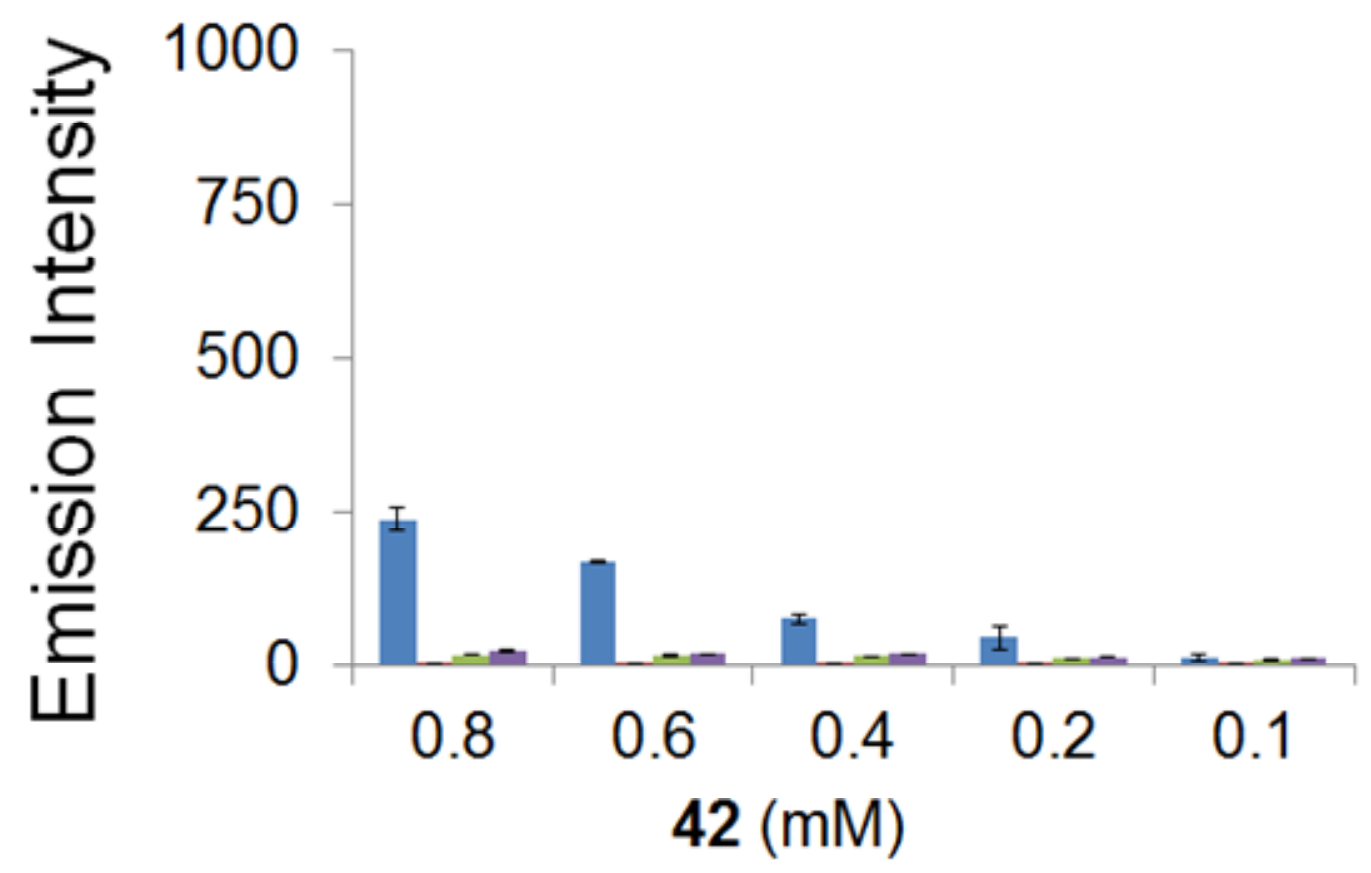

Figure S3. Fluorescence emission at $445 \mathrm{~nm}(\lambda$ ex $307 \mathrm{~nm})$ for reactions: compound $42(0.1-0.8 \mathrm{mM})+$ NADPH:cytochrome P450 reductase (1.1 U/mL), NADPH (0.1-0.8 mM) under anaerobic(blue) and aerobic (red), and a non-fluorescent electron acceptor 1-methyl-2-nitro-5-carbethoxyimidazole $(0.1-0.8 \mathrm{mM})+$ NADPH:cytochrome P450 reductase $(1.1 \mathrm{U} / \mathrm{mL})$, NADPH $(0.1-0.8 \mathrm{mM})$ under anaerobic (green) and aerobic (purple). Reactions were incubated for $18 \mathrm{~h}$ in sodium phosphate buffer at (12 mM, pH 7.4) at 24 ${ }^{\circ} \mathrm{C}$, then diluted with aerobic sodium phosphate buffer $(12 \mathrm{mM}, \mathrm{pH} 7.4)$ and the fluorescence measured ( $\lambda$ ex $307 \mathrm{~nm}, \lambda \mathrm{em} 445 \mathrm{~nm}$ ). It is important to note that NADPH exhibits fluorescence with an emission maximum at $445 \mathrm{~nm}$. However, control experiments showed that any NADPH left unconsumed at the end of the anaerobic reactions described here is ultimately converted to the non-fluorescent NADP+ product by enzyme-driven redox cycling of the electron accepting organic substrate upon opening the reaction vessel to air and dilution with aerobic buffer prior to fluorescence measurements. 
Synthesis of 1,2-di(quinolin-6-yl)diazene oxide (45). We employed a variation on the literature procedure of Boge et al. ${ }^{2}$ To a solution of compound $42(0.5 \mathrm{~g}, 2.87 \mathrm{mmol})$ in a mixture of EtOH: $\mathrm{CH}_{2} \mathrm{Cl}_{2}(1: 1,20 \mathrm{~mL})$ at $0{ }^{\circ} \mathrm{C}$ in an ice/salt bath was added Raney nickel slurry (0.5 mL, active catalyst in water, Sigma-Aldrich cat. number 221678). To this mixture, hydrazine hydrate $(1.5 \mathrm{~mL}, 30 \mathrm{mmol})$ portions were added over the course of $3 \mathrm{~h}$ with stirring until $\mathbf{4 2}$ was consumed (TLC) and the resulting mixture stirred overnight. The solid was removed by filtration and the resulting solution dried by extraction with brine and then over sodium sulfate. The compound was purified by column chromatography on silica gel eluted with ethyl acetate in the first column separation and second column chromatography separation on silica gel was done with $\mathrm{MeOH}: \mathrm{CH}_{2} \mathrm{Cl}_{2}$ (99:1) to obtain 45 , a yellow solid, in pure form $\left(100 \mathrm{mg}, \mathrm{R}_{\mathrm{f}}\right.$ value $=0.25$ in $4 \% \mathrm{MeOH}$ in $\left.\mathrm{CH}_{2} \mathrm{Cl}_{2}\right){ }^{1} \mathrm{H} \mathrm{NMR}\left(\mathrm{CDCl}_{3}, 300 \mathrm{MHz}\right): \delta \mathrm{ppm} 9.14(\mathrm{~d}, \mathrm{~J}=2.5 \mathrm{~Hz}, 1 \mathrm{H}), \delta 9.00(\mathrm{dd}, \mathrm{J}=$ $4.5 \mathrm{~Hz}, \mathrm{~J}=1.5 \mathrm{~Hz}, 1 \mathrm{H}), \delta 8.93(\mathrm{dd}, \mathrm{J}=4.5 \mathrm{~Hz}, \mathrm{~J}=1.5 \mathrm{~Hz}, 1 \mathrm{H}), \delta 8.82(\mathrm{~d}, \mathrm{~J}=2.5 \mathrm{~Hz}$ $1 \mathrm{H}), \delta 8.67(\mathrm{~d}, \mathrm{~J}=9.0 \mathrm{~Hz}, 1 \mathrm{H}), \delta 8.31(\mathrm{dd}, \mathrm{J}=9.0 \mathrm{~Hz}, \mathrm{~J}=1.5 \mathrm{~Hz}, 1 \mathrm{H}), \delta 8.21(\mathrm{~m}, 4 \mathrm{H}), \delta$ $7.49(\mathrm{dd}, \mathrm{J}=8.5 \mathrm{~Hz}, \mathrm{~J}=4.5 \mathrm{~Hz}, 1 \mathrm{H}), 7.42(\mathrm{dd}, \mathrm{J}=8.5 \mathrm{~Hz}, \mathrm{~J}=4.5 \mathrm{~Hz}, 1 \mathrm{H}), 1.23$ grease. ${ }^{13} \mathrm{C} \mathrm{NMR}\left(\mathrm{CDCl}_{3}, 75.5 \mathrm{MHz}\right): \delta 152.86,151.97,149.64,148.72,146.01,141.93,137.88$, $137.76,130.95,130.32,129.32,128.46,127.73,123.76,123.40,122.68,122.64,122.09$; HRMS (ESI, $[\mathrm{M}+\mathrm{H}]^{+}$) m/z calcd for $\mathrm{C}_{18} \mathrm{H}_{13} \mathrm{~N}_{4} \mathrm{O}$ 301.1089, found 301.1080. ${ }^{2}$ Boge, N.; Kruger, S.; Schroder, M.; Meier, C.; Synthesis 2007, 24, 3907-3914. 


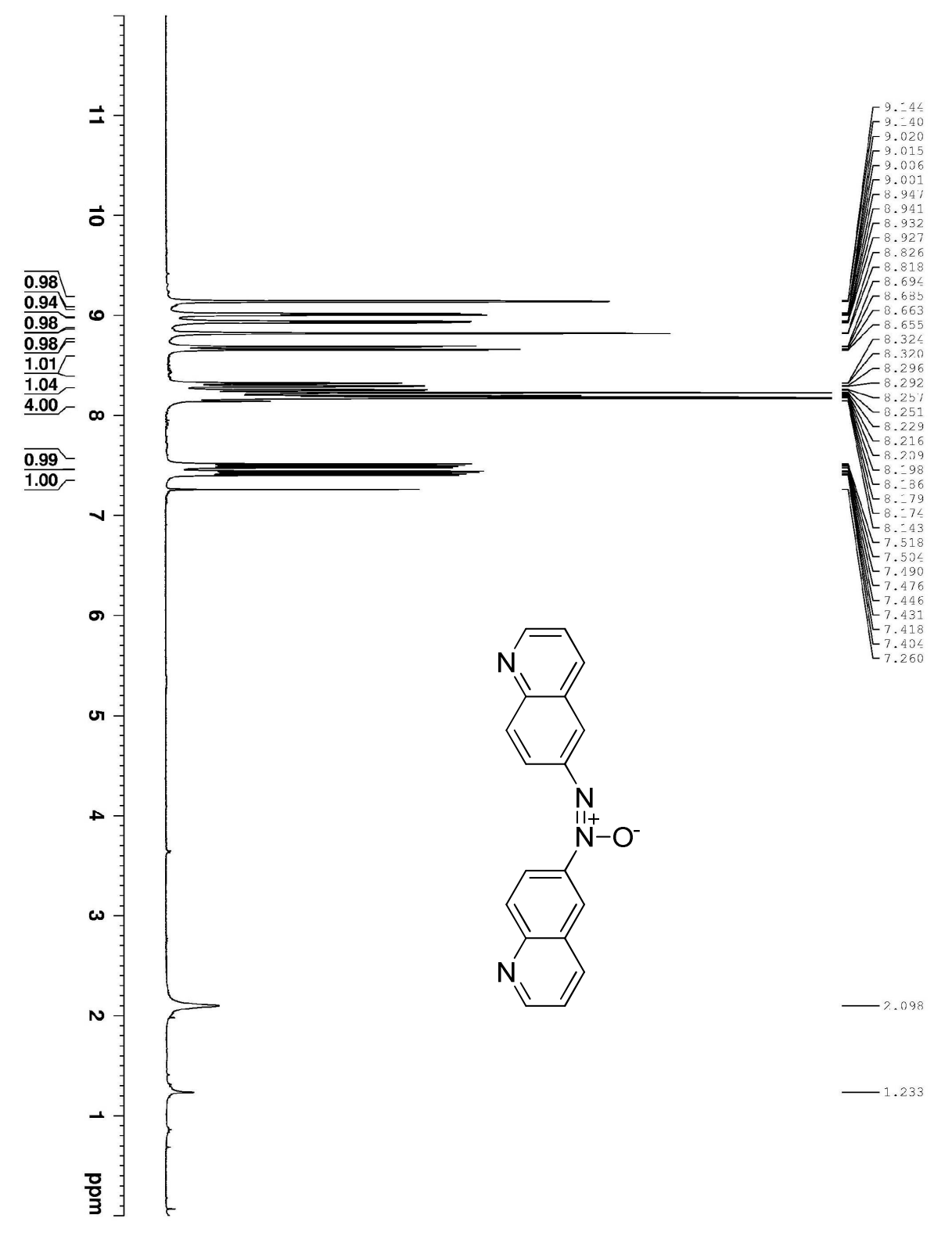

Figure S3. ${ }^{1} \mathrm{H} \mathrm{NMR}$ of $\mathbf{4 5}\left(\mathrm{CDCl}_{3}, 300 \mathrm{MHz}\right)$ 

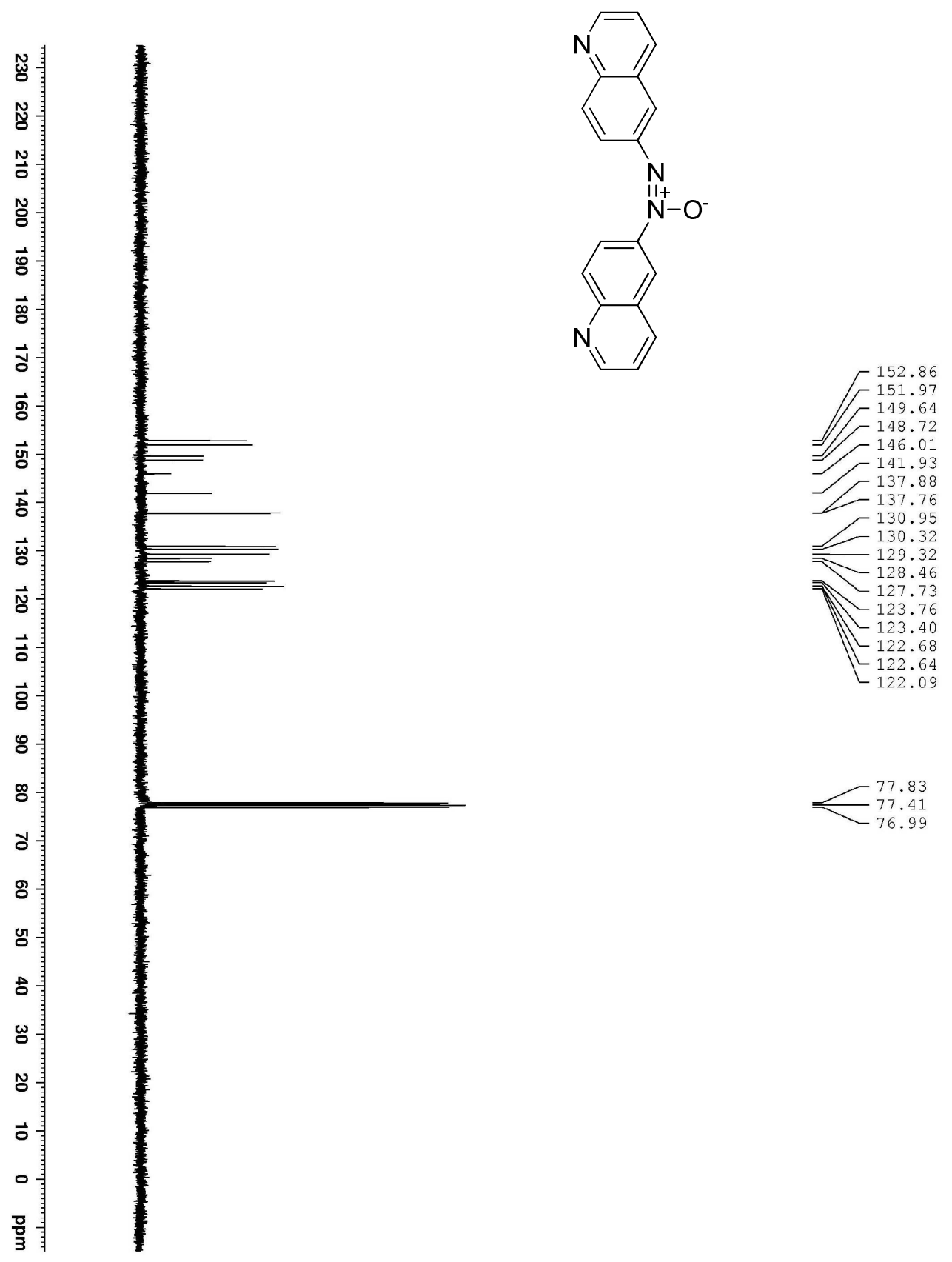

Figure S4. ${ }^{13} \mathrm{C}$ NMR of $\mathbf{4 5}\left(\mathrm{CDCl}_{3}, 75.5 \mathrm{MHz}\right)$ 


\section{Preparation of pyrido[3,2-f]quinolino[6,5-c]cinnoline 3-oxide (44) via alkaline}

glucose reduction of $\mathbf{4 2 .}^{3}$ A solution of $\mathbf{4 2}(1.0 \mathrm{~g}, 5.61 \mathrm{mmol})$ in $\mathrm{NaOH}(20 \%$ aqueous solution, $10 \mathrm{~mL}$ ) and was heated to $90{ }^{\circ} \mathrm{C}$ with stirring. To this solution, D-(+) glucose $(1.3 \mathrm{~g}, 7.21 \mathrm{mmol})$ was added over $30 \mathrm{~min}$ and stirred for $1 \mathrm{~h}$. The mixture was extracted with EtOAc $(20 \mathrm{~mL})$ and the combined organic extracts washed with brine and dried over magnesium sulfate. The mixture separated by column chromatography on silica gel and eluented with ethyl acetate and $\mathrm{MeOH}(99: 1)$ to obtain the helicene 44, a yellow solid(300 mg, 18\% yield). ${ }^{1} \mathrm{H}$ NMR $\left(\mathrm{CDCl}_{3}, 500 \mathrm{MHz},\right): \delta 9.15(\mathrm{~d}, \mathrm{~J}=4.5 \mathrm{~Hz} 1 \mathrm{H}), 9.05$ $(\mathrm{m}, 2 \mathrm{H}), 8.87(\mathrm{~d}, \mathrm{~J}=9.0 \mathrm{~Hz}, 1 \mathrm{H}), 8.67(\mathrm{~d}, \mathrm{~J}=9.0 \mathrm{~Hz}, 1 \mathrm{H}), 8.44(\mathrm{~d} \mathrm{~J}=9.0 \mathrm{~Hz}, 1 \mathrm{H}), 8.40$ $(\mathrm{d} J=9.0 \mathrm{~Hz}, 1 \mathrm{H}), 8.23(\mathrm{~d}, \mathrm{~J}=9.0 \mathrm{~Hz}, 1 \mathrm{H}), 7.46(\mathrm{dd}, \mathrm{J}=9.0 \mathrm{~Hz}, \mathrm{~J}=4.5 \mathrm{~Hz}, 1 \mathrm{H}), 7.41$ $(\mathrm{dd}, \mathrm{J}=9.0 \mathrm{~Hz}, \mathrm{~J}=4.5 \mathrm{~Hz}, 1 \mathrm{H}) .{ }^{13} \mathrm{C}-\mathrm{NMR}\left(\mathrm{CDCl}_{3}, 125.8 \mathrm{MHz},\right): \delta 153.35,151.47$, $149.71,148.53,144.08,137.09,136.02,134.79,134.28,133.41,128.00,127.45,123.52$, 123.34, 121.75, 120.56, 120.46, 114.21; HRMS (ESI, $\left.[\mathrm{M}+\mathrm{H}]^{+}\right) \mathrm{m} / z$ calcd $\mathrm{C}_{18} \mathrm{H}_{11} \mathrm{~N}_{4} \mathrm{O}$ calculated mass 299.0933; actual mass 299.0934 Crystals for X-ray analysis were obtained by dissolving the pure compound in minimum amount of warm $\mathrm{MeOH}$, followed by slow evaporation $(3 \mathrm{~d})$ in a $2 \mathrm{~mL}$ vial.

${ }^{3}$ Galbraith, H. W.; Degering, E. F.; Hitch, E. F. J. Am. Chem. Soc. 1951, 73:1323 


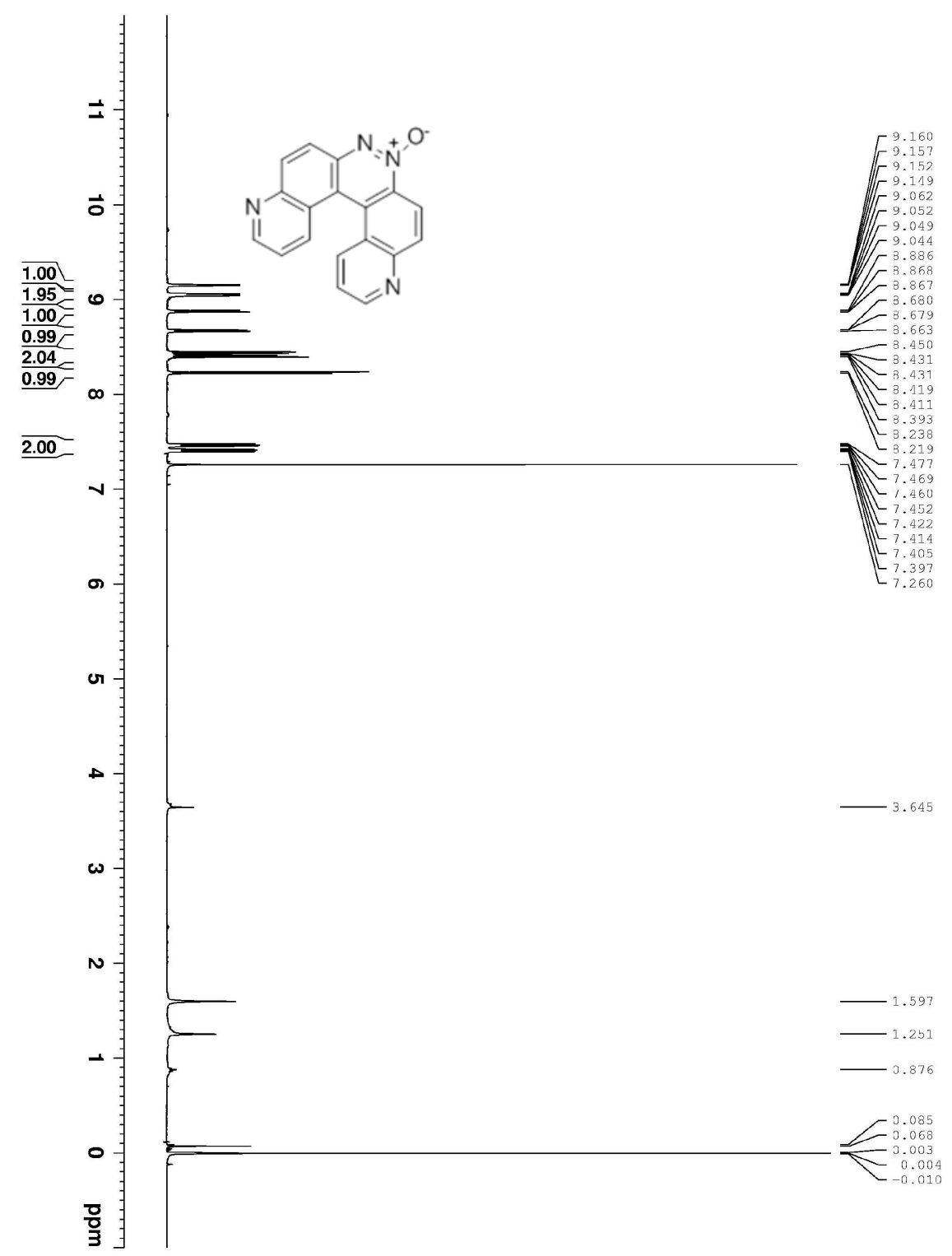

Figure S5. ${ }^{1} \mathrm{H}$ NMR of $44\left(\mathrm{CDCl}_{3}, 500 \mathrm{MHz}\right)$ 


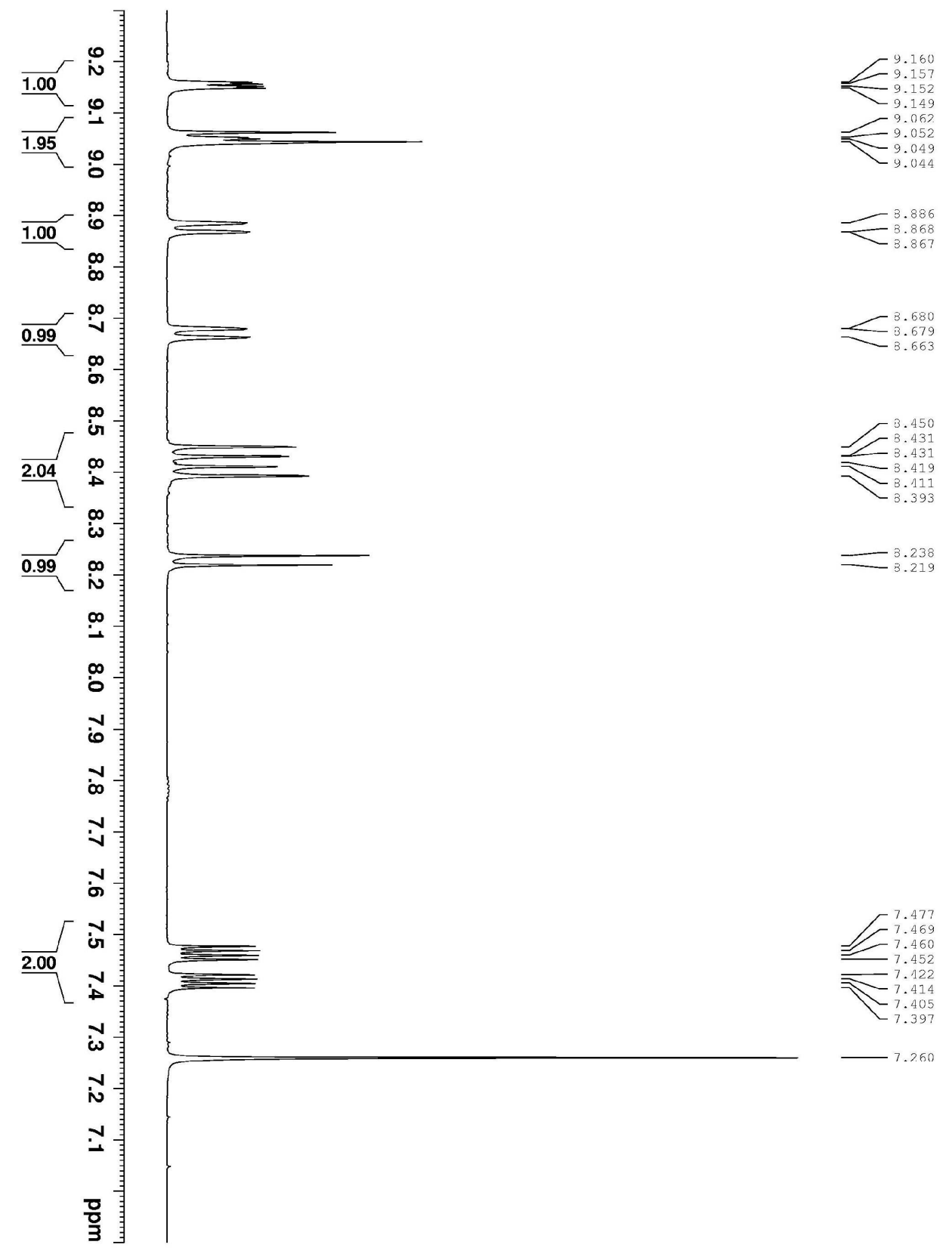

Figure S6. ${ }^{1} \mathrm{H}$ NMR of $\mathbf{4 4}$ aromatic region $\left(\mathrm{CDCl}_{3}, 500 \mathrm{MHz}\right)$ 


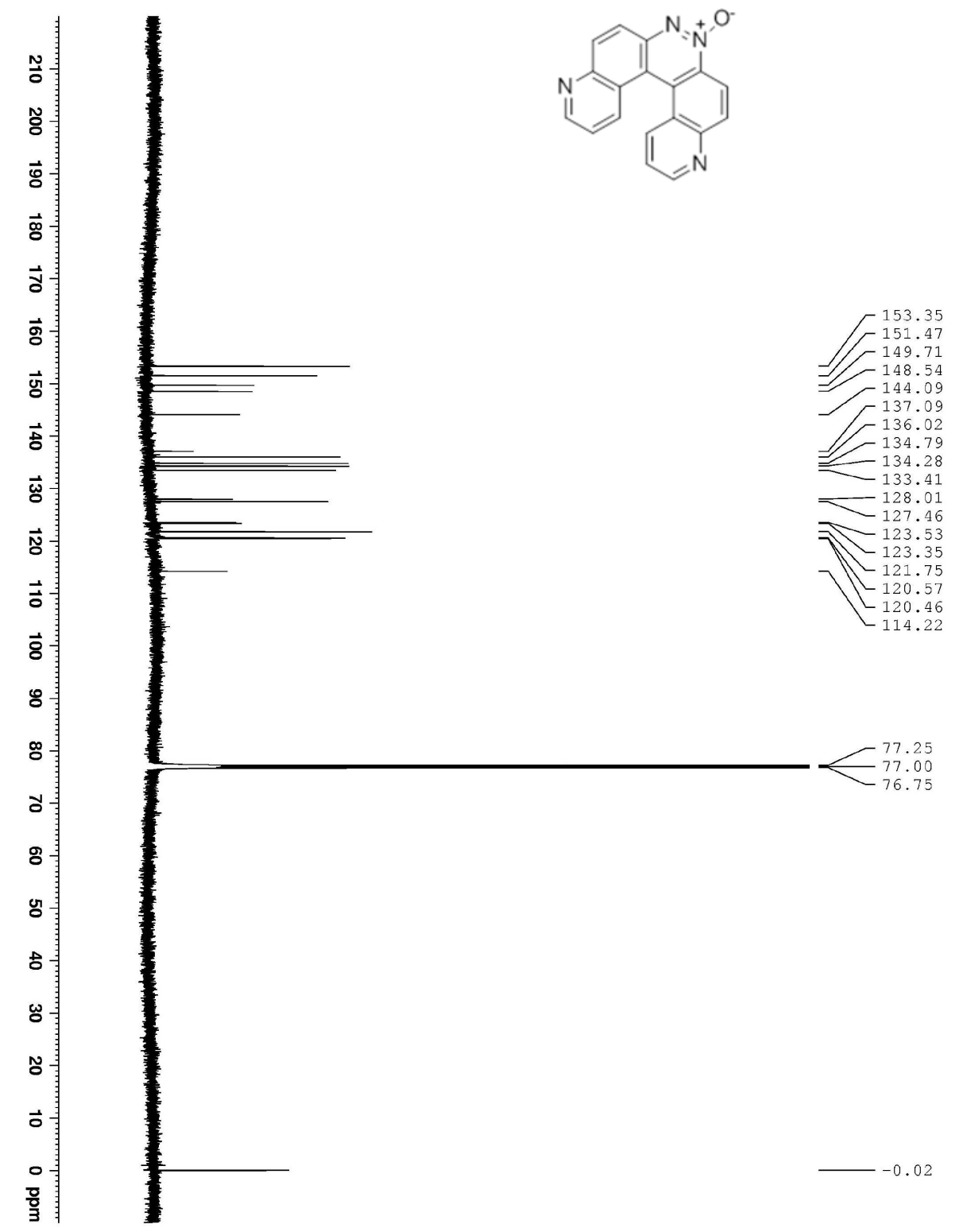

Figure S6. ${ }^{13} \mathrm{C}$ NMR of $\mathbf{4 4}\left(\mathrm{CDCl}_{3}, 125.77 \mathrm{MHz}\right)$ 


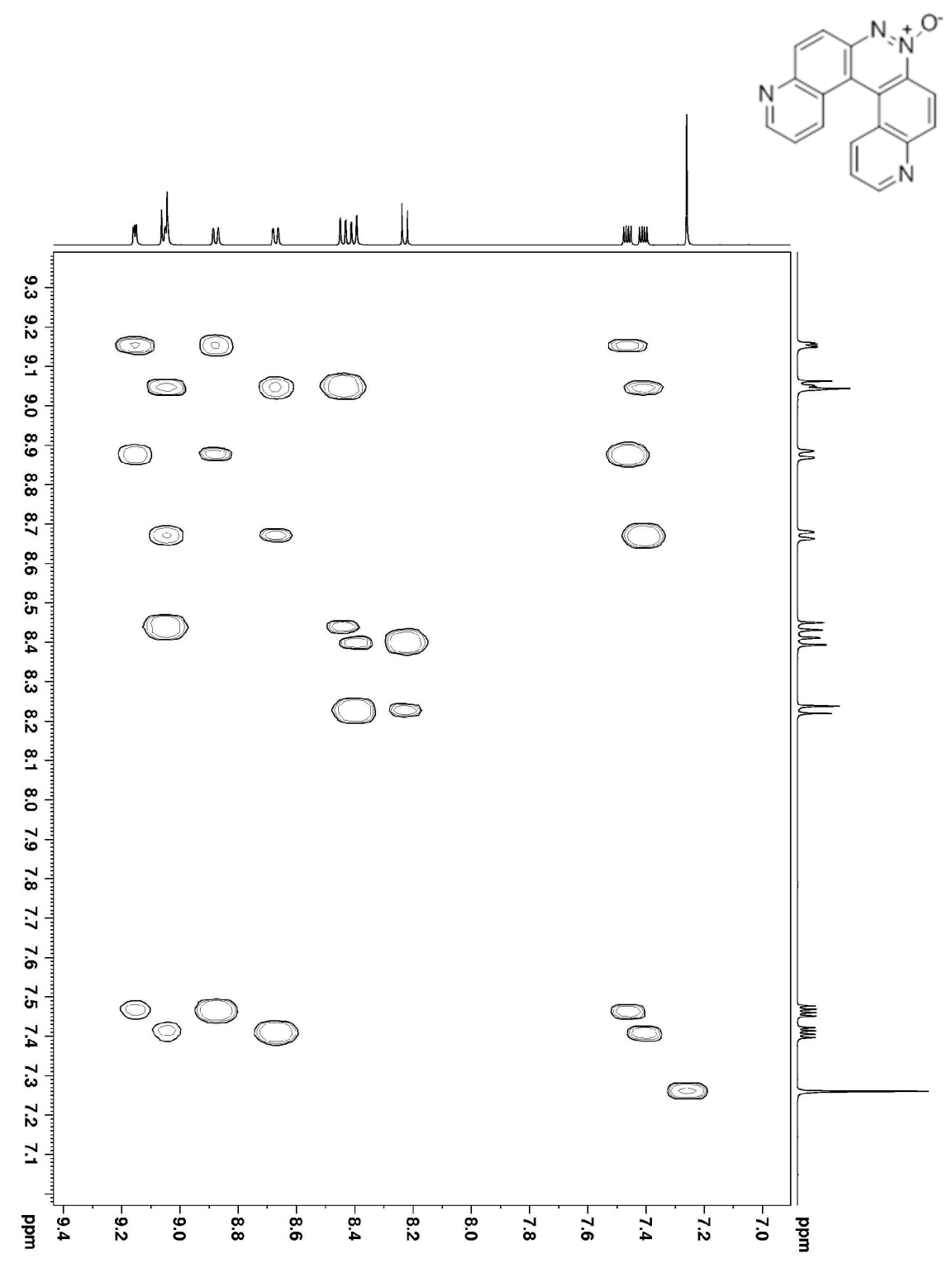

Figure S7. ${ }^{1} \mathrm{H}-{ }^{1} \mathrm{H}$ TOCSY of $44\left(\mathrm{CDCl}_{3}, 500 \mathrm{MHz}\right)$ 


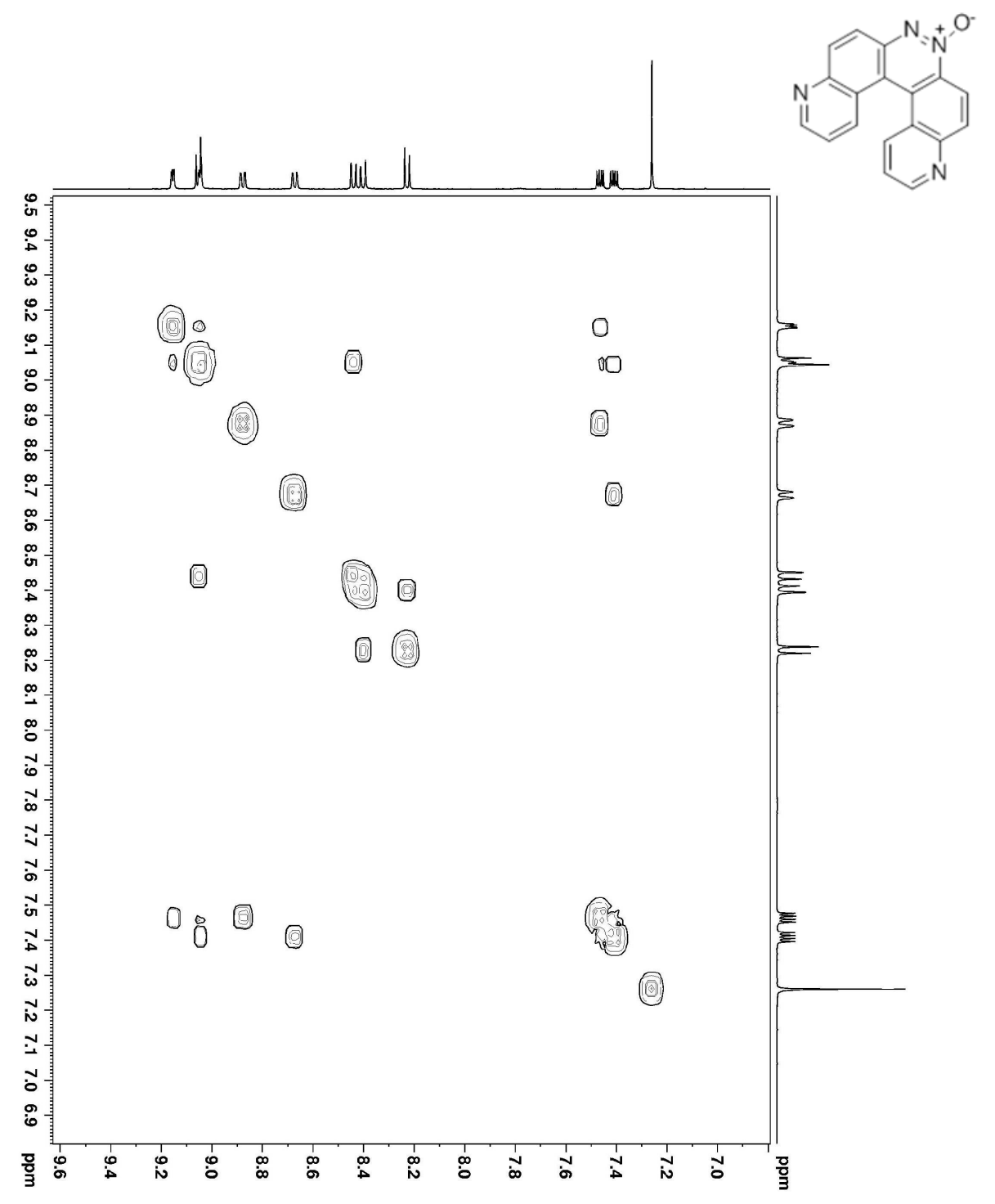

Figure S8. ${ }^{1} \mathrm{H}-{ }^{1} \mathrm{H}$ COSY of $44\left(\mathrm{CDCl}_{3}, 500 \mathrm{MHz}\right)$ 


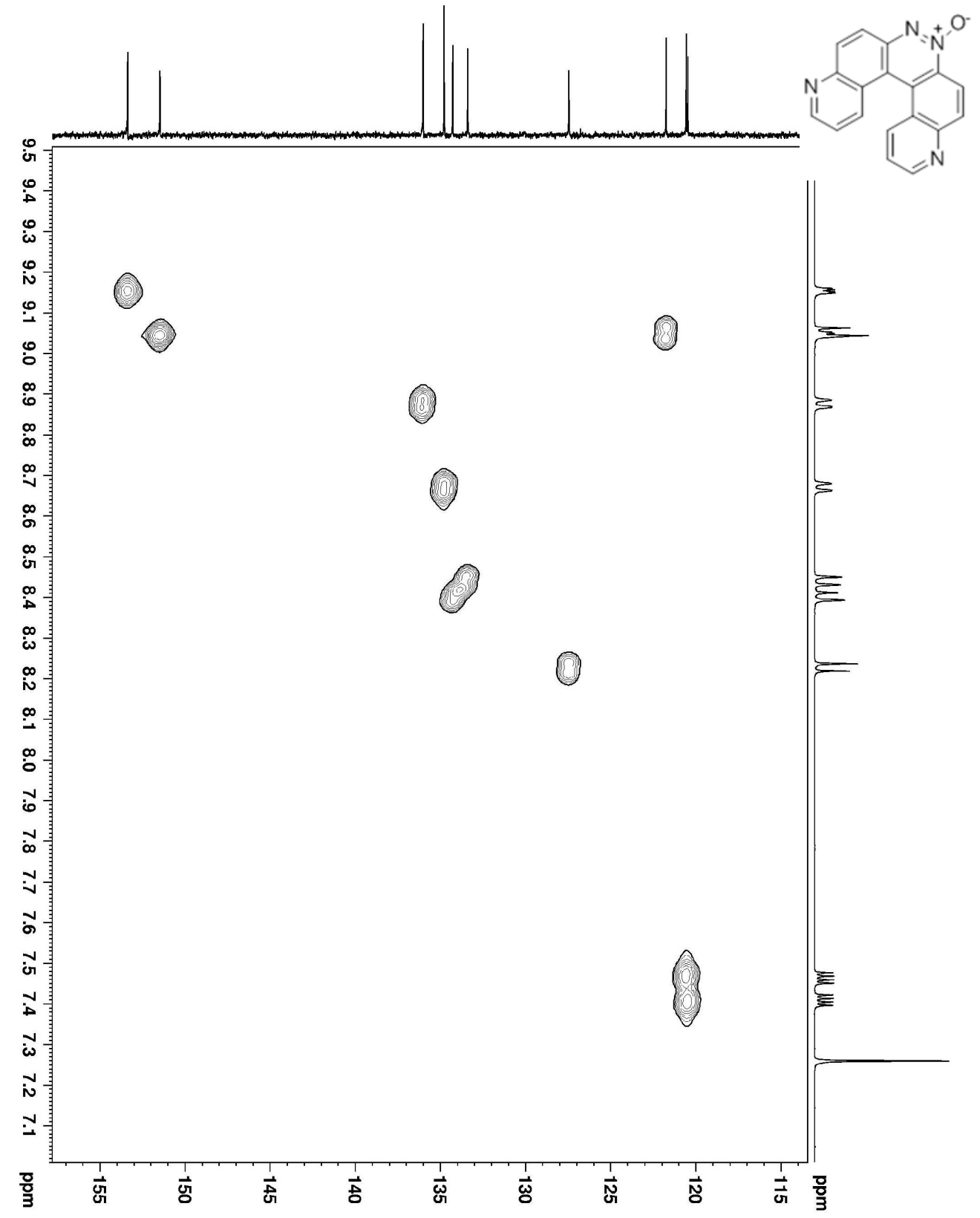

Figure S9. ${ }^{1} \mathrm{H}-{ }^{13} \mathrm{C}$ HMQC of $\mathbf{4 4}\left(\mathrm{CDCl}_{3}, 500\right.$ and $\left.125.77 \mathrm{MHz}\right)$ : 


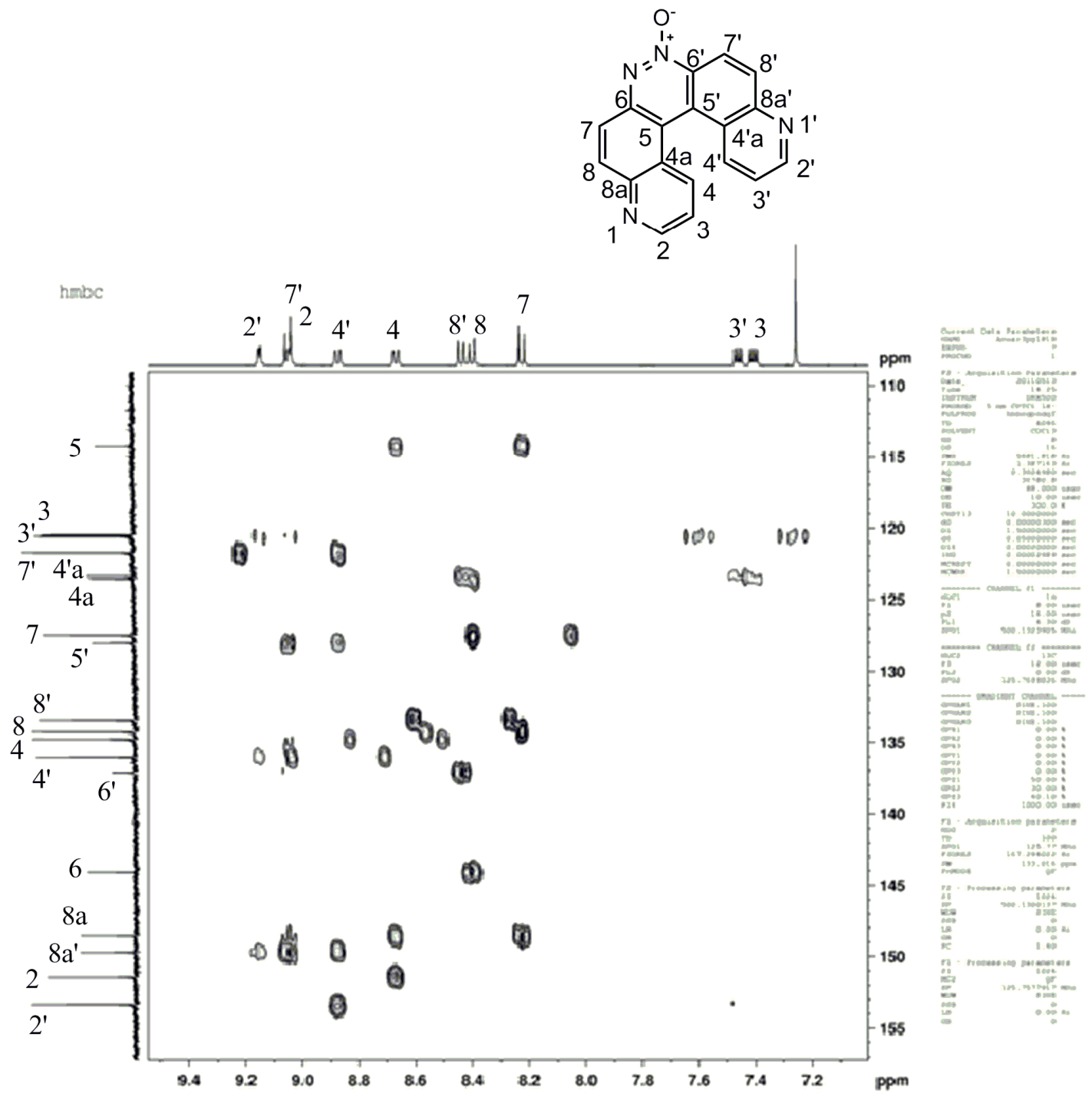

Figure S10. ${ }^{1} \mathrm{H}-{ }^{13} \mathrm{C}$ HMBC of $44\left(\mathrm{CDCl}_{3}, 500\right.$ and $\left.125.77 \mathrm{MHz}\right)$ : 


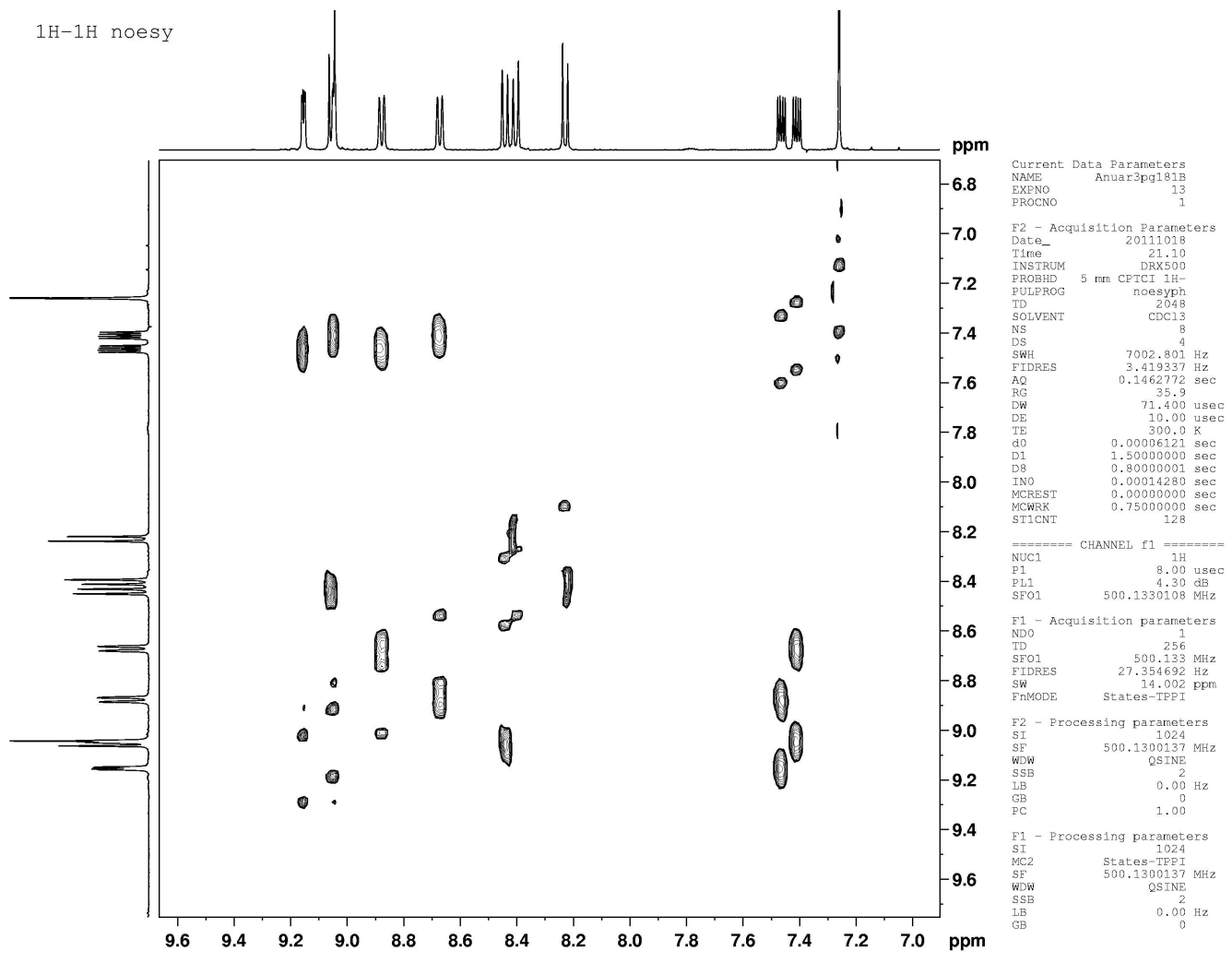

Figure S11. ${ }^{1} \mathrm{H}-{ }^{1} \mathrm{H}$ NOESY of $44\left(\mathrm{CDCl}_{3}, 500 \mathrm{MHz}\right)$ : 


\section{Enzymatic generation of pyrido[3,2-f]quinolino[6,5-c]cinnoline 3-oxide (44)}

Compound 42 (50 mM, in $0.2 \mathrm{~mL}$ DMF) was mixed with sodium phosphate buffer $(0.3$ $\mathrm{mL}, 10 \mathrm{mM}, \mathrm{pH} 7.4)$ and water $(12.0 \mathrm{~mL})$ in an argon-purged glove bag and the solution purged with argon (20 min). To this mixture was added NADPH (25 mg, $0.033 \mathrm{mmol})$ and NADPH:cytochrome P450 reductase $(0.03 \mathrm{~mL}$ of a $0.35 \mathrm{U} / \mathrm{mL}$ solution). The resulting mixture was stirred inside the argon-filled glove bag for $18 \mathrm{~h}$. The reaction was then extracted with ethyl acetate $(20 \mathrm{~mL})$, the combined organic extract washed with brine and dried with magnesium sulfate. Column chromatography on silica gel eluted with ethyl acetate and $\mathrm{MeOH}$ (99:1), followed by preparative TLC eluted with ethyl acetate and $\mathrm{MeOH}(99: 1)$ gave 4 (five reactions combined to yield $0.300 \mathrm{mg}, 2 \%$ yield). The 1H-NMR and LC/MS properties of this material matched that of authentic 44 prepared as described above. 


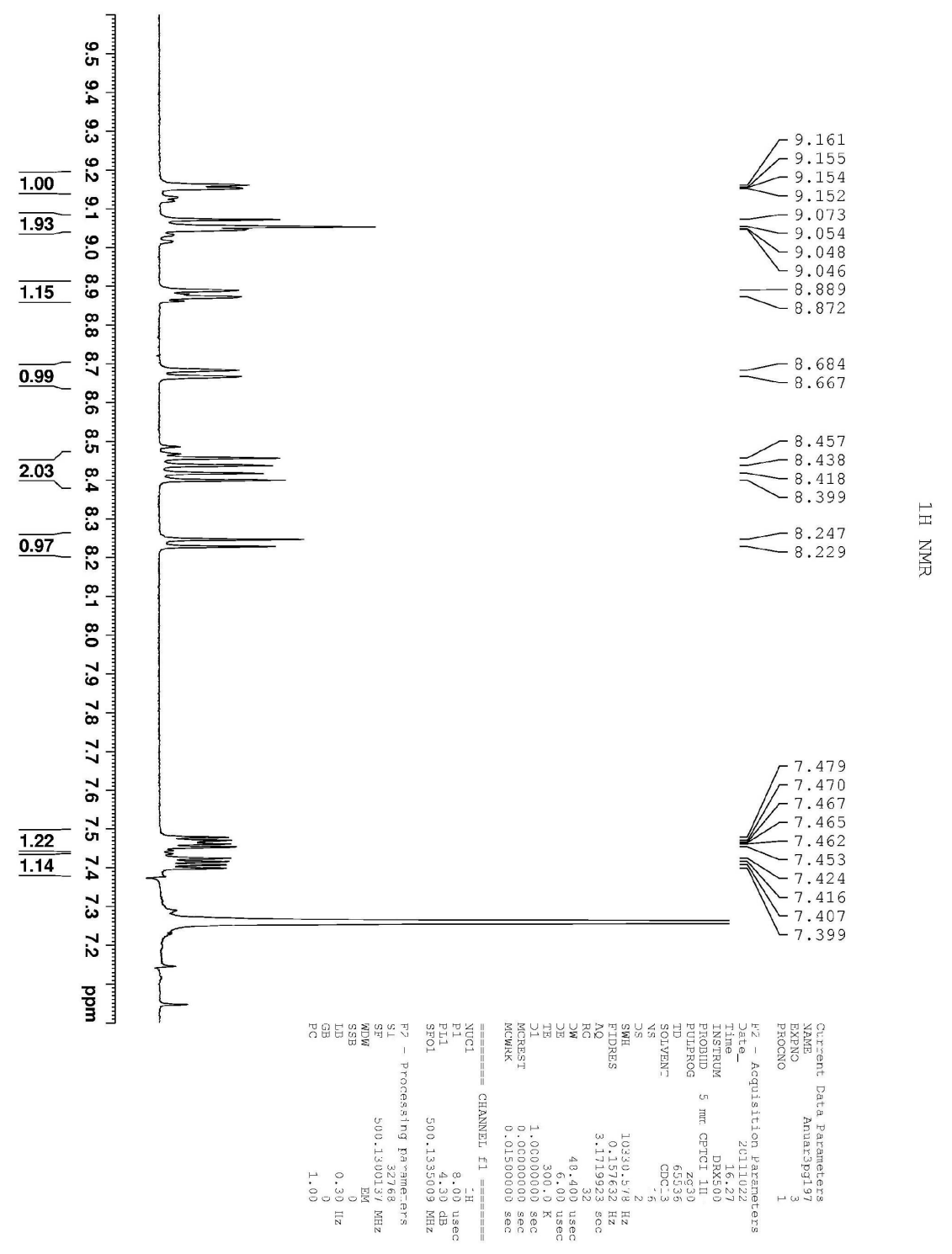

Figure S12. ${ }^{1} \mathrm{H}$ NMR of $\mathbf{4 4}\left(\mathrm{CDCl}_{3}, 500 \mathrm{MHz}\right)$, obtained from NADPH and NADPH:cytochrome P450 reductase mediated synthesis 


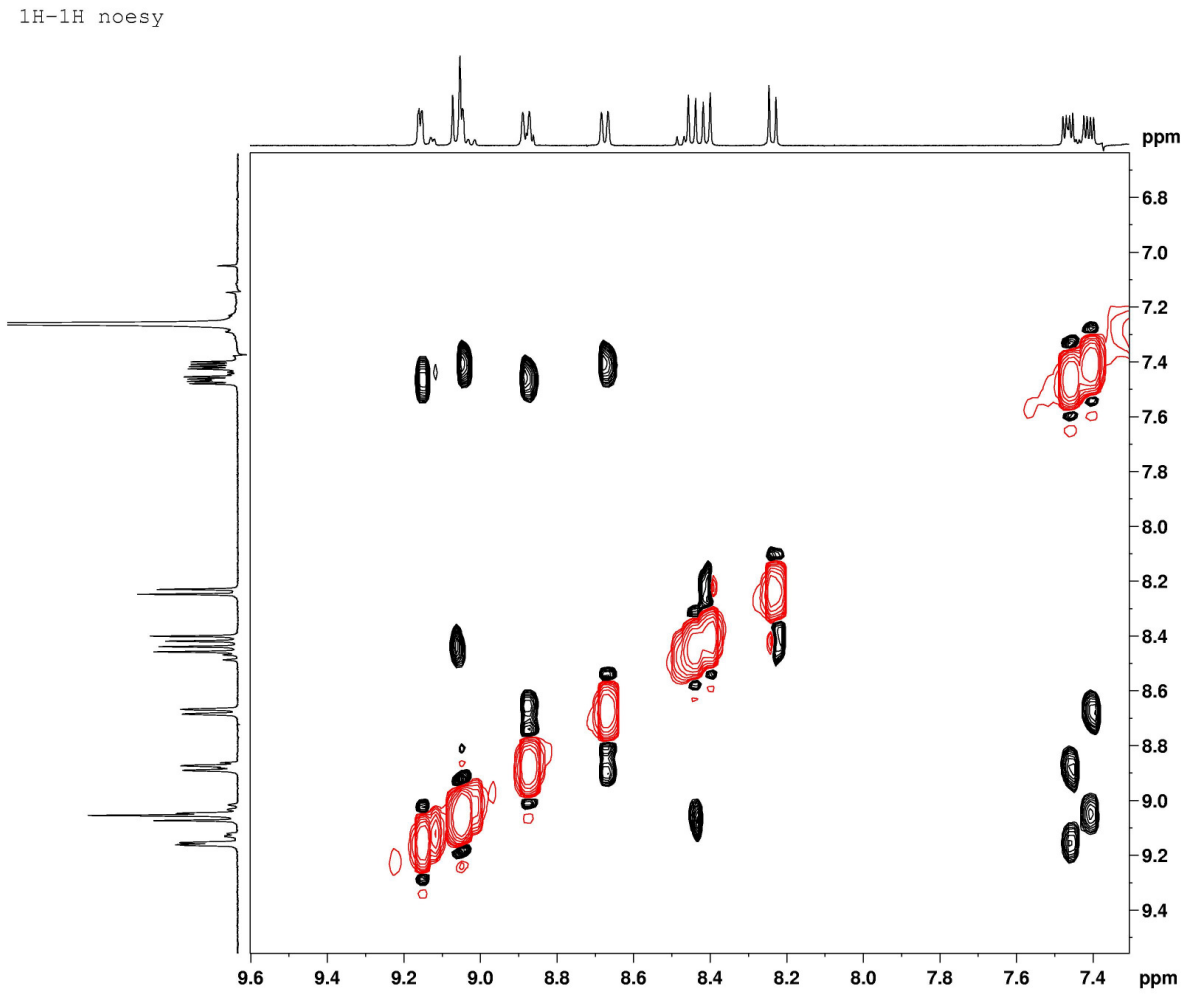

Figure S13. ${ }^{1} \mathrm{H}-{ }^{1} \mathrm{H}$ NOESY of $44\left(\mathrm{CDCl}_{3}, 500 \mathrm{MHz}\right)$, obtained from NADPH and NADPH:cytochrome P450 reductase mediated synthesis 


\section{References for chapter 2}

1. (a) Cejudo-Martin, P.; Johnson, R. S., A new notch in the HIF belt: how hypoxia impacts differentiation. Cell 2005, 9, 575-576; (b) Parmar, K.; Mauch, P.; Vergillo, J.; Sackstein, R.; Down, J. D., Distribution of hematopoietic stem cells in the bone marrow according to regional hypoxia. Proc. Nat. Acad. Sci. USA 2007, 104, 5431-5

2. Simon, M. C.; Keith, B., The role of oxygen availability in embryonic development and stem cell function. Nat. Rev. Mol. Cell Biol. 2008, 9, 285-296.

3. Brown, J. M., The hypoxic cell: a target for selective cancer therapy-eighteenth Bruce F. Cain memorial award lecture. Cancer Res. 1999, 59 (Copyright (C) 2012 American Chemical Society (ACS). All Rights Reserved.), 5863-5870.

4. Harris, A. L., Hypoxia - a key regulatory factor in tumour growth. Nat. Rev. Cancer 2002, 2, 38-47.

5. (a) Evans, S. M.; Kachur, A. V.; Shiue, C.-Y.; Hustinx, R.; Jenkins, W. T.; Shive, G. G.; Karp, J. S.; Alavi, A.; Lord, E. M.; Dolbier, W. R.; Koch, C. J., Noninvasive detection of tumor hypoxia using the 2-nitroimidazole [18F]EF1. J. Nucl. Med. 2000, 41, 327-336; (b) Koch, C. J., Measurements of absolute oxygen levels in cells and tissues using oxygen sensors and 2-nitroimidazole EF5. Methods Enzymol. 2002, 352, 3-31.

6. Nordsmark, M.; Loncaster, J.; Aquino-Parsons, C.; Chou, S.-C.; Ladekarl, M.; Havsteen, H.; Lindegaard, J. C.; Davidson, S. E.; Varia, M.; West, C.; Hunter, R.; Overgaard, J.; Raleigh, J. A., Measurements of hypoxia using pimonidazole and polarographic oxygen-sensitive electrodes in human cervix carcinomas. Radiother. Oncol. 2003, 67, 35-44.

7. (a) Dai, M.; Zhu, W.; Xu, Y.; Qian, X.; Liu, Y.; Xiao, Y.; You, Y., Versatile nitro-fluorophore as highly effective sensor for hypoxic tumor cells: design, imaging, and evaluation. J. Fluoresc. 2008, 18 (2), 591-597; (b) Stratford, M. R. L.; Clarke, E. D.; Hodgkiss, R. J.; Middleton, R. W.; Wardman, P., Nitroaryl compounds as potential fluorescent probes for hypoxia. II. Identification and properties of reductive metabolites. Int. J. Radiat. Oncol. Biol. Phys. 1984, 10, 1353-1356. 
8. (a) Wardman, P.; Clarke, E. D.; Hodgkiss, R. J.; Middleton, R. W.; Parrick, J.; Stratford, M. R. L., Nitroaryl compounds as potential fluorescent probes for hypoxia. I. Chemical criteria and constraints. Int. J. Radiat. Oncol. Biol. Phys. 1984, 10, 1347-1351; (b) Zhu, W.; Dai, M.; Xu, Y.; Qian, X., Novel nitroheterocyclic hypoxic markers for solid tumor: synthesis and biological evaluation. Bioorg. Med. Chem. Lett. 2008, 16, 3255-3260.

9. (a) Wardman, P.; Dennis, M. F.; Everett, S. A.; Patel, K. B.; Stratford, M. R. L.; Tracy, M., Radicals from one-electron reduction of nitro compounds, aromatic N-oxides and quinones: the kinetic basis for hypoxia-selective, bioreductive drugs. Biochem. Soc. Trans 1995, 61, 171-194; (b) Fitzsimmons, S. A.; Workman, P. A.; Grever, M.; Paull, K.; Camalier, R.; Lewis, A. D., Reductase enzyme expression across the National Cancer Institute tumor cell line panel: correlation with sensitivity to mitomycin C and E09. $J$. Natl. Cancer Inst. 1996, 88, 259-269; (c) Rooseboom, M.; Commandeur, J. N. M.; Vermeulen, N. P. E., Enzyme-catalyzed activation of anticancer prodrugs. Pharm. Rev. 2004, 56, 53-102; (d) Wilson, W. R.; Anderson, R. F.; Denny, W. A., Hypoxia-selective antitumor agents. 1. Relationships between structure, redox properties and hypoxiaselective cytotoxicity for 4-substituted derivatives of nitracrine. J. Med. Chem. 1989, 32, 23-30; (e) Denny, W. A.; Wilson, W. R., Considerations for the design of nitrophenyl mustards as agents with selective toxicity for hypoxic tumor cells. J. Med. Chem. 1986, $29(6), 879-887$.

10. Chen, Y.; Hu, L., Design of anticancer prodrugs for reductive activation. Med. Res. Rev. 2009, 29 (1), 29-64.

11. Rajapakse, A.; Gates, K. S., Hypoxia-Selective, Enzymatic Conversion of 6Nitroquinoline into a Fluorescent Helicene: Pyrido[3,2-f]quinolino[6,5-c]cinnoline 3Oxide. J. Org. Chem. 2012, 77, 3531-3537.

12. (a) Danieli, E.; Shabat, D., Molecular probe for enzymatic activity with dual output. Bioorg. Med. Chem. 2007, 15, 7318-7324; (b) Tanaka, F.; Thayumanavan, R.; Barbas, C. F., Fluorescent detection of carbon-carbon bond formation. J. Am. Chem. Soc. 2003, 125, 8523-8528; (c) Brynes, P. J.; Bevilacqua, P.; Green, A., 6-Aminoquinoline as a fluorogenic leaving group in peptide cleavage reactions: a new fluorogenic substrate for chymotrypsin. Anal. Biochem. 1981, 116, 408-413; (d) Huang, W.; Hicks, S. N.; Sondek, J.; Zhang, Q., A fluorogenic, small molecule reporter for mammalian phospholipase C isozymes. ACS Chem Biol. 2011, 6 (3), 223-228.

13. (a) Smith, G. C. M.; Tew, D. G.; Wolf, C. R., Dissection of NADPH-cytochrome P450 oxidoreductase into distinct 
functional domains. Proc. Nat. Acad. Sci. USA 1994, 91 (Aug), 8710-8714; (b) Walton, M. I.; Wolf, C. R.; Workman, P., Molecular enzymology of the reductive bioactivation of hypoxic cell cytotoxins. Int. J. Radiat. Oncol. Biol. Phys. 1989, 16, 983-986; (c) Wen, B.; Coe, K. J.; Rademacher, P.; Fitch, W. L.; Monshouwer, M.; Nelson, S. D., Comparison of in vitro bioactivation of flutamide and its cyano analogue: evidence for reductive activation by human NADPH:cytochrome P450 reductase. Chem. Res. Toxicol. 2008, 21 (12), 2393-2406; (d) Solano, B.; Junnotula, V.; Marin, A.; Villar, R.; Burguete, A.; Vicente, E.; Perez-Silanes, S.; Monge, A.; Dutta, S.; Sarkar, U.; Gates, K. S., Synthesis and biological evaluation of new 2-arylcarbonyl-3-trifluoromethylquinoxaline 1,4dioxide derivatives and their reduced analogues. J. Med. Chem. 2007, 50 (22), 54855492.

14. (a) Pizzolatti, M. G.; Yunes, R. A., Azoxybenzene formation from nitrosobenzene and phenylhydroxylamine. A unified view of the catalysis and mechanisms of the reactions. J. Chem. Soc. Perkin 2 1990, 759-764; (b) Agrawal, A.; Tratnyek, P. G., Reduction of nitroaromatic compounds by zero-valent iron metal. Env. Sci. Technol. 1996, 30 (1), 153-160.

15. (a) Fletcher, T. L.; Namkung, M. J., Derivatives of fluorene. IV. Raney nickelhydrazine hydrate reduction of various mono- and dinitrofluorene derivatives; some new 9-substituted fluorenes. J. Org. Chem. 1958, 23, 680-683; (b) Furst, A.; Moore, R. E., Reductions with hydrazine hydrate catalyzed by Raney nickel. II. Aromatic nitro compounds to intermediate products. J. Am. Chem. Soc. 1957, 79, 5492-5493.

16. (a) Holt, P. F.; Went, C. W., Polycyclic cinnoline derivatives. Part XIII. The cyclisation of azo-compounds and the ultraviolet absorption of benzo[g]naphtho[1,2c]cinnoline. J. Chem. Soc. 1963, 4099-4102; (b) Morrison, D. J.; Trefz, T. K.; Piers, W. E.; McDonald, R.; Parvez, M., 7:8,9:10-Dibenzo-1,2,3,4-tetrafluorotriphenylene: synthesis, structure, and photophysical properties of a novel [5] helicene. J. Org. Chem. 2005, 70, 5309-5312.

17. Huisgen, R., Beiträge und deutungsversuche zur reaktionsweise aromatischer bicylen. Liebigs Ann. 1948, 559 (2), 101-152.

18. Farrar, W. V., Polycyclic reduction products of 6-nitroquinoline. J. Chem. Soc. 1965, 799-800.

19. Galbraith, H. W.; Degering, E. F.; Hitch, E. F., The reduction of aromatic nitro compounds with glucose. J. Am. Chem. Soc. 1951, 73, 1323-1324. 
20. Silva, R. S. F.; de Amorim, M. B.; Pinto, M. d. C. F. R.; Emery, F. S.; Goulart, M. O. F.; Pinto, A. V., Chemoselective oxidation of benzophenazines by m-CPBA: Noxidation vs. oxidative cleavage. J. Braz. Chem. Soc. 2007, 18 (4), 759-764.

21. Rajapakse, A.; Barnes, C. L.; Gates, K. S., Synthesis and Crystal Structure of the Azoxydichinyl Helicene, Pyrido[3,2-f]quinolino[6,5-c]cinnoline 5-Oxide Monohydrate. J. Chem. Crystallog. 2011,

22. (a) Fuchs, T.; Chowdhary, G.; Barnes, C. L.; Gates, K. S., 3-Amino-1,2,4benzotriazine 4-Oxide: Characterization of a New Metabolite Arising From Bioreductive Processing of the Antitumor Agent 3-Amino-1,2,4-benzotriazine 1,4-Dioxide (Tirapazamine). J. Org. Chem. 2001, 66, 107-114; (b) Fitzsimmons, S. A.; Lewis, A. D.; Riley, R. J.; Workman, P., Reduction of 3-amino-1,2,4-benzotriazine-1,4,-di-N-oxide to a DNA-damaging species: a direct role for NADPH:cytochrome P450 oxidoreductase. Carcinogenesis 1994, 15 (8), 1503-1510.

23. (a) Duan, J.-X.; Jiao, H.; Kaizerman, J.; Stanton, T.; Evans, J. W.; Lan, L.; Lorente, G.; Banica, M.; Jung, D.; Wang, J.; Ma, H.; Li, X.; Yang, Z.; Hoffman, R. M.; Ammons, W. S.; Hart, C. P.; Matteucci, M., Potent and highly selective hypoxiaactivated achiral phosphoramidate mustards as anticancer drugs. J. Med. Chem. 2008, 51, 2412-2420; (b) Patterson, A. V.; Ferry, D. M.; Edmunds, S. J.; Gu, Y.; Singleton, R. S.; Patel, K. B.; Pullen, S. M.; Hicks, K. O.; Syddall, S. P.; Atwell, G. J.; Yang, S.; Denny, W. A.; Wilson, W. R., Mechanism of action and preclinical antitumor activity of the novel hypoxia-activated DNA cross-linking agent PR-104. Clin. Cancer Res. 2007, 13 (13), 3922-3932.

24. Mulcahy, R. T.; Gipp, J. J.; Schmidt, J. P.; Joswig, C.; Borch, R. F., Nitrobenzyl Phosphorodiamidates as Potential Hypoxia-Selective Alkylating Agents. J. Med. Chem. 1994, 37, 1610-15. 


\section{Chapter 3}

\section{Hypoxia-selective enzymatic conversion of 6-nitroquinoline to the}

\section{fluorescent product, 6-aminoquinoline}

\subsection{Hypoxia is an attractive target to develop fluorescent probes}

Studies carried out on tumor physiology suggested that solid tumors contain low oxygenated areas (hypoxic regions). ${ }^{1}$ Irregular vascularization, present inside tumors causes hypoxic conditions. ${ }^{2}$ Further research, conducted on hypoxia over decades had established the importance of hypoxia in tumor biology. ${ }^{3}$ Hypoxia selects for malignant phenotypes, which are unable to undergo apoptosis and result in poor prognosis. ${ }^{4}$ Moreover, hypoxic regions contain cancer stem cells which can differentiate and cause metastases. ${ }^{5}$ Hence, hypoxic regions are considered as targets of interest in tumor biology. Fluorescent based probing agents may be useful to mark low oxygenated regions. ${ }^{6}$ Organic compound which can produce fluorescent response, selectively within tumor, may select as a candidate fluorescent probe for detecting hypoxic tumors.

\subsection{Fluorescent Probes to Detect Hypoxia}

Nitroaryl groups can undergo enzyme mediated reduction in hypoxia. ${ }^{7}$ The final product of the reduction process is hydroxyl amine and/or amine. ${ }^{8}$ Under normal oxygenated conditions, single electron reduced nitro radical gets back oxidized to nitro group. ${ }^{9}$ Hence the first reduction step is oxygen sensitive. ${ }^{7 \mathrm{~d}, 10}$ This sensitivity has been exploited by nitroaromatic prodrugs to spare normal oxygenated cells. ${ }^{11}$ Nitro-based 
anticancer prodrugs are selectively toxic to low-oxygenated tumors and that may be due to the oxygen-sensitive reduction of nitro group. ${ }^{12}$ These prodrugs have been further tested for their oxygen sensitivity and enzymatic activation in hypoxia. ${ }^{11}$ Nitro-based agents which are used to mark hypoxic regions in radio imaging and immunihistochemical staining techniques. ${ }^{13}$ Along with these methods, nitro-based fluorescent probes would provide an attractive mean to visualize low oxygenated regions. ${ }^{6 a, b, 14}$ In the designing step, a non-fluorescent nitroaromatic compound can be selected as a fluorescent probe when the respective amino compound is fluorescent. In addition, these probes should be substrates for cellular reductases, which can supply electrons to nitro-amine reduction (Scheme 3.1).

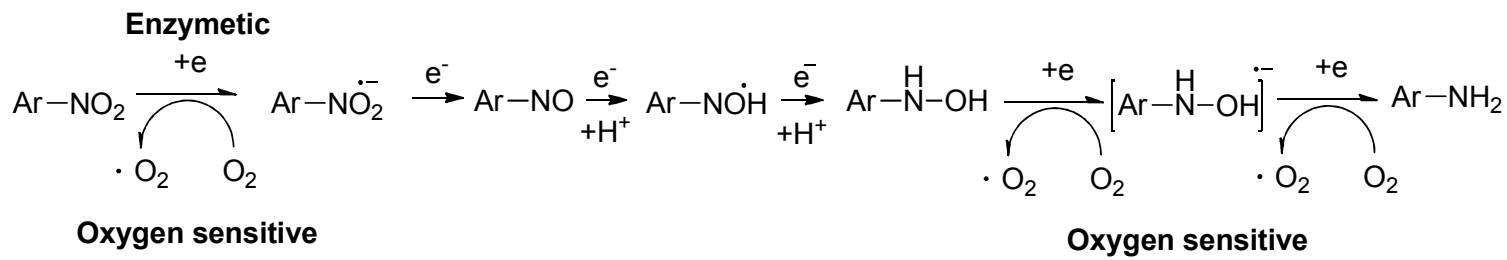

Scheme 3.1. Enzymatic reduction steps of a typical nitroaromatic compound

Based on this strategy, non-fluorescent 6-nitroquinoline (42) is tested as a nitroaryl fluorescent probe to detect hypoxia. ${ }^{15}$ In addition, a metabolic study is carried out to identify fluorescent and non-fluorescent metabolites. Under hypoxia, a reductive metabolism of 42 can be reduced to 6-aminoquinoline (43, Scheme 3.2), which is a known fluorophore used in biochemical assays. ${ }^{16}$ The production of non-fluorescent dimer 6,6'-azoxyquinoline 45 also can be anticipated (Scheme 3.2). Moreover, $205 \mathrm{~nm}$ stokes shift can be obtained by the reduction assay. ${ }^{16 \mathrm{~d}}$ 
<smiles>O=[N+]([O-])c1ccc2ncccc2c1</smiles>

42

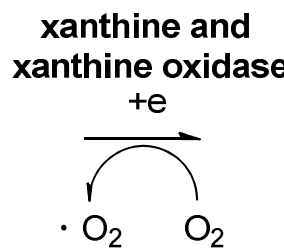

$\mathrm{H}_{2} \mathrm{~N}$<smiles></smiles>

43

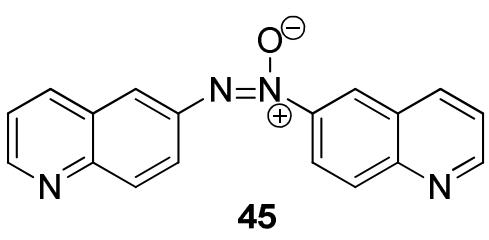

Scheme 3.2. Hypoxic metabolism of $\mathbf{4 2}$ forms fluorescent 43

Similar hypoxic metabolism of $\mathbf{4 2}$ by NADPH:cytochrome P450 reductase (CYP450R) produced 45 and fluorescent helicene, pyrido[3,2-f]quinolino[6,5-c]cinnoline 3-oxide (44, chapter 1 scheme 3.3). ${ }^{15}$ The anticipated fluorescent product 43 was not produced by the reducing system CYP450R (Scheme 3.2). Alternatively, another enzymatic reducing system xanthine and xanthine oxidase may be used to test metabolism of $\mathbf{4 2}$ in hypoxia.

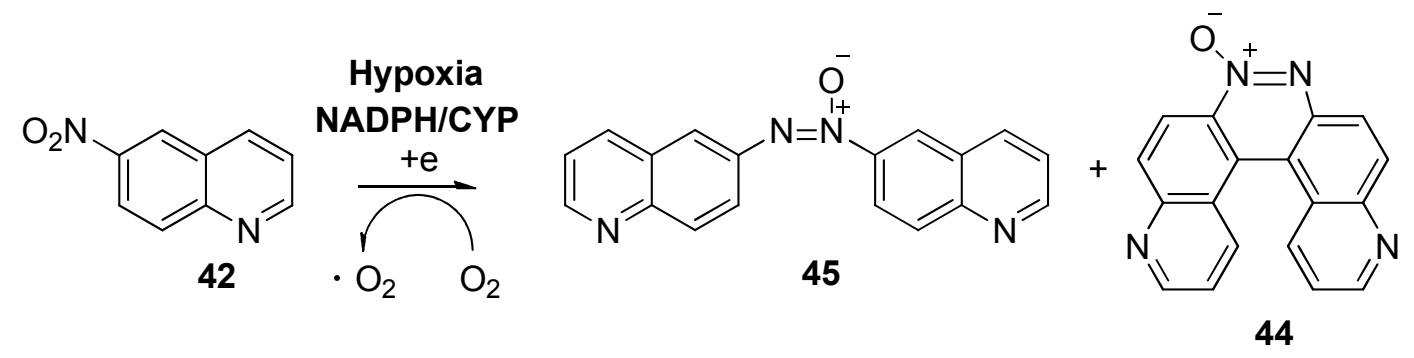

Scheme 3.3. CYP450R mediates conversion of $\mathbf{4 2}$ into fluorescent metabolites

Xanthine and xanthine oxidase system is known to reductively activate bio reducible compounds and conduct one electron reduction under hypoxic conditions. ${ }^{17}$ Accordingly, hypoxic conditions were applied to solutions, by conducting three cycles of freeze-pump-thawing. ${ }^{18}$ The deoxygenated reaction solutions, 42 and reducing system were mixed inside an argon purged glove bag. The compound $\mathbf{4 2}$ is non-fluorescent in solutions. Anaerobic incubation of $\mathbf{4 2}$ with xanthine and xanthine oxidase produced 12- 
fold fluorescence increase at $530 \mathrm{~nm}$ (Figure 3.1A, purple column). When xanthine concentration is increased, emission at $530 \mathrm{~nm}$ is increased.
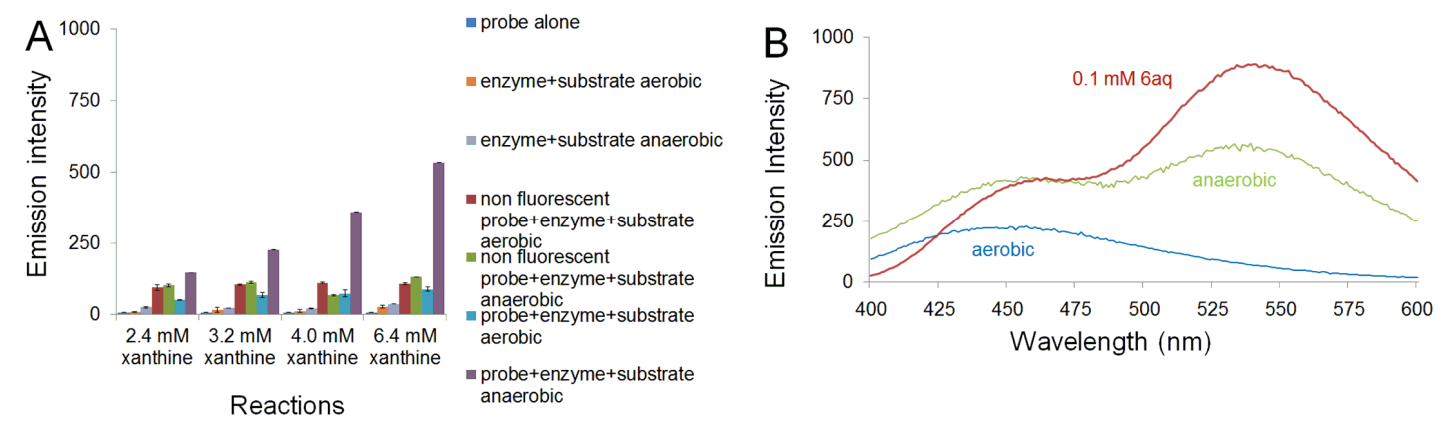

Figure 3.1 Enzymatic conversions of $\mathbf{4 2}$ to a fluorescent product selectively under hypoxic conditions. A. Fluorescence emission at $530 \mathrm{~nm}\left(\lambda_{\mathrm{ex}} 340 \mathrm{~nm}\right)$. Each set of assays depicted in the bar graph consists of (from left to right): a control sample of compound $\mathbf{4 2}$ alone $(0.8 \mathrm{mM}) \mathbf{\square}$, a control reaction composed of xanthine oxidase $(2.4 \mathrm{U} / \mathrm{mL})$ and xanthine $(2.4 \mathrm{mM}, 3.2 \mathrm{mM}, 4.0 \mathrm{mM}$ and $6.4 \mathrm{mM})$ under aerobic conditions $\square$, a control reaction composed of xanthine oxidase $(2.4 \mathrm{U} / \mathrm{mL})$ and xanthine $(2.4 \mathrm{mM}, 3.2$ $\mathrm{mM}, 4.0 \mathrm{mM}$ and $6.4 \mathrm{mM}$ ) under anaerobic conditions - , a control reaction composed of xanthine oxidase $(2.4 \mathrm{U} / \mathrm{mL})$, xanthine $(2.4 \mathrm{mM}, 3.2 \mathrm{mM}, 4.0 \mathrm{mM}$ and $6.4 \mathrm{mM})$ and the non-fluorescent electron acceptor, 1,2,4-benzotriazine 1,4-dioxide, (6.4 mM) under aerobic conditions $\boldsymbol{\square}$, a control reaction composed of xanthine oxidase $(2.4 \mathrm{U} / \mathrm{mL})$, xanthine $(2.4 \mathrm{mM}, 3.2 \mathrm{mM}, 4.0 \mathrm{mM}$ and $6.4 \mathrm{mM})$ and the non-fluorescent electron acceptor, 1,2,4-benzotriazine 1,4-dioxide, $(6.4 \mathrm{mM})$ under anaerobic conditions $\boldsymbol{\square}$, a reaction composed of xanthine oxidase $(2.4 \mathrm{U} / \mathrm{mL})$, xanthine $(2.4 \mathrm{mM}, 3.2 \mathrm{mM}, 4.0 \mathrm{mM}$ and $6.4 \mathrm{mM})$ and 42 under aerobic conditions $\square$, a reaction composed of xanthine oxidase $(2.4 \mathrm{U} / \mathrm{mL})$, xanthine $(2.4 \mathrm{mM}, 3.2 \mathrm{mM}$, $4.0 \mathrm{mM}$ and $6.4 \mathrm{mM}$ ) and $\mathbf{4 2}$ under anaerobic conditions $\boldsymbol{~}$. Reactions were incubated for $18 \mathrm{~h}$ in sodium phosphate buffer at $(12 \mathrm{mM}, \mathrm{pH} 7.4)$ at $24^{\circ} \mathrm{C}$, diluted with aerobic sodium phosphate buffer $(12 \mathrm{mM}, \mathrm{pH}$ 7.4), and the fluorescence measured $\left(\lambda_{\mathrm{ex}} 340 \mathrm{~nm}, \lambda_{\mathrm{em}} 530 \mathrm{~nm}\right)$. B. Fluorescence spectra of reaction mixtures generated in the aerobic and anaerobic metabolism of $\mathbf{4 2}$ by xanthine oxidase $(2.4 \mathrm{U} / \mathrm{mL})$ and xanthine $(6.4 \mathrm{mM})$ carried out as described in the Experimental Section and fluorescence spectrum of 6aminoquinoline $\left(\mathbf{4 3}, 0.1 \mathrm{mM}, \lambda_{\mathrm{ex}} 340 \mathrm{~nm}\right.$, in sodium phosphate buffer, $10 \mathrm{mM}, \mathrm{pH}$ 7.4).

When the fluorescent emission of anaerobic $\mathbf{4 2}$ reduction by xanthine and xanthine oxidase is inspected, the shape of the fluorescent curve is clear different from that of $\mathbf{4 4}$, which is generated by the metabolism of $\mathbf{4 2}$ by NADPH:cytochrome P450 reductase. ${ }^{15}$ The fluorescence curve of $\mathbf{4 4}$ contains two distinct emission maxima, at 440 and $460 \mathrm{~nm}$. The shape of the curve, obtained from xanthine oxidase mediated 
metabolism of $\mathbf{4 2}$ resembles fluorescence spectrum of $\mathbf{4 3}$ (Figure 3.1B, green and red curves). The fluorescence intensity of aerobic reaction, containing $\mathbf{4 2}$, at $530 \mathrm{~nm}$ region, is low relative to the corresponding anaerobic reaction (Figure 3.10, E). When non fluorescent electron acceptor benzotriazine 1,2,4-di-oxide is incubated with xanthine and xanthine oxidase under aerobic and anaerobic conditions, low fluorescence intensity is

detected at $530 \mathrm{~nm}$ region (Figure $3 \mathrm{~A}$, columns red and green). ${ }^{15}$ Xanthine and xanthine oxidase produced fluorescence, in low intensities under aerobic and anaerobic conditions may be due to the decomposition of cofactor of xanthine oxidase (Figure 3.10, C and D). ${ }^{19}$

\subsection{LC/MS analysis of the reaction mixtures generated by hypoxic metabolism of 42 by xanthine/xanthine oxidase}

To identify metabolites, produced in the enzymatic reduction reaction we analyzed reaction mixtures using LC/MS. The complete LC/MS analysis includes results of reaction mixtures and authentic compounds (Figures 3.2 and 3.3). The anaerobic reaction mixture of two equivalents of xanthine shows the presence of $\mathbf{5 0}$ (Figure 3.2 panels $\mathrm{A}, \mathrm{B}$ and $\mathrm{E}$ ). Compound $\mathbf{5 0}$ is fluorescent at $450 \mathrm{~nm}$ region (Figure 3.10, A). The contribution of $\mathbf{5 0}$ to the fluorescence at $530 \mathrm{~nm}$ region is minimal because it is unstable due to condensation with 49 to form $\mathbf{4 5}$. The mass to charge value $(\mathrm{m} / \mathrm{z})$ of $\mathrm{M}+\mathrm{H}$ ion of peak at 3.1 min on HPLC matches with that of authentic $\mathbf{5 0}$ (Figure 3.3, A and B). In the same mixture, the $\mathrm{m} / \mathrm{z}$ of $\mathrm{M}+\mathrm{H}$ ion of peak at $4.5 \mathrm{~min}$ on the HPLC (Figure 3.2, F) is the same as that of the authentic $\mathbf{4 3}$ (Figure 3.3, C and D), consistent with the fluorescent results (Figure 3.1B, curves green and red). The $\mathrm{m} / \mathrm{z}$ of $(\mathrm{M}+\mathrm{H})$ ion of the eluent at 5.5 min shows 285.1, which is the $\mathrm{M}+\mathrm{H} \mathrm{m} / \mathrm{z}$ value of $\mathbf{5 3}$ (Figure 3.2, A and scheme 3.4). In 
the same reaction mixture the product eluting at $14.6 \mathrm{~min}$ showed $\mathrm{m} / \mathrm{z}$ of 190.9 (Figure 3.2, A and G). The authentic LC analysis of $\mathbf{5 1}$ is consistent with the product eluting at 14.6 min in Figure 3.2, panel A (Figure 3.3 panels E and F). When 42 is incubated in the presence of xanthine oxidase, formation of $\mathbf{5 1}$ is possible as a metabolite along the reduction profile. ${ }^{15,20}$ The product eluting at $16.4 \mathrm{~min}$ shows $\mathrm{m} / \mathrm{z}$ value of 158.9 , which is the $\mathrm{M}+\mathrm{H}$ ion of nitroso, 49. (Figure 3.2, A, B, C and $\mathrm{H}$ )

The product eluting at $19.1 \mathrm{~min}$ on HPLC showed $\mathrm{m} / \mathrm{z}$ of 301.1 as the $(\mathrm{M}+\mathrm{H})$ ion (Figure 3.2 panels A and I). We employed Raney nickel mediated chemical reduction of 42, with hydrazine hydrate to obtain $45^{21}$ The authentic LC analysis of $\mathbf{4 5}$ is consistent with the product eluting at 19.1 min (Figure 3.3, I and J). There is no contribution to the fluorescence of anaerobic reactions by 45 (Figure 3.1A, purple column). The product appears at $24.7 \mathrm{~min}$, with $\mathrm{m} / \mathrm{z}$ of 282.9 may be an isomer of $\mathbf{5 2}$, which is not formed in these reactions (Figure 3.2, A and J, Figure 3.3, K and L, scheme 3.4).

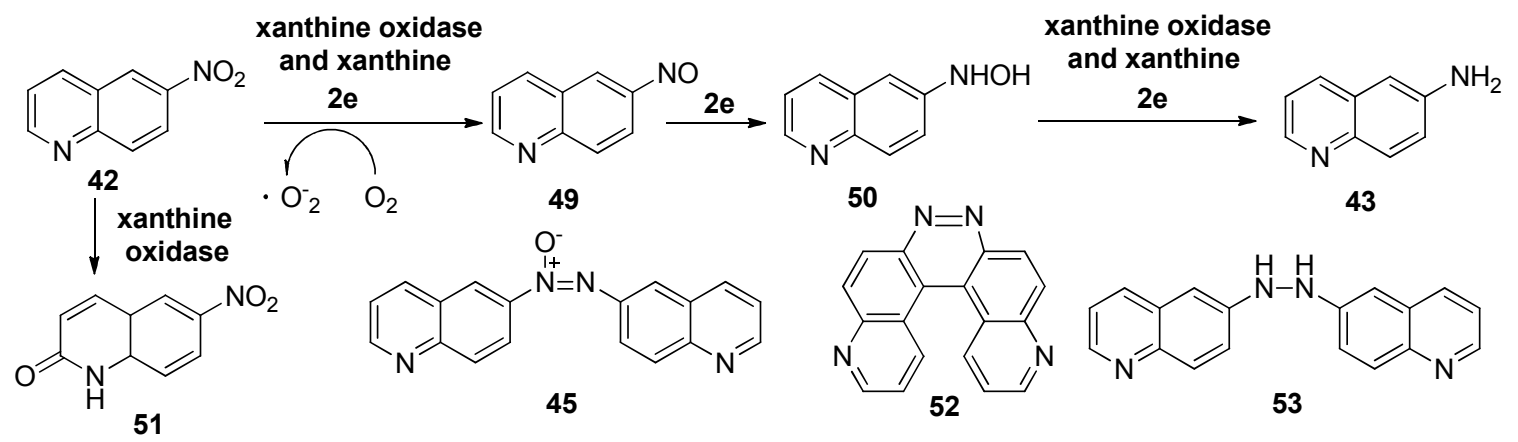

Scheme 3.4. Hypoxic metabolism of 42 by xanthine and xanthine oxidase

The reaction mixture containing $2.4 \mathrm{mM}$ xanthine shows diminished amounts of 51 (Figure 3.2, B). Similarly, in $4.0 \mathrm{mM}$ anaerobic xanthine assay, $\mathbf{5 1}$ and $\mathbf{5 0}$ are not present (Figure 3.2, C). When the xanthine amount is increase to $6.4 \mathrm{mM}$, under anaerobic conditions, as seen on the HPLC trace only 43, 45 and an isomer of $\mathbf{5 2}$ are 
formed (Figure 3.2, D). Fluorescent product 44 is not detected in the current study

(Figure 3.3, G and $\mathrm{H}$ ).
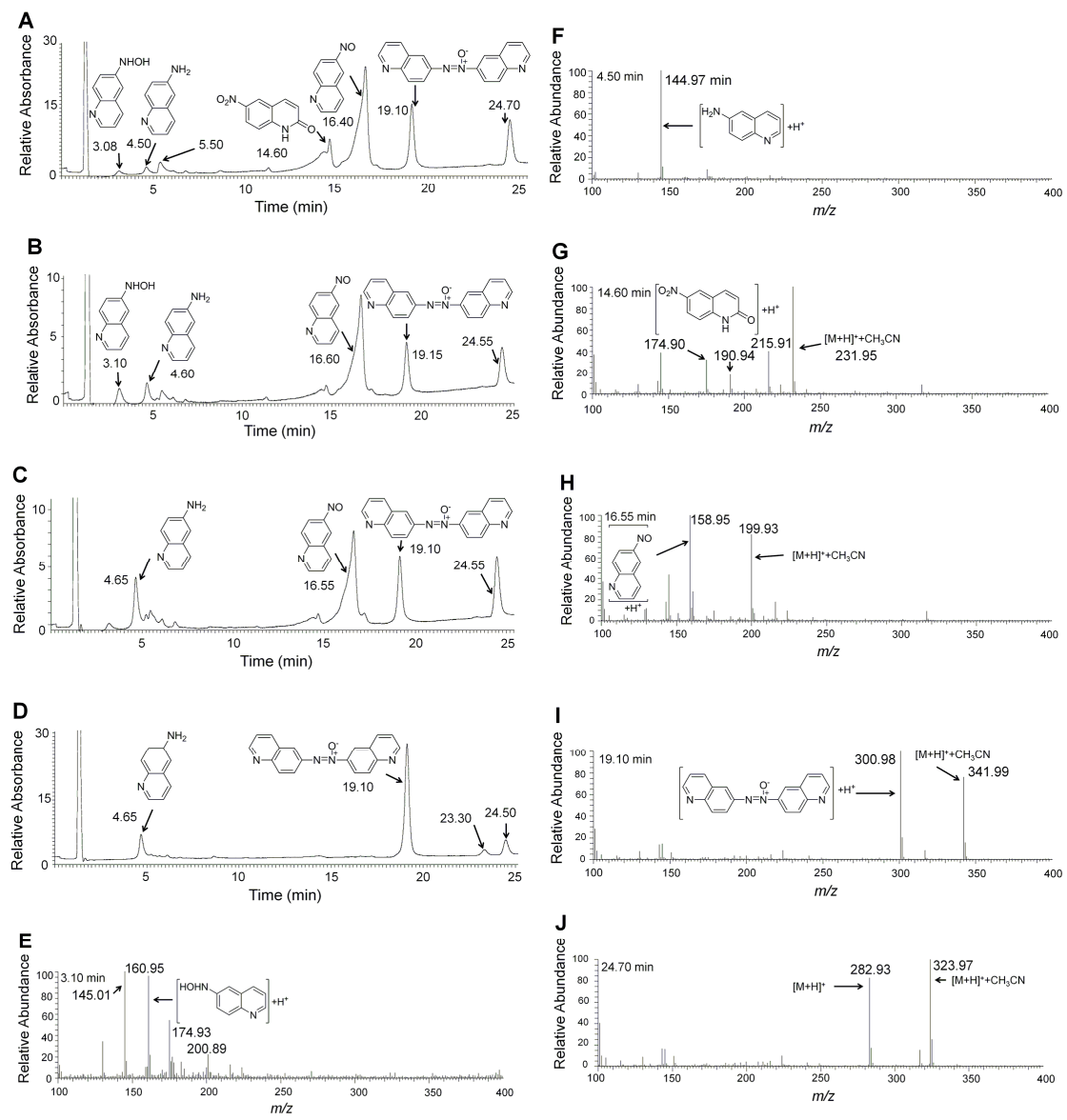

Figure 3.2. LC/MS analysis of reaction mixture, generated by anaerobic metabolism of $\mathbf{4 2}$. Compound $\mathbf{4 2}$ $(0.8 \mathrm{mM})$, xanthine oxidase $(2.4 \mathrm{U} / \mathrm{mL})$ and xanthine were mixed under anaerobic conditions and the reaction was carried out as described in the experimental section. The reaction was dried and products dissolved in methanol. The mixture was eluted with a gradient of $99 \%$ A (water containing $0.1 \%$ acetic acid) and 1\% B (acetonitrile containing $0.1 \%$ acetic acid) followed by linear increase to $90 \% \mathrm{~B}$ over 30 min. The elution was continued at $90 \% \mathrm{~B}$ for 3 min and then B was decreased to $1 \%$ over next 8 min. A flow rate of $0.35 \mathrm{~mL} / \mathrm{min}$ was used and the metabolites were detected at $254 \mathrm{~nm}$. Mass spectra were obtained using electrospray ionization in the positive ion mode. Panel A: HPLC trace of the anaerobic reaction mixture with xanthine $(1.6 \mathrm{mM})$ monitoring absorbance at $254 \mathrm{~nm}$. Panel B: HPLC of the anaerobic reaction mixture with xanthine $(2.4 \mathrm{mM})$ monitoring absorbance at $254 \mathrm{~nm}$. Panel C: HPLC trace of the anaerobic reaction mixture with xanthine $(4.0 \mathrm{mM})$ monitoring absorbance at $254 \mathrm{~nm}$. Panel D: HPLC trace of the anaerobic reaction mixture with xanthine $(6.4 \mathrm{mM})$ monitoring absorbance at $254 \mathrm{~nm}$. Panel E: LC/MS spectrum of product eluting at $3.08 \mathrm{~min}$ in panels A and B. Panel F: LC/MS spectrum of the product eluting at $4.50 \mathrm{~min}$ in panels $\mathrm{A}, \mathrm{B}, \mathrm{C}$ and $\mathrm{D}$. Panel G: LC/MS spectrum for of the product eluting at $14.60 \mathrm{~min}$ in panel A. Panel H: LC/MS spectrum for of the product eluting at $16.40 \mathrm{~min}$ in panels A, B, and C. Panel I: LC/MS spectrum for of the product eluting at $19.10 \mathrm{~min}$ in panels A, B, C and D. Panel J: LC/MS spectrum for of the product eluting at 24.50 min in panels A, B, C and D. 

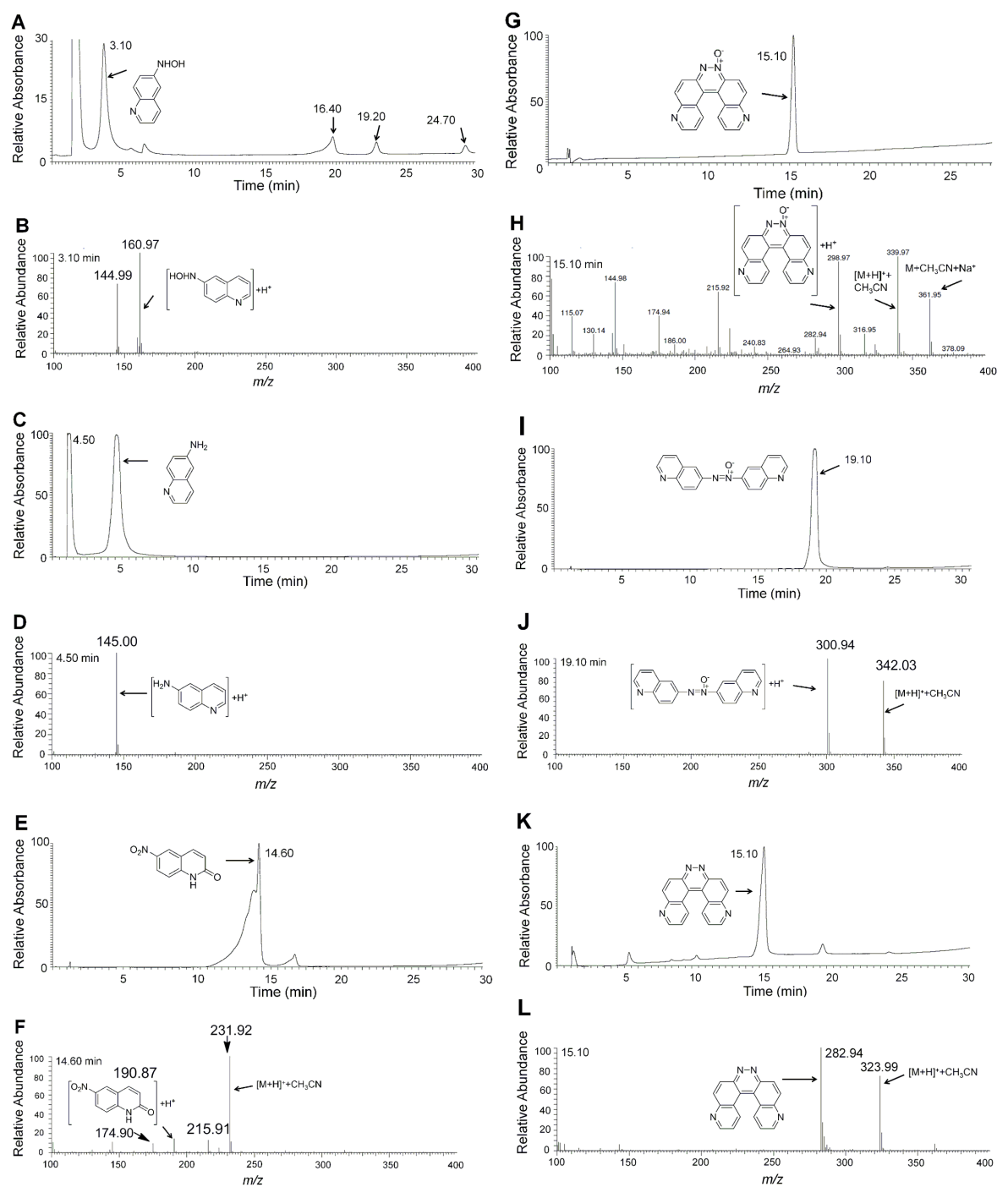

Figure 3.3. LC/MS analysis of authentic compounds. The compounds were dissolved in methanol. The mixture was eluted with a gradient of $99 \%$ A (water containing $0.1 \%$ acetic acid) and $1 \%$ B (acetonitrile containing $0.1 \%$ acetic acid) followed by linear increase to $90 \% \mathrm{~B}$ over $30 \mathrm{~min}$. The elution was continued at $90 \% \mathrm{~B}$ for $3 \mathrm{~min}$ and then B was decreased to $1 \%$ over next $8 \mathrm{~min}$. A flow rate of $0.35 \mathrm{~mL} / \mathrm{min}$ was used and the metabolites were detected at $254 \mathrm{~nm}$. Mass spectra were obtained using electrospray ionization in the positive ion mode. Panel A: HPLC trace of $\mathbf{5 0}$ monitoring absorbance at $254 \mathrm{~nm}$. Panel B: LC/MS spectrum of 50. Panel C: HPLC trace of $\mathbf{4 3}$ monitoring at $254 \mathrm{~nm}$. Panel D: LC/MS spectrum of $\mathbf{4 3}$ eluting at $4.50 \mathrm{~min}$. Panel E: HPLC trace of $\mathbf{5 1}$ monitoring at $254 \mathrm{~nm}$. Panel F: LC/MS spectrum of 51eluting at 14.60 min. Panel G: HPLC trace of $\mathbf{4 4}$ monitoring at $254 \mathrm{~nm}$. Panel H: LC/MS spectrum of $\mathbf{4 4}$ eluting at 15.10 min. Panel I: HPLC trace of $\mathbf{4 5}$ monitoring at $254 \mathrm{~nm}$. Panel J: LC/MS spectrum of $\mathbf{4 5}$. Panel K: HPLC trace of $\mathbf{5 2}$ monitoring at $254 \mathrm{~nm}$. Panel K: LC/MS spectrum of $\mathbf{5 2}$. 


\subsection{LC/MS analysis of the reaction mixtures generated by aerobic metabolism of 42}

\section{by xanthine/xanthine oxidase}

Starting compound $\mathbf{4 2}$ is remaining in the mixture while $\mathbf{5 1}$ and $\mathbf{4 5}$ appeared as new products under aerobic conditions (Scheme 3.4). None of the compounds are fluorescent.
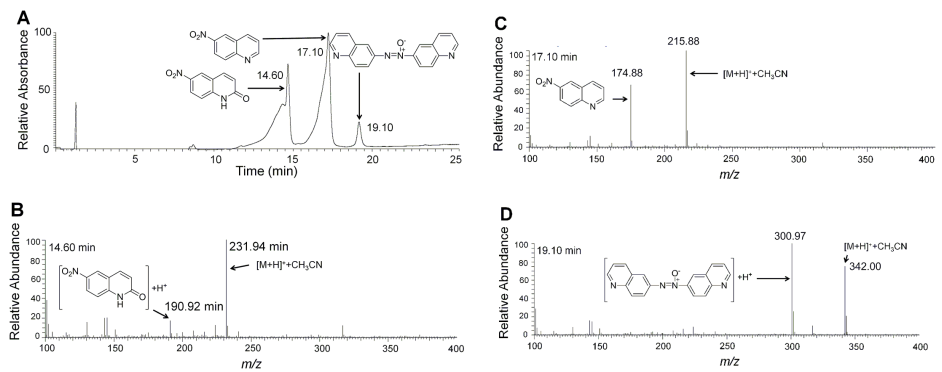

Figure 3.4 LC/MS analysis of the reaction mixture generated by aerobic metabolism of $\mathbf{4 2}$. Compound $\mathbf{4 2}$ $(0.8 \mathrm{mM})$ xanthine oxidase $(2.4 \mathrm{U} / \mathrm{mL})$ and xanthine $(6.4 \mathrm{mM})$ were mixed and the reaction was carried out as described in the experimental section. The reaction was dried and products dissolved in methanol. The mixture was eluted with a gradient of $99 \%$ A (water containing $0.1 \%$ acetic acid) and $1 \% \mathrm{~B}$ (acetonitrile containing $0.1 \%$ acetic acid) followed by linear increase to $90 \% \mathrm{~B}$ over $30 \mathrm{~min}$. The elution was continued at $90 \% \mathrm{~B}$ for $3 \mathrm{~min}$ and then $\mathrm{B}$ was decreased to $1 \%$ over next $8 \mathrm{~min}$. A flow rate of $0.35 \mathrm{~mL} / \mathrm{min}$ was used and the metabolites were detected at $254 \mathrm{~nm}$. Mass spectra were obtained using electrospray ionization in the positive ion mode. Panel A: HPLC of the aerobic reaction mixture monitoring absorbance at $254 \mathrm{~nm}$. Panel B: LC/MS spectrum of the product eluting at $14.60 \mathrm{~min}$. Panel C: LC/MS spectrum of the product eluting at $17.10 \mathrm{~min}$. Panel D: LC/MS spectrum for of the product eluting at $19.10 \mathrm{~min}$.

\subsection{Xanthine oxidase oxidizes aryl carbon, bonded to heteroatom of 42 to produce 6-}

\section{nitroquinolone 51}

The compound 51 (Figure 3.3, E), was synthesized using xanthine oxidase and 42 as the starting material. There is evidence for oxidation of aromatic carbon, adjacent to nitrogen by enzyme xanthine oxidase. ${ }^{22}$ It was clear from the metabolic results of aerobic reaction of $\mathbf{4 2}$ by xanthine oxidase that xanthine oxidase does oxidation chemistry on $\mathbf{4 2}$, as a substrate when reduction of $\mathbf{4 2}$ is diminished in the presence of oxygen (Figure 3.4, 
A). Moreover, at lower concentration of xanthine, under hypoxia $\mathbf{5 1}$ was produced as a main metabolite.

We speculated that xanthine oxidase should be able to convert 42 to $\mathbf{5 1}$ under aerobic conditions and xanthine is not required for the oxidation process. When $\mathbf{4 2}$ stirred with xanthine oxidase in aqueous media, $\mathbf{5 1}$ was obtained in milligram amounts (Scheme $3.5)$.

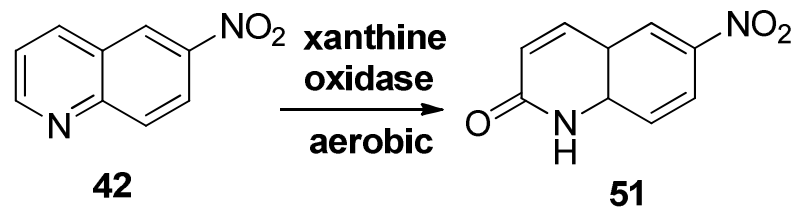

Scheme 3.5. Enzymatic generation of 51 by $\mathbf{4 2}$ using xanthine oxidase

Chemical characterization of $\mathbf{5 1}$ was conducted by NMR, HRMS and crystallography analysis (Figure 3.5 and experimental). Analysis of the ${ }^{1} \mathrm{H}-\mathrm{NMR}$ spectrum of $\mathbf{5 1}$ clearly shows the absence of the resonance for the proton adjacent to the nitrogen of the heterocyclic quinoline ring and a new resonance is seen on ${ }^{13} \mathrm{C}$ spectrum at $165 \mathrm{ppm}$ diagnostic for the carbonyl carbon of the quinolone system.

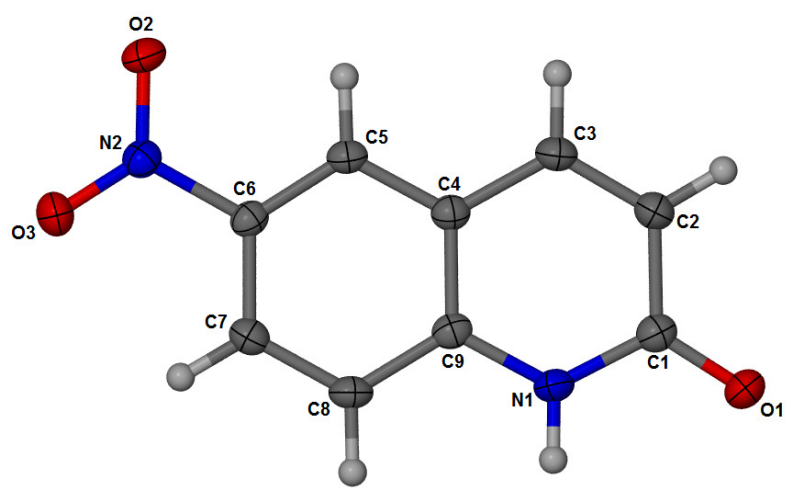

Figure 3.5. ORTEP diagram of $\mathbf{5 1}$ 
When enzymatically synthesized $\mathbf{5 1}$ was analyzed on LC/MS (Figure 3.3, E and F), retention time and $\mathrm{m} / \mathrm{z}$ matched with that which eluted with anaerobic and aerobic reactions (Figures 3.2, A and G, 3.3, E and $\mathrm{F}$ and 3.4, $\mathrm{A}$ and $\mathrm{B}$ ).

\subsection{Hypoxia-selective conversion of hydroxylamine 50 to amino 43}

It is well established that enzymatic reduction of nitroaroamtics proceeds via intermediates nitroso and hydroxylamine to produce amine product. ${ }^{7 \mathrm{ac}, \mathrm{c}} 10,23$ The final reduction step from intermediate hydroxylamine to amine is not well studied in the current literature. ${ }^{24}$ The final reduction step of the reduction profile of $\mathbf{4 2}$ is studied using $\mathbf{5 0}$ and the reduction of $\mathbf{5 0}$ is tested by xanthine and xanthine oxidase system under aerobic and anaerobic conditions. Characterization of enzyme mediated reduction of aromatic hydroxylamine to amine has not been reported (Scheme 3.6).

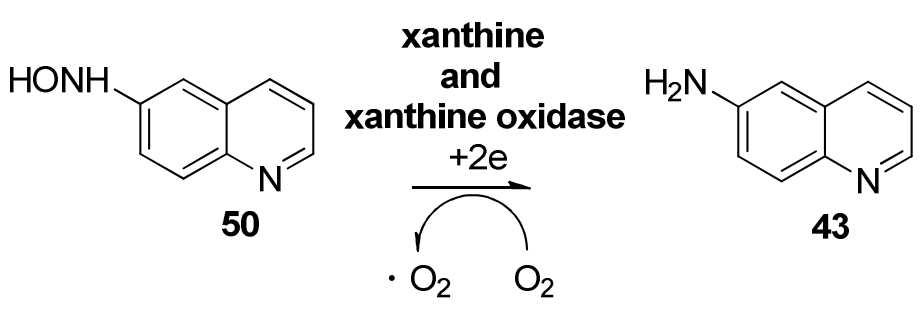

Scheme 3.6 Enzymatic generation of $\mathbf{4 3}$ by xanthine and xanthine oxidase

Hydroxylamine $\mathbf{5 0}$ has been chemically synthesized using hydrazine hydrate in the presence of Raney nickel and characterized using NMR, HRMS and crystallographic methods. The LC/MS characterization of $\mathbf{5 0}$ shows spontaneous formation of $\mathbf{4 9}$ and $\mathbf{4 5}$ (Figure 3.3, panels A and B). The hypoxic incubation of $\mathbf{5 0}$ with xanthine oxidase and xanthine shows fluorescence growth at $530 \mathrm{~nm}$ and the fluorescence increases with xanthine concentration (Figure 3.6 A). 

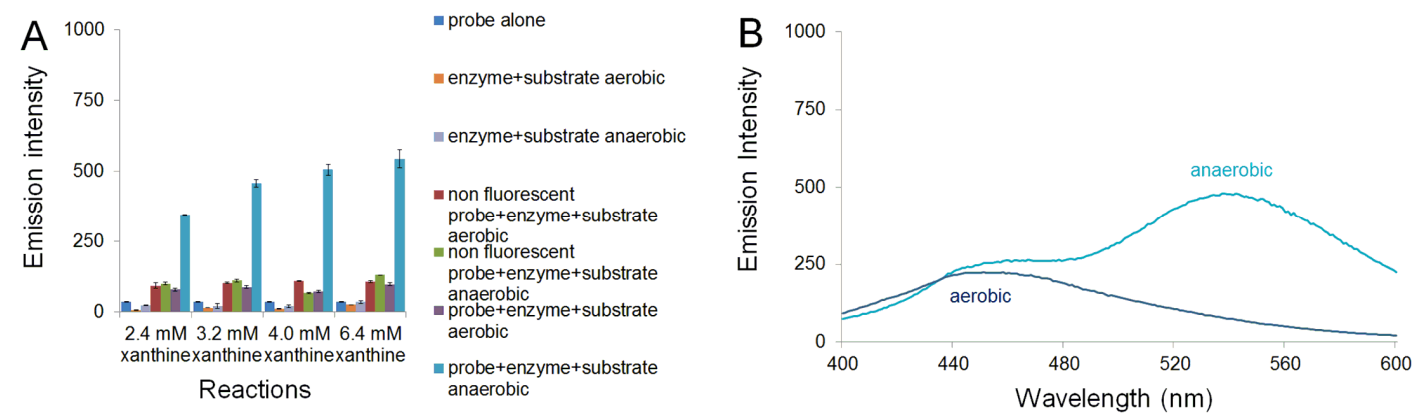

Figure 3.6. Enzymatic conversion of 50 to fluorescent 43 under hypoxic conditions. A. Fluorescence emission at $530 \mathrm{~nm}\left(\lambda_{\mathrm{ex}} 340 \mathrm{~nm}\right)$. Each set of assays depicted in the bar graph consists of (from left to right): a control sample of compound $\mathbf{5 0}$ alone $(0.8 \mathrm{mM}) \boldsymbol{\square}$, a control reaction composed of xanthine oxidase $(2.4 \mathrm{U} / \mathrm{mL})$ and xanthine $(2.4 \mathrm{mM}, 3.2 \mathrm{mM}, 4.0 \mathrm{mM}$ and $6.4 \mathrm{mM})$ under aerobic $\square$, a control reaction composed of xanthine oxidase $(2.4 \mathrm{U} / \mathrm{mL})$ and xanthine $(2.4 \mathrm{mM}, 3.2 \mathrm{mM}, 4.0 \mathrm{mM}$ and $6.4 \mathrm{mM})$ under anaerobic conditions $\square$, a control reaction composed of xanthine oxidase $(2.4 \mathrm{U} / \mathrm{mL})$, xanthine $(2.4$ $\mathrm{mM}, 3.2 \mathrm{mM}, 4.0 \mathrm{mM}$ and $6.4 \mathrm{mM}$ ) and the non-fluorescent electron acceptor, 1,2,4-benzotriazine 1,4dioxide, $(6.4 \mathrm{mM})$ under aerobic conditions $\boldsymbol{b}$, a control reaction composed of xanthine oxidase $(2.4$ $\mathrm{U} / \mathrm{mL}$ ), xanthine $(2.4 \mathrm{mM}, 3.2 \mathrm{mM}, 4.0 \mathrm{mM}$ and $6.4 \mathrm{mM})$ and the non-fluorescent electron acceptor, 1,2,4benzotriazine 1,4-dioxide, $(6.4 \mathrm{mM})$ under anaerobic conditions $\square$, a reaction composed of xanthine oxidase $(2.4 \mathrm{U} / \mathrm{mL})$, xanthine $(2.4 \mathrm{mM}, 3.2 \mathrm{mM}, 4.0 \mathrm{mM}$ and $6.4 \mathrm{mM})$ and $\mathbf{5 0}$ under aerobic conditions $\boldsymbol{\square}$, a reaction composed of xanthine oxidase $(2.4 \mathrm{U} / \mathrm{mL})$, xanthine $(2.4 \mathrm{mM}, 3.2 \mathrm{mM}, 4.0 \mathrm{mM}$ and $6.4 \mathrm{mM})$ and 50 under anaerobic conditions $\square$. Reactions were incubated for $18 \mathrm{~h}$ in sodium phosphate buffer at (12 mM, pH 7.4) at $24{ }^{\circ} \mathrm{C}$, diluted with aerobic sodium phosphate buffer $(12 \mathrm{mM}, \mathrm{pH} 7.4)$, and the fluorescence was measured $\left(\lambda_{\mathrm{ex}} 340 \mathrm{~nm}, \lambda_{\mathrm{em}} 530 \mathrm{~nm}\right)$. B. Fluorescence spectra of aerobic and anaerobic reaction mixtures containing $\mathbf{5 0}(0.8 \mathrm{mM})$, xanthine oxidase $(2.4 \mathrm{U} / \mathrm{mL})$, and xanthine $(3.2 \mathrm{mM})$.

In the aerobic reaction, fluorescence growth is not detected (Figure 3.10 panel F).

The shape of the fluorescence curve of the anaerobic reaction is similar to 43 in solution

(Figure 3.6 B). The LC/MS analysis of anaerobic reaction shows the presence of $\mathbf{4 3}$ and

45. The evidence shows the oxygen sensitivity of reduction of $\mathbf{5 0}$ by xanthine and xanthine oxidase, to form 43 (Figure 3.7). 

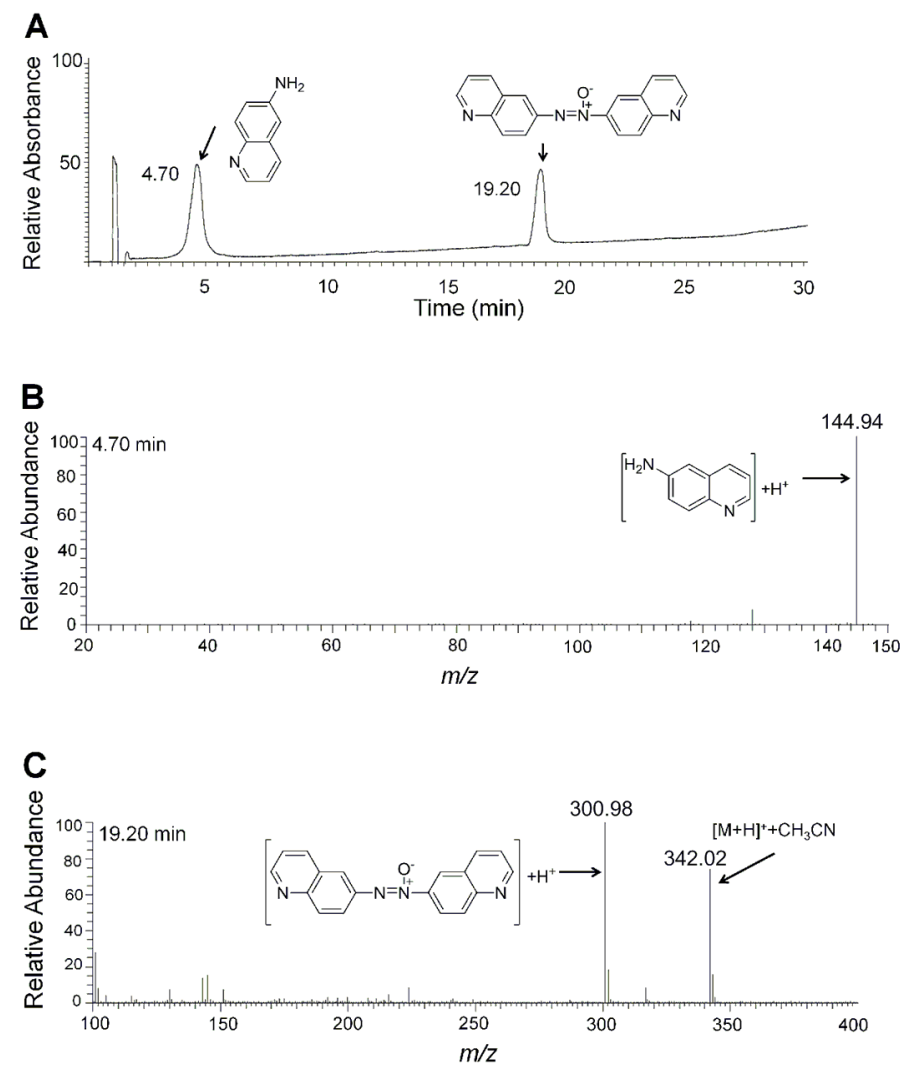

Figure 3.7. LC/MS analysis of the reaction mixture generated by anaerobic metabolism of $\mathbf{5 0}$. Compound $50(0.8 \mathrm{mM})$,xanthine oxidase $(2.4 \mathrm{U} / \mathrm{mL})$ and xanthine $(6.4 \mathrm{mM})$ were mixed and the reaction was carried out as described in the experimental section. The reaction was dried and products dissolved in methanol. The mixture was eluted with a gradient of $99 \%$ A (water containing $0.1 \%$ acetic acid) and $1 \% \mathrm{~B}$ (acetonitrile containing $0.1 \%$ acetic acid) followed by linear increase to $90 \% \mathrm{~B}$ over $30 \mathrm{~min}$. The elution was continued at $90 \% \mathrm{~B}$ for $3 \mathrm{~min}$ and then B was decreased to $1 \%$ over next $8 \mathrm{~min}$. A flow rate of 0.35 $\mathrm{mL} / \mathrm{min}$ was used and the metabolites were detected at $254 \mathrm{~nm}$. Mass spectra were obtained using electrospray ionization in the positive ion mode. Panel A: HPLC trace of the anaerobic reaction mixture monitoring absorbance at $254 \mathrm{~nm}$. Panel B: LC/MS spectrum of the product eluting at $4.70 \mathrm{~min}$. Panel C: LC/MS spectrum of the product eluting at $19.20 \mathrm{~min}$. 


\subsection{Hypoxia-selective conversion of 6-nitroquinolone 51 to 6-aminoquinolone 54}<smiles>O=c1ccc2cc([N+](=O)[O-])ccc2[nH]1</smiles>

51

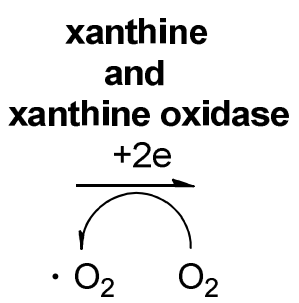<smiles>Nc1ccc2[nH]c(=O)ccc2c1</smiles>

54

Scheme 3.7. Enzymatic generation of $\mathbf{5 4}$ from $\mathbf{5 1}$ by xanthine and xanthine oxidase is hypoxia selective

We speculated that the 6-aminoquinolone $\mathbf{5 4}$ may be fluorescent. The compound

54 was chemically synthesized by reducing $\mathbf{5 1}$ on palladium/charcoal hydrogenation to obtain the fluorescent spectrum (Figure 3.10 panel B). Then, hypoxia selective reduction of $\mathbf{5 1}$ by xanthine and xanthine oxidase system is tested. The anaerobic reaction produced expected fluorescence of 54 (Scheme 3.7). A Sixteen fold increase of fluorescence is obtained against the aerobic reaction (Figure 3.8).
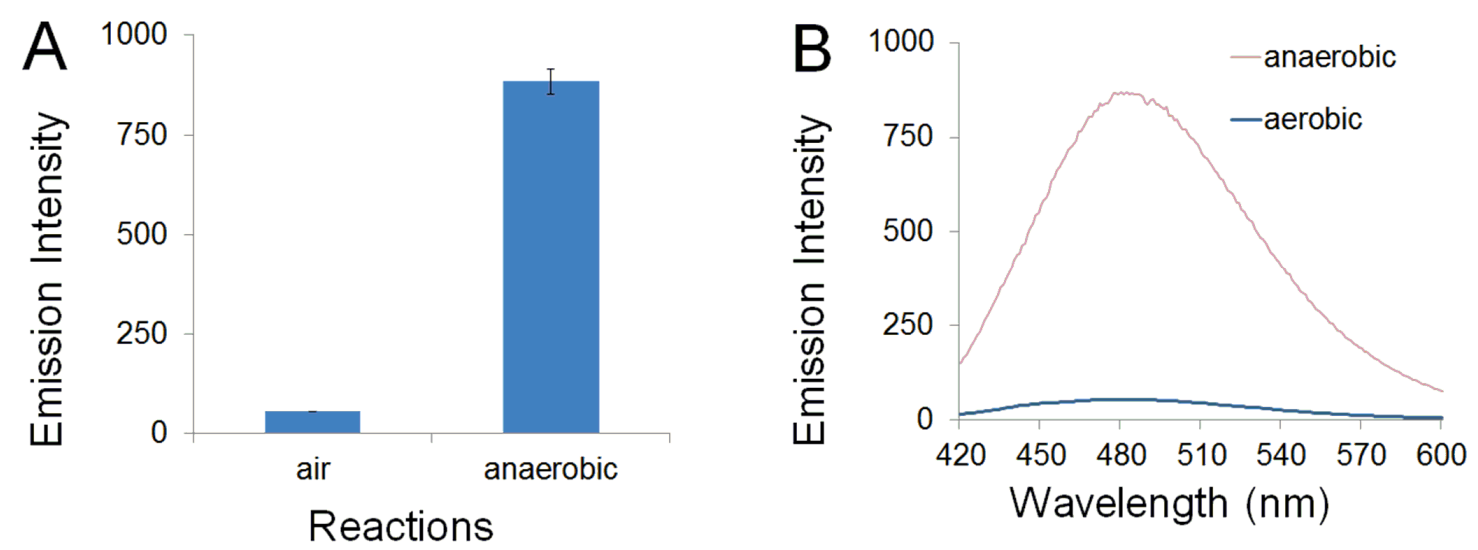

Figure 3.8. Enzymatic conversions of $\mathbf{5 1}$ to $\mathbf{5 4}$ under hypoxic conditions. A. Fluorescence emission at 485 $\mathrm{nm}(\lambda$ ex $390 \mathrm{~nm})$ for $\mathbf{5 1}(0.8 \mathrm{mM})+$ xanthine oxidase $(2.4 \mathrm{U} / \mathrm{mL})$ and xanthine $(3.2 \mathrm{mM})$ under aerobic conditions, $\mathbf{5 1}(0.8 \mathrm{mM})+$ xanthine oxidase $(2.4 \mathrm{U} / \mathrm{mL})$ and xanthine $(3.2 \mathrm{mM})$ under anaerobic conditions, Reactions were incubated for $18 \mathrm{~h}$ in sodium phosphate buffer at $(12 \mathrm{mM}, \mathrm{pH} 7.4)$ at $24{ }^{\circ} \mathrm{C}$, then diluted with aerobic sodium phosphate buffer (12 mM, pH 7.4) and the fluorescence measured $\left(\lambda_{\mathrm{ex}} 390 \mathrm{~nm}, \lambda_{\mathrm{em}}\right.$ $485 \mathrm{~nm}$ ). B. Fluorescence spectra (in sodium phosphate buffer, $10 \mathrm{mM}, \mathrm{pH} 7.4$ ) of the reaction mixture generated in the aerobic metabolism of $\mathbf{5 1}$ by xanthine oxidase $(2.4 \mathrm{U} / \mathrm{mL})$ and xanthine $(3.2 \mathrm{mM})(\mathrm{pink}$, $\lambda_{\mathrm{em}} 485 \mathrm{~nm}$ ) and fluorescence spectrum (in sodium phosphate buffer, $10 \mathrm{mM}, \mathrm{pH} 7.4$ ) of the reaction mixture generated in the aerobic metabolism of $\mathbf{5 1}$ by xanthine oxidase $(2.4 \mathrm{U} / \mathrm{mL})$ and xanthine $(3.2 \mathrm{mM})$ (blue) $\lambda_{\text {em }} 485 \mathrm{~nm}$. 


\subsection{Enzymatic conversion of $\mathbf{4 2}$ to 6-nitroquinolone 51 followed by hypoxia-selective conversion to 6-aminoquinolone 54}

LC/MS analysis of anaerobic and aerobic metabolism of $\mathbf{4 2}$ reveals that under low concentrations of xanthine, $\mathbf{4 2}$ was oxidized to form $\mathbf{5 1}$ and that oxidation can dominate over reduction of nitro under low oxygen levels. Upon forming 51, xanthine oxidase can perform nitro reduction on $\mathbf{5 1}$, under hypoxia to produce $\mathbf{5 4}$ in the same reaction mixture (Scheme 3.8).

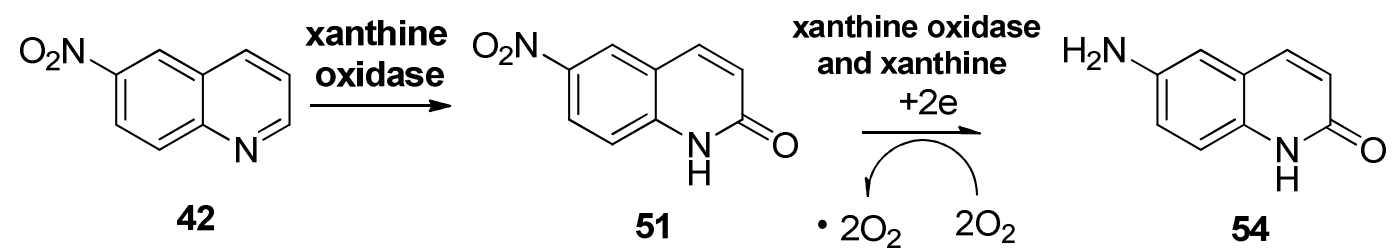

Scheme 3.8 Enzymatic generation of 51 from 42 and production of 54 from 51

In the assay we used 0.5 molar equivalent of xanthine, $0.4 \mathrm{mM}$, with $\mathbf{4 2}$ and xanthine oxidase and carried out the normal enzymatic reactions under anaerobic and aerobic conditions. In the fluorescence assays a ten-fold increase of fluorescence was obtained against the aerobic reaction mixture (Figure 3.9). 

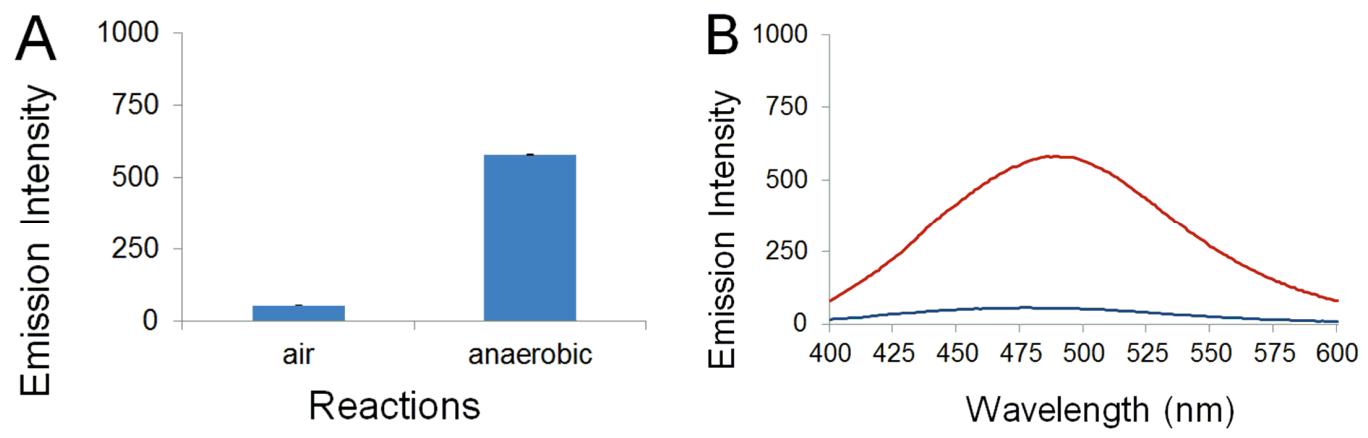

Figure 3.9 Enzymatic conversion of $\mathbf{4 2}$ to $\mathbf{5 1}$ and reduction to $\mathbf{5 4}$ in hypoxia. A. Fluorescence emission at $485 \mathrm{~nm}(\lambda \mathrm{ex} 390 \mathrm{~nm})$ for $1(0.8 \mathrm{mM})+$ xanthine oxidase $(2.4 \mathrm{U} / \mathrm{mL})$ and xanthine $(0.4 \mathrm{mM})$ under aerobic conditions.Compound $1(0.8 \mathrm{mM})+$ xanthine oxidase $(2.4 \mathrm{U} / \mathrm{mL})$ and xanthine $(0.4 \mathrm{mM})$ were incubated for $18 \mathrm{~h}$ in sodium phosphate buffer at $(12 \mathrm{mM}, \mathrm{pH} 7.4)$ at $24{ }^{\circ} \mathrm{C}$ under hypoxia, then diluted with aerobic sodium phosphate buffer (12 mM, pH 7.4) and the fluorescence measured ( $\lambda$ ex $390 \mathrm{~nm}, \lambda \mathrm{em} 485 \mathrm{~nm})$. B. Fluorescence spectra (in sodium phosphate buffer, $10 \mathrm{mM}, \mathrm{pH}$ 7.4) of the reaction mixtures generated in the anaerobic(red) and aerobic(blue) metabolism of 42 by xanthine oxidase $(2.4 \mathrm{U} / \mathrm{mL})$ and xanthine $(0.4$ $\mathrm{mM})(\lambda \mathrm{em}$ at $485 \mathrm{~nm})$

\subsection{Conclusions}

In the current work, we provide evidence for the hypoxia-selective conversion of 6-nitroquinoline 42 to 6-aminoquinoline 43 , by xanthine/xanthine oxidase enzyme system. The reduction steps are consecutive one electron additions, as seen in scheme 3.1. In addition, condensation occurs between $\mathbf{5 0}$ and $\mathbf{4 9}$ to produce $\mathbf{4 5}$. The chemical synthesis and complete characterization of $\mathbf{5 0}$ facilitates the analysis of the oxygen sensitivity of final reduction step. Fluorescent and LC/MS analysis of reduction of $\mathbf{5 0}$ in hypoxia, by xanthine and xanthine oxidase show the presence of fluorescent 43 . This finding is important and striking because the existing evidence in the literature discusses only the oxygen sensitivity of the first reduction step of nitro compounds. ${ }^{7 \mathrm{~d}, 10,25}$ The evidence we provide supports the existence of multiple oxygen sensitive reduction steps over the enzymatic reduction of nitro aromatic compound. In an early work, related to the 
reduction of $\mathbf{4 2}$ by $\mathrm{CYP} 450 \mathrm{R}^{15}$, together with current xanthine and xanthine oxidasemediated reduction of $\mathbf{4 2}$ in hypoxia shows different product profile and metabolism that may occur on a single nitro compound. The comparison reveals that the inability of CYP450R to reduce intermediate 50, under the conditions we applied, leaving them to condense to form byproducts.

We observed the oxidation of $\mathbf{4 2}$ to $\mathbf{5 1}$, conducted by xanthine oxidase (51, Scheme 3.4). The ability of xanthine oxidase to oxidize aromatic carbon atoms next to nitrogen is well documented. ${ }^{2 \mathrm{~b},}{ }^{22 \mathrm{~d}}$ The oxidizing capability of xanthine oxidase is responsible for the transformation of $\mathbf{4 2}$ to 51. The aerobic assays show the oxidation product 51 as a major product. Upon reduction 51 produces fluorescent 54, which emits at $490 \mathrm{~nm}$ (data not shown) under assay conditions. In assays, when xanthine concentration is increased the yield of $\mathbf{5 1}$ decreases. Hence, it can be concluded that under anaerobic conditions xanthine/xanthine oxidase system efficiently reduces $\mathbf{4 2}$. The oxidizing ability of xanthine oxidase slows when conditions for reduction is favored.

Reduction of 51, in a separate experiment by xanthine/xanthine oxidase system, under hypoxia produces fluorescence at $485 \mathrm{~nm}$. The emission parameters of $\mathbf{5 4}$ match with the fluorescence obtained from the anaerobic metabolism of $\mathbf{5 1}$ (data not shown). The fluorescent enhancement obtained with $\mathbf{5 1}$ grants future experiments on $\mathbf{5 1}$ as a potential fluorescent probe to detect hypoxia.

Finally, the work we presented shows the ability of $\mathbf{4 2}$ to be used as a fluorescent probe that can be activated by one electron reductases, under hypoxia. Chemical characterization of metabolites, produced from enzymatic reduction of nitroaromatic compounds is essential to understand the complexity of nitroaromatic reduction. 


\subsection{Experimental}

Materials and methods. Chemicals were purchased from following sources: Sodium phosphate, glucose, NADPH, cytochrome p450 reductase, DMF, Raney nickel slurry in water, silica gel plates for thin layer chromatography and silica gel $(0.04-0.063 \mathrm{~mm}$ pore size) for column chromatography were obtained from Sigma Aldrich (St. Louis, MO); 6aminoquinoline, 6-nitroquinoline, and hydrazine hydrate from Alfa-Aesar (Ward Hill, MA). deuterated NMR solvents were from Cambridge Isotope Laboratories (Andover, MA); ethyl acetate, dichloromethane, methanol, hexane, ethanol, HPLC water and HPLC acetonitrile from Fischer; The compound 1,2,4-benzotriazine-1,4-di-N-oxide was made following literature methods. ${ }^{1}$ High resolution mass spectrometry (HRMS) analyses were performed at the mass spectroscopy facility of the University of Illinois ChampaignUrbana and low resolution mass spectroscopic analyses were carried out at the University of Missouri-Columbia. ${ }^{1} \mathrm{H}$ and ${ }^{13} \mathrm{C}$ NMR experiments and were done on a Bruker Avance DRX300 with $5 \mathrm{~mm}$ broadband probe and Bruker Avance DRX500 with CPTCI probe using deuterated NMR solvents methanol $\left(\mathrm{CD}_{3} \mathrm{OD}\right)$ and chloroform $\left(\mathrm{CDCl}_{3}\right)$ at the University of Missouri-Columbia. The reference peaks were set to $3.31 \mathrm{ppm}$ and 49.00 ppm for deuterated methanol and $7.26 \mathrm{ppm}$ and $77.00 \mathrm{ppm}$ for deuterated chloroform from tetramethylsilane for the ${ }^{1} \mathrm{H}$ and ${ }^{13} \mathrm{C}$ spectra respectively. The fluorescence spectra were obtained on a Varian Cary Eclipse Fluorescence Spectrophotometer equipped with xenon flash lamp with instrumental slit width settings at $10 \mathrm{~nm}$ employing a $10 \mathrm{~mm}$ path length quartz cuvette. 

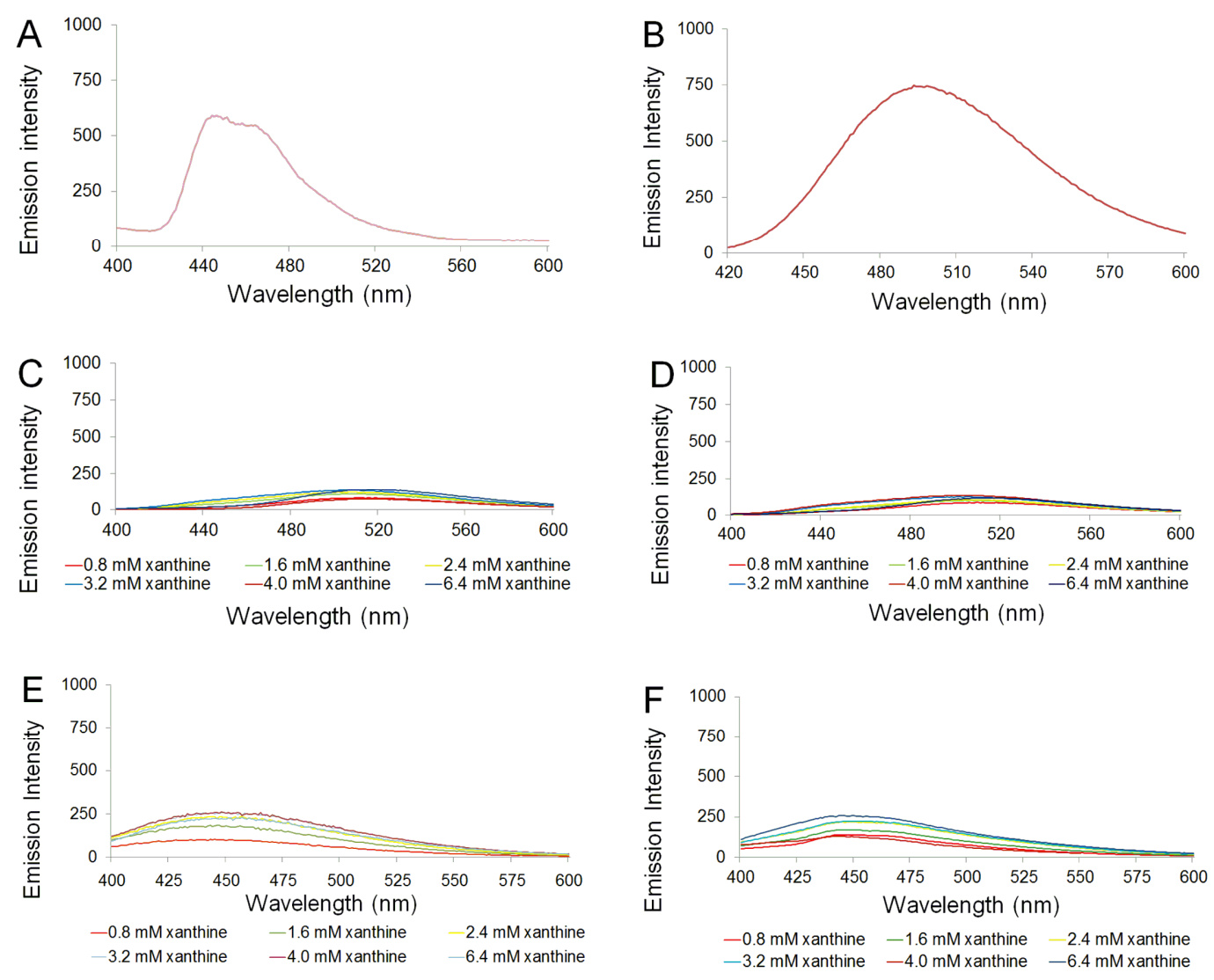

Figure 3.10. Fluorescence spectra of control reactions. A: Fluorescence spectrum of $\mathbf{5 0} \square\left(0.03 \mathrm{mM}, \lambda_{\mathrm{ex}}\right.$ $340 \mathrm{~nm}$, in sodium phosphate buffer, $10 \mathrm{mM}, \mathrm{pH}$ 7.4). B: Fluorescence spectrum of $\mathbf{5 4}\left(0.003 \mathrm{mM}, \lambda_{\mathrm{ex}}\right.$ $390 \mathrm{~nm}$, in sodium phosphate buffer, $10 \mathrm{mM}, \mathrm{pH}$ 7.4). C: Fluorescence spectra $\left(\lambda_{\mathrm{ex}} 340 \mathrm{~nm}\right.$, in sodium phosphate buffer, $10 \mathrm{mM}, \mathrm{pH} 7.4)$ of control reactions composed of xanthine oxidase $(2.4 \mathrm{U} / \mathrm{mL})$, xanthine ( $2.4 \mathrm{mM}, 3.2 \mathrm{mM}, 4.0 \mathrm{mM}$ and $6.4 \mathrm{mM}$ ) and a non-fluorescent electron acceptor 1,2,4-benzotriazine 1,4dioxide $(6.4 \mathrm{mM})$ under aerobic conditions ( referred to brown bar in figure 3.1, $\mathbf{\square}$ ), D: Fluorescence spectra of control reactions composed of xanthine oxidase $(2.4 \mathrm{U} / \mathrm{mL})$, xanthine $(2.4 \mathrm{mM}, 3.2 \mathrm{mM}, 4.0 \mathrm{mM}$ and $6.4 \mathrm{mM})$ and a non-fluorescent electron acceptor 1,2,4-benzotriazine 1,4-dioxide $(6.4 \mathrm{mM})$ under anaerobic conditions (referred to green bar in figure $3.1 \mathrm{~A},-$ ) E: Fluorescence spectra $\left(\lambda_{\mathrm{ex}} 340 \mathrm{~nm}\right.$, in sodium phosphate buffer, $10 \mathrm{mM}, \mathrm{pH} 7.4$ ) of reactions composed of xanthine oxidase (2.4 U/mL), xanthine $(2.4 \mathrm{mM}, 3.2 \mathrm{mM}, 4.0 \mathrm{mM}$ and $6.4 \mathrm{mM}$ ) and $\mathbf{4 2}$ under aerobic conditions ( blue bar in figure $3.1 \mathrm{~A}, \square$ ), F: Fluorescence spectra $\left(\lambda_{\mathrm{ex}} 340 \mathrm{~nm}\right.$, in sodium phosphate buffer, $10 \mathrm{mM}, \mathrm{pH}$ 7.4) of reactions composed of xanthine oxidase $(2.4 \mathrm{U} / \mathrm{mL})$, xanthine $(2.4 \mathrm{mM}, 3.2 \mathrm{mM}, 4.0 \mathrm{mM}$ and $6.4 \mathrm{mM})$ and $\mathbf{5 0}$ under aerobic conditions. 


\section{Synthesis of 6-hydroxylaminoquinoline 50:}

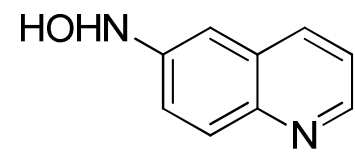

6-nitroquinoline $(0.5 \mathrm{~g}, 2.87 \mathrm{mmol}) 42$ was stirred in $20 \mathrm{~mL}$ of $\mathrm{EtOH} / \mathrm{CH}_{2} \mathrm{Cl}_{2}$

$(1: 1)$ at $0^{0} \mathrm{C}$ and $0.5 \mathrm{~mL}$ of was Raney nickel slurry (active catalyst in water-sigma 221678) was added. Then, 10 molar eq. of hydrazine hydrate was added drop wise and stirred for 1 hour while purging nitrogen gas. The solid was filtered and the organic mixture was dried using brine and sodium sulfate. The compound $\mathbf{5 0}$ was separated by column chromatography using EtOAc and $\mathrm{MeOH} / \mathrm{CH}_{2} \mathrm{Cl}_{2}$ solvents. To obtain crystals, the pure product was dissolved in warm EtOAc and was cooled rapidly to isolate yellow crystals. ${ }^{1} \mathrm{H}-\mathrm{NMR}\left(\mathrm{CD}_{3} \mathrm{OD}, 300 \mathrm{MHz},\right): \delta 8.53(\mathrm{~d}, \mathrm{~J}=5.0 \mathrm{~Hz}, 1 \mathrm{H}), 8.07(\mathrm{~d}, \mathrm{~J}=8.0 \mathrm{~Hz}$, 1H), $7.82(\mathrm{~m}, 1 \mathrm{H}), 7.33(\mathrm{~m}, 3 \mathrm{H}) .{ }^{13} \mathrm{C} \mathrm{NMR}\left(\mathrm{CD}_{3} \mathrm{OD}, 300 \mathrm{MHz}\right): \delta$ 151.40, 147.64, 144.76, 136.72, 131.05, 129.15, 122.54, 121.01, 107.68. HRMS (ESI, M+H' ${ }^{+}$m/z calcd for $\mathrm{C}_{9} \mathrm{H}_{9} \mathrm{~N}_{2} \mathrm{O}$ 160.0715, found 160.0707 


\section{Synthesis of 1,2-di(quinolin-6-yl)diazene oxide 45}

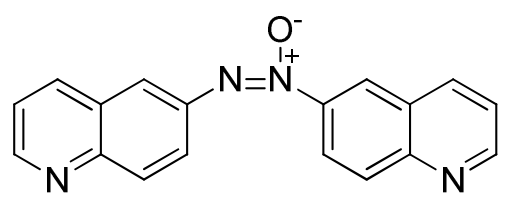

We employed a variation on the literature procedure of Boge $e t$ al. ${ }^{2}$ To a solution of compound $42(0.5 \mathrm{~g}, 2.87 \mathrm{mmol})$ in a mixture of $\mathrm{EtOH}: \mathrm{CH}_{2} \mathrm{Cl}_{2}(1: 1,20 \mathrm{~mL})$ at $0{ }^{\circ} \mathrm{C}$ in an ice/salt bath was added Raney nickel slurry $(0.5 \mathrm{~mL}$, active catalyst in water, SigmaAldrich cat. number 221678). To this mixture, hydrazine hydrate $(1.5 \mathrm{~mL}, 30 \mathrm{mmol})$ portions were added over the course of $3 \mathrm{~h}$ with stirring until $\mathbf{4 2}$ was consumed (TLC) and the resulting mixture stirred overnight. The solid was removed by filtration and the resulting solution dried by extraction with brine and then over sodium sulfate. The compound was purified by column chromatography on silica gel eluted with ethyl acetate in the first column separation and the second column chromatography separation on silica gel was done with $\mathrm{MeOH}: \mathrm{CH}_{2} \mathrm{Cl}_{2}$ (99:1) to obtain the product, a yellow solid, in pure form $\left(100 \mathrm{mg}, \mathrm{R}_{\mathrm{f}}\right.$ value $=0.25$ in $4 \% \mathrm{MeOH}$ in $\left.\mathrm{CH}_{2} \mathrm{Cl}_{2}\right){ }^{1} \mathrm{H} \mathrm{NMR}\left(\mathrm{CDCl}_{3}, 300 \mathrm{MHz}\right): \delta$ ppm $9.14(\mathrm{~d}, \mathrm{~J}=2.5 \mathrm{~Hz}, 1 \mathrm{H}), \delta 9.00(\mathrm{dd}, \mathrm{J}=4.5 \mathrm{~Hz}, \mathrm{~J}=1.5 \mathrm{~Hz}, 1 \mathrm{H}), \delta 8.93(\mathrm{dd},, \mathrm{J}=4.5$ $\mathrm{Hz}, \mathrm{J}=1.5 \mathrm{~Hz}, 1 \mathrm{H}), \delta 8.82(\mathrm{~d}, \mathrm{~J}=2.5 \mathrm{~Hz}, 1 \mathrm{H}), \delta 8.67(\mathrm{~d}, \mathrm{~J}=9.0 \mathrm{~Hz}, 1 \mathrm{H}), \delta 8.31(\mathrm{dd}, \mathrm{J}=$ $9.0 \mathrm{~Hz}, \mathrm{~J}=1.5 \mathrm{~Hz}, 1 \mathrm{H}), \delta 8.21(\mathrm{~m}, 4 \mathrm{H}), \delta 7.49(\mathrm{dd}, \mathrm{J}=8.5 \mathrm{~Hz}, \mathrm{~J}=4.5 \mathrm{~Hz}, 1 \mathrm{H}), 7.42(\mathrm{dd}$, $\mathrm{J}=8.5 \mathrm{~Hz}, \mathrm{~J}=4.5 \mathrm{~Hz}, 1 \mathrm{H}), 1.23$ grease. ${ }^{13} \mathrm{C} \mathrm{NMR}\left(\mathrm{CDCl}_{3}, 75.5 \mathrm{MHz}\right): \delta$ 152.86, 151.97, $149.64,148.72,146.01,141.93,137.88,137.76,130.95,130.32,129.32,128.46,127.73$, 123.76, 123.40, 122.68, 122.64, 122.09; HRMS (ESI, $[\mathrm{M}+\mathrm{H}]^{+}$) m/z calcd for $\mathrm{C}_{18} \mathrm{H}_{13} \mathrm{~N}_{4} \mathrm{O}$ 301.1089, found 301.1080. ${ }^{2}$ Boge, N.; Kruger, S.; Schroder, M.; Meier, C.; Synthesis 2007, 24, 3907-3914. 


\section{Synthesis of 52}<smiles>c1cnc2ccc3nnc4ccc5ncccc5c4c3c2c1</smiles>

The compound $44(0.01 \mathrm{~g}, 0.0335 \mathrm{mmol})$ in $70 \%$ EtOH:water $(2.5 \mathrm{~mL})$ was added with sodium dithionite $(0.012 \mathrm{~g}, 0.07 \mathrm{mmol}$ ) and was refluxed for $30 \mathrm{~min}$. The reaction mixture was filtered and dried with brine and magnesium sulfate. The crude material was separated by silica gel column chromatography using EtOAc to obtain the product 52. ${ }^{1} \mathrm{H}-\mathrm{NMR}\left(\mathrm{CDCl}_{3}, 500 \mathrm{MHz}\right): \delta 9.11(\mathrm{~d}, \mathrm{~J}=4.5 \mathrm{~Hz}, 2 \mathrm{H}), 9.01(\mathrm{~d}, \mathrm{~J}=8.0$ $\mathrm{Hz}, 2 \mathrm{H}), 8.85(\mathrm{~d}, \mathrm{~J}=9.0 \mathrm{~Hz}, 2 \mathrm{H}), 8.46(\mathrm{~d}, \mathrm{~J}=9.0 \mathrm{~Hz}, 2 \mathrm{H}), 7.43(\mathrm{dd}, \mathrm{J}=8.0 \mathrm{~Hz}, \mathrm{~J}=4.5$ $\mathrm{Hz}, 2 \mathrm{H}) .{ }^{13} \mathrm{C}-\mathrm{NMR}\left(\mathrm{CDCl}_{3}, 125.77 \mathrm{MHz}\right): \delta 152.66,149.77,146.06,136.07,132.75$, 130.81, 123.18, 120.14, 119.28. HRMS (ESI, M+H $\mathrm{H}^{+}$) $/ z$ calcd $\mathrm{C}_{18} \mathrm{H}_{11} \mathrm{~N}_{4}$ calculated mass 283.0984; actual mass 283.0982

\section{Synthesis of 6-nitroquinolone 51}<smiles>O=c1ccc2cc([N+](=O)[O-])ccc2[nH]1</smiles>

6-nitroquinoline (250 mg, $1.315 \mathrm{mmol}) \mathbf{4 2}$ was dissolved in warm DMF (1 mL) and squirted into warm water $(300 \mathrm{~mL})$ while stirring vigorously. Then warm sodium phosphate (500 mM, $100 \mathrm{~mL}, \mathrm{pH} 7.4)$ was added while stirring. Then xanthine oxidase $(100 \mu \mathrm{L}, 0.005 \mathrm{U} / \mathrm{mL})$ was added in 12-hour intervals for 3 days. The organic material was extracted to EtOAc and dried using brine and sodium sulfate. The product was 
separated by column chromatography using hexane and ethyl acetate to obtain $4 \mathrm{mg}$ of product 51. The crystals were obtained by dissolving the pure compound in minimum amount of warm ethyl acetate and slow evaporation for 3 days.

${ }^{1} \mathrm{H}-\mathrm{NMR}\left(\mathrm{CD}_{3} \mathrm{OD}, 500 \mathrm{MHz}\right): \delta 8.64(\mathrm{~d}, \mathrm{~J}=2.5 \mathrm{~Hz}, 1 \mathrm{H}), 8.36(\mathrm{dd}, \mathrm{J}=9.0 \mathrm{~Hz}, \mathrm{~J}=2.5$ $\mathrm{Hz}, 1 \mathrm{H}), 8.09(\mathrm{~d}, \mathrm{~J}=9.0 \mathrm{~Hz}, 1 \mathrm{H}), 7.46(\mathrm{~d}, \mathrm{~J}=9.0 \mathrm{~Hz}, 1 \mathrm{H}), 6.73(\mathrm{~d}, \mathrm{~J}=9.0 \mathrm{~Hz}, 1 \mathrm{H}) ;{ }^{13} \mathrm{C}-$ NMR $\left(\mathrm{CD}_{3} \mathrm{OD}, 125.77 \mathrm{MHz}\right) \delta 165.01,144.11,144.05,142.25,126.28,125.37,124.33$, 120.63, 117.44 ; HRMS (ESI, $\mathrm{M}+\mathrm{H}^{+}$) $\mathrm{m} / z$ calcd $\mathrm{C}_{9} \mathrm{H}_{7} \mathrm{~N}_{2} \mathrm{O}_{3}$ calculated mass 191.0457; actual mass 191.0456

\section{Synthesis of 6-aminoquinolone 54}

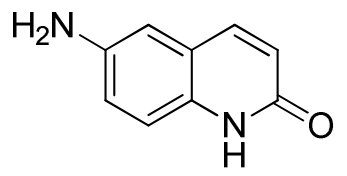

6-nitroquinolone (10 mg, $0.05 \mathrm{mmol}) \mathbf{5 1}$ was dissolved in $\mathrm{MeOH}(10 \mathrm{~mL})$ and was added with Pd on activated carbon $(0.5 \mathrm{mg})$. The hydrogen gas was bubbled for 10 mins. The reaction mixture was filtered and organic material was dried using brine and sodium sulfate. The product was separated by silica gel column chromatography using $1 \%$ methanol:ethyl acetate as the mobile solvent system to obtain $2 \mathrm{mg}$ of product $54 .{ }^{1} \mathrm{H}$ - NMR (CD $\left.\mathrm{CD}_{3} \mathrm{OD}, 500 \mathrm{MHz},\right): \delta 7.80(\mathrm{dd}, \mathrm{J}=9.0 \mathrm{~Hz}, \mathrm{~J}=3.3 \mathrm{~Hz} 1 \mathrm{H}), 7.16(\mathrm{~d}, \mathrm{~J}=9.0 \mathrm{~Hz}$, 1H), $7.02(\mathrm{~d}, \mathrm{~J}=9.0 \mathrm{~Hz}, 1 \mathrm{H}), 6.92(\mathrm{t}, \mathrm{J}=3.3, \mathrm{~J}=3.1 \mathrm{~Hz}, 1 \mathrm{H}), 6.54(\mathrm{dd}, \mathrm{J}=9.0 \mathrm{~Hz}, 3.1$ $\mathrm{Hz}, 1 \mathrm{H}), 1.28$ grease. ${ }^{13} \mathrm{C}-\mathrm{NMR}\left(\mathrm{CD}_{3} \mathrm{OD}, 125.77 \mathrm{MHz}\right): \delta 164.59,144.90,142.29$, 132.46, 122.52, 122.05, 121.45, 117.50, 112.34. HRMS (ESI, $\mathrm{M}+\mathrm{H}^{+}$) $\mathrm{m} / z$ calcd $\mathrm{C}_{9} \mathrm{H}_{9} \mathrm{~N}_{2} \mathrm{O}$ calculated mass 161.0715; actual mass 161.0714 


\section{Procedure for hypoxic metabolism.}

In a typical enzymatic reaction, 42 ( $4 \mu \mathrm{L}$ from $50 \mathrm{mM}$ in $\mathrm{DMF}$, final concentration $0.8 \mathrm{mM}), \mathbf{5 0}, \mathbf{5 1}$ or non-fluorescent electron acceptor $(24 \mu \mathrm{L}$ from $50 \mathrm{mM}$ in $15 \%$ DMF water, final concentration $6.4 \mathrm{mM}$ ), was added to xanthine in water(20-160 $\mu \mathrm{L}$ of $10 \mathrm{mM}$, final concentration $0.8 \mathrm{mM}-6.4 \mathrm{mM}$. Then, xanthine oxidase $(20 \mu \mathrm{L}$ from $20 \mathrm{U} / \mathrm{mL}$, final concentration $2.4 \mathrm{U} / \mathrm{mL})$, sodium phosphate buffer $(6 \mu \mathrm{L}$ from $50 \mathrm{mM}$, final concentration $12 \mathrm{mM}, \mathrm{pH}$ 7.4) and HPLC water were added to xanthine-42 solution to obtain the final solution $(0.25 \mathrm{~mL}$, less than $2 \% \mathrm{DMF})$ at room temperature $\left(24^{0} \mathrm{C}\right)$. In anaerobic reactions, all reagents except xanthine oxidase were de-gassed in glass tubes by three freeze pump thaw cycles. The glass tubes were broke open inside an argon-purged glove bag and bubbled with argon for five minutes. All reagents were mixed inside the glove bag. Upon mixing, the containers were wrapped with aluminum foil to prevent exposure to light.

\section{Procedure for Fluorescence experiment}

Upon completion of incubation reaction solution was diluted up to $1 \mathrm{~mL}$ with sodium phosphate buffer $(50 \mathrm{mM}, \mathrm{pH} 7.4)$ in HPLC water and then was added to the cuvette. In anaerobic experiments, upon completion the reaction mixtures were taken out of glove bag and kept $1 \mathrm{~h}$ under atmospheric conditions prior to the dilutions.

Procedure for LC/MS analysis. In vitro enzymatic metabolism of $\mathbf{4 2}$ or $\mathbf{5 0}$ was carried out as described above and the resulting products were extracted into ethyl acetate and dried using brine followed by roto vap evaporation of ethyl acetate. The solid was redissolved in methanol and analyzed by LC/MS in the positive ion mode. Separation of metabolites was carried using a C18 reverse phase Phenomenex Luna column $(5 \mu \mathrm{m}$ 
particle size, $100 \mathrm{~A} 0$ pore size, $150 \mathrm{~mm}$ length, $2.00 \mathrm{~mm}$ i.d.) and a ThermoSeparations liquid chromatograph (TSP4000) and the metabolites were detected by their UVabsorbance at $254 \mathrm{~nm}$. The elution started with a gradient of A, 99\% HPLC water $(0.1 \%$ acetic acid) and B acetonitrile ( $0.1 \%$ acetic acid) followed by a linear increase to $90 \% \mathrm{~B}$ over the course of $30 \mathrm{~min}$. The elution was continued at $90 \%$ B for $3 \mathrm{~min}$ and decreased to $1 \%$ over the next $8 \mathrm{~min}$. A flow rate of $0.35 \mathrm{~mL} / \mathrm{min}$ was used. The LC/ESI-MS analyses were carried out in the positive ion mode on a Finnigan TSQ 7000 triple quadrupole instrument using a $250 \mathrm{kV}$ needle voltage and at a capillary temperature of $250{ }^{\circ} \mathrm{C}$. 


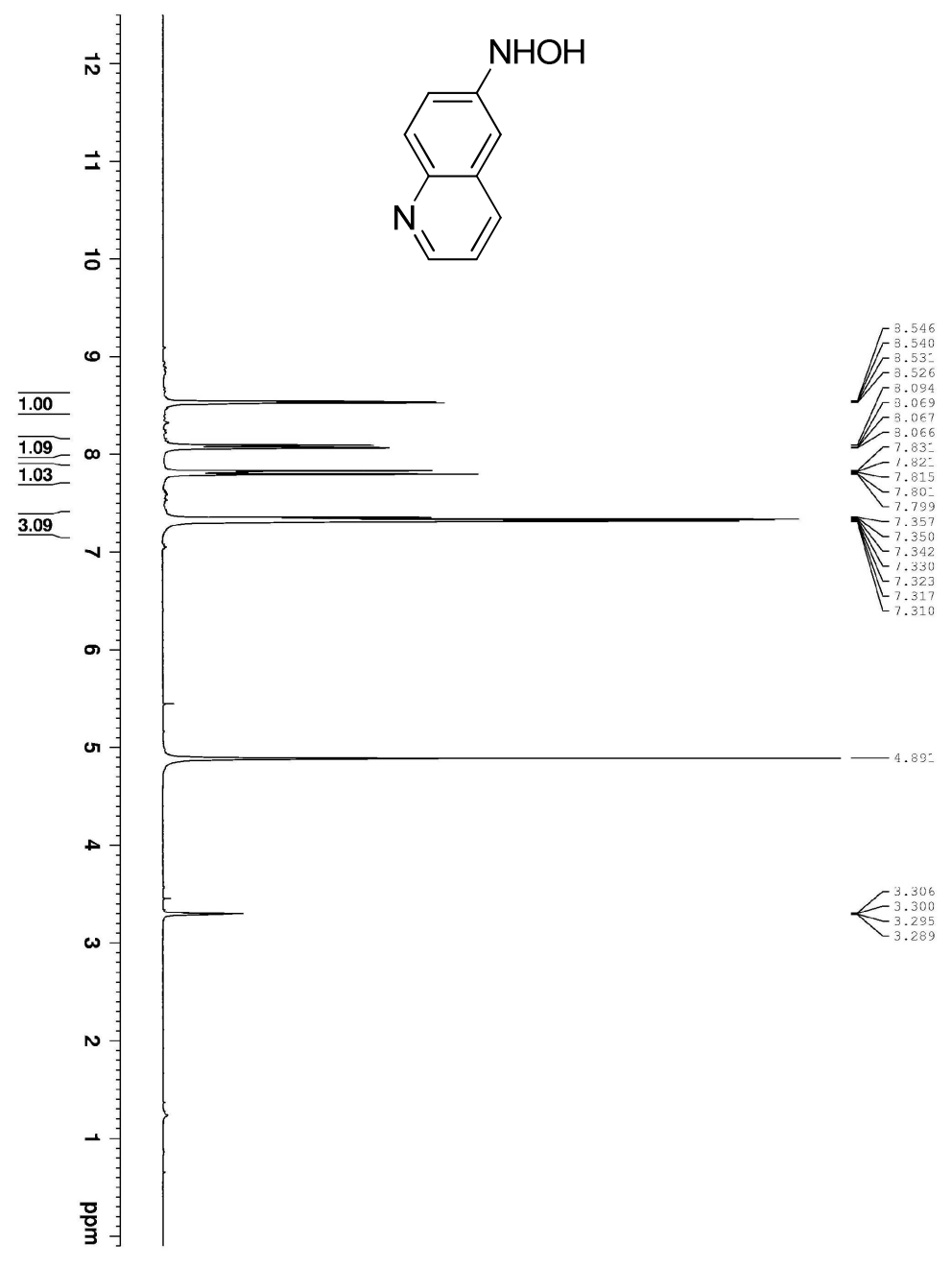

${ }^{1} \mathrm{H}-\mathrm{NMR}$ of $\mathbf{5 0}(300 \mathrm{MHz}, \mathrm{MeOD})$ 


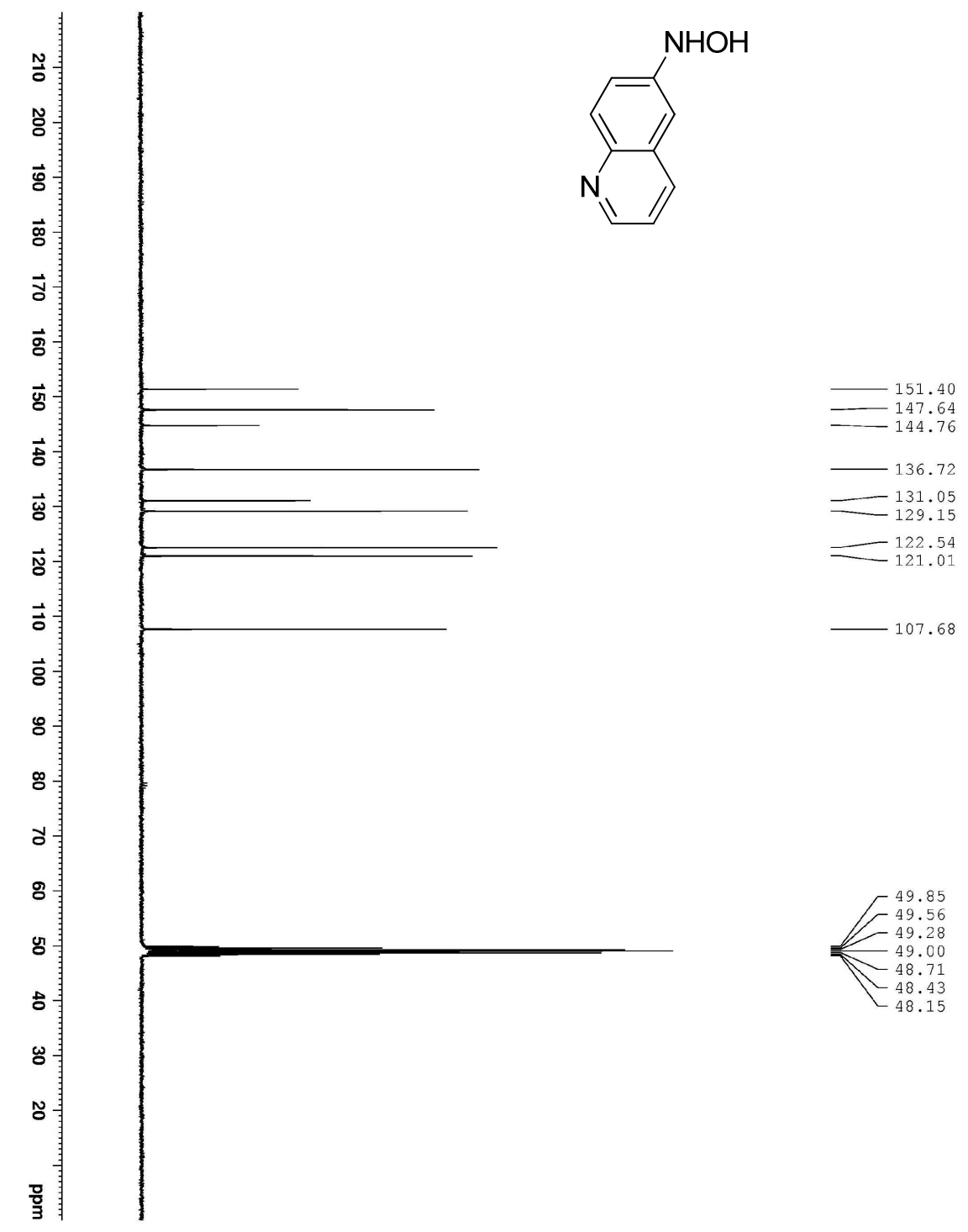

${ }^{13} \mathrm{C}$ NMR of $\mathbf{5 0}(\mathrm{MeOD}, 125.77 \mathrm{MHz})$ 


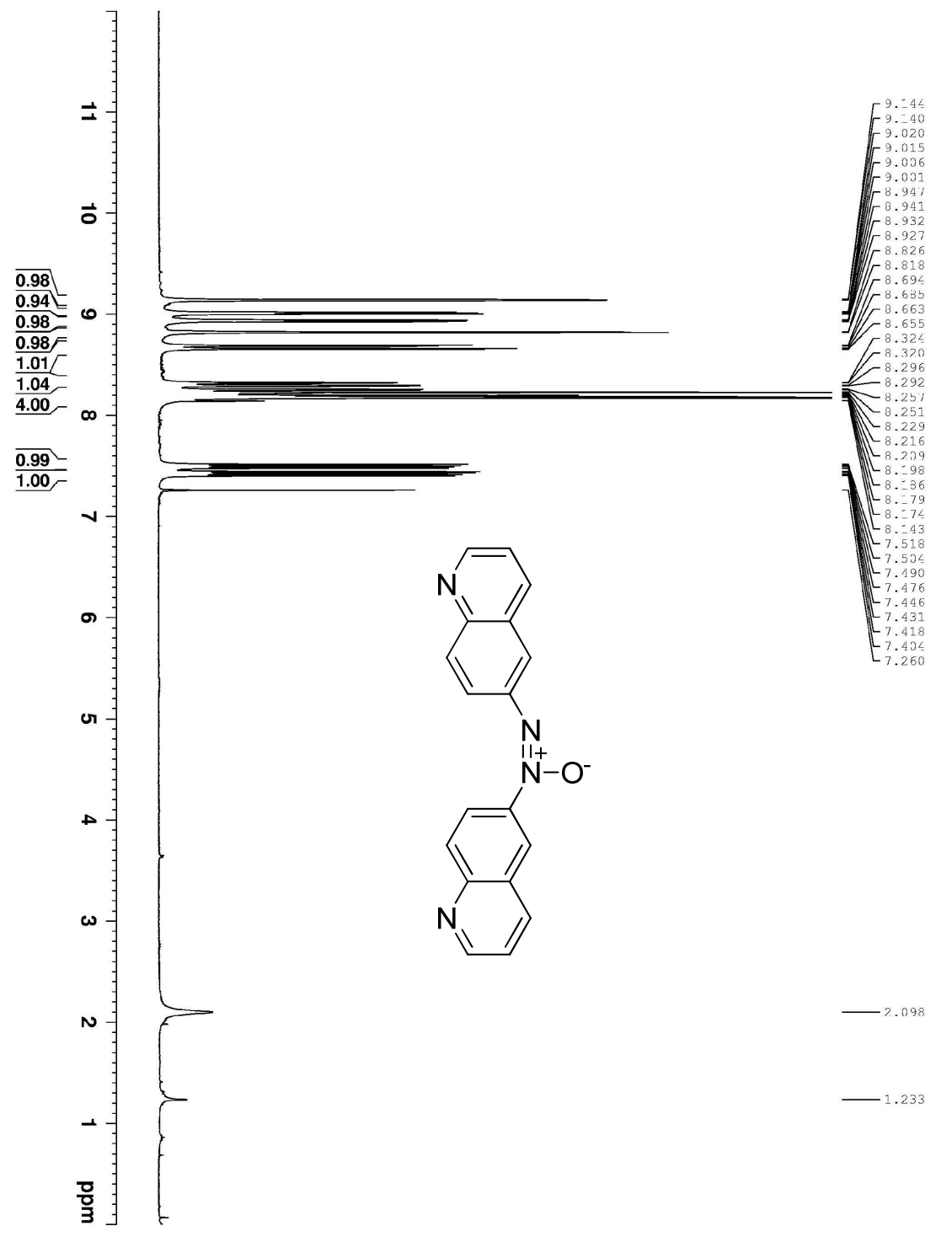

${ }^{1} \mathrm{H}$ NMR of $\mathbf{4 5}\left(\mathrm{CDCl}_{3}, 300 \mathrm{MHz}\right)$ 

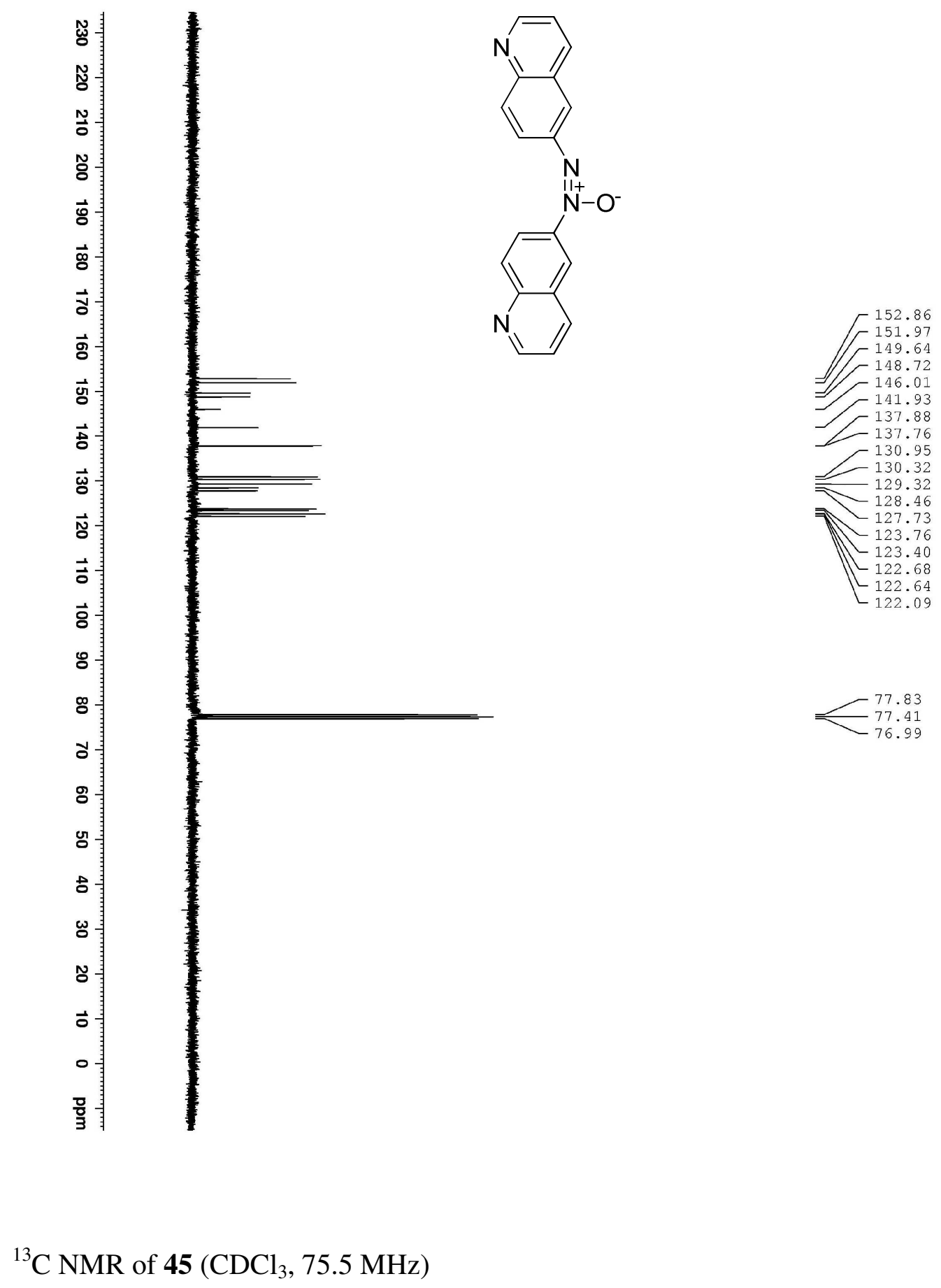

${ }^{\mathrm{C}} \mathrm{NMR}$ of $45\left(\mathrm{CDCl}_{3}, 75.5 \mathrm{MHz}\right)$ 


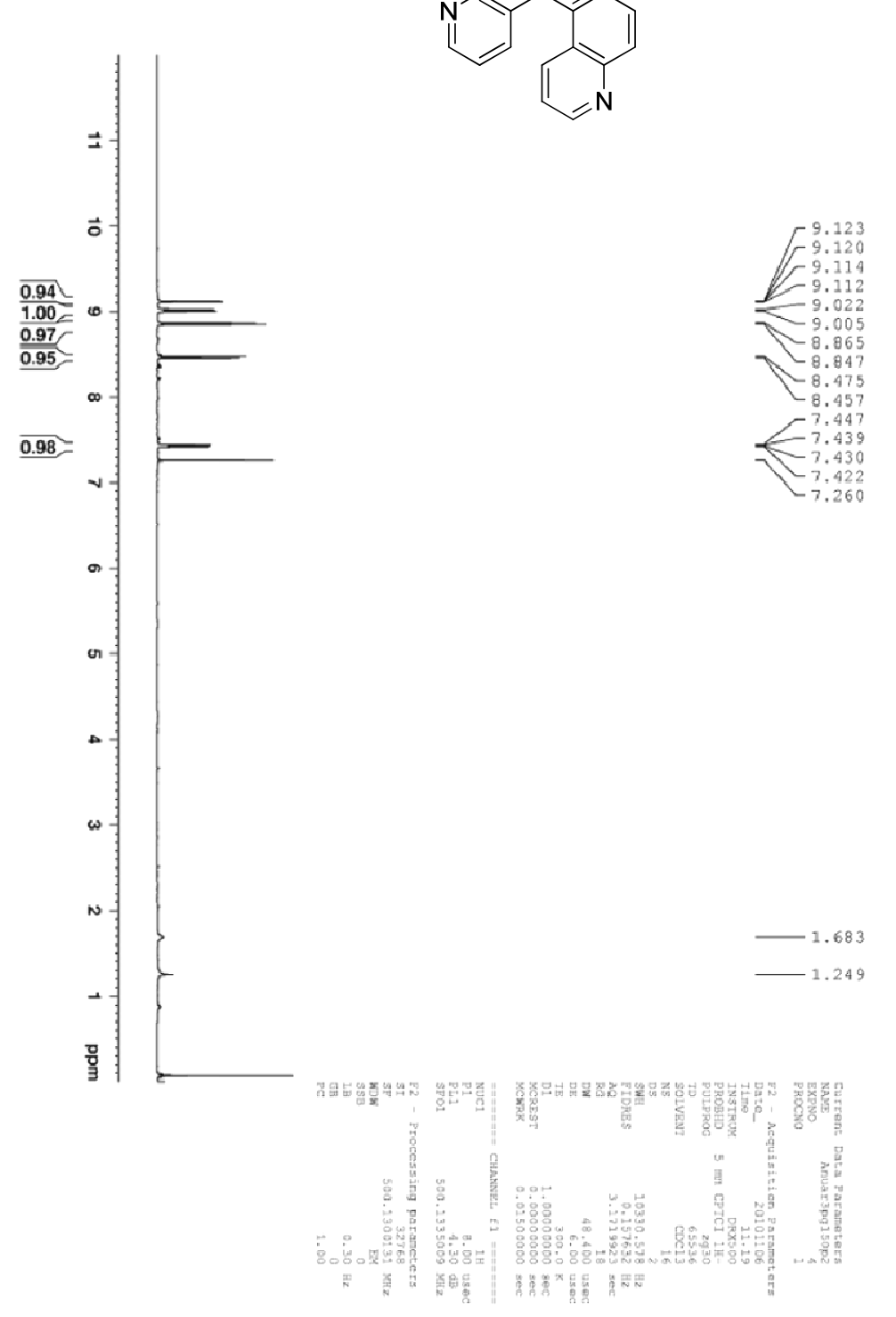

${ }^{1} \mathrm{H}$ NMR of $\mathbf{5 2}\left(\mathrm{CDCl}_{3}, 500 \mathrm{MHz}\right)$ 


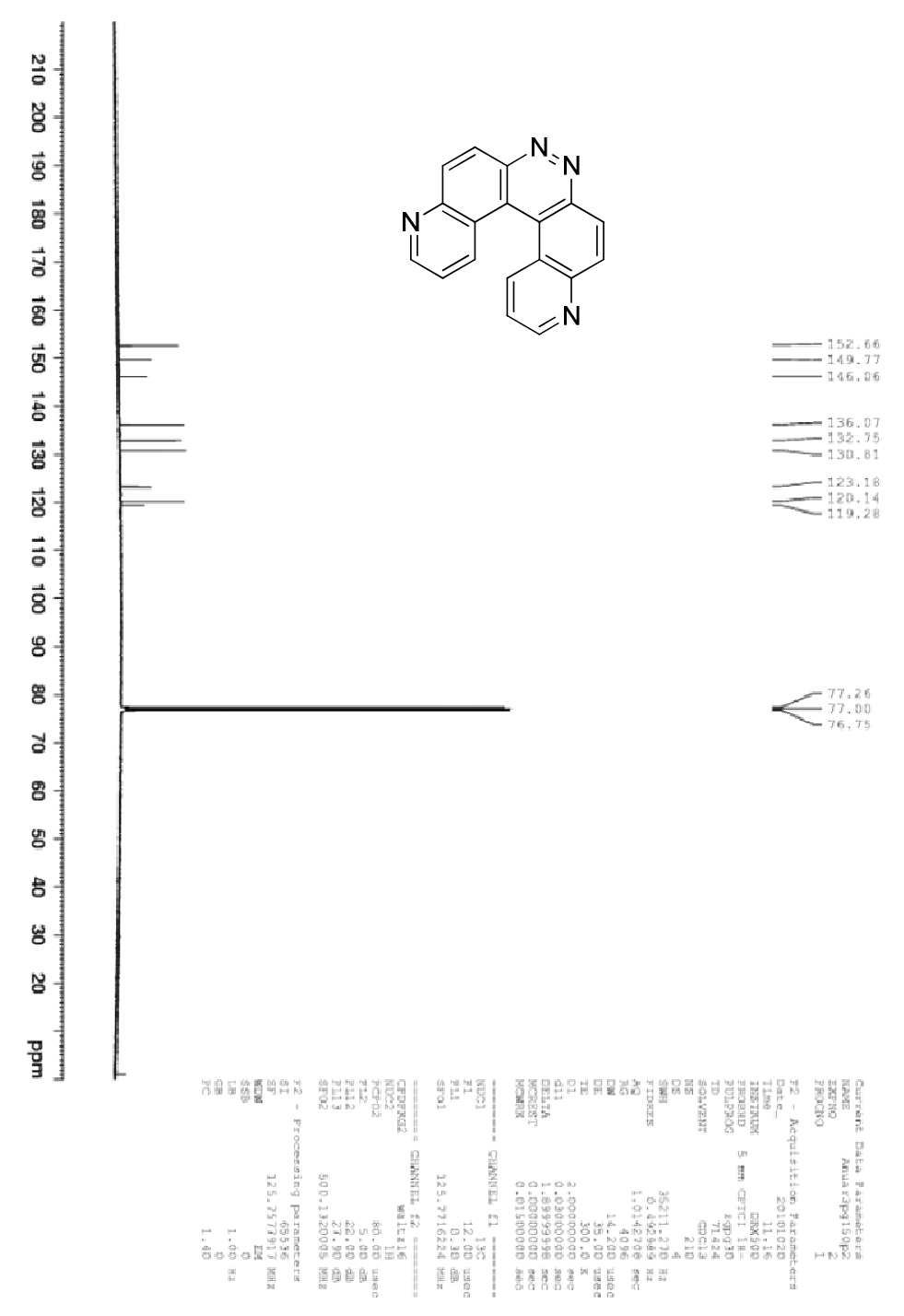

${ }^{13} \mathrm{C}$ NMR of $\mathbf{5 2}\left(\mathrm{CDCl}_{3}, 125.77 \mathrm{MHz}\right)$ 


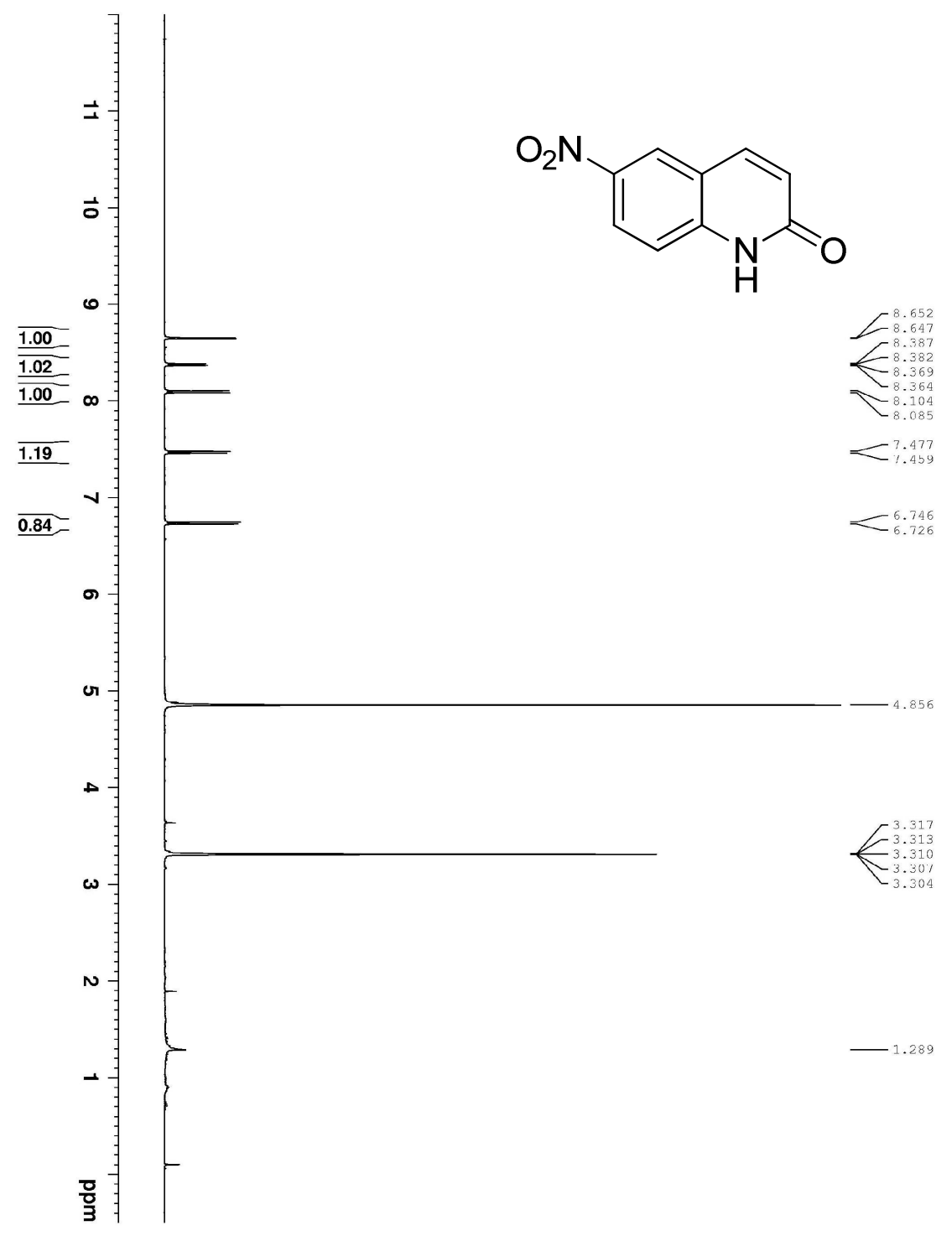

${ }^{1} \mathrm{H}-\mathrm{NMR}$ of 51 (500 MHz, MeOD) 


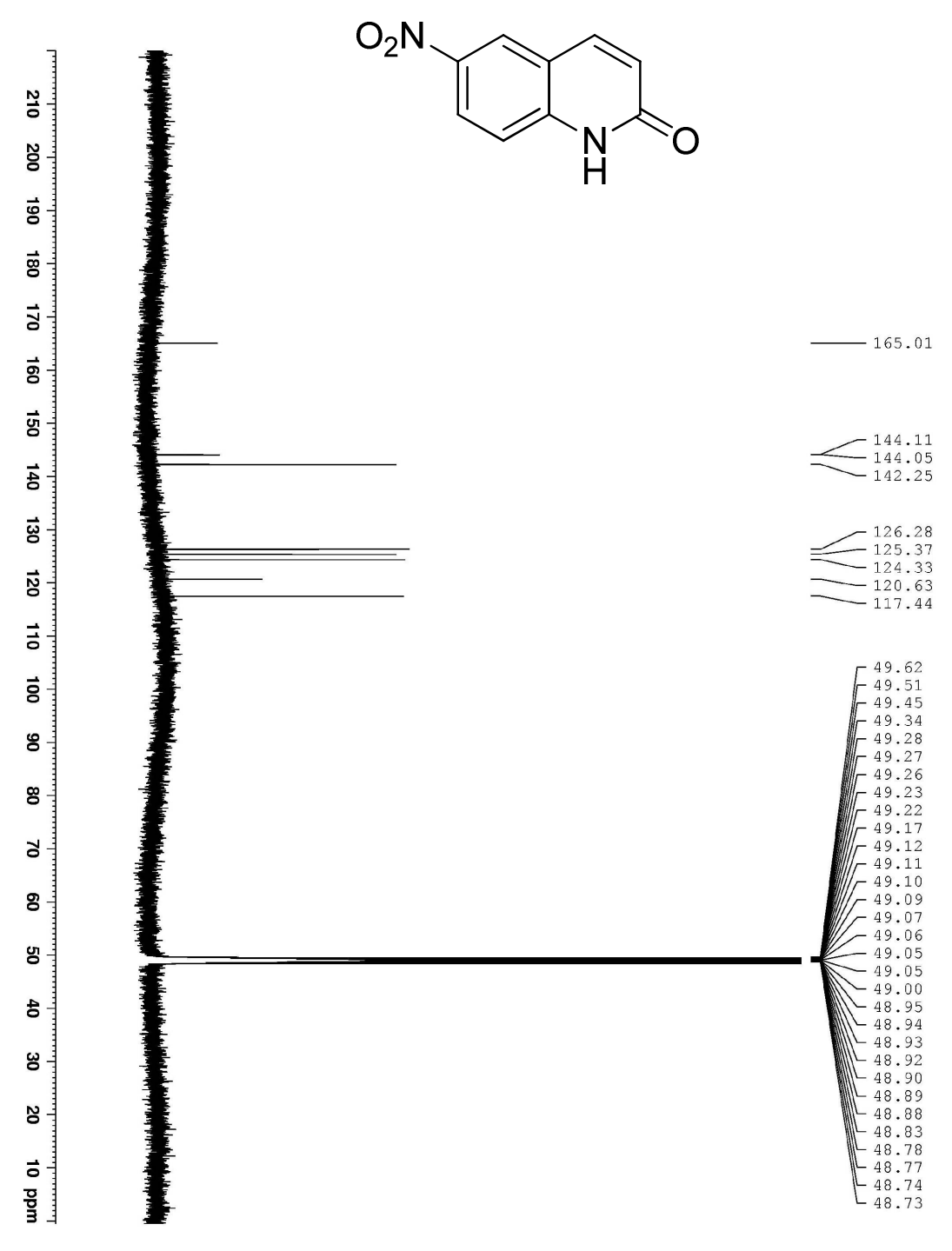

${ }^{13} \mathrm{C}$ NMR of $\mathbf{5 1}(\mathrm{MeOD}, 125.77 \mathrm{MHz})$ 


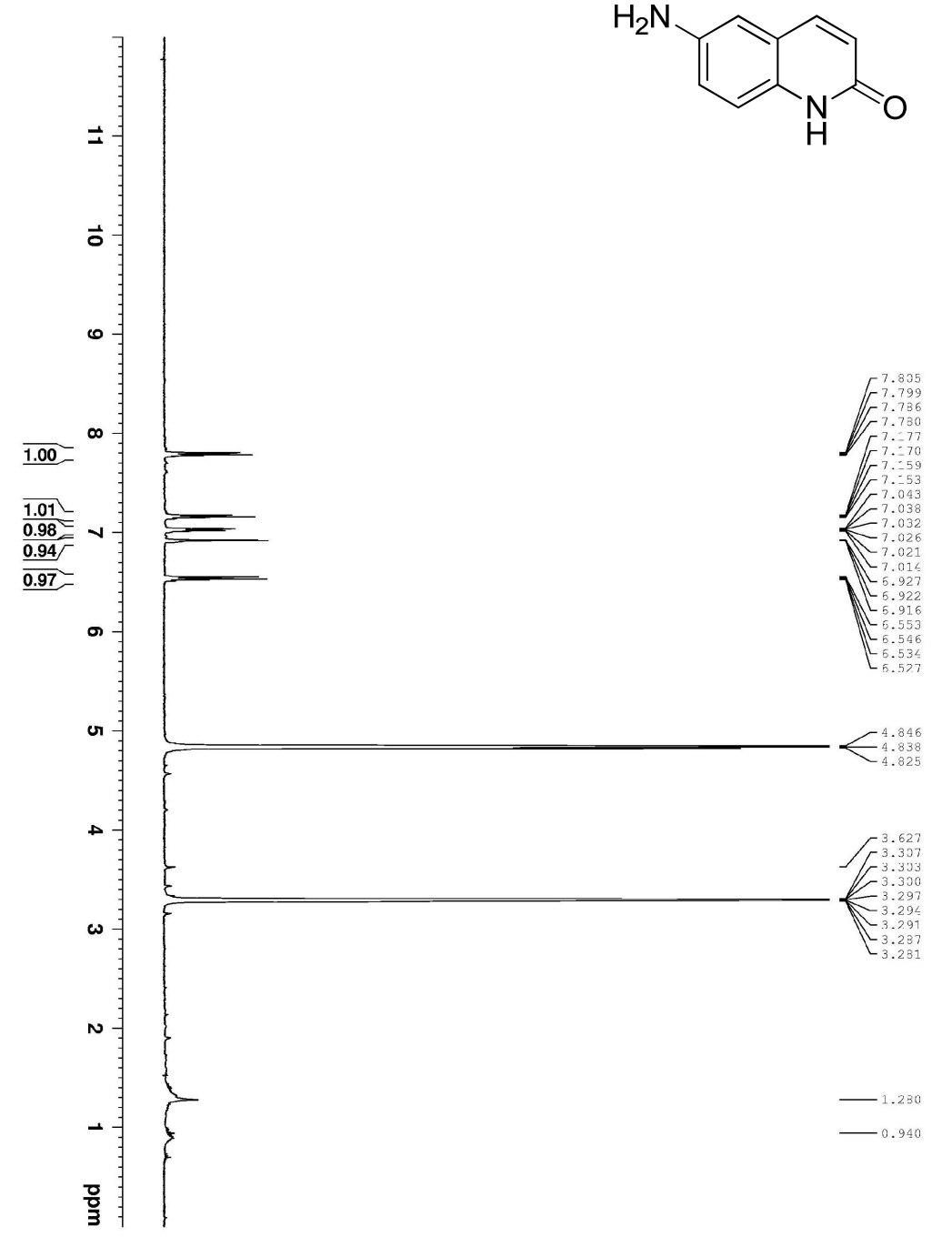

${ }^{1} \mathrm{H}$ NMR of $\mathbf{5 4}\left(\mathrm{CDCl}_{3}, 500 \mathrm{MHz}\right)$ 


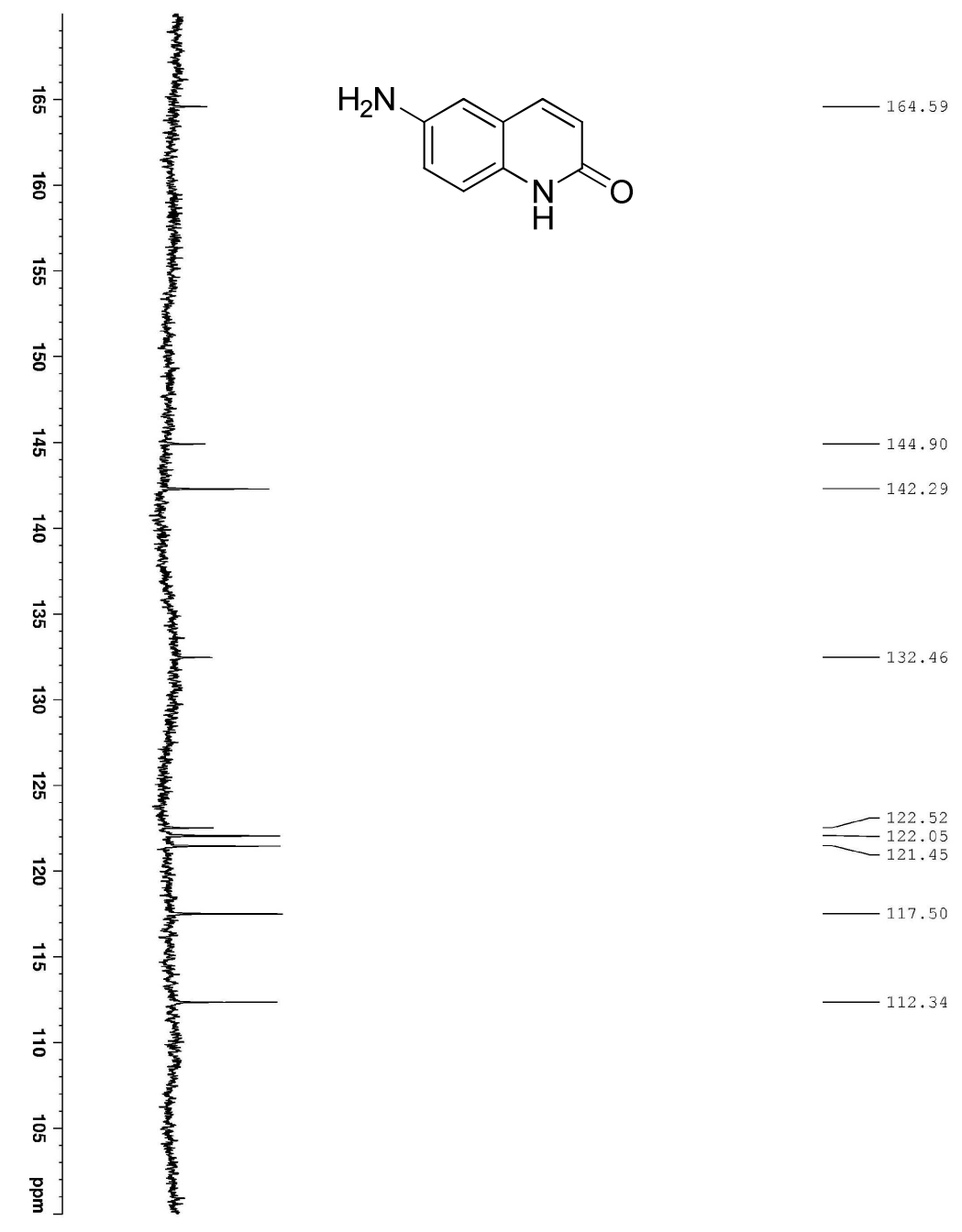

${ }^{13} \mathrm{C}$ NMR of $\mathbf{5 4}\left(\mathrm{CDCl}_{3}, 125.77 \mathrm{MHz}\right)$ 


\section{References of chapter 3}

1. Tomlinson, R. H.; Gray, L. H., The histological structure of some human lung cancers and the possible implications for radiotherapy. Br. J. Cancer 1955, 9, 539-549.

2. (a) Vaupel, P.; Kallinowski, F.; Okunieff, P., Blood flow, oxygen and nutrient supply, and metabolic microenvironment of human tumors: a review. Cancer Res. 1989, 49 (23), 6449-6465; (b) Brown, J. M.; Wilson, W. R., Exploiting tumor hypoxia in cancer treatment. Nature Rev. Cancer 2004, 4 (6), 437-447; (c) Brown, J. M., The hypoxic cell: A target for selective cancer therapy. Cancer Res. 1999, 59, 5863-5870.

3. Bertout, J. A.; Patel, S. A.; Simon, M. C., The impact of O2 availability on human cancer. Nat. Rev. Cancer 2008, 8 (Dec ), 967-975.

4. Vaupel, P., Hypoxia and Aggressive tumor phenotype: Implications for therapy and prognosis. Oncologist 2008, 13 (suppl 3), 21-26.

5. (a) Hill, R. P.; Delphine, T. M.-E.; Hedley, D. W., Cancer stem cells, hypoxia and metastasis. Semin. Radiat. Oncol. 2009, 19 (2), 106-111; (b) Vaupel, P.; Mayer, A., Hypoxia in cancer: significance and impact on clincal outcome. Cancer Metastasis Rev. 2007, 26, 225-239.

6. (a) Wardman, P.; Clarke, E. D.; Hodgkiss, R. J.; Middleton, R. W.; Parrick, J.; Stratford, M. R. L., Nitroaryl compounds as potential fluorescent probes for hypoxia. I. Chemical criteria and constraints. Int. J. Radiat. Oncol. Biol. Phys. 1984, 10, 1347-1351; (b) Stratford, M. R. L.; Clarke, E. D.; Hodgkiss, R. J.; Middleton, R. W.; Wardman, P., Nitroaryl compounds as potential fluorescent probes for hypoxia. II. Identification and properties of reductive metabolites. Int. J. Radiat. Oncol. Biol. Phys. 1984, 10, 13531356; (c) Weissleder, R.; Tung, C.-H.; Mahmood, U.; Bogdanov, A. J., In vivo imaging of tumors with protease-activated near-infrared fluorescent probes. Nature Biotechnol. 1999, $17,375-378$.

7. (a) Fitzsimmons, S. A.; Workman, P. A.; Grever, M.; Paull, K.; Camalier, R.; Lewis, A. D., Reductase enzyme expression across the National Cancer Institute tumor cell line panel: correlation with sensitivity to mitomycin C and E09. J. Natl. Cancer Inst. 1996, 88, 259-269; (b) Wardman, P.; Dennis, M. F.; Everett, S. A.; Patel, K. B.; Stratford, M. R. L.; Tracy, M., Radicals from one-electron reduction of nitro compounds, aromatic N-oxides and quinones: the kinetic basis for hypoxia-selective, bioreductive drugs. Biochem. Soc. Trans 1995, 61, 171-194; (c) Rooseboom, M.; Commandeur, J. N. 
M.; Vermeulen, N. P. E., Enzyme-catalyzed activation of anticancer prodrugs. Pharm. Rev. 2004, 56, 53-102; (d) Denny, W. A.; Wilson, W. R., Considerations for the design of nitrophenyl mustards as agents with selective toxicity for hypoxic tumor cells. J. Med. Chem. 1986, 29 (6), 879-887.

8. Moselen, J. W.; Hay, M. P.; Denny, W. A.; Wilson, W. R., N-[2-(2-Methyl-5nitroimidazolyl)ethyl]-4-(2-nitroimidazolyl)butanamide (NSC 639862), a bisnitroimidazole with enhanced selectivity as a bioreductive drug. Cancer Res. 1995, 55, 574-80.

9. Wardman, P.; Candeis, L. P.; Everett, S. A.; Tracy, M., Radiation chemistry applied to drug design. Int. J. Radiat. Biol. 1994, 65, 35-41.

10. Wilson, W. R.; Anderson, R. F.; Denny, W. A., Hypoxia-selective antitumor agents. 1. Relationships between structure, redox properties and hypoxia-selective cytotoxicity for 4-substituted derivatives of nitracrine. J. Med. Chem. 1989, 32, 23-30.

11. Duan, J.-X.; Jiao, H.; Kaizerman, J.; Stanton, T.; Evans, J. W.; Lan, L.; Lorente, G.; Banica, M.; Jung, D.; Wang, J.; Ma, H.; Li, X.; Yang, Z.; Hoffman, R. M.; Ammons, W. S.; Hart, C. P.; Matteucci, M., Potent and highly selective hypoxia-activated achiral phosphoramidate mustards as anticancer drugs. J. Med. Chem. 2008, 51, 2412-2420.

12. (a) Borch, R. F.; Liu, J.; Schmidt, J. P.; Marakovitz, J. T.; Joswig, C.; Gipp, J. J.; Mulcahy, R. T., Synthesis and evaluation of nitroheterocyclic phosphoramidates as hypoxia-selective alkylating agents. J. Med. Chem. 2000, 43, 2258-2265; (b) Thomson, P.; Naylor, M. A.; Everett, S. A.; Stratford, M. R. L.; Lewis, G.; Hill, S.; Patel, K. B.; Wardman, P.; Davis, P. D., Synthesis and biological properties of bioreductively targeted nitrothienyl prodrugs of combretastatin A-4. Mol. Cancer. Ther. 2006, 5 (11), 2886-2894; (c) Thomson, P.; Naylor, M. A.; Stratford, M. R. L.; Lewis, G.; Hill, S.; Patal, K. B.; Wardman, P.; Davis, P. D., Hypoxia-driven elimination of thiopurines from their nitrobenzyl prodrugs. Bioorg. Med. Chem. Lett. 2007, 17, 4320-4322.

13. (a) Evans, B. J.; Doi, J. T.; Musker, W. K., Fluorine-19 NMR study of the reaction of p-fluorobenzenethiol and disulfide with periodate and other selected oxidizing agents. J. Org. Chem. 1990, 55 (8), 2337-2344; (b) Koch, C. J., Measurements of absolute oxygen levels in cells and tissues using oxygen sensors and 2-nitroimidazole EF5. Methods Enzymol. 2002, 352, 3-31.

14. (a) Dai, M.; Zhu, W.; Xu, Y.; Qian, X.; Liu, Y.; Xiao, Y.; You, Y., Versatile nitro-fluorophore as highly effective sensor for hypoxic tumor cells: design, imaging, and 
evaluation. J. Fluoresc. 2008, 18 (2), 591-597; (b) Zhu, W.; Dai, M.; Xu, Y.; Qian, X., Novel nitroheterocyclic hypoxic markers for solid tumor: synthesis and biological evaluation. Bioorg. Med. Chem. Lett. 2008, 16, 3255-3260.

15. Rajapakse, A.; Gates, K. S., Hypoxia-Selective, Enzymatic Conversion of 6Nitroquinoline into a Fluorescent Helicene: Pyrido[3,2-f]quinolino[6,5-c]cinnoline 3Oxide. J. Org. Chem. 2012, 77, 3531-3537.

16. (a) Brynes, P. J.; Bevilacqua, P.; Green, A., 6-Aminoquinoline as a fluorogenic leaving group in peptide cleavage reactions: a new fluorogenic substrate for chymotrypsin. Anal. Biochem. 1981, 116, 408-413; (b) Danieli, E.; Shabat, D., Molecular probe for enzymatic activity with dual output. Bioorg. Med. Chem. 2007, 15, 7318-7324; (c) Tanaka, F.; Thayumanavan, R.; Barbas, C. F., Fluorescent detection of carbon-carbon bond formation. J. Am. Chem. Soc. 2003, 125, 8523-8528; (d) Huang, W.; Hicks, S. N.; Sondek, J.; Zhang, Q., A fluorogenic, small molecule reporter for mammalian phospholipase C isozymes. ACS Chem Biol. 2011, 6 (3), 223-228.

17. (a) Laderoute, K. L.; Wardman, P.; Rauth, M., Molecular mechanisms for the hypoxia-dependent activation of 3-amino-1,2,4-benzotriazine 1,4-dioxide (SR4233). Biochem. Pharmacol. 1988, 37 (8), 1487-1495; (b) Daniels, J. S.; Gates, K. S., DNA Cleavage by the Antitumor Agent 3-Amino-1,2,4-benzotriazine 1,4-Dioxide (SR4233): Evidence for Involvement of Hydroxyl Radical. J. Am. Chem. Soc. 1996, 118 (14), 33803385; (c) Birincioglu, M.; Jaruga, P.; Chowdhury, G.; Rodriguez, H.; Dizdaroglu, M.; Gates, K. S., DNA Base Damage by the Antitumor Agent 3-Amino-1,2,4-benzotriazine 1,4-Dioxide (Tirapazamine). J. Am. Chem. Soc. 2003, 125 (38), 11607-11615; (d) Jones, G. D. D.; Weinfeld, M., Dual action of tirapazamine in the induction of DNA strand breaks. Cancer Res. 1996, 56, 1584-1590.

18. (a) Chowdhury, G.; Kotandeniya, D.; Barnes, C. L.; Gates, K. S., Enzymeactivated, hypoxia-selective DNA damage by 3-amino-2-quinoxalinecarbonitrile 1,4-diN-oxide. Chem. Res. Toxicol. 2004, 17 (11), 1399-1405; (b) Junnotula, V.; Rajapakse, A.; Abrillaga, L.; Lopez de Cerain, A.; Solano, B.; Villar, R.; Monge, A.; Gates, K. S., DNA strand cleaving properties and hypoxia-selective cytotoxicity of 7-chloro-2thienylcarbonyl-3-trifluoromethylquinoxaline 1,4-dioxide. Bioorg. Med. Chem. 2010, 18, 3125-3132.

19. Claassen, V. P.; Oltmann, L. F.; Van't, R. J.; Brinkman, U. A. T.; Stouthamer, A. H., Purification of molybdenum cofactor and its fluorescent oxidation products. FEBS Lett. 1982, 142, 133-7. 
20. (a) Pizzolatti, M. G.; Yunes, R. A., Azoxybenzene formation from nitrosobenzene and phenylhydroxylamine. A unified view of the catalysis and mechanisms of the reactions. J. Chem. Soc. Perkin 2 1990, 759-764; (b) Agrawal, A.; Tratnyek, P. G., Reduction of nitroaromatic compounds by zero-valent iron metal. Env. Sci. Technol. 1996, 30 (1), 153-160.

21. (a) Furst, A.; Moore, R. E., Reductions with hydrazine hydrate catalyzed by Raney nickel. II. Aromatic nitro compounds to intermediate products. J. Am. Chem. Soc. 1957, 79, 5492-5493; (b) Fletcher, T. L.; Namkung, M. J., Derivatives of fluorene. IV. Raney nickel-hydrazine hydrate reduction of various mono- and dinitrofluorene derivatives; some new 9-substituted fluorenes. J. Org. Chem. 1958, 23, 680-683.

22. (a) Krenitsky, T. A.; Neil, S. M.; Elion, G. B.; Hitchings, G. H., A comparison of the specificities of xanthine oxidase and aldehyde oxidase. Arch. Biochem. Biophys. 1972, 150, 585-599; (b) McCormack, J. J.; Allen, B. A.; Hodnett, C. N., Oxidation of quinazoline and quinoxaline by xanthine oxidase and aldehyde oxidase. J. Heterocyclic Chem. 1978, 15, 1249-1254; (c) Rastelli, G.; Costantino, L.; Albasini, A., A model of the interaction of substrates and inhibitors with xanthine oxidase. J. Am. Chem. Soc. 1997, 119, 3007-3016; (d) Ganley, B.; Chowdhury, G.; Bhansali, J.; Daniels, J. S.; Gates, K. S., Redox-activated, hypoxia-selective DNA cleavage by quinoxaline 1,4-di-N-oxide. Bioorg. Med. Chem. 2001, 9, 2395-2401.

23. (a) Walton, M. I.; Wolf, C. R.; Workman, P., Molecular enzymology of the reductive bioactivation of hypoxic cell cytotoxins. Int. J. Radiat. Oncol. Biol. Phys. 1989, 16, 983-986; (b) Wen, B.; Coe, K. J.; Rademacher, P.; Fitch, W. L.; Monshouwer, M.; Nelson, S. D., Comparison of in vitro bioactivation of flutamide and its cyano analogue: evidence for reductive activation by human NADPH:cytochrome P450 reductase. Chem. Res. Toxicol. 2008, 21 (12), 2393-2406.

24. Kazanis, S.; McClelland, R. A., Electrophilic intermediate in the reaction of glutathione with nitrosoarenes. J. Am. Chem. Soc. 1992, 114, 3052-3059.

25. Chen, Y.; Hu, L., Design of anticancer prodrugs for reductive activation. Med. Res. Rev. 2009, 29 (1), 29-64. 


\section{Chapter 4}

\section{Mechanistic analysis related to the oxidative DNA Damage caused by 1,2,4-benzotraizine-di-oxides, TPZ and analogs of TPZ}

\subsection{Introduction}

Tirapazamine, 33, (TPZ), 3-amino-1,2,4-benzotriazine 1,4-dioxide is currently in

phase I, II and III clinical trials for tumor therapy. ${ }^{1}$ TPZ emerged as the lead compound among di $N$-oxide bioreductive drugs. ${ }^{2}$ TPZ causes cytotoxicity to cell, as found in low oxygenated regions (hypoxic) in solid tumors. ${ }^{3}$ It is believed that the anti-cancer activity caused by TPZ originates from its ability to cleave DNA under hypoxia. ${ }^{4}$ The DNA damage, caused to tumor cells by TPZ arises from the drug radical anion, which is produced by the reduction of TPZ by cellular reductases under low oxygen levels. ${ }^{5}$ The enzymatic reduction of TPZ is an oxygen sensitive reaction. ${ }^{3 a, 6}$ The oxygen sensitivity is due to the oxidation of TPZ radical anion 37, which is formed by the main forward reduction step, back to the parent TPZ. ${ }^{7}$ Molecular oxygen forms superoxide radical in the back oxidation step. ${ }^{8}$ The oxidative stress arises due to the superoxide radical formation, in normal oxygenated conditions, but this process is reduced by cellular defense system against reactive oxygen species, which is a collection of enzymes such as glutathione peroxidase, peroxiredoxins, catalase, and superoxide dismutase. ${ }^{9}$ In hypoxia TPZ radical anion 37 gets protonated to a drug radical $34 .{ }^{10}$ DNA is the prime target of 
the oxidizing species generated following the reduction of TPZ. ${ }^{11}$ The neutral drug radical 34 generates a DNA damaging radical species before ultimately producing the major metabolite 35 (Scheme 4.1). ${ }^{12}$

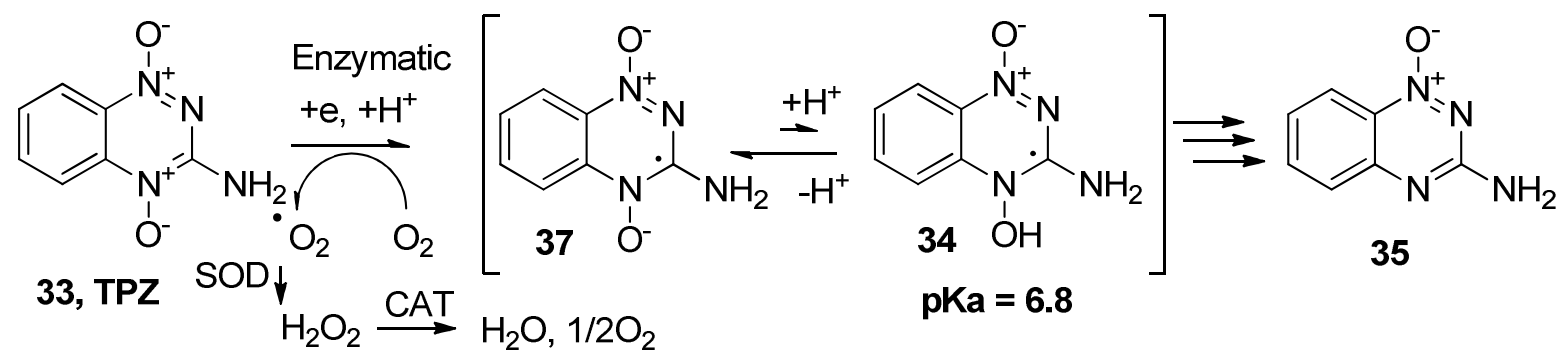

Scheme 4.1. Enzymatic reduction of $\mathbf{3 3}$ produces DNA damaging radicals and oxidative stress

The oxidative damage to DNA, caused by TPZ is characterized as proton abstraction from deoxyribose sugar backbone and DNA bases. ${ }^{5 b}$ The oxidative damage to DNA leads to DNA strand breaks. ${ }^{13}$ The chemical nature of the DNA damaging species that is emitted during the oxygen sensitive enzymatic reduction of TPZ is not completely characterized. $^{10,14}$

\subsection{Mechanistic evidence for the oxidizing radical formation by TPZ}

Research carried out by our group suggests that the activated TPZ produces a radical anion $\mathbf{3 7}$ and under low oxygen levels $\mathbf{3 7}$ undergoes protonation to produce $\mathbf{3 4}$, followed by a homolytic bond scission on $\mathbf{3 4}$ releases hydroxyl radical and produces $1-\mathrm{N}$ oxide metabolite 35. ${ }^{4 \mathrm{a}, 14 \mathrm{c}, 15}$ Similar homolytic fragmentation is proposed on Barton's $N$ hydroxypyridinethione esters in literature. ${ }^{16}$ Another report on $N$-(alkoxy) pyridinium salts discusses homolytic fragmentation induced by photo-induction. ${ }^{17}$ Moreover, radical scavenging experiments and DNA cleavage pattern studies suggest that homolytic fragmentation of di- $N$-oxides such as $\mathbf{3 4}$ to produce hydroxyl radical is chemically 
plausible. $^{4 \mathrm{a}, 14 \mathrm{c}}$ Another hypothesis proposed by Denny and co-workers, suggests that 34 undergoes dehydration to form benzotriazinyl radical $\mathbf{3 8}$ and they provide evidence for $\mathbf{3 8}$ as the species that is responsible for the DNA damage caused by TPZ. ${ }^{10,14 a, ~ b}$ Intermediate $\mathbf{3 4}$ is, generated radiolytically and has been tested for DNA damage. ${ }^{18}$ Similar organic radical formation is reported when hydroxyl radicals are generated by pulse radiolysis in the presence of toluene to produce benzyl radicals. ${ }^{19}$

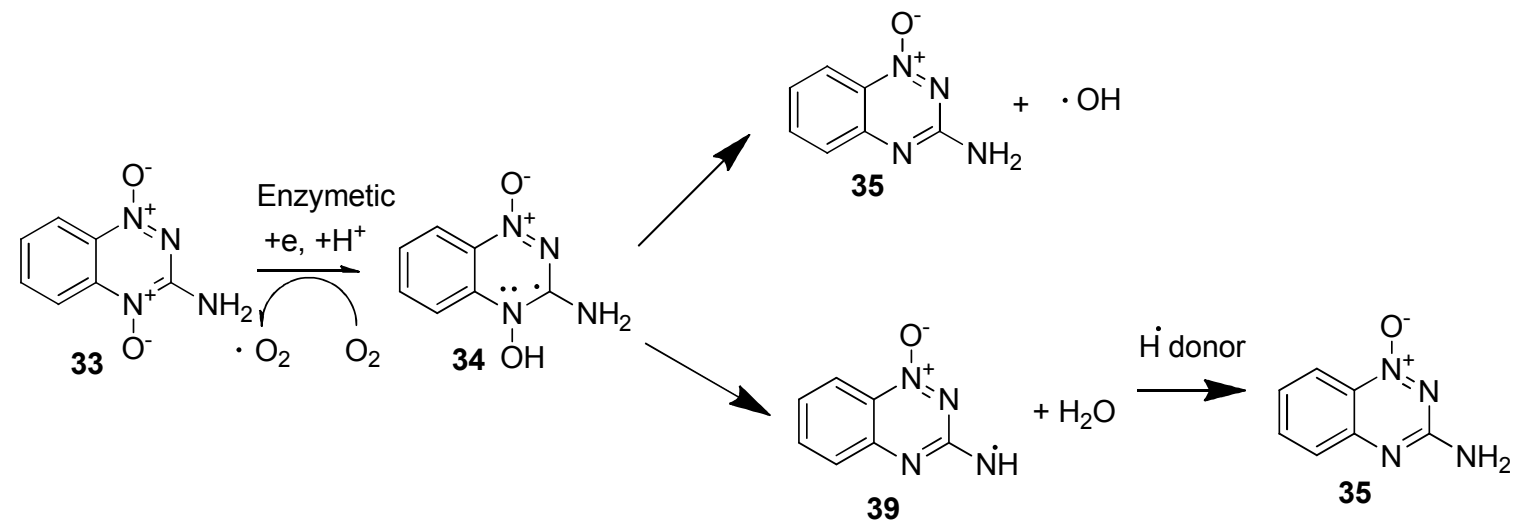

Scheme 4.2. Different mechanisms are proposed to explain enzymatic metabolism of $\mathbf{3 3}$

We feel that mechanistic investigation of bio-reductive activation of TPZ under low oxygen concentrations may provide a better understanding on the chemical structure of the DNA damaging species and could be important in designing novel TPZ analogs.

\subsection{Hypothesis and design of experiments}

The benzotriazine 1,4-dioxide analog (desH) $\mathbf{5 5}$ may be used to analyze the dehydration mechanism of benzotriazine di-oxides. Metabolic studies of $\mathbf{5 5}$ when $\mathbf{5 5}$ was enzymatically reduced, in hypoxia may produce $\mathbf{5 9}$ as the major metabolite. ${ }^{20}$ The enzymatic metabolism of $\mathbf{5 5}$ might be similar to that of 1,2,4-benzotriazine 1,4-dioxide drug class; the major metabolite formed is 1,2,4-benzotriazine 1-mono-oxide. ${ }^{14 c}$ The reduction profile of $\mathbf{5 5}$ mirrors the metabolism of 1,2,4-benzotriazine 1,4-dioxide 
(Scheme 4.3) ${ }^{20}$ In the enzyme mediated, one electron reduction of $\mathbf{5 5}$, radical anion $\mathbf{5 6}$, is produced and under normal oxygen concentration, $\mathbf{5 6}$ can be oxidized back to $\mathbf{5 5}^{20}$ Under hypoxia 56 gets protonated to form the drug radical 57, which produces the DNA damaging species and the major metabolite $59 .^{20 \mathrm{~b}}$ The dehydration mechanism produces radical $\mathbf{5 8}$ by eliminating a water molecule. The radical $\mathbf{5 8}$ may abstract a proton from an organic substrate to undergo re-aromatization to form $\mathbf{5 9}$ (lower arm). Alternatively, hydroxyl radical mechanism performs homolytic fragmentation on $\mathbf{5 7}$ to produce hydroxyl radical and the major metabolite $\mathbf{5 9}$.

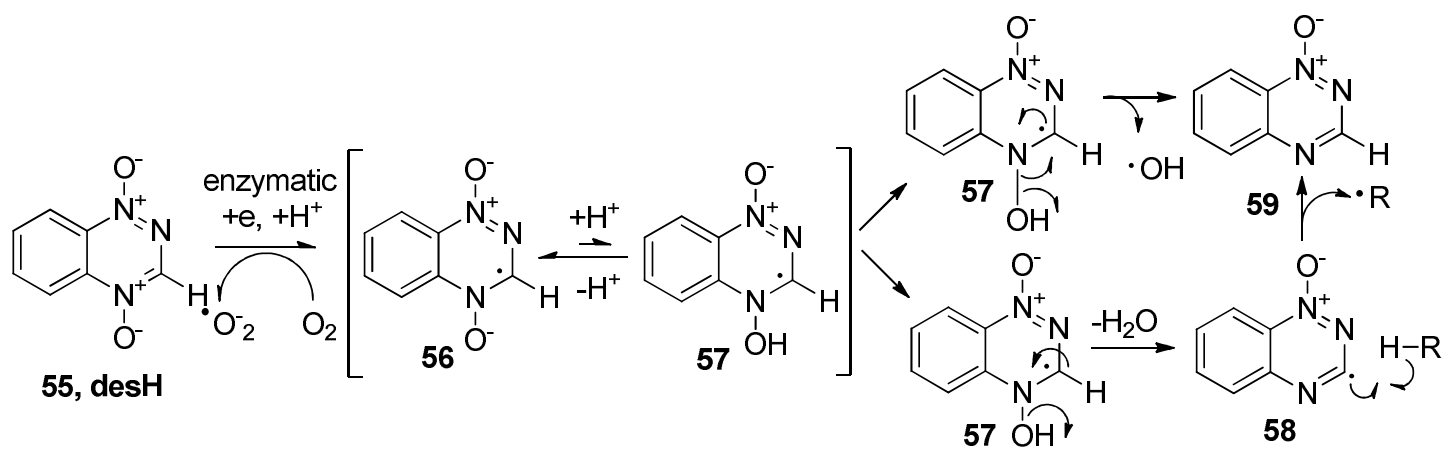

Scheme 4.3. Enzymatic reduction of $\mathbf{5 5}$ under low oxygen concentrations forms major metabolite $\mathbf{5 9}$

In the design, we speculated that deuterated analog of 1,2,4-benzotriazine- 1,4dioxide 60 (desD) may offer a new approach to analyze the dehydration mechanism. When 1,2,4-benzotriazine- 1,4-dioxide $\mathbf{6 0}$ is reductively activated to radical anion $\mathbf{6 1}$, protonation occurs to form neutral radical 62. The homolytic fragmentation of $\mathbf{6 3}$ produces hydroxyl radical and the major metabolite $\mathbf{6 3}$. When the dehydration mechanism occurs on 60, the neutral drug radical 62 converts to radical 58 and 58 may abstract a deuterium from an organic substrate to produce 63. Similarly, when $\mathbf{5 5}$ is reductively activated under hypoxia, in the presence of a deuterated organic substrate, the 
dehydration mechanism might produce radical $\mathbf{5 8}$ and, upon deuterium abstraction major metabolite 63. Accordingly, the loss or incorporation of deuterium/hydrogen can be detected when the isotopic content of the major metabolite 1-oxide is analyzed using mass spectrometry (Scheme 4.4).

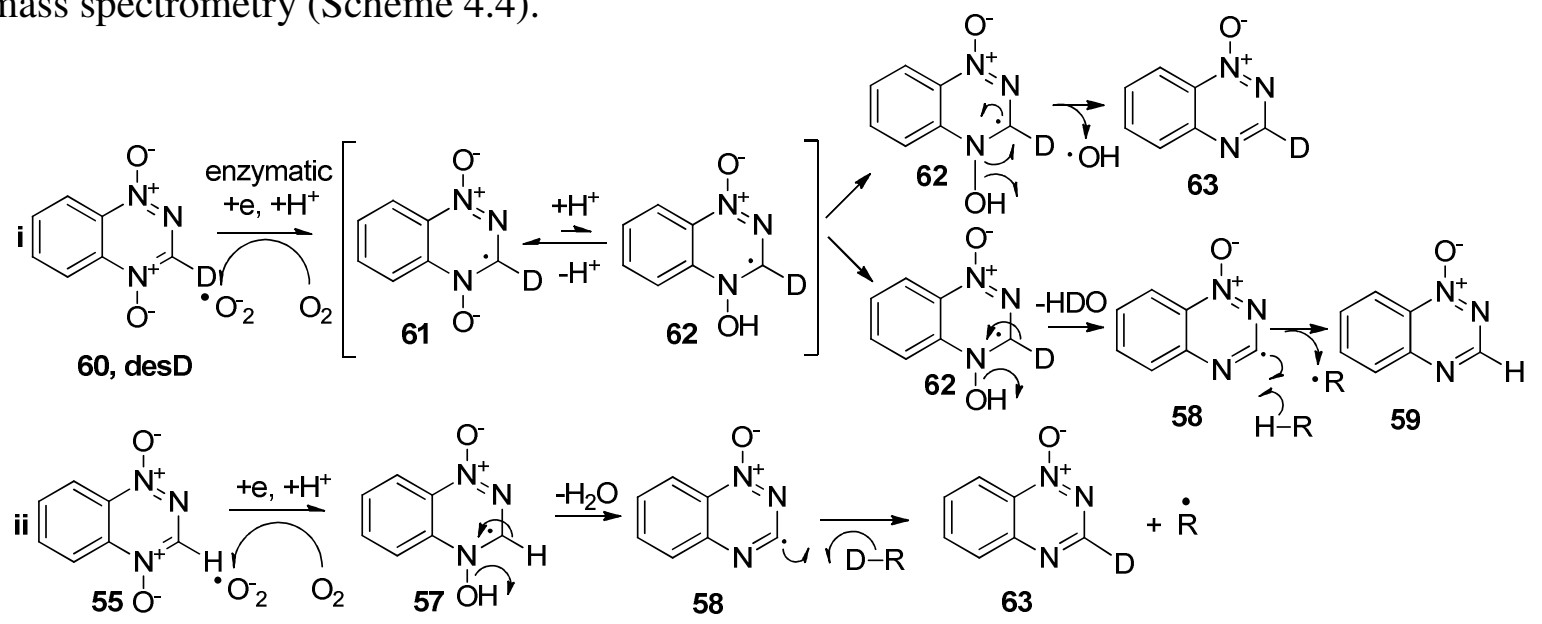

Scheme 4.4. Isotopic content of major metabolite of $\mathbf{5 5 / 6 0}$ determines mechanism

\subsection{Examine the dehydration mechanism in relation to the release of oxidizing species from 1,2,4-benzotriazine-di-oxide}

Various TPZ analogs such as 3-methyl-1,2,4-benzotriazine 1,4-dioxide (Me-TPZ)

and 1,2,4-benzotriazine 1,4-dioxide, $\mathbf{5 5}$, have been used in cytotoxicity assays. ${ }^{21}$ The anti-cancer activity of these analogs is similar and comparable to that of TPZ. Structurally and functionally similar benzotriazine di-oxide analogs can be used as tools to study the chemical nature of DNA damaging species and mechanism for the formation of DNA damaging species. ${ }^{14 b, c, 22}$ A study carried out by Raman Junnotula in our group used 3-methyl-1,2,4-benzotriazine 1,4-dioxide (MeTPZ) to investigate the formation of benzotriazinyl radical and explored the dehydration mechanism. ${ }^{20 \mathrm{~b}}$ The current chapter describes a similar related mechanistic study. In the beginning, compounds 55 and 60 are 
synthesized. The metabolism and DNA damaging properties of $\mathbf{5 5}$ and $\mathbf{6 0}$ were compared against TPZ for their ability to cause DNA damage under reductive enzyme activated hypoxic conditions.

\subsection{Chemical Synthesis of 1,2,4-benzotriazine-1,4-dioxide}

The compound 1,2,4-benzotriazine 1,4-dioxide 55 was obtained by known methods using TPZ as the starting material in the preparation. Briefly, in an argon-purged glove bag two glass vials were added with TPZ in anhydrous DMF and tert-butyl nitrite in anhydrous DMF (argon was purged upon preparing stock solutions). Then, the tertbutyl nitrite solution was heated to $65^{\circ} \mathrm{C}$, and to this TPZ in DMF was added slowly over 10 min. Then the mixture was cooled to room temperature. The solution was removed from the glove bag, and DMF was removed using high vacuum. Brownish yellow crude material was used to perform column chromatography, followed by preparative thin layer chromatography separated product 55. The deuterated analog 60 was prepared using deuterated DMF as the solvent. Synthesis of $\mathbf{5 5}$ was followed exactly to prepare and separate 60. The compound 3-amino 1,2,4-benzotriazine 1-N oxide 35 was used as the starting material to prepare 1,2,4-benzotriazine 1- $N$ oxides 59 and 63. Same procedure, which was followed to synthesize 55 was adopted in the preparation of 59.and 63, using deuterated DMF as the solvent.

4.6 DNA-damaging properties of 1,2,4-benzotriazine-1,4-dioxide analogs and TPZ

\subsubsection{TPZ analogs perform concentration dependent DNA damage}

Cytotoxicity caused by TPZ and 1,2,4-benzotriazine-1,4-dioxide 55 are similar. ${ }^{21 a}$ In TPZ, the cytotoxicity derives from its ability to initiate oxidative damage to cellular 
DNA. In the current work, the damage to DNA caused by TPZ was analyzed using plasmid DNA damage based assays. In the plasmid DNA-based assay, the supercoiled form I DNA molecule converts to form II when a hydrogen atom is abstracted from the sugar phosphate backbone. The DNA which is nicked will be converted to form II and intact DNA, the form I, is detected and quantified on agarose gel-based method. ${ }^{23}$ Similar DNA-damaging study with $\mathbf{5 5}$ and $\mathbf{6 0}$ provides a comparative DNA damage study among TPZ drug class. In the anaerobic assays TPZ, 55 or 60 were activated using NADPH:cytochrome P450 reductase and upon activation the oxidative DNA damage would assume on plasmid DNA. Gel pictures obtained upon completion of assays, conducted using TPZ, 55 and 60 showed an increase in the amount of form II DNA with the concentration of respective di- $N$-oxide (Figures 4.1, 4.2 and 4.3).

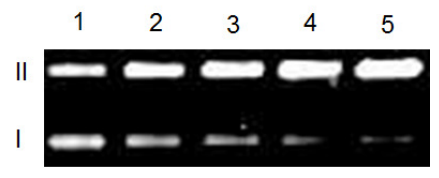

Figure 4.1: Cleavage of supercoiled plasmid DNA by $33(50-250 \mu \mathrm{M})$ in the presence of NADPH:cytochrome P450 reductase as an activating system. All reactions contained DNA $(33 \mu \mathrm{g} / \mathrm{mL}$, pGL-2 Basic), sodium phosphate buffer $(50 \mathrm{mM}, \mathrm{pH} 7.0)$, acetonitrile $(2.5 \% \mathrm{v} / \mathrm{v})$, catalase $(100 \mu \mathrm{g} / \mathrm{mL})$, superoxide dismutase $(10 \mu \mathrm{g} / \mathrm{mL})$, and desferal $(1 \mathrm{mM})$ and were incubated under anaerobic conditions at $24{ }^{\circ} \mathrm{C}$ for $6 \mathrm{~h}$, followed by agarose gel electrophoretic analysis. lane $1,33(50 \mu \mathrm{M})+\mathrm{NADPH}(500 \mu \mathrm{M})+$ reductase $(33 \mathrm{mU} / \mathrm{mL})(\mathrm{S}=0.75 \pm 0.04)$; lane $2,33(100 \mu \mathrm{M})+\mathrm{NADPH}(500 \mu \mathrm{M})+$ reductase $(33$ $\mathrm{mU} / \mathrm{mL})(\mathrm{S}=1.25 \pm 0.14) ;$ lane 3, $33(150 \mu \mathrm{M})+\mathrm{NADPH}(500 \mu \mathrm{M})+$ reductase $(33 \mathrm{mU} / \mathrm{mL})(\mathrm{S}=1.74 \pm$ $0.21)$; lane 4, $33(200 \mu \mathrm{M})+\mathrm{NADPH}(500 \mu \mathrm{M})+$ reductase $(33 \mathrm{mU} / \mathrm{mL})(\mathrm{S}=2.58 \pm 0.14)$; lane $5, \mathbf{3 3}(250$ $\mu \mathrm{M})+\mathrm{NADPH}(500 \mu \mathrm{M})+$ reductase $(33 \mathrm{mU} / \mathrm{mL})(\mathrm{S}=3.53 \pm 0.32)$. The value $\mathrm{S}$ represents the mean number of strand breaks per plasmid molecule and is calculated using the equation $S=-\ln f_{I}$, where $f_{I}$ is the fraction of plasmid present as form I. 


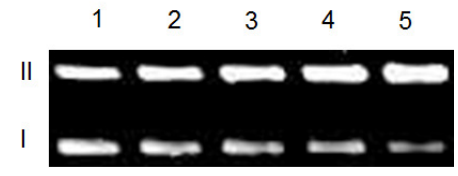

Figure 4.2: Cleavage of supercoiled plasmid DNA by $55(50-250 \mu \mathrm{M})$ in the presence of NADPH:cytochrome P450 reductase as an activating system. All reactions contained DNA $(33 \mu \mathrm{g} / \mathrm{mL}$, pGL-2 Basic), sodium phosphate buffer (50 mM, pH 7.0), acetonitrile $(2.5 \% \mathrm{v} / \mathrm{v})$, catalase $(100 \mu \mathrm{g} / \mathrm{mL})$, superoxide dismutase $(10 \mu \mathrm{g} / \mathrm{mL})$, and desferal $(1 \mathrm{mM})$ and were incubated under anaerobic conditions at $24{ }^{\circ} \mathrm{C}$ for $6 \mathrm{~h}$, followed by agarose gel electrophoretic analysis. lane $1,55(50 \mu \mathrm{M})+\mathrm{NADPH}(500 \mu \mathrm{M})+$ reductase $(33 \mathrm{mU} / \mathrm{mL})(\mathrm{S}=0.77 \pm 0.02)$; lane $2,55(100 \mu \mathrm{M})+\mathrm{NADPH}(500 \mu \mathrm{M})+$ reductase $(33$ $\mathrm{mU} / \mathrm{mL})(\mathrm{S}=1.10 \pm 0.08) ;$ lane $3, \mathbf{5 5}(150 \mu \mathrm{M})+\mathrm{NADPH}(500 \mu \mathrm{M})+$ reductase $(33 \mathrm{mU} / \mathrm{mL})(\mathrm{S}=1.27 \pm$ 0.07); lane 4, $55(200 \mu \mathrm{M})+\mathrm{NADPH}(500 \mu \mathrm{M})+$ reductase $(33 \mathrm{mU} / \mathrm{mL})(\mathrm{S}=1.71 \pm 0.17)$; lane $5, \mathbf{5 5}(250$ $\mu \mathrm{M})+\mathrm{NADPH}(500 \mu \mathrm{M})+$ reductase $(33 \mathrm{mU} / \mathrm{mL})(\mathrm{S}=2.19 \pm 0.20)$. The value $\mathrm{S}$ represents the mean number of strand breaks per plasmid molecule and is calculated using the equation $S=-\ln f_{I}$, where $f_{I}$ is the fraction of plasmid present as form $\mathrm{I}^{24}$

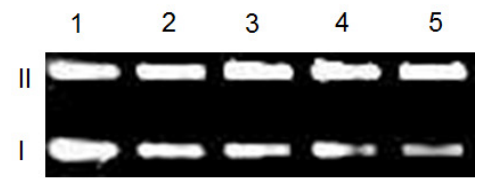

Figure 4.3: Cleavage of supercoiled plasmid DNA by $60(50-250 \mu \mathrm{M})$ in the presence of NADPH:cytochrome P450 reductase as an activating system. All reactions contained DNA $(33 \mu \mathrm{g} / \mathrm{mL}$, pGL-2 Basic), sodium phosphate buffer $(50 \mathrm{mM}, \mathrm{pH} 7.0)$, acetonitrile $(2.5 \% \mathrm{v} / \mathrm{v})$, catalase $(100 \mu \mathrm{g} / \mathrm{mL})$, superoxide dismutase $(10 \mu \mathrm{g} / \mathrm{mL})$, and desferal $(1 \mathrm{mM})$ and were incubated under anaerobic conditions at $24{ }^{\circ} \mathrm{C}$ for $6 \mathrm{~h}$, followed by agarose gel electrophoretic analysis. lane $1,60(50 \mu \mathrm{M})+\mathrm{NADPH}(500 \mu \mathrm{M})+$ reductase $(33 \mathrm{mU} / \mathrm{mL})(\mathrm{S}=0.66 \pm 0.04)$; lane $2,60(100 \mu \mathrm{M})+\mathrm{NADPH}(500 \mu \mathrm{M})+$ reductase $(33$ $\mathrm{mU} / \mathrm{mL})(\mathrm{S}=0.87 \pm 0.07) ;$ lane $3, \mathbf{6 0}(150 \mu \mathrm{M})+\mathrm{NADPH}(500 \mu \mathrm{M})+$ reductase $(33 \mathrm{mU} / \mathrm{mL})(\mathrm{S}=1.12 \pm$ $0.12) ;$ lane 4, $60(200 \mu \mathrm{M})+\mathrm{NADPH}(500 \mu \mathrm{M})+$ reductase $(33 \mathrm{mU} / \mathrm{mL})(\mathrm{S}=1.36 \pm 0.03)$; lane $5, \mathbf{6 0}(250$ $\mu \mathrm{M})+\mathrm{NADPH}(500 \mu \mathrm{M})+$ reductase $(33 \mathrm{mU} / \mathrm{mL})(\mathrm{S}=1.81 \pm 0.22)$. The value $\mathrm{S}$ represents the mean number of strand breaks per plasmid molecule and is calculated using the equation $S=-\ln f_{I}$, where $f_{I}$ is the fraction of plasmid present as form I.

The amount of nicking can be represented as $S$ values $\left(S=-\ln f_{I}\right.$, where $f_{I}$ is the fraction of plasmid present as form I) of TPZ, 55 and 60 . The $S$ values of TPZ, $\mathbf{5 5}$ and 60 show a positive correlation between DNA strand cleavage and respective drug 
concentration. As the concentration of drug is increased, under identical enzyme mediated reductive activation, the DNA damage is increased (Figures 4.1, 4.2, 4.3 and 4.4). This behavior is a reported trend among $N$-di-oxides when they are metabolized in the presence of plasmid DNA under reductively activated hypoxic conditions. ${ }^{25}$ In addition, control experiments were carried out without the activating enzyme, substrate or drugs to show that the observed DNA damage occurs solely due to the reductively activation of di-N-oxides. Reductive activation, under aerobic conditions, of TPZ, $\mathbf{5 5}$ or 60 is unable to produce considerable DNA damage compared to anaerobic reactions (Table 1).

\subsubsection{DNA damage is decreased by radical scavengers}

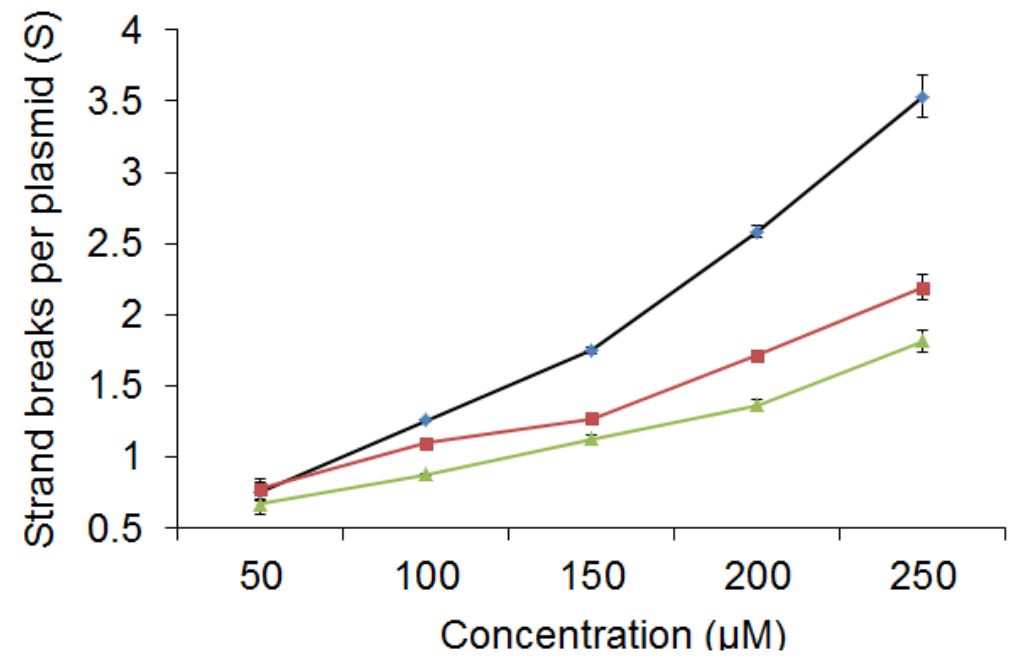

Figure 4.4. Comparison of DNA cleavage by reductively activated 33, 55 and 60 under anaerobic conditions (black line-strand cleavage by 33, red line-55 and green line-60. Supercoiled plasmid DNA (33 $\mu \mathrm{g} / \mathrm{mL}$, pGL-2 Basic) was incubated with drug $(50-250 \mu \mathrm{M})$, NADPH $(500 \mu \mathrm{M})$, cytochrome P450 reductase $(33 \mathrm{mU} / \mathrm{mL})$, catalase $(100 \mu \mathrm{g} / \mathrm{mL})$, superoxide dismutase $(10 \mu \mathrm{g} / \mathrm{mL})$, sodium phosphate buffer $(50 \mathrm{mM}, \mathrm{pH} 7.0)$, acetonitrile $(0.5-2.5 \% \mathrm{v} / \mathrm{v})$, and desferal $(1 \mathrm{mM})$ under anaerobic conditions at room temperature for $6 \mathrm{~h}$, followed by agarose gel electrophoretic analysis. The values, $\mathrm{S}$, derived from agarose gel data and represent the mean number of strand breaks per plasmid molecule and were calculated using the equation $S=-\ln f_{I}$, where $f_{I}$ is the fraction of plasmid present as form $I^{24}$ Background cleavage in the untreated plasmid was subtracted to allow direct comparison of DNA cleavage yields between different experiments. 


\begin{tabular}{|l|l|l|}
\hline Reaction & $\%$ form II & S value \\
\hline DNA alone & 17.4 & $0.19 \pm 0.07$ \\
\hline $\begin{array}{l}\text { NADPH:cytochrome P450 } \\
\text { reductase/NADPH aerobic }\end{array}$ & 14.3 & $0.15 \pm 0.06$ \\
\hline NADPH:cytochrome P450 reductase & 17.3 & $0.19 \pm 0.02$ \\
\hline $\mathbf{5 5}$ alone & 16.5 & $0.18 \pm 0.03$ \\
\hline $\begin{array}{l}\mathbf{5 5}+\text { NADPH:cytochromeP450 } \\
\text { reductase/NADPH aerobic }\end{array}$ & 17.0 & $0.18 \pm 0.03$ \\
\hline $\mathbf{6 0}$ alone & 29.3 & $0.38 \pm 0.70$ \\
\hline $\mathbf{6 0 + N A D P H : c y t o c h r o m e P 4 5 0}$ & 17.0 & $0.19 \pm 0.01$ \\
\hline reductase/NADPH aerobic & 25.8 & $0.29 \pm 0.74$ \\
\hline $\mathbf{5 5}$ alone & 16.5 & $0.18 \pm 0.03$ \\
\hline $\begin{array}{l}\mathbf{5 5}+\text { NADPH:cytochromeP450 } \\
\text { reductase/NADPH aerobic }\end{array}$ & 20.7 & \\
\hline $\mathbf{3 3}$ alone & & \\
\hline $\mathbf{3 3 + N A D P H : c y t o c h r o m e P 4 5 0}$ & & \\
\hline reductase/NADPH aerobic & & \\
\hline
\end{tabular}

Table 4.1. Cleavage of plasmid DNA in control reactions 
To test the chemical nature of the DNA damaging species, plasmid DNA based damaging assays were carried out in the presence of radical scavenging agents as a reagent in reaction solutions. The DNA damage caused by $\mathbf{3 3}$, under reductive enzyme activity in hypoxia, diminishes in the presence of radical scavenging agents such as methanol, ethanol, $t$-butanol, DMSO and mannitol. Analogous radical scavenging assays were carried out using $\mathbf{5 5}$ and $\mathbf{6 0}$. The agarose gels obtained from the radical scavenging assays of $\mathbf{5 5}$ and $\mathbf{6 0}$ are qualitatively and quantitatively comparable with those obtained with 33 (Figures 4.5, 4.6 and 4.7). The DNA damage caused by reductive activation of 33, 55 and 60 under hypoxia has been decreased by the addition of radical scavengers. It is well established that the radical scavengers used in the current assay reacts with hydroxyl radicals. Hence, homolytic fragmentation mechanism, which is proposed to explain the formation of hydroxyl radical in the metabolism of $\mathbf{3 3}$, is also plausible to occur when $\mathbf{5 5}$ and $\mathbf{6 0}$ undergo reductive activation in our assay conditions

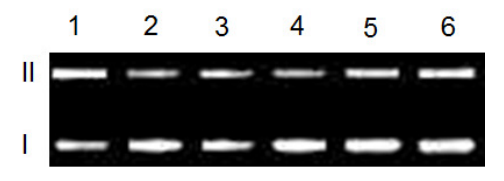

Figure 4.5. Cleavage of supercoiled plasmid DNA by $33(25 \mu \mathrm{M})$ in the presence of NADPH:cytochrome P450 reductase as an activating system is reduced by radical scavengers. All reactions contained DNA (33 $\mu \mathrm{g} / \mathrm{mL}$, pGL-2 Basic), sodium phosphate buffer $(50 \mathrm{mM}, \mathrm{pH} 7.0)$, acetonitrile $(2.5 \% \mathrm{v} / \mathrm{v})$, catalase $(100 \mu \mathrm{g} /$ $\mathrm{mL})$, superoxide dismutase $(10 \mu \mathrm{g} / \mathrm{mL})$, and desferal $(1 \mathrm{mM})$ and were incubated under anaerobic conditions at $24{ }^{\circ} \mathrm{C}$ for $4 \mathrm{~h}$, followed by agarose gel electrophoretic analysis. Lane $1,33(50 \mu \mathrm{M})+$ NADPH $(500 \mu \mathrm{M})+$ reductase $(33 \mathrm{mU} / \mathrm{mL})(S=0.67 \pm 0.09)$; lanes 2-6, $33(50 \mu \mathrm{M})+\mathrm{NADPH}(500 \mu \mathrm{M})$ + reductase $(33 \mathrm{mU} / \mathrm{mL})+$ methanol $(500 \mathrm{mM}$, lane 2$)(S=0.32 \pm 0.01)$; ethanol $(500 \mathrm{mM}$, lane 3$)(S=$ $0.35 \pm 0.04)$; tert-butyl alcohol (500 mM, lane 4) $(S=0.32 \pm 0.05)$; DMSO (500 mM, lane 5) $(S=0.35 \pm$ $0.06)$; mannitol $(500 \mathrm{mM}$, lane 6) $(S=0.32 \pm 0.05)$;. The value $S$ represents the mean number of strand breaks per plasmid molecule and is calculated using the equation $S=-\ln f_{\mathrm{I}}$, where $f_{\mathrm{I}}$ is the fraction of plasmid present as form I. 


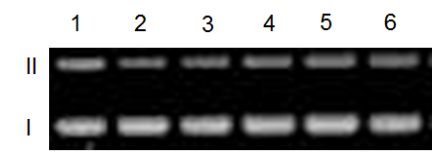

Figure 4.6. Cleavage of supercoiled plasmid DNA by $\mathbf{5 5}(50 \mu \mathrm{M})$ in the presence of NADPH:cytochrome P450 reductase as an activating system is reduced by radical scavengers. All reactions contained DNA (33 $\mu \mathrm{g} / \mathrm{mL}, \mathrm{pGL}-2$ Basic), sodium phosphate buffer $(50 \mathrm{mM}, \mathrm{pH} 7.0)$, acetonitrile $(2.5 \% \mathrm{v} / \mathrm{v})$, catalase $(100 \mu \mathrm{g} /$ $\mathrm{mL})$, superoxide dismutase $(10 \mu \mathrm{g} / \mathrm{mL})$, and desferal $(1 \mathrm{mM})$ and were incubated under anaerobic conditions at $24{ }^{\circ} \mathrm{C}$ for $4 \mathrm{~h}$, followed by agarose gel electrophoretic analysis. Lane $1,55(50 \mu \mathrm{M})+$ NADPH $(500 \mu \mathrm{M})+$ reductase $(33 \mathrm{mU} / \mathrm{mL})(S=0.66 \pm 0.13) ;$ lanes 2-6, $55(50 \mu \mathrm{M})+\mathrm{NADPH}(500 \mu \mathrm{M})$ + reductase $(33 \mathrm{mU} / \mathrm{mL})+$ methanol $(500 \mathrm{mM}$, lane 2$)(S=0.25 \pm 0.08)$; ethanol $(500 \mathrm{mM}$, lane 3$)(S=$ $0.29 \pm 0.08)$; tert-butyl alcohol $(500 \mathrm{mM}$, lane 4) $(S=0.27 \pm 0.04)$; DMSO (500 mM, lane 5) $(S=0.30 \pm$ $0.04)$; mannitol (500 mM, lane 6) $(S=0.28 \pm 0.07)$;. The value $S$ represents the mean number of strand breaks per plasmid molecule and is calculated using the equation $S=-\ln f_{\mathrm{I}}$, where $f_{\mathrm{I}}$ is the fraction of plasmid present as form I.

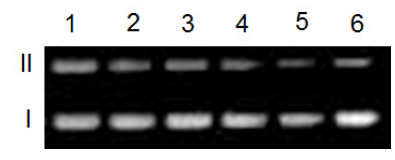

Figure 4.7. Cleavage of supercoiled plasmid DNA by $60(50 \mu \mathrm{M})$ in the presence of NADPH:cytochrome P450 reductase as an activating system is reduced by radical scavengers. All reactions contained DNA (33 $\mu \mathrm{g} / \mathrm{mL}$, pGL-2 Basic), sodium phosphate buffer (50 mM, pH 7.0), acetonitrile (2.5\% v/v), catalase (100 $\mu \mathrm{g} /$ $\mathrm{mL})$, superoxide dismutase $(10 \mu \mathrm{g} / \mathrm{mL})$, and desferal $(1 \mathrm{mM})$ and were incubated under anaerobic conditions at $24{ }^{\circ} \mathrm{C}$ for $4 \mathrm{~h}$, followed by agarose gel electrophoretic analysis. Lane $1,60(50 \mu \mathrm{M})+$ NADPH $(500 \mu \mathrm{M})+$ reductase $(33 \mathrm{mU} / \mathrm{mL})(S=0.58 \pm 0.10)$; lanes 2-6, $60(50 \mu \mathrm{M})+\mathrm{NADPH}(500 \mu \mathrm{M})$ + reductase $(33 \mathrm{mU} / \mathrm{mL})+$ methanol $(500 \mathrm{mM}$, lane 2$)(S=0.36 \pm 0.06)$; ethanol $(500 \mathrm{mM}$, lane 3$)(S=$ $0.36 \pm 0.06)$; tert-butyl alcohol (500 mM, lane 4) $(S=0.38 \pm 0.05)$; DMSO (500 mM, lane 5$)(S=0.35 \pm$ $0.06)$; mannitol $(500 \mathrm{mM}$, lane 6) $(S=0.37 \pm 0.09)$;. The value $S$ represents the mean number of strand breaks per plasmid molecule and is calculated using the equation $S=-\ln f_{\mathrm{I}}$, where $f_{\mathrm{I}}$ is the fraction of plasmid present as form I. 


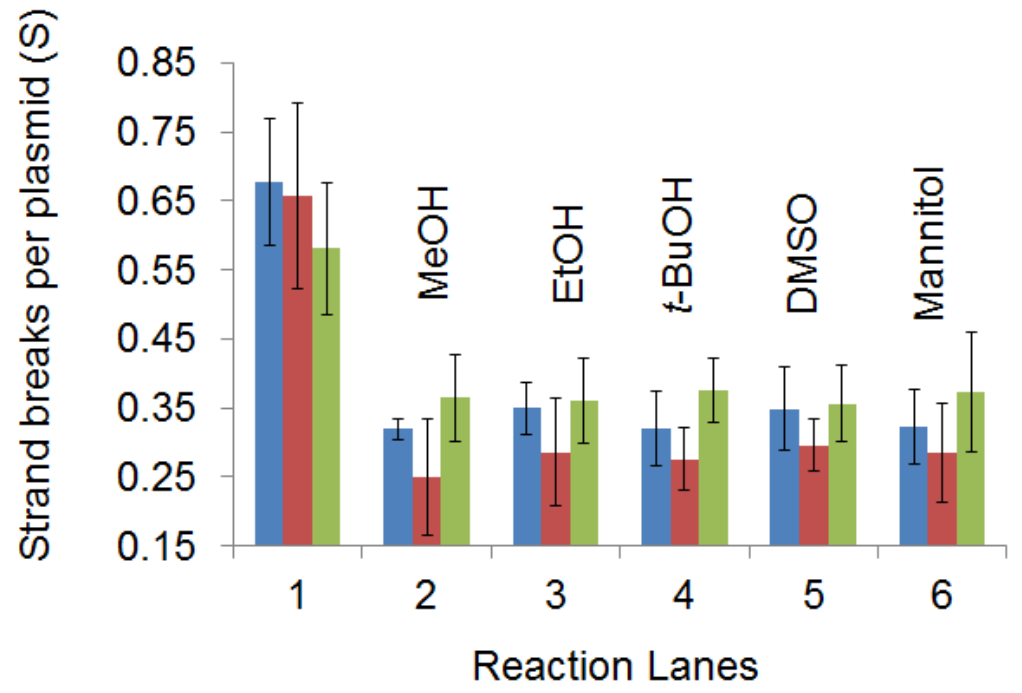

Figure 4.8. Comparison of DNA cleavage by reductively activated 33 (blue), 55 (red) or 60 (green) under anaerobic conditions and DNA cleavage is inhibited by radical scavengers. Supercoiled plasmid DNA (33 $\mu \mathrm{g} / \mathrm{mL}$, pGL-2 Basic) was incubated with drug $(50 \mu \mathrm{M})$, NADPH $(500 \mu \mathrm{M})$, cytochrome P450 reductase (33 mU/mL), catalase $(100 \mu \mathrm{g} / \mathrm{mL})$, superoxide dismutase $(10 \mu \mathrm{g} / \mathrm{mL})$, sodium phosphate buffer $(50 \mathrm{mM}$, $\mathrm{pH} 7.0)$, acetonitrile $(0.5-2.5 \% \mathrm{v} / \mathrm{v})$, and desferal $(1 \mathrm{mM})$ under anaerobic conditions at room temperature for $4 \mathrm{~h}$, followed by agarose gel electrophoretic analysis. Lane 1 , drug $(50 \mu \mathrm{M})+\mathrm{NADPH}(500 \mu \mathrm{M})+$ reductase $(33 \mathrm{mU} / \mathrm{mL})$; lanes $2-6$, drug $(50 \mu \mathrm{M})+\mathrm{NADPH}(500 \mu \mathrm{M})+$ reductase $(33 \mathrm{mU} / \mathrm{mL})+$ methanol (500 mM, lane 2); ethanol (500 mM, lane 3); tert-butyl alcohol (500 mM, lane 4); DMSO (500 mM, lane 5); mannitol (500 mM, lane 6); The values, $\mathrm{S}$, derived from agarose gel data and represent the mean number of strand breaks per plasmid molecule and were calculated using the equation $S=-\ln f_{I}$, where $f_{I}$ is the fraction of plasmid present as form I. Background cleavage in the untreated plasmid was subtracted to allow direct comparison of DNA cleavage yields between different experiments.

\subsection{Examining the chemical mechanism of bioreductive metabolism of 55 and 60}

Metabolite identification showed that the reductive activation of drugs under anaerobic conditions produced $1-N-$ oxide. In this way, the metabolism mirrors TPZ. ${ }^{20}$ Cytotoxicity assay results of TPZ and $\mathbf{5 5}$ show comparable anti-cancer activity. Hence, it can be suggested that TPZ and $\mathbf{5 5}$ would follow the same mechanism of DNA damage which forms the oxidizing radical under reductively activated conditions in hypoxia. To 
test the DNA damaging mechanism, we designed comparative metabolic experiments with 55 and the isotopically labeled analog of 55, 60.

\subsection{Metabolic studies of 55 and 60 with organic substrate}

Metabolic studies were carried out to test the metabolism of $\mathbf{6 0}$ and $\mathbf{5 5}$ by enzymatic reducing system in the presence of an organic substrate. To test the metabolism of $\mathbf{6 0}$, NADPH:cytochrome P450 reductase and NADPH was used as the enzyme system and $\mathrm{CH}_{3} \mathrm{OH}$ was added as the organic substrate. The reaction was carried out under anaerobic conditions in aqueous sodium phosphate buffer at $\mathrm{pH}$ 7.4. Upon metabolism the reaction mixture was subjected to be analyzed by LC/MS for the metabolites of 60 . Anaerobic metabolism of 60 produced 63 as the major metabolite with 64 and 65 as minor metabolites. In a metabolic analysis carried out using 55 with $\mathrm{CD}_{3} \mathrm{OD}$ in deuterated water under anaerobic conditions using sodium phosphate buffer at pD 6.6 produced major metabolite 59 and minor metabolites 66 and 67 (Scheme 4.5). 
<smiles></smiles>
60<smiles>[O-]c1n[n+]([O-])c2ccccc2[n+]1[O-]</smiles>
55

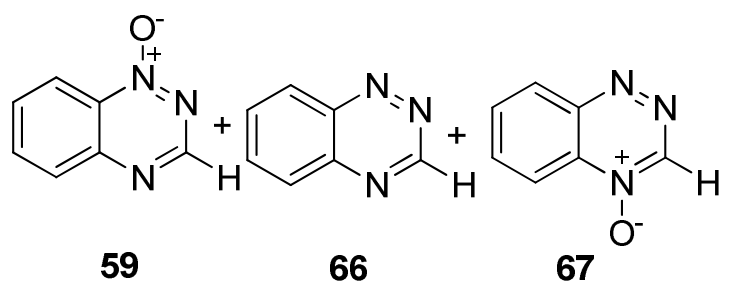

Scheme 4.5 Enzymatic metabolism of 60 and 55 with organic substrate in anoxia

The complete LC/MS analysis for the metabolism of $\mathbf{6 0}$ shows retained deuterium in metabolites 63, 64 and 65 (Figure 4.9 panels A, C, D and E). Hence benzotriazine radical 58 is unlikely to be formed in the bio-reductive metabolism of $\mathbf{6 0}$ (Scheme 4.4). Moreover, in the LC/MS analysis of metabolites 59, 66 and 67, derived from metabolism of $\mathbf{5 5}$ shows no exchange of deuterium into metabolites (Figure 4.9 panels F, H, I and J). Similar to the metabolism of $\mathbf{6 0}$, compound $\mathbf{5 5}$ may not form the benzotriazine radical $\mathbf{5 8}$ over the anaerobic bio-reduction process (Scheme 4.4). 

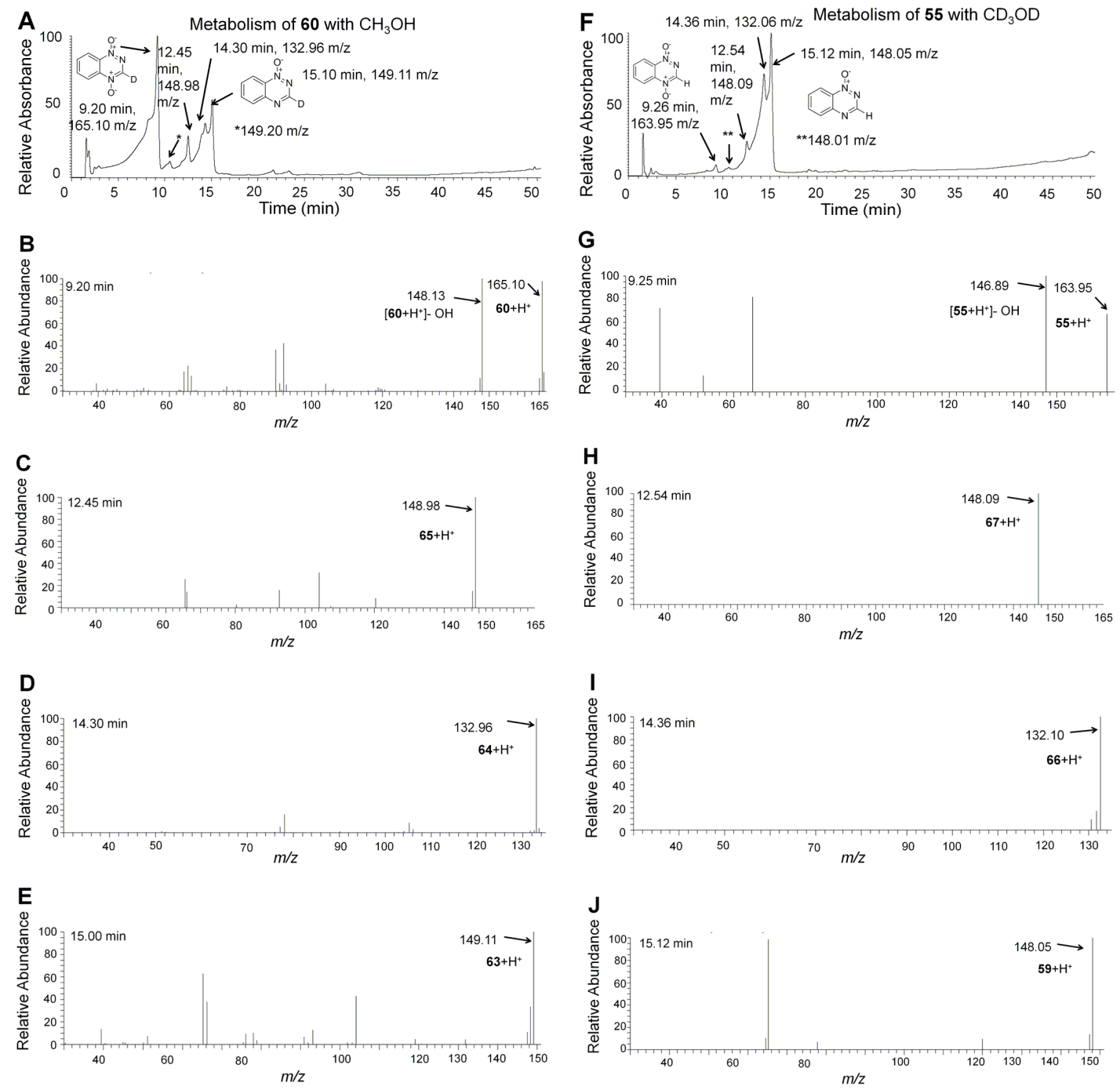

Figure 4.9. LC/MS analysis of anaerobic metabolism of 55 and $60(0.5 \mathrm{mM})$ by cytochrome p450 reductase $(0.4 \mathrm{U} / \mathrm{mL})$ and NADPH $(0.5 \mathrm{mM})$. The enzymatic reduction of $\mathbf{5 5} / \mathbf{6 0}$ was carried out as described in the experimental section. The reaction was dried and products dissolved in methanol. The mixture was eluted with a gradient of $99 \% \mathrm{~A}$ (water containing $0.1 \%$ acetic acid) and $1 \% \mathrm{~B}$ (acetonitrile containing $0.1 \%$ acetic acid) followed by linear increase to $90 \% \mathrm{~B}$ over $30 \mathrm{~min}$. The elution was continued at $90 \% \mathrm{~B}$ for $3 \mathrm{~min}$ and then B was decreased to $1 \%$ over next $8 \mathrm{~min}$. A flow rate of $0.35 \mathrm{~mL} / \mathrm{min}$ was used and the metabolites were detected at $254 \mathrm{~nm}$. Mass spectra were obtained using electrospray ionization in the positive ion mode. Panel A: HPLC of the anaerobic reaction mixture of $\mathbf{6 0}$ monitoring absorbance at $254 \mathrm{~nm}$. Panel B: LC/MS of 60; eluting at $9.2 \mathrm{~min}$. Panel C: LC/MS of metabolites of 60; product eluting at $12.45 \mathrm{~min}$. Panel D: LC/MS of metabolites of $\mathbf{6 0}$; product eluting at $14.30 \mathrm{~min}$. Panel E: LC/MS of metabolites of $\mathbf{6 0}$; product eluting at $15.00 \mathrm{~min}$. Panel F: HPLC of the anaerobic reaction mixture of $\mathbf{5 5}$ monitoring absorbance at $254 \mathrm{~nm}$. Panel G: LC/MS of 55 eluting at $9.25 \mathrm{~min}$. Panel H: LC/MS of metabolites of 55; product eluting at $12.54 \mathrm{~min}$. Panel I: LC/MS of metabolites of 55; product eluting at 14.36 min. Panel J: LC/MS of metabolites of 55; product eluting at $15.12 \mathrm{~min}$. 
LC/MS analysis of authentic $\mathbf{6 0}, \mathbf{6 3}, \mathbf{5 5}$, and 59, using the same LC/MS method, used to analyze anaerobic reaction mixtures of $\mathbf{6 0}$ and $\mathbf{5 5}$ metabolism shows comparable retention times and mass values with that of LC/MS analysis of $\mathbf{6 0}$ and $\mathbf{5 5}$ shown in figure 4.11 .
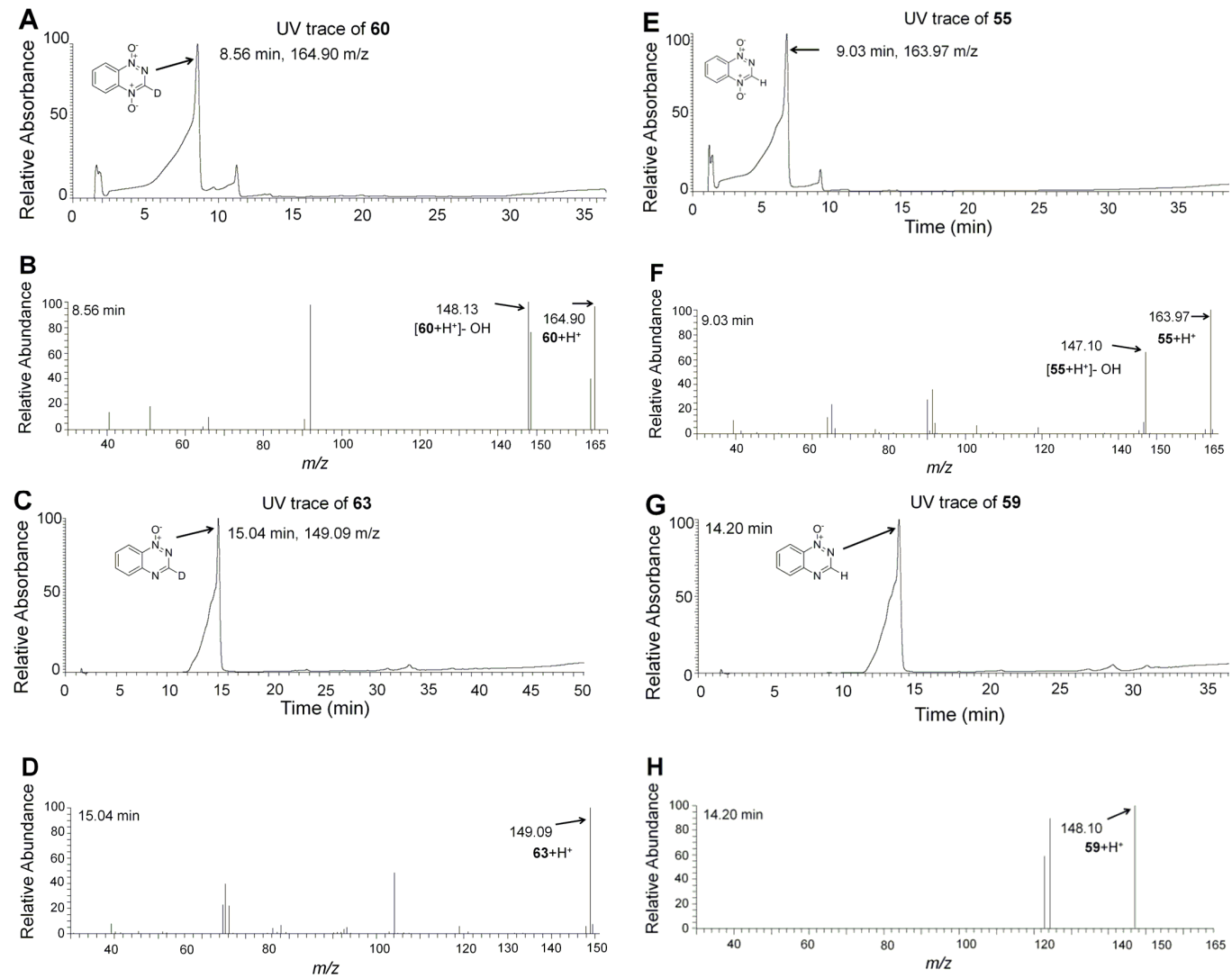

Figure 4.10. LC/MS analysis of authentic 60, 63, 55 and 59. The products dissolved in methanol. The mixture was eluted with a gradient of $99 \%$ A (water containing $0.1 \%$ acetic acid) and $1 \%$ B (acetonitrile containing $0.1 \%$ acetic acid) followed by linear increase to $90 \% \mathrm{~B}$ over $30 \mathrm{~min}$. The elution was continued at $90 \%$ B for $3 \mathrm{~min}$ and then B was decreased to $1 \%$ over next $8 \mathrm{~min}$. A flow rate of $0.35 \mathrm{~mL} / \mathrm{min}$ was used and the metabolites were detected at $254 \mathrm{~nm}$. Mass spectra were obtained using electrospray ionization in the positive ion mode. Panel A: HPLC of $\mathbf{6 0}$ monitoring absorbance at $254 \mathrm{~nm}$. Panel B: LC/MS of $\mathbf{6 0}$ eluting at $8.56 \mathrm{~min}$. Panel C: HPLC of $\mathbf{6 3}$ monitoring absorbance at $254 \mathrm{~nm}$ Panel D: LC/MS of $\mathbf{6 3}$ eluting at $15.04 \mathrm{~min}$. Panel E: HPLC of $\mathbf{5 5}$ monitoring absorbance at $254 \mathrm{~nm}$. Panel F: LC/MS of $\mathbf{5 5}$ eluting at 9.03 min. Panel G: HPLC of $\mathbf{5 9}$ monitoring absorbance at $254 \mathrm{~nm}$. Panel H: LC/MS of $\mathbf{5 9}$ eluting at 14.20 min. 


\subsection{Deuterium incorporation into 55}

The dehydration mechanism is further tested using 55 and 60 (Scheme 4.4). In the initial one electron reduction step the di-oxide $\mathbf{5 5}$ or $\mathbf{6 0}$ will convert to a radical anion and upon protonation, drug radicals $\mathbf{5 7}$ and $\mathbf{6 2}$ may persist under low oxygen levels. In order to follow the dehydration mechanism, removal of water molecule from $\mathbf{5 7}$ and $\mathbf{6 2}$ should form radical cation $\mathbf{5 8}$ and $\mathbf{5 8}$ can abstract hydrogen from an organic substrate (Scheme 4.4). If the dehydration mechanism is plausible, the hydrogen of organic substrate may be abstracted into the major metabolite. HRMS analysis of major metabolite is able to show isotopic content which shows any hydrogen abstraction event (Scheme 4.4). To test the dehydration mechanism, 55 was activated in the presence of $\mathrm{CD}_{3} \mathrm{OD}$, in $\mathrm{D}_{2} \mathrm{O}$-sodium phosphate buffer medium at $\mathrm{pD}$ 6.6. The major metabolite 1- $N$ oxide was separated and HRMS data suggests molecular formula $\mathrm{C}_{7} \mathrm{H}_{5} \mathrm{~N}_{3} \mathrm{O}$ for the molecular ion peak (M) with $\mathrm{m} / \mathrm{z}$ of 147.1 . Formation of $\mathbf{6 3}$, resulted by dehydration mechanism might have produced a molecular ion peak having $\mathrm{m} / \mathrm{z}$ of 148.1 , which is the $\mathrm{M}+1$ ion in the current assay. The intensity of $\mathrm{M}+1$ ion is $2 \%$ higher than that of a control experiment, carried out using $\mathbf{5 5}$ in the presence of $\mathrm{CH}_{3} \mathrm{OH}$ in aqueous sodium phosphate buffer at $\mathrm{pH} 7.4$. The $2 \%$ difference of $\mathrm{m} / \mathrm{z}$ of $\mathrm{M}+1$, between 55 in $\mathrm{CD}_{3} \mathrm{OD}$ reaction and 55 in $\mathrm{CH}_{3} \mathrm{OH}$ control may have caused due to the presence of naturally abundant isotopes such as $13 \mathrm{C}, 15 \mathrm{~N}$ and $2 \mathrm{H}$ or may be occurrence of dehydration mechanism as a minor reaction (Figure 4.11). 

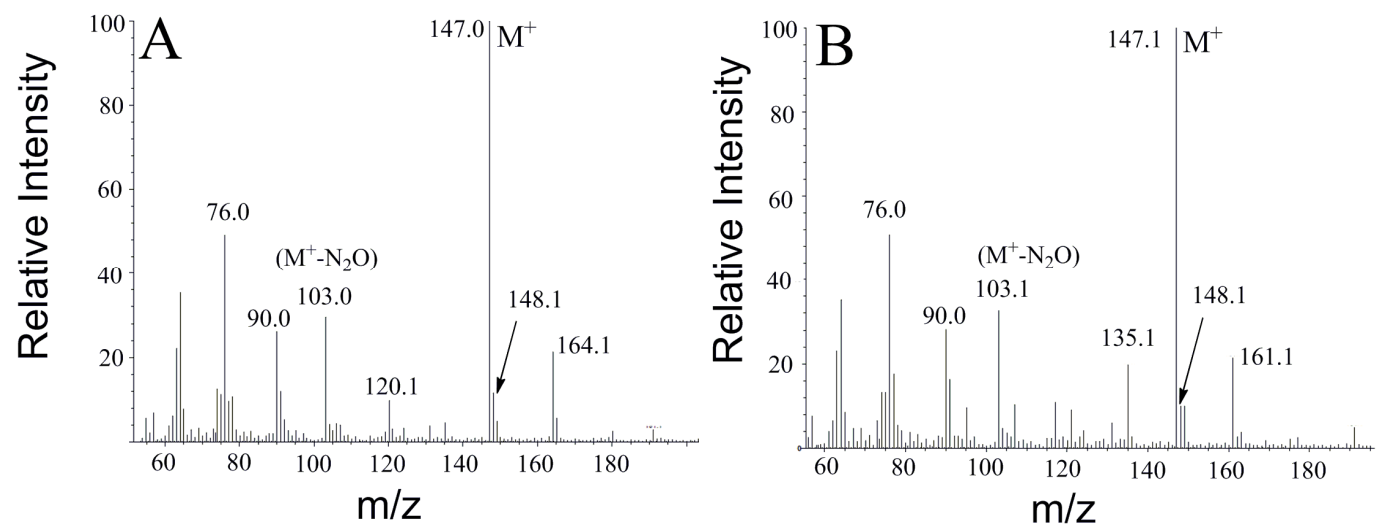

Figure 4.11. HRMS of the major metabolite 1- $N$-oxide $\mathbf{5 9}$ arising from metabolism of $\mathbf{5 5}$ under reductively activated conditions in hypoxia. Briefly $55(10 \mathrm{mM})$ was incubated with NADPH $(500 \mathrm{mM})$ and NADPH:cytochrome P450 reductase $(0.5 \mathrm{U} / \mathrm{mL})$ in argon purged bag with either A) sodium phosphate buffer $(30 \mathrm{mM})$ at $\mathrm{pD} 6.6$ in $\mathrm{D}_{2} \mathrm{O}$ and $\mathrm{CD}_{3} \mathrm{OD}(2 \mathrm{mM})$ were added and incubated over 4 hours. $\left.\mathrm{B}\right)$ sodium phosphate buffer $(30 \mathrm{mM})$ at $\mathrm{pH} 7.4$ in $\mathrm{H}_{2} \mathrm{O}$ and $\mathrm{CH}_{3} \mathrm{OH}(2 \mathrm{M})$ were added and incubated over 4 hours. Upon completion reactions $\mathrm{A}$ and $\mathrm{B}$ were extracted to EtOAc and dried in vacuum. Thin layer chromatography was used to separate the major $1-N$-oxide metabolite in both $\mathrm{A}$ and $\mathrm{B}$. Then corresponding area related to the $\mathrm{R}_{\mathrm{f}}$ value for $1-\mathrm{N}$-oxide was scratched using a metal blade to collect silica. The organic material was extracted to EtOAc from silica and dried in vacuum. The dry organic extract was dissolved in $\mathrm{CH}_{3} \mathrm{CN}$ and directed for HRMS analysis.

\subsection{Isotope washout from drug 60}

Metabolism of $\mathbf{6 0}$ was carried out under anaerobic reducing conditions in the presence of $\mathrm{CH}_{3} \mathrm{OH}$ in sodium phosphate buffer at $\mathrm{pH} 7.4$ to study the isotopic content of the major metabolite using HRMS. Under dehydration mechanism, deuterium of $\mathbf{6 0}$ is removed as water and the major metabolite $\mathbf{5 9}$ may form via benzotriazinyl radical $\mathbf{5 8}$ (Scheme 4.4). HRMS analysis of molecular ion (M) of the major metabolite shows $\mathrm{C}_{7} \mathrm{H}_{4} \mathrm{DN}_{3} \mathrm{O}$ as the molecular formula with $\mathrm{m} / \mathrm{z}$ of 148.1 . Due to dehydration mechanism, if $59 \mathrm{had}$ formed, $\mathrm{m} / \mathrm{z}$ of the molecular ion should be $147.1 \mathrm{~m} / \mathrm{z}$. When the peak intensity of M-1 ion, formed from the reaction $\mathbf{6 0}$ with $\mathrm{CH}_{3} \mathrm{OH}$ is compared with the control, $\mathbf{6 0}$ with $\mathrm{CD}_{3} \mathrm{OD}$ in $\mathrm{D}_{2} \mathrm{O}$-sodium phosphate buffer medium at $\mathrm{pD} 6.6$, shows only $3 \%$ 
increase in the former reaction, $\mathbf{6 0}$ with $\mathrm{CH}_{3} \mathrm{OH}$. This $3 \%$ increase might have occurred due to dehydration mechanism, which had occurred as a minor reaction path (Figure 4.12).
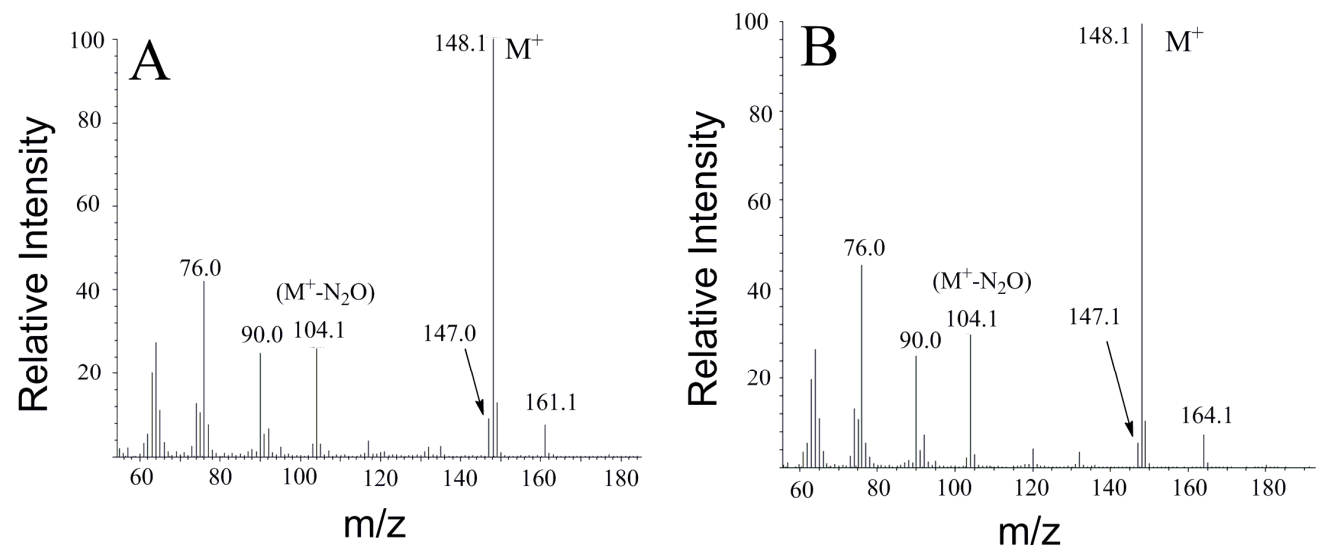

Figure 4.12. HRMS of the major metabolite $1-N$-oxide 63 arising from metabolism of 60 under reductively activated conditions in hypoxia. Briefly $60(10 \mathrm{mM})$ was incubated with NADPH $(500 \mathrm{mM})$ and NADPH:cytochrome P450 reductase $(0.5 \mathrm{U} / \mathrm{mL})$ in argon purged bag with either A) sodium phosphate buffer (30mM) at $\mathrm{pH} 7.4$ in $\mathrm{H}_{2} \mathrm{O}$ and $\mathrm{CH}_{3} \mathrm{OH}(2 \mathrm{mM})$ were added and incubated over 4 hours. B) Sodium phosphate buffer $(30 \mathrm{mM})$ at $\mathrm{pD} 6.6$ in $\mathrm{D}_{2} \mathrm{O}$ and $\mathrm{CD}_{3} \mathrm{OD}(2 \mathrm{mM})$ were added and incubated over 4 hours. Upon completion reactions $\mathrm{A}$ and $\mathrm{B}$ were extracted to EtOAc and dried in vacuum. Thin layer chromatography was used to separate the $1-N$-oxide in A and B. Then corresponding area related to the $\mathrm{R}_{\mathrm{f}}$ value for $1-N$-oxide was scratched using a metal blade to collect silica. The organic material was extracted to EtOAc and dried in vacuum. The dry organic extract was dissolved in $\mathrm{CH}_{3} \mathrm{CN}$ and directed for HRMS analysis.

\subsection{Isotope replacement analysis and dehydration mechanism}

The results of metabolic experiments of 55, with $\mathrm{CD}_{3} \mathrm{OD}$ and $\mathbf{6 0}$ in the presence of $\mathrm{CH}_{3} \mathrm{OH}$ suggest that the dehydration mechanism may occur as a minor path, responsible for enzyme mediated activation of 1,2,4-benzotraizine-1,4-dioxides under hypoxia. Alternatively, hemolysis of $\mathrm{N}-\mathrm{O}$ bond, which is evident by radical scavenging studies, suggests that hydroxyl radical might be the oxidizing radical formed in the

metabolism of $\mathbf{5 5}$ and 60. The homolytic fragmentation over the bio-reductive 
metabolism of $\mathbf{5 5}$ and $\mathbf{6 0}$ is possible to occur as the major metabolic path under hypoxic bio-reductive conditions.

\subsection{Conclusion}

The work related to this chapter describes the use of 1,2,4-benzotriazine-1,4dioxide $\mathbf{5 5}$ as a mechanistic handle to analyze dehydration mechanism. The dehydration mechanism is proposed to explain the chemical structure of the oxidizing radical, released by these $N$ oxide drugs in hypoxia under reductive activation. ${ }^{10,12,26}$ The drug 1,2,4-benzotriazine-1,4-dioxide may have formed benzotriazinyl radical as a minor

oxidizing radical via dehydration mechanism. ${ }^{10}$ In our study we showed that drugs $\mathbf{5 5}$ and 60 produce DNA cleavage, comparable to the DNA damage caused by 33 . In addition, the radical scavenging experiments with 33,55 and 60 showed reduced DNA damage and diminished DNA damage suggest the involvement of hydroxyl radical as the major DNA damaging process. $^{4 \mathrm{a}, 14 \mathrm{c}}$

The results of the experiments, carried out to test deuterium incorporation to $\mathbf{5 5}$ in the presence of $\mathrm{CD}_{3} \mathrm{OD}$ and deuterium release from $\mathbf{6 0}$, in the presence of $\mathrm{CH}_{3} \mathrm{OH}$ were not consistent with the dehydration mechanism as the major mechanism in the enzymatic metabolism of 1,2,4-benzotriazine-1,4-dioxide.

Finally, based on various experiment results related to mechanistic studies on $N$ di-oxides, it can be concluded that the one electron reduction of 1,2,4-benzotriazine-1,4dioxide produces hydroxyl radical as the oxidizing species which might be the major source that carries out DNA cleavage. 


\subsection{Experimental}

4.12.1 Materials. Materials were of the highest purity available and were obtained from following sources: cytochrome P450 reductase, NADPH, sodium phosphate, mannitol, DMSO desferal, , catalase, and superoxide dismutase (SOD) from Sigma Chemical Co. (St. Louis, MO); agarose from Seakem; HPLC grade solvents (acetonitrile, methanol, ethanol, tert-butyl alcohol, ethyl acetate, hexane, and acetic acid) from Fischer (Pittsburgh, PA); ethidium bromide from Roche Molecular Biochemicals (Indianapolis, IN). Standard protocol was used to prepare plasmid DNA pGL2BASIC. ${ }^{27}$ Published methods in literature were followed to prepare TPZ $\mathbf{1}$ and other N-oxides. ${ }^{20 a, 28}$

\subsubsection{Synthesis of 1,2,4-benzotriazine-1,4-bioxide 55}

Argon was purged into dry DMF for 5 min inside an argon filled glove bag. Then TPZ (115mg, $0.644 \mathrm{mmol})$ was dissolved in $(2 \mathrm{~mL})$ DMF. To another degassed DMF sample $(2 \mathrm{~mL})$ tert-butyl nitrite $(0.25 \mathrm{ml}, 2.05 \mathrm{mmol})$ was added and heated to $65^{\circ} \mathrm{C}$ inside the glove bag. To this solution, TPZ was added and heated for $10 \mathrm{~min}$ at $65^{\circ} \mathrm{C}$ with stirring. Upon completion reaction time the reaction mixture was cooled to room temperature and DMF was removed by vacuum. Then column chromatography $(1: 1$ EtOAc/hexane) was performed to obtain (40 mg, $34 \%$ ). Deuterated DMF was used in the preparation of 3 position deuterated 1,2,4-benzotriazine-1,4-dioxide. $\mathrm{R}_{\mathrm{f}}$ of is $0.50(100 \%$ EtOAc): ${ }^{1} \mathrm{H}$ NMR (Acetone, $500 \mathrm{MHz}$ ): $\delta 9.04$ (s, 1H), $8.42(\mathrm{dd}, 2 \mathrm{H}), 8.15(\mathrm{~m}, 1 \mathrm{H}), 8.03$ (m, 1H). ${ }^{13} \mathrm{C}-\mathrm{NMR}$ (Acetone, $125.8 \mathrm{MHz}$ ): $\delta$ 142.73, 141.01, 136.50, 136.01, 133.54, 122.20, 120.19; HRMS $\left(\mathrm{ES}^{+},[\mathrm{M}+\mathrm{H}]\right) \mathrm{m} / z$ calcd $\mathrm{C}_{7} \mathrm{H}_{6} \mathrm{~N}_{3} \mathrm{O}_{2}$ calculated mass 164.0460; actual mass 164.0453. 


\subsubsection{Synthesis of 3 position deuterated 1,2,4-benzotriazine-1,4-dioxide 60}

The procedure used to synthesize $\mathbf{5 5}$ was followed to prepare $\mathbf{6 0}$. In synthesis, deuterated DMF was used instead of DMF.

${ }^{1} \mathrm{H}$ NMR (Acetone, $500 \mathrm{MHz}$ ): $\delta 8.42(\mathrm{dd}, 2 \mathrm{H}), 8.15(\mathrm{~m}, 1 \mathrm{H}), 8.03(\mathrm{~m}, 1 \mathrm{H}) .{ }^{13} \mathrm{C}-\mathrm{NMR}$ (Acetone, $125.8 \mathrm{MHz}$ ): $\delta 142.47(\mathrm{t}, \mathrm{J}=32.7 \mathrm{~Hz}$ ), 141.02, 136.52, 136.02, 133.54, 122.20, 120.18; HRMS $\left(\right.$ ES $\left.^{+},[\mathrm{M}+\mathrm{H}]\right) \mathrm{m} / z$ calcd $\mathrm{C}_{7} \mathrm{H}_{5} \mathrm{DN}_{3} \mathrm{O}_{2}$ calculated mass 165.0523; actual mass 165.0515 .

\subsubsection{Synthesis of 1,2,4-benzotriazine-1-oxide 59}

Anhydrous DMF was bubbled with argon for 5 min inside a argon filled glove bag. Then 35 (365mg, $2.2 \mathrm{mmol}$ ) was dissolved in (3 mL) DMF. To another DMF sample ( $3 \mathrm{~mL}$ ) tert-butyl nitrite $(1.07 \mathrm{ml}, 8.8 \mathrm{mmol})$ was added and heated to $65^{\circ} \mathrm{C}$ inside the glove bag. To this solution TPZ was added and heated for $10 \mathrm{~min}$ at $65^{\circ} \mathrm{C}$ with stirring. Upon completion reaction time the reaction mixture was cooled to room temperature and DMF was removed by vacuum. Then column chromatography (1:1 EtOAc/hexane) was performed to obtain $(77 \mathrm{mg}, 34 \%) . \mathrm{R}_{\mathrm{f}}=0.50(100 \% \mathrm{EtOAc})$

${ }^{1} \mathrm{H}$ NMR (Acetone, $\left.300 \mathrm{MHz}\right): \delta$ ppm $9.05(\mathrm{~s}, 1 \mathrm{H}), \delta 8.42(\mathrm{~d}, \mathrm{~J}=8.5 \mathrm{~Hz}, 1 \mathrm{H}), \delta 8.11(\mathrm{~m}$, 2H), $\delta 7.91(\mathrm{~m}, 1 \mathrm{H}){ }^{13} \mathrm{C}$ NMR (Acetone, $\left.75.5 \mathrm{MHz}\right): \delta$ 155.02, 148.32, 136.66, 131.99, 130.05, 120.63; HRMS $\left(\mathrm{ES}^{+},[\mathrm{M}+\mathrm{H}]\right) \mathrm{m} / \mathrm{z}$ calcd $\mathrm{C}_{7} \mathrm{H}_{6} \mathrm{~N}_{3} \mathrm{O}$ calculated mass 148.0511; actual mass 148.0517 . 


\subsubsection{Synthesis of 1,2,4-benzotriazine-3-deuterium-1-oxide 63}

The synthetic method used to prepare $\mathbf{5 9}$ was exactly followed to synthesized $\mathbf{6 3}$ and deuterated DMF was used instead of DMF. ${ }^{1} \mathrm{H}$ NMR (Acetone, $300 \mathrm{MHz}$ ): $\delta \mathrm{ppm}$ $8.40(\mathrm{~d}, \mathrm{~J}=8.5 \mathrm{~Hz}, 1 \mathrm{H}), 8.08(\mathrm{~m}, 2 \mathrm{H}), 7.88(\mathrm{~m}, 1 \mathrm{H}){ }^{13} \mathrm{C}$ NMR (Acetone, $\left.75.5 \mathrm{MHz}\right): \delta$ $154.72(\mathrm{t}, \mathrm{J}=32.7 \mathrm{~Hz}), 148.34,136.66,131.99,130.06,120.64$; HRMS $\left(\mathrm{ES}^{+},[\mathrm{M}+\mathrm{H}]\right)$ $\mathrm{m} / \mathrm{z}$ calcd $\mathrm{C}_{7} \mathrm{H}_{5} \mathrm{DN}_{3} \mathrm{O}$ calculated mass 149.0574; actual mass 149.0579.

\subsubsection{DNA damage assays}

In normal anaerobic DNA cleaving assay, the drug TPZ, 55 or $61(5-25 \mu \mathrm{M})$ was incubated with supercoiled plasmid DNA (33 $\mu \mathrm{g} / \mathrm{mL}$, pGL-2 Basic), NADPH $(500 \mu \mathrm{M})$, cytochrome P450 reductase $(33 \mathrm{mU} / \mathrm{mL})$, catalase $(100 \mu \mathrm{g} / \mathrm{mL})$, superoxide dismutase (10 $\mu \mathrm{g} / \mathrm{mL})$, sodium phosphate buffer $(50 \mathrm{mM}, \mathrm{pH} 7.0)$, acetonitrile $(0.5-2.5 \% \mathrm{v} / \mathrm{v})$, and desferal $(1 \mathrm{mM})$ under anaerobic conditions at $25{ }^{\circ} \mathrm{C}$ for $4 \mathrm{~h}$. Three freeze-pump-thaw cycles were performed on all solutions except enzymes, NADPH, and DNA. To prepare reaction mixtures deoxygenated water was used in an argon-filled glove bag and cytochrome $\mathrm{P} 450$ reductase was added as the last reagent to start the reaction. Then the reaction containers were kept in the argon purged glove bag upon wrapped in aluminum 
foil to prevent exposure to light. The reactions were quenched by addition of $5 \mu \mathrm{L}$ of $50 \%$ glycerol loading buffer and were loaded onto a $0.9 \%$ agarose gel and electrophoresed for approximately $2.0 \mathrm{~h}$ at $85 \mathrm{~V}$ in $1 \mathrm{x}$ TAE buffer. Upon completion of electrophoretic separation, the gels were removed and soaked in an aqueous ethidium bromide $(0.3 \mu \mathrm{g} / \mathrm{mL})$ solution for staining for $4 \mathrm{~h}$. To visualize DNA UVtransillumination was performed on gels and DNA band quantification was performed using quantity one imaging system. The values reported are not corrected for differential staining of form I and form II DNA by ethidium bromide.

The radical scavenging DNA damage assays were performed following the above typical procedure. The radical scavenging reagents methanol, ethanol, tert-butyl alcohol, DMSO, or mannitol $(500 \mathrm{mM})$ were added inaddition to the other reagents prior to the addition of cytochrome P450 reductase. All aerobic reactions were carried out using non de oxygenated soluitons under normal atmosphericconditions.

\subsubsection{Metabolic studies related to drugs}

In a typical metabolic assay, all solutions except cytochrome $\mathrm{P} 450$ reductase (330 $\mathrm{mU} / \mathrm{mL})$, catalase $(100 \mu \mathrm{g} / \mathrm{mL})$ were degassed by three cycles of freeze-pump-thaw cycles. The $N$ di-oxide $(\mu \mathrm{M})$ was mixed with desferal $(1 \mathrm{mM})$ in sodium phosphate buffer $(\mathrm{pH} 7,50 \mathrm{mM}), \mathrm{NADPH}(500 \mu \mathrm{M})$, catalase $(100 \mu \mathrm{g} / \mathrm{mL})$, and superoxide dismutase (10 $\mu \mathrm{g} / \mathrm{mL}$ ) followed by the addition of cytochrome P450 reductase (330 mU/mL). Upon $4 \mathrm{hr}$ incubation under argon at $25{ }^{\circ} \mathrm{C}$, the organic was extracted to EtOAc $(0.5 \mathrm{~mL})$ twice and dried using roto vap. Then the dry reaction mixture was dissolved in $0.5 \mathrm{~mL} \mathrm{MeOH}$ and was analyzed by LC employing a C18 reverse phase Rainin Microsorb-MV column (5 
$\mu \mathrm{m}$ particle size, $100 \AA$ pore size, $25 \mathrm{~cm}$ length, $4.6 \mathrm{~mm}$ i.d.) eluted with gradient starting at $50 \% \mathrm{~A}(0.5 \%$ acetic acid in water) and $50 \% \mathrm{~B}$ (acetonitrile) followed by linear increase to $80 \% \mathrm{~B}$ from $0 \mathrm{~min}$ to $40 \mathrm{~min}$. A flow rate of $0.6 \mathrm{~mL} / \mathrm{min}$ was used and the products were monitored by their UV-absorbance at $254 \mathrm{~nm}$. LC/ESI-MS experiments were carried out on a Finnigan TSQ 7000 triple quadrupole instrument interfaced to a ThermoSeparations liquid chromatograph (TSP4000). Positive ion electrospray was used as the means of ionization. The heated inlet capillary temperature was $250{ }^{\circ} \mathrm{C}$ and electrospray needle voltage was $4.5 \mathrm{kV}$. Nitrogen sheath gas was supplied at 80 psi and the LC/ESI-MS analysis was done in the positive ion mode.

\subsubsection{HRMS studies related to drugs}

In a typical metabolic assay, all solutions except cytochrome $\mathrm{P} 450$ reductase (330 $\mathrm{mU} / \mathrm{mL})$, catalase $(100 \mu \mathrm{g} / \mathrm{mL})$ were degassed by three cycles of freeze-pump-thaw cycles. The $\mathrm{N}$ di-oxide $(\mu \mathrm{M})$ was mixed with desferal $(1 \mathrm{mM})$ in sodium phosphate buffer $(\mathrm{pH} 7,50 \mathrm{mM})$ and NADPH $(500 \mu \mathrm{M})$ followed by the addition of cytochrome P450 reductase $(330 \mathrm{mU} / \mathrm{mL})$. Upon $4 \mathrm{hr}$ incubation under argon at $25{ }^{\circ} \mathrm{C}$, the organic was extracted to EtOAc $(0.5 \mathrm{~mL})$ twice and dried using roto vap. Then the dry reaction mixture was dissolved in $0.5 \mathrm{~mL} \mathrm{CH}_{3} \mathrm{CN}$ and used to spot on TLC plates. The preparative TLC was run using (1:1 EtOAc/hexane) as the solvent system. The major metabolite mono $\mathrm{N}$ oxide was co-spotted when preparation TLC was run. Upon completion the TLC plates were dried in air and the area correspond to 1-N-oxide co-migration was scratched using a metal blade. The dry silica was re-dissolved in EtOAc and EtOAc was removed 
to a glass vial. The EtOAc was dried under roto-vap, protected from light and kept in the freezer. The dry samples were sent for HRMS analysis. 


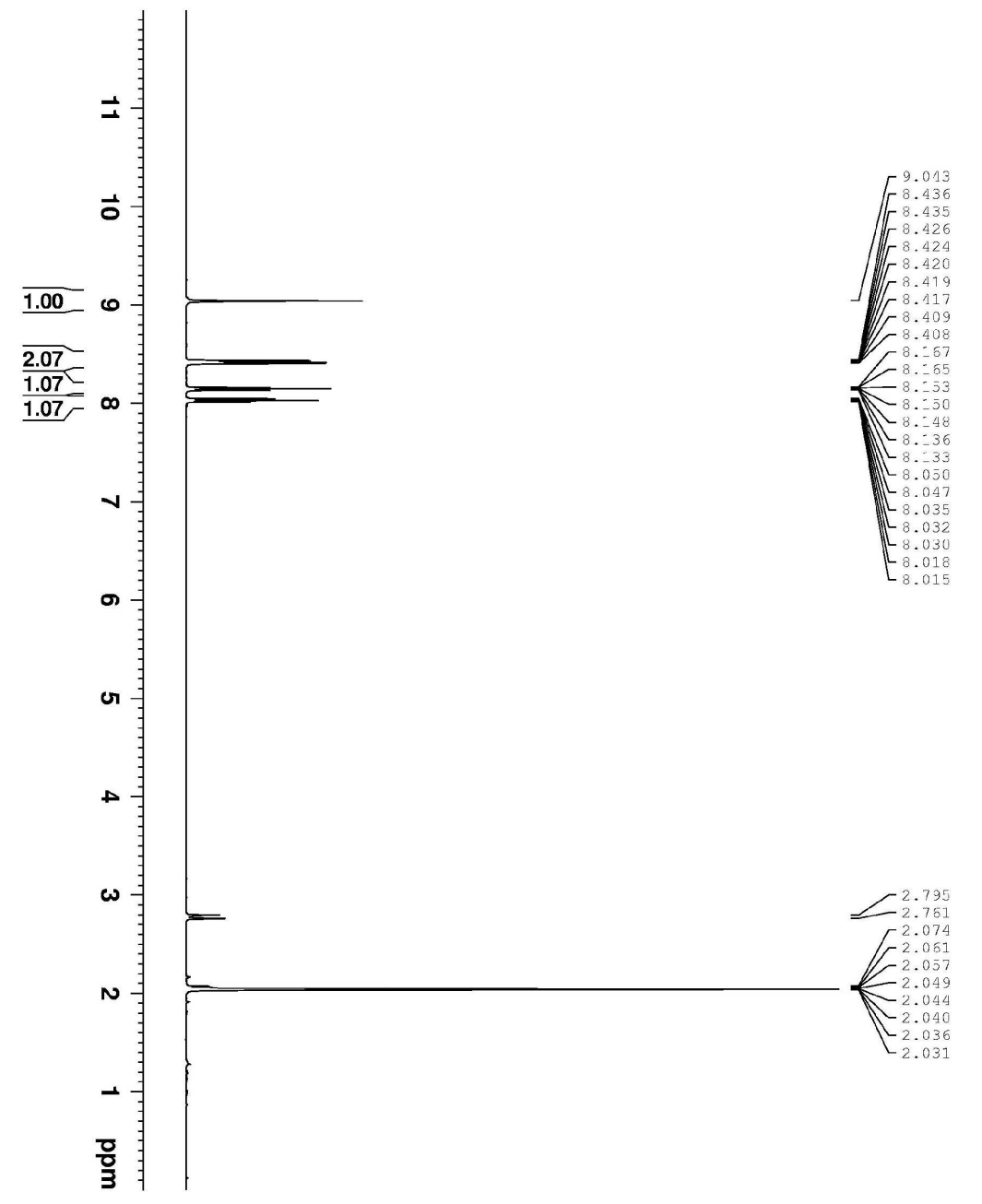

${ }^{1} \mathrm{H}$ NMR of 55 (Acetone, $500 \mathrm{MHz}$ ) 


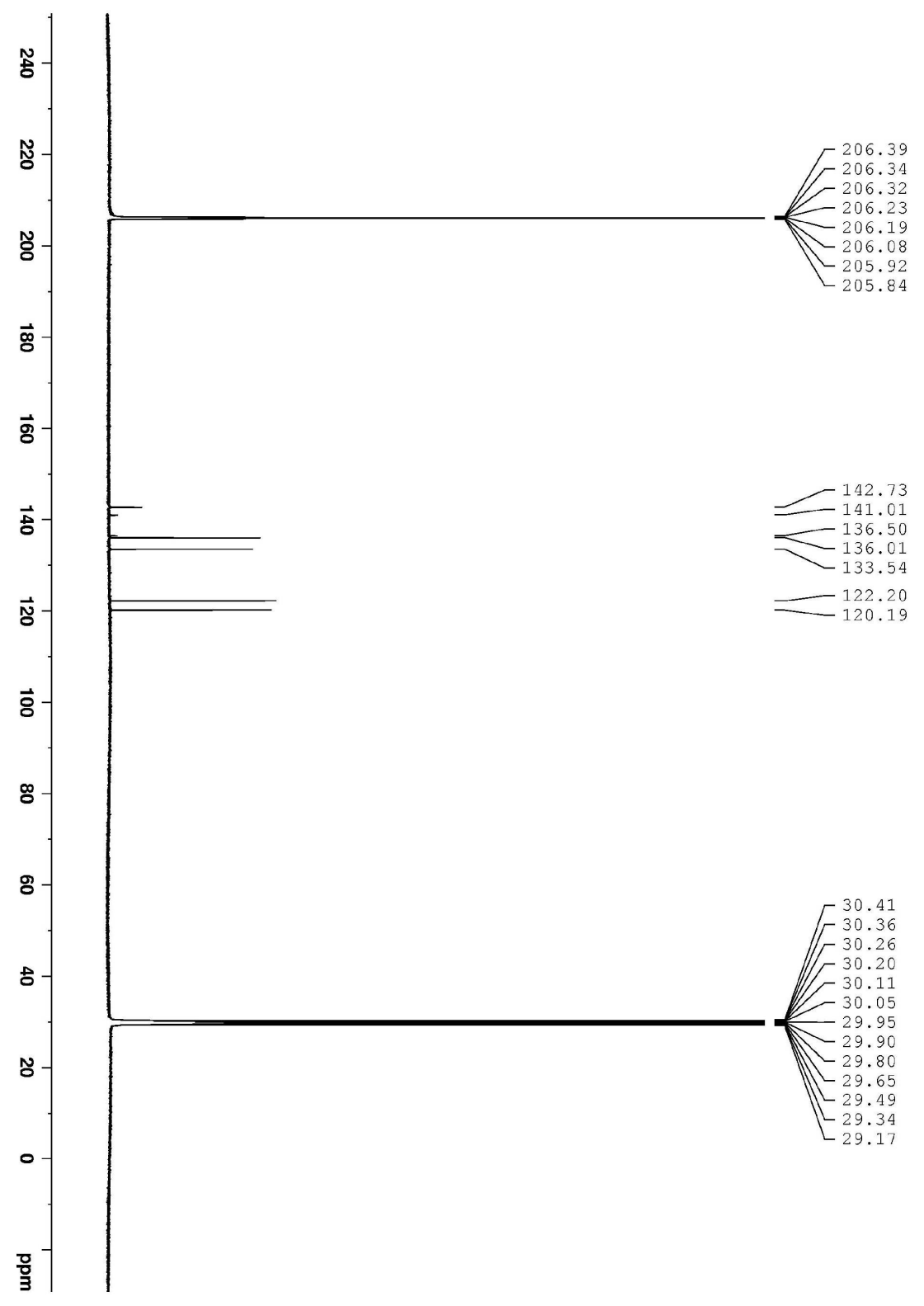

${ }^{13} \mathrm{C}$ NMR of $\mathbf{5 5}$ (Acetone, 125.77 MHz) 

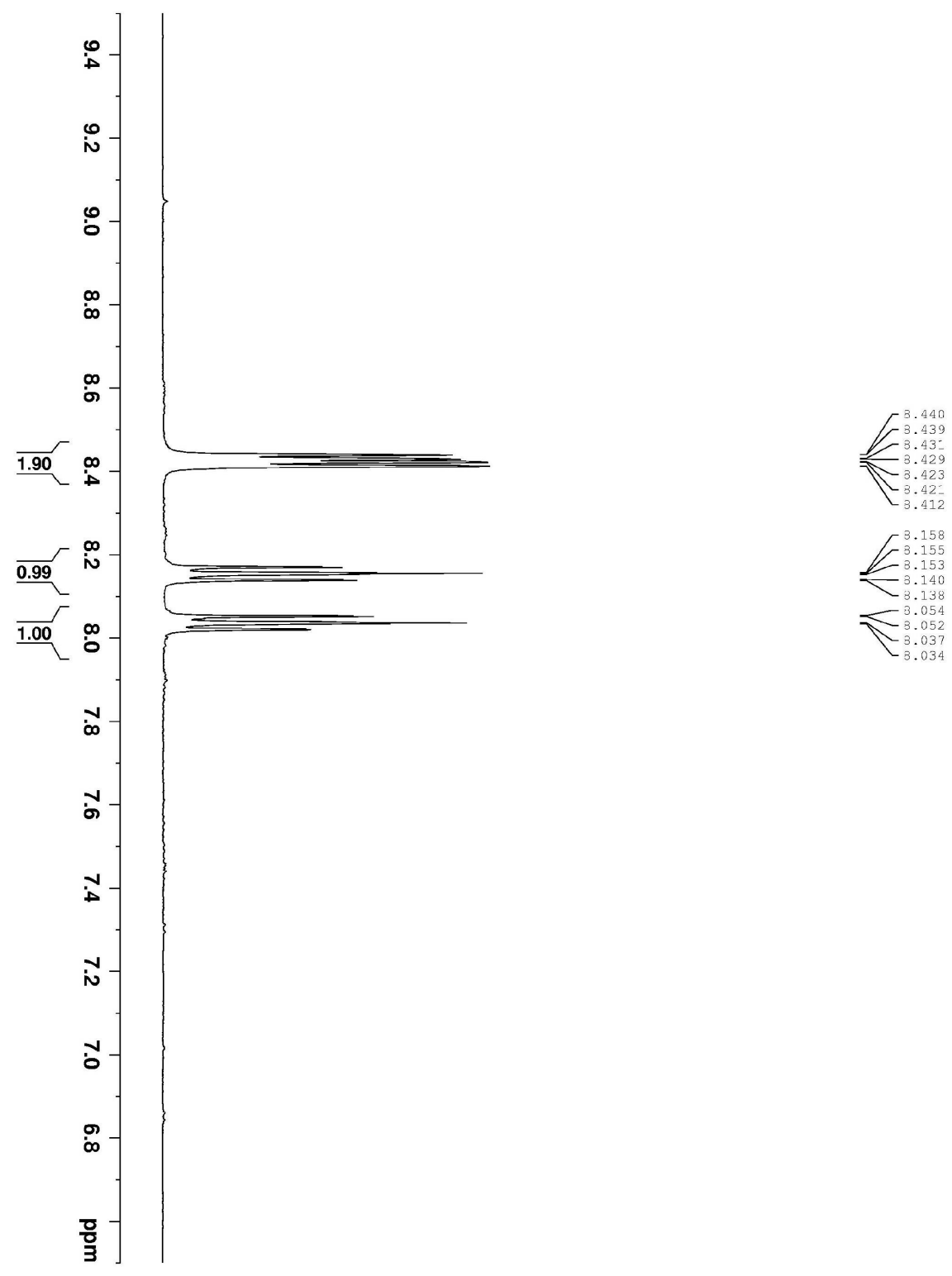

${ }^{1} \mathrm{H}$ NMR of 60 (Acetone, $500 \mathrm{MHz}$ ) 

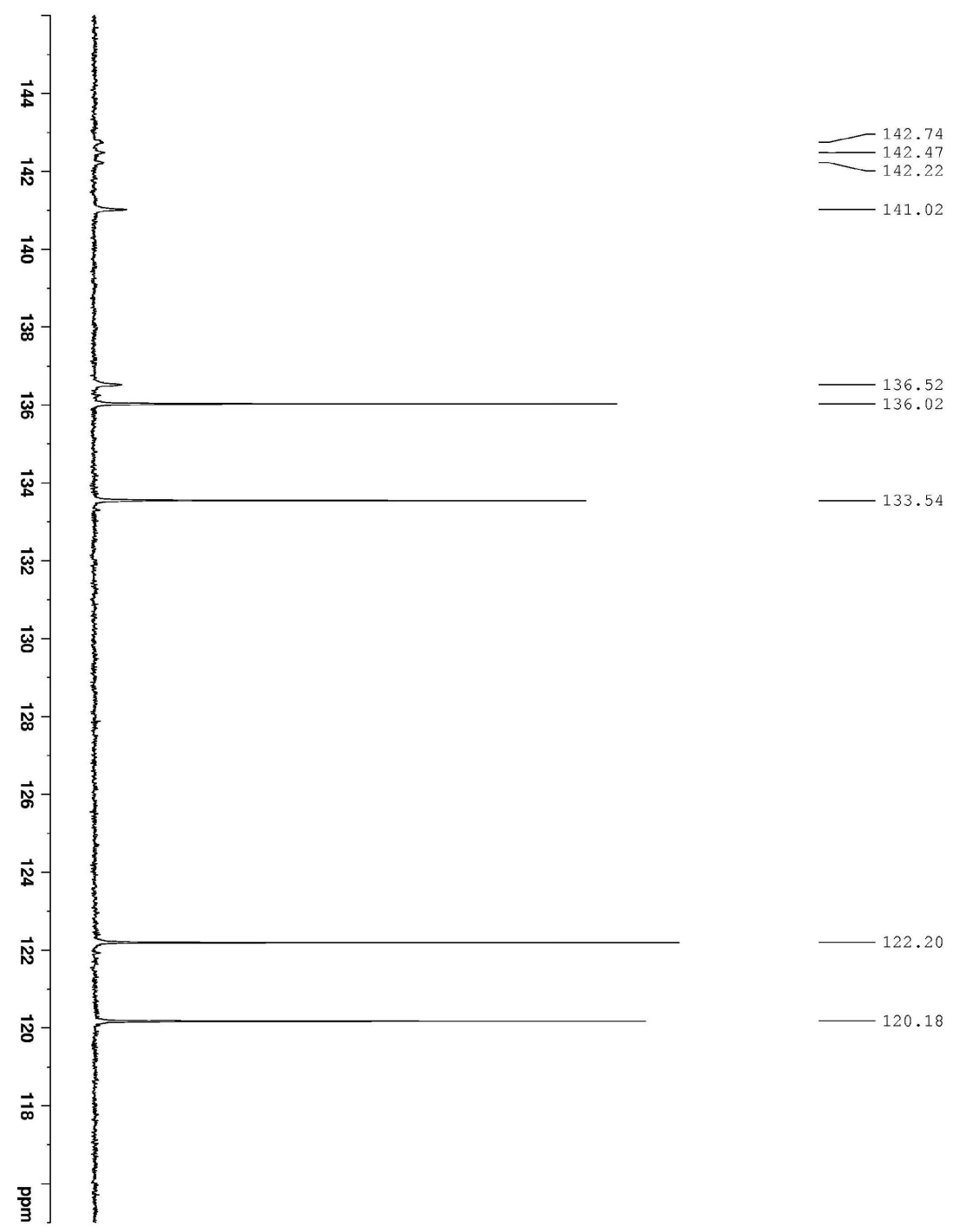

$-141.02$

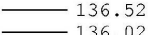

136.02

133.54

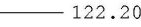

120.18

${ }^{13} \mathrm{C}$ NMR of $\mathbf{6 0}$ (Acetone, $125.77 \mathrm{MHz}$ ) 


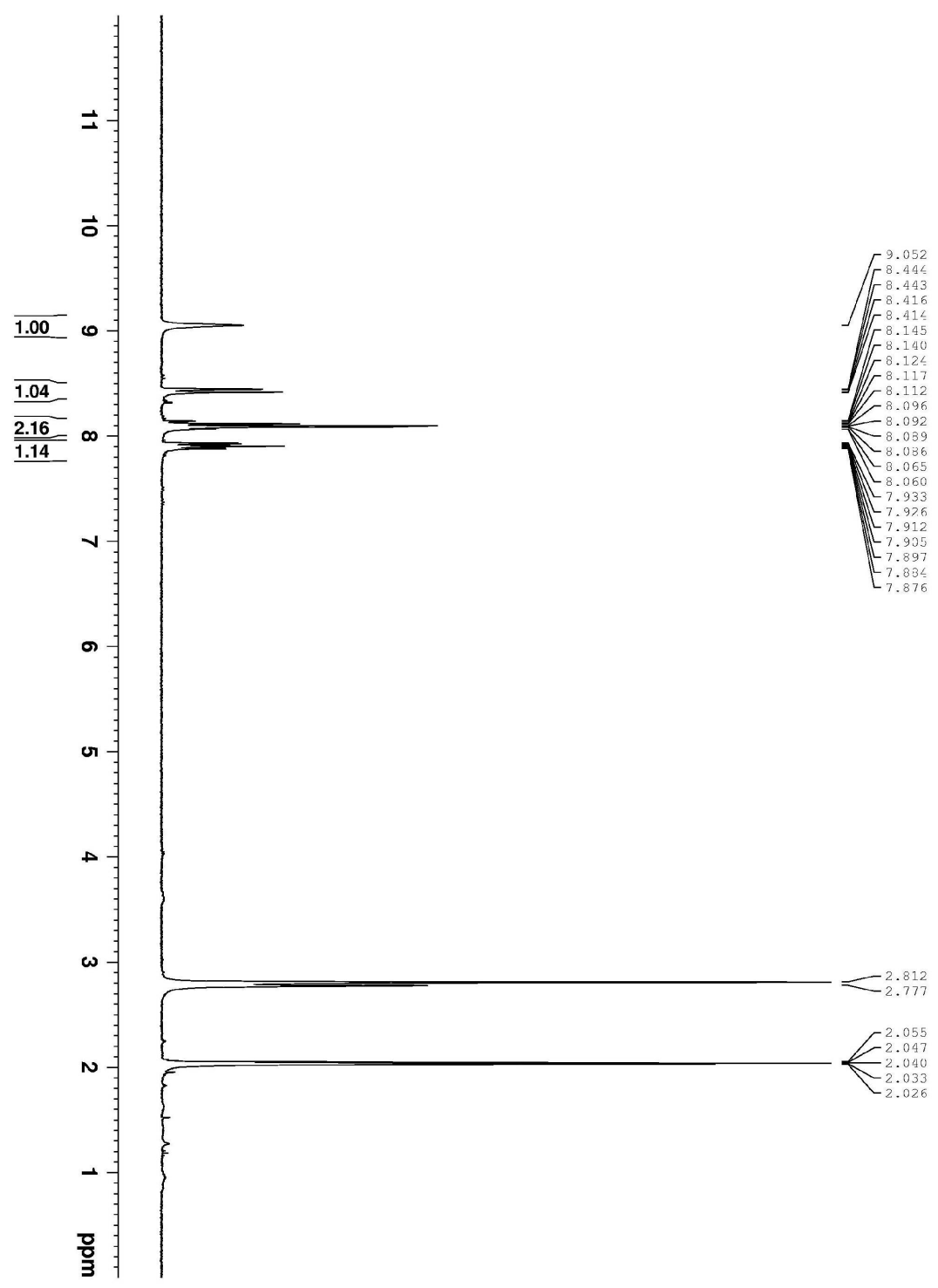

${ }^{1} \mathrm{H}$ NMR of $\mathbf{5 9}$ (Acetone, $300 \mathrm{MHz}$ ) 


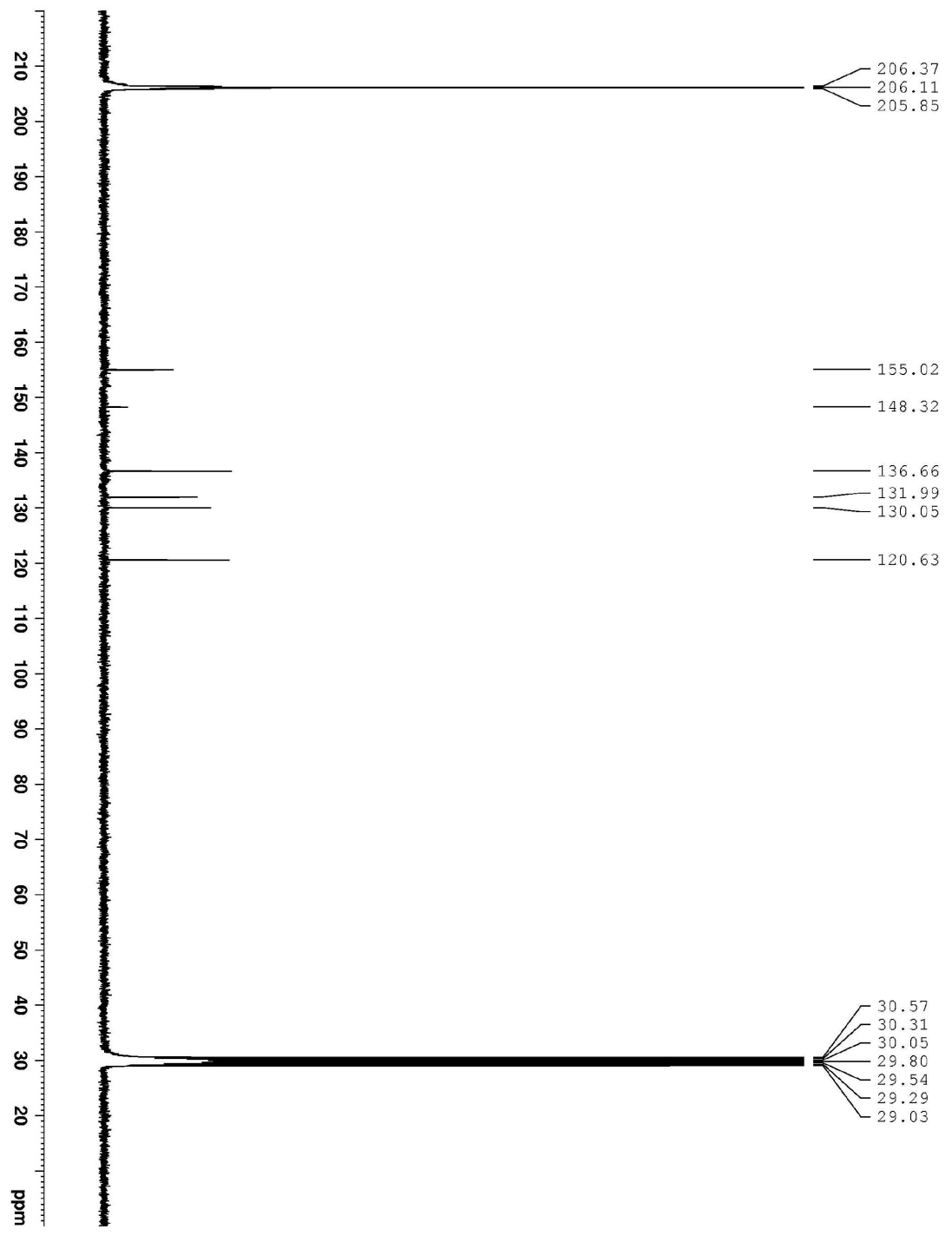

${ }^{13} \mathrm{C}$ NMR of $\mathbf{5 9}$ (Acetone, $75 \mathrm{MHz}$ ) 

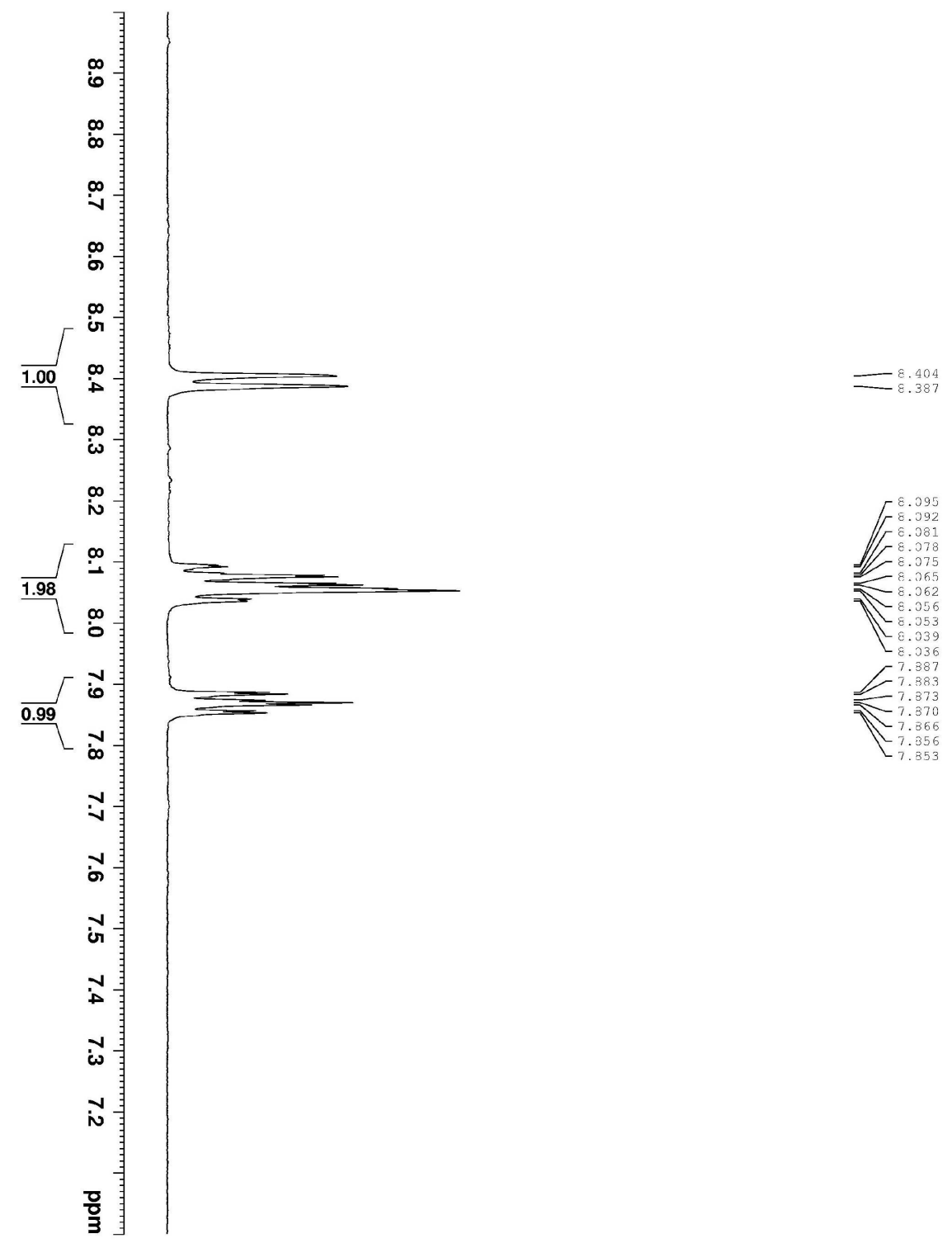

${ }^{1} \mathrm{H}$ NMR of 63 (Acetone, $500 \mathrm{MHz}$ ) 


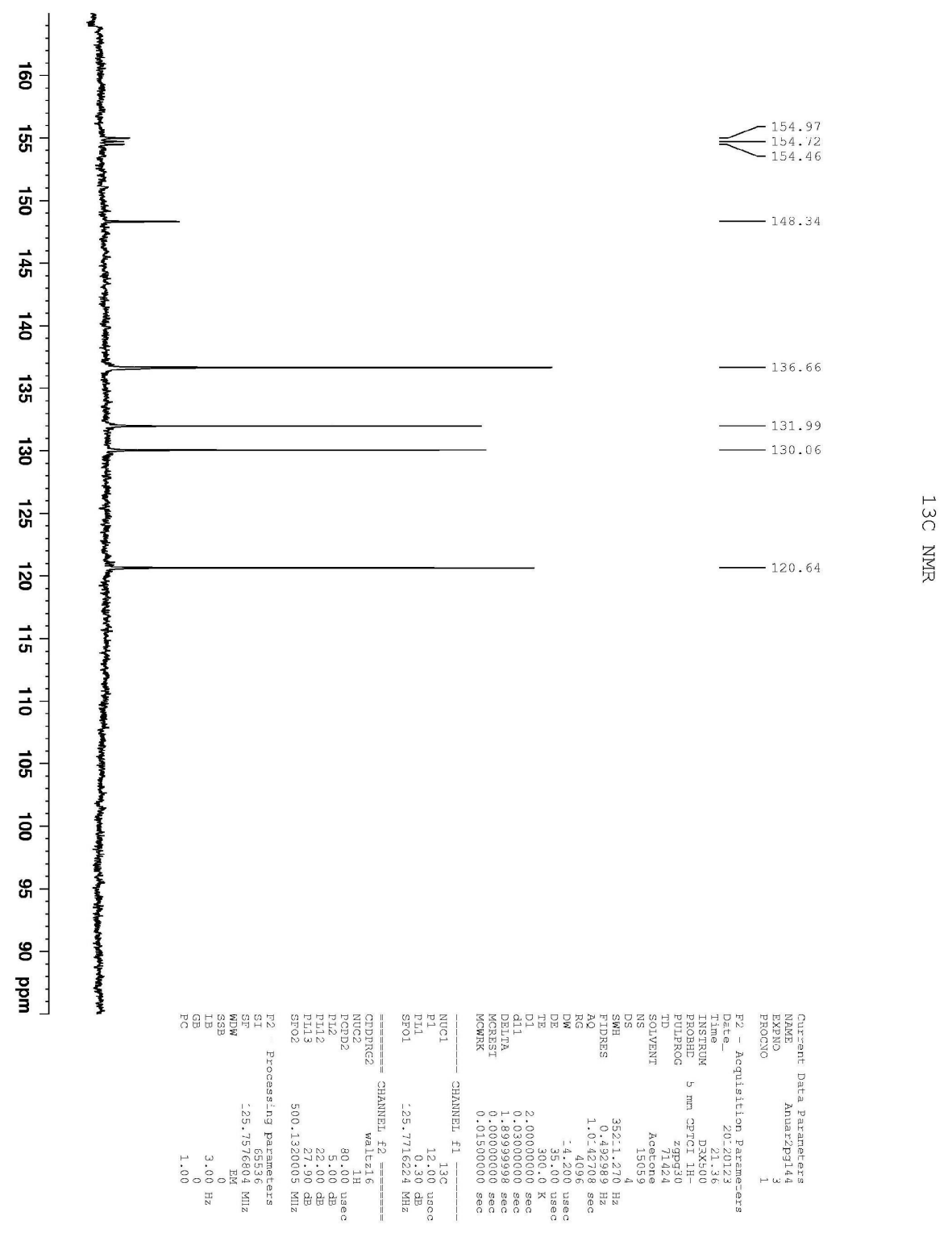

${ }^{13} \mathrm{C}$ NMR of 63 (Acetone, 125.77 MHz) 


\section{References for chapter 4}

1. (a) Gatineau, M.; Rixe, O.; Le, C. T., Tirapazamine with cisplatin and vinorelbine in patients with advanced non-small-cell lung cancer: A phase I/II study. Clin. Lung Cancer 2005, 6, 293-298; (b) Le, Q.-T. X.; Moon, J.; Redman, M.; Williamson, S. K.; Lara, P. N., Jr.; Goldberg, Z.; Gaspar, L. E.; Crowley, J. J.; Moore, D. F., Jr.; Gandara, D. R., Phase II study of tirapazamine cisplatin, and etoposide and concurrent thoracic radiotherapy for limited-stage small-cell lung cancer: SWOG 0222. J. Clin. Oncol. 2009, 27, 3014-3019; (c) Le, Q.-T.; Fisher, R.; Oliner, K. S.; Young, R. J.; Cao, H.; Kong, C.; Graves, E.; Hicks, R. J.; McArthur, G. A.; Peters, L.; O'Sullivan, B.; Giaccia, A.; Rischin, D., Prognostic and Predictive Significance of Plasma HGF and IL-8 in a Phase III Trial of Chemoradiation with or without Tirapazamine in Locoregionally Advanced Head and Neck Cancer. Clin. Cancer Res. 2012, 18, 1798-1807; (d) Rischin, D.; Peters, L. J.; O'Sullivan, B.; Giralt, J.; Fisher, R.; Yuen, K.; Trotti, A.; Bernier, J.; Bourhis, J.; Ringash, J.; Henke, M.; Kenny, L., Tirapazamine, cisplatin, and radiation versus cisplatin and radiation for advanced squamous cell carcinoma of the head and neck (TROG 02.02, HeadSTART): a phase III trial of the trans-tasman radiation oncology group. J. Clin. Oncol. 2010, 28 (18), 2989-2995.

2. (a) McKeown, S. R.; Cowen, R. L.; Williams, K. J., Bioreductive drugs: from concept to clinic. Clin Oncol (R Coll Radiol) 2007, 19, 427-42; (b) Sarkar, U.; Glaser, R.; Parsons, Z. D.; Barnes, C. L.; Gates, K. S., Synthesis, Crystal Structure, and Rotational Energy Profile of 3-Cyclopropyl-1,2,4-benzotriazine 1,4-Di-N-oxide. J. Chem. Crystallogr. 2010, 40, 624-629.

3. (a) Zeman, E. M.; Brown, J. M.; Lemmon, M. J.; Hirst, V. K.; Lee, W. W., SR4233: a new bioreductive agent with high selective toxicity for hypoxic mammalian cells. Int J Radiat Oncol Biol Phys 1986, 12, 1239-42; (b) Laderoute, K. L.; Wardman, P.; Rauth, M., Molecular mechanisms for the hypoxia-dependent activation of 3-amino1,2,4-benzotriazine 1,4-dioxide (SR4233). Biochem. Pharmacol. 1988, 37 (8), 14871495; (c) Tocher, J. H.; Virk, N. S.; Edwards, D. I., Electrochemical properties as a function of $\mathrm{pH}$ for benzotriazine di-N-oxides. Free Rad. Res. Commun. 1990, 10 (4-5), 295-302.

4. (a) Daniels, J. S.; Gates, K. S., DNA Cleavage by the Antitumor Agent 3-Amino1,2,4-benzotriazine 1,4-Dioxide (SR4233): Evidence for Involvement of Hydroxyl Radical. J. Am. Chem. Soc. 1996, 118 (14), 3380-3385; (b) Birincioglu, M.; Jaruga, P.; Chowdhury, G.; Rodriguez, H.; Dizdaroglu, M.; Gates, K. S., DNA Base Damage by the Antitumor Agent 3-Amino-1,2,4-benzotriazine 1,4-Dioxide (Tirapazamine). J. Am. Chem. Soc. 2003, 125 (38), 11607-11615. 
5. (a) Wardman, P.; Priyadarsini, K. I.; Dennis, M. F.; Everett, S. A.; Naylor, M. A.; Patel, K. B.; Stratford, I. J.; Stratford, M. R. L.; Tracy, M., Chemical properties which control selectivity and efficacy of aromatic N-oxide bioreductive drugs. Br. J. Cancer 1996, 74, S70-S74; (b) Biedermann, K. A.; Wang, J.; Graham, R. P., SR 4233 cytotoxicity and metabolism in DNA repair-competant and DNA repair-deficient cell lines. Br. J. Cancer 1991, 63, 358-362.

6. Tocher, J. H.; Edwards, D. I., Electrochemical studies of tirapazamine: generation of the one-electron reduction product. Free Radical Res. 1994, 21, 277-83.

7. Brown, J. M., SR 4233 (tirapazamine): a new anticancer drug exploiting hypoxia in solid tumors. Br. J. Cancer 1993, 67, 1163-70.

8. Butler, J.; Hoey, B. M., DNA and Free Radicals. In Redox cycling drugs and DNA damage, Halliwell, B.; Aruoma, O. I., Eds. Ellis Horwood: New York, NY, 1993; pp 243-273.

9. (a) Sies, H., Biochemistry of Oxidative Stress. Angew. Chem. Int. Ed. Eng. 1986, 25, 1058-1071; (b) Brown, J. M.; Wilson, W. R., Exploiting tumor hypoxia in cancer treatment. Nat. Rev. Cancer 2004, 4, 437-447; (c) Finkel, T.; Holbrook, N. J., Oxidants, oxidative stress and the biology of ageing. Nature 2000, 408 (Nov 9), 239-247; (d) Wood, Z. A.; Poole, L. B.; Karplus, P. A., Peroxiredoxin evolution and the regulation of hydrogen peroxide signaling. Science 2003, 300 (5619), 650-653.

10. Anderson, R. F.; Shinde, S. S.; Hay, M. P.; Gamage, S. A.; Denny, W. A., Activation of 3-Amino-1,2,4-benzotriazine 1,4-Dioxide Antitumor Agents to Oxidizing Species Following Their One-Electron Reduction. J. Am. Chem. Soc. 2003, 125, 748-756.

11. (a) Wang, J.; Biedermann, K. A.; Wolf, C. R.; Brown, J. M., Metabolism of the bioreductive cytotoxin SR 4233 by tumor cells: Enzymic studies. Br. J. Cancer 1993, 67, 321-5; (b) Siim, B. G.; Van, Z. P. L.; Brown, J. M., Tirapazamine-induced DNA damage measured using the comet assay correlates with cytotoxicity towards hypoxic tumor cells in vitro. Br. J. Cancer 1996, 73, 952-960; (c) Cahill, A.; White, I. N., Reductive metabolism of 3-amino-1,2,4-benzotriazine-1,4-dioxide (SR 4233) and the induction of unscheduled DNA synthesis in rat and human derived cell lines. Carcinogenesis 1990, $11,1407-11$.

12. Baker, M. A.; Zeman, E. M.; Hirst, V. K.; Brown, J. M., Metabolism of SR 4233 by Chinese hamster ovary cells: basis of selective hypoxic cytotoxicity. Cancer Res. 1988, 48, 5947-52. 
13. (a) Fitzsimmons, S. A.; Lewis, A. D.; Riley, R. J.; Workman, P., Reduction of 3amino-1,2,4-benzotriazine-1,4,-di-N-oxide to a DNA-damaging species: a direct role for NADPH:cytochrome P450 oxidoreductase. Carcinogenesis 1994, 15 (8), 1503-1510; (b) Jones, G. D. D.; Weinfeld, M., Dual action of tirapazamine in the induction of DNA strand breaks. Cancer Res. 1996, 56, 1584-1590.

14. (a) Shinde, S. S.; Hay, M. P.; Patterson, A. V.; Denny, W. A.; Anderson, R. F., Spin trapping of radicals other than the hydroxyl radical upon reduction of the anticancer agent tirapazamine by cytochrome P450 reductase. J. Am. Chem. Soc. 2009, 131 (40), 14220-14221; (b) Shinde, S. S.; Maroz, A.; Hay, M. P.; Patterson, A. V.; Denny, W. A.; Anderson, R. F., Characterization of Radicals Formed Following Enzymatic Reduction of 3-Substituted Analogues of the Hypoxia-Selective Cytotoxin 3-Amino-1,2,4Benzotriazine 1,4-Dioxide (Tirapazamine). J. Am. Chem. Soc. 2010, 132 (8), 2591-2599; (c) Junnotula, V.; Sarkar, U.; Sinha, S.; Gates, K. S., Initiation of DNA strand cleavage by 1,2,4-benzotriazine 1,4-dioxides: mechanistic insight from studies of 3-methyl-1,2,4benzotriazine 1,4-dioxide. J. Am. Chem. Soc. 2009, 131, 1015-1024.

15. Chowdhury, G.; Junnutula, V.; Daniels, J. S.; Greenberg, M. M.; Gates, K. S., DNA strand damage analysis provides evidence that the tumor cell-specific cytotoxin tirapazamine produces hydroxyl radical and acts as a surrogate for $\mathrm{O}_{2}$. J. Am. Chem. Soc. 2007, 129, 12870-12877.

16. (a) Barton, D. H. R.; Crich, D.; Motherwell, W. B., The invention of new radical chain reactions. Part VIII. Radical chemistry of thiohydroxamic esters; a new method for the generation of carbon radicals from carboxylic acids. Tetrahedron 1985, 41 (19), 3901-3924; (b) Barton, D. H. R.; Jasberenyi, J. C.; Morrell, A. I., pyridinethione generation of hydroxyl radical. Tetrahedron Lett. 1991, 32, 311-314; (c) Adam, W.; Ballmaier, D.; Epe, B.; Grimm, G. N.; Saha-Moller, C. R., N-Hydroxypyridinethiones as photochemical hydroxyl radical sources for oxidative DNA damage. Angew. Chem. Int. Ed. Eng. 1995, 34 (19), 2156-2158.

17. (a) Wölfle, I.; Lodays, J.; Sauerwein, B.; Schuster, G. B., Photoinduced electron transfer reactions: Nitrogen-oxygen bond cleavage in reduced N-(aryloxy)pyridinium and N,N'-dialkoxy-4,4'-bipyridinium salts. J. Am. Chem. Soc. 1992, 114, 9304-9309; (b) Aveline, B. M.; Kochevar, I. E.; Redmond, R. W., N-Hydroxypyridine-2(1H)-thione: Not a selective generator of hydroxyl radicals in aqueous solution. J. Am. Chem. Soc. 1996, $118,289-290$.

18. Shinde, S. S.; Anderson, R. F.; Hay, M. P.; Gamage, S. A.; Denny, W. A., Oxidation of 2-Deoxyribose by Benzotriazinyl Radicals of Antitumor 3-Amino-1,2,4benzotriazine 1,4-Dioxides. J. Am. Chem. Soc. 2004, 126 (25), 7865-7874. 
19. Christensen, H. C.; Sehested, K.; Hart, E. J., Formation of benzyl radicals by pulse radiolysis of toluene in aqueous solutions. J. Phys. Chem. 1973, 77 (8), 983-987.

20. (a) Fuchs, T. E. Bioorganic chemistry of DNA-damaging heterocyclic n-oxides. 2003; (b) Junnotula, V. Chemical mechanisms underlying the medicinal activity of metabolically-activated N-oxide antitumor agents. 2008.

21. (a) Kelson, A. B.; McNamara, J. P.; Pandey, A.; Ryan, K. J.; Dorie, M. J.; McAfee, P. A.; Menke, D. R.; Brown, J. M.; Tracy, M., 1,2,4-Benzotriazine 1,4-dioxides. An important class of hypoxic cytotoxins with antitumor activity. Anticancer Drug Des 1998, 13, 575-92; (b) Zeman, E. M.; Baker, M. A.; Lemmon, M. J.; Pearson, C. I.; Adams, J. A.; Brown, J. M.; Lee, W. W.; Tracy, M., Structure-activity relationships for benzotriazine di-N-oxides. Int. J. Radiat. Oncol., Biol., Phys. 1989, 16, 977-81.

22. Shinde, S. S.; Hay, M. P.; Patterson, A. V.; Denny, W. A.; Anderson, R. F., Spin Trapping of Radicals Other Than the B7OH Radical upon Reduction of the Anticancer Agent Tirapazamine by Cytochrome P450 Reductase. J. Am. Chem. Soc. 2009, 131, 14220-14221.

23. (a) Mitra, K.; Kim, W.; Daniels, J. S.; Gates, K. S., Oxidative DNA cleavage by the antitumor antibiotic leinamycin and simple 1,2-dithiolan-3-one 1-oxides: Evidence for thiol-dependent conversion of molecular oxygen to DNA-cleaving oxygen radicals mediated by polysulfides. J. Am. Chem. Soc. 1997, 119, 11691-11692; (b) Ganley, B.; Chowdhury, G.; Bhansali, J.; Daniels, J. S.; Gates, K. S., Redox-activated, hypoxiaselective DNA cleavage by quinoxaline 1,4-di-N-oxide. Bioorg. Med. Chem. 2001, 9, 2395-2401.

24. Hertzberg, R. P.; Dervan, P. B., Cleavage of DNA with methidiumpropyl-EDTAIron(II): Reaction conditions and product analyses. Biochemistry 1984, 23, 3934-3945.

25. (a) Chowdhury, G.; Kotandeniya, D.; Barnes, C. L.; Gates, K. S., Enzymeactivated, hypoxia-selective DNA damage by 3-amino-2-quinoxalinecarbonitrile 1,4-diN-oxide. Chem. Res. Toxicol. 2004, 17 (11), 1399-1405; (b) Junnotula, V.; Rajapakse, A.; Abrillaga, L.; Lopez de Cerain, A.; Solano, B.; Villar, R.; Monge, A.; Gates, K. S., DNA strand cleaving properties and hypoxia-selective cytotoxicity of 7-chloro-2thienylcarbonyl-3-trifluoromethylquinoxaline 1,4-dioxide. Bioorg. Med. Chem. 2010, 18, 3125-3132. 
26. Laderoute, K.; Rauth, A. M., Identification of two major reduction products of the hypoxic cell toxin 3-amino-1,2,4-benzotriazine-1,4-dioxide. Biochem. Pharmacol. 1986, $35,3417-3420$.

27. Sambrook, J.; Fritsch, E. F.; Maniatis, T., Molecular Cloning: A Lab Manual. Cold Spring Harbor Press: Cold Spring Harbor, NY, 1989.

28. Daniels, J. S.; Gates, K. S.; Tronche, C.; Greenberg, M. M., Direct evidence for bimodal DNA damage induced by tirapazamine. Chem. Res. Toxicol. 1998, 11 (11), 1254-1257. 


\section{Chapter 5}

\section{Synthesis of bioreductivly activated nitroaromatic triggers}

\subsection{Qualitative and quantitative determination of hypoxia}

Chapters 1, 2 and 3 described the importance of hypoxia or low oxygen concentration to tumor physiology and tumor therapy. Detection and quantification of oxygen levels is immerging as an important tool in the treatment of tumors. ${ }^{1}$ Various methods of characterization for tumor hypoxia have been introduced to the research community. ${ }^{2}$ As discussed in previous chapters, there is a demand for suitable fluorescent probes to detect hypoxia. ${ }^{3}$ A complete description of small molecule fluorescent probe, which can detect hypoxia, was included in chapters 2 and 3. In a similar approach, a compound which can undergo hypoxia selective enzymatic bioreduction and maintain oxygen sensitive reduction may be coupled to a fluorophore, to construct fluorescent probes to detect hypoxia. ${ }^{4}$ Nitroaromatic compounds such as para nitrobenzyl, 2nitroimidazole and 5-nitrothienyl groups and tirapazamine might be used as a bioreductive aromatic compound which can undergo oxygen-sensitive reduction and release the fluorescent molecule (Scheme 5.1).<smiles>[R]OCc1ccc([N+](=O)[O-])cc1</smiles>

paranitrobenzyl<smiles>[R]OCc1cnc([N+](=O)[O-])n1C</smiles>

2-nitroimidazole<smiles>[R]OCc1ccc([N+](=O)[O-])s1</smiles>

5-nitrothienyl<smiles>Nc1n[n+]([O-])c2ccccc2[n+]1[O-]</smiles>

TPZ $\mathrm{O}^{-}$

$\mathrm{R}=$ Bioactive compound

Scheme 5.1. Bioreducible moieties can be used as oxygen sensors 


\subsection{Goal: Constructing suitable nitroaromatic fluorescent probe for hypoxia}

Current research on bio-reductive pro-drugs suggests that oxygen sensitive bioreducible species such as nitro-benzyl, 2-nitroimidazole and 5-nitrothienyl groups, when appended to cytotoxic agents to mask the drug activity, show encouraging selective drug delivery toward low oxygenated tumors. In order to test the performance of nitro-phenyl group as an oxygen sensor, Borche and coworkers attached phosphoramidite toxin to produce series of prodrugs (Scheme 5.2). ${ }^{5}$ Following the same design strategy, fluorophores can be attached to nitroaromatic groups using suitable coupling reactions.

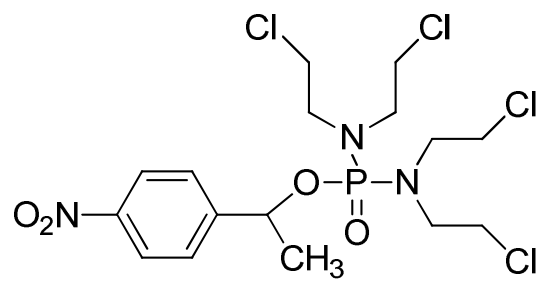

26

Scheme 5.2. Nitrophenyl benzyl phosphoramadite prodrugs

The in vitro cytotoxicity studies with $\mathbf{2 6}$ suggest that nitrophenyl may be a suitable bioreducible moiety which can be reduced enzymatically in hypoxia. The reduction process produces electron rich hydroxylamine or amine compounds which can ultimately release the active compound and imine methide upon 1-6 elimination (Scheme $5.3)$.

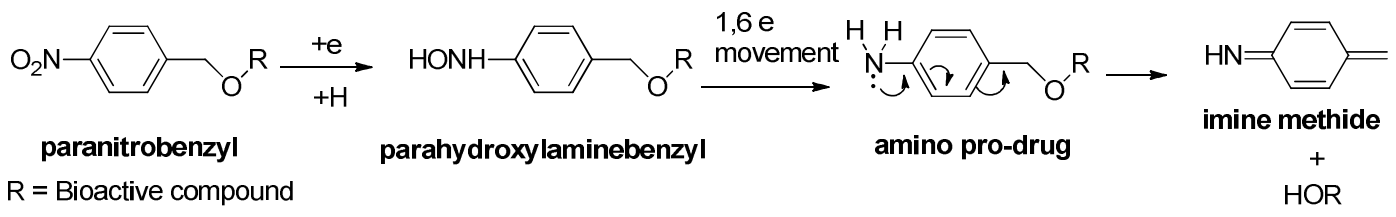

Scheme 5.3. 1,6-elimination of active drug species 
Such a prodrug, with a flourophore, was made using nitrophenyl benzyl bromide 68, over a nucleophilic displacement reaction with 7-hydroxyl-4-methyl coumarine 69, a known fluorophore which possess a better stokes shift and quantum yield, to produce nitrophenyl-coumarin compound $\mathbf{7 0}$ (Scheme 5.3). ${ }^{6}$

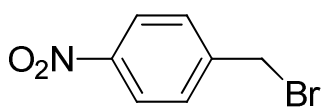

68<smiles>Cc1cc(=O)oc2cc(O)ccc12</smiles>

69

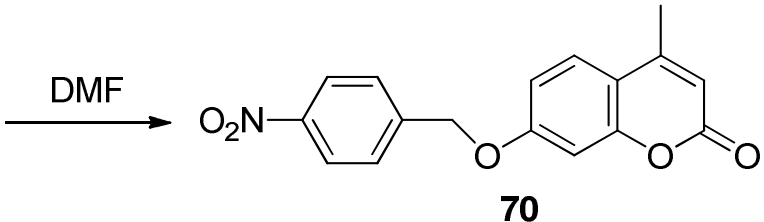

70

Scheme 5.4. Synthesis of 70

Bioreductive in vitro assays were carried out using 70, with NADPH:cytochrome p450 reductase;NADPH and xanthine:xanthine oxidase reducing systems. The poor release of 69 is comparable to low amount of release of thiopurine, which was attached to nitrobenzyl in the pro-drug form. ${ }^{7}$ While concluding that nitrophenyl group is not compatible for enzymatic reducing systems NADPH:cytochrome p450 reductase;NADPH and xanthine:xanthine oxidase, however we set out to construct other nitroaromatic bioreducible groups 5-nitrothienyl and 2-nitroimidazole.

\subsection{Synthesis of 5-nitrothienyl moiety, 2-(5-Nitrothien-2-yl) propan-2-ol (73)}

Nitrothiephenes are bioreducible nitroaromatic group, which can be reduced by cellular reductases under low oxygen levels. ${ }^{8}$ In addition, methyl groups on the benzylic carbon facilitates effective drug release from the probe. ${ }^{9}$ Hence, Nitrothienyl 2-(5Nitrothien-2-yl) propan-2-ol 73 was prepared as a nitroaromatic trigger candidate. Methyl magnesium bromide was added to 2-acetylthiophene $\mathbf{7 1}$, in ethyl ether to afford thiophene alcohol 72. Compound 72 was separated by column chromatography. Nitration 
on the 5 carbon of $\mathbf{7 2}$ was done using acetic anhydride: Nitric acid nitration mixture. To a cold solution of $\mathbf{7 2}$ in acetic anhydride, fuming nitric acid was added while mixing at $70^{0} \mathrm{C} .{ }^{10}$ Upon neutralizing, using sodium bicarbonate, the product 2-(5-nitrothien-2-yl) propan-2-ol (73) was separated and purified using column chromatography (Scheme 5.5).

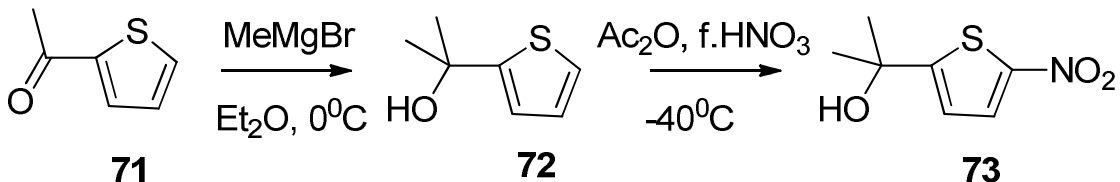

Scheme 5.5. Synthesis of 2-(5-nitrothien-2-yl) propan-2-ol 73

\subsection{Synthesis of 1-methyl-2-nitro-5-hydroxymethyl imidazole 79}

The compound 2-nitro-1-methyl imidazole group has been used as a component of bioreductive prodrugs. ${ }^{2 a}$, 4a, 11 The amino compound 1-methyl-2-amino-imidazole may be used as the starting compound to reach the desired nitro imidazole group. In the synthesis, published by Bellani and Lancini was modified in the preparation of 1-methyl2-amino-5-carbethoxyimidazole $76 .{ }^{12}$ Briefly, Ethyl formate was added to ethyl sarcocine ester (74) powder and the mixture was cooled below $0^{0} \mathrm{C}$. Then $\mathrm{NaH}$ was added gradually and stirred for 14 hrs. Then, trituration using hexane produced a thick liquid and was separated from hexane. The residue was mixed with ethanol and $\mathrm{HCl}$, followed by heating at $100^{\circ} \mathrm{C}$ with vigorous stirring for $1 \mathrm{hr}$. Then the reaction was cooled and added with cyanamide, $10 \%$ acetic acid and sodium acetate and heated at $90^{\circ} \mathrm{C}$ for $90 \mathrm{~min}$. Then the reaction was cooled and the $\mathrm{pH}$ adjusted to 1 using $\mathrm{HCl}$. The solvent was removed by rotary evaporation below $45^{\circ} \mathrm{C}$ until the volume had reduced to one fifth of the initial volume. Then the $\mathrm{pH}$ was raised to $8-9$ using $\mathrm{KHCO}_{3}$. Ethyl acetate was used to separate 
organic layer and the extract was dried with $\mathrm{MgSO}_{4}$. Compound 76 was isolated by column chromatography (Scheme 5.5).

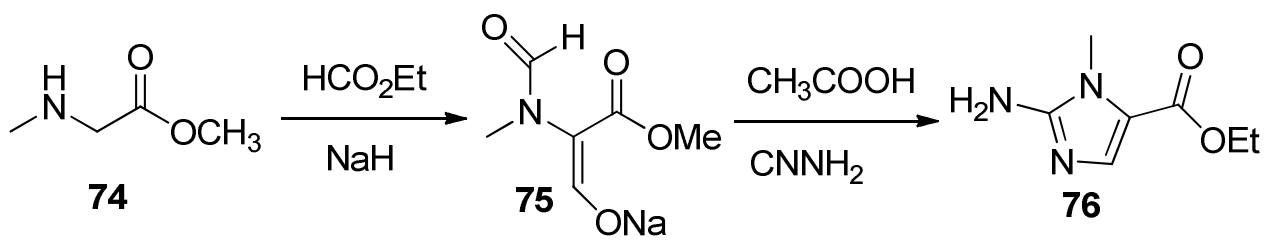

Scheme 5.6. Synthesis of $\mathbf{7 6}$ from sarcocine ethyl ester $\mathbf{7 4}$

The nitration of $\mathbf{7 6}$ afforded the nitro imidazole compound 1-methyl-2-nitro-5carbethoxyimidazole $\mathbf{7 7}$. In the synthesis, the compound $\mathbf{7 9}$ was added to acetic acid and the acetic acid/79 mixture was added to a sodium nitrite solution, which is at $0^{0} \mathrm{C}$, drop wise while stirring. Overnight stirring at room temperature was followed by extraction of the organic material into methylene chloride. The methylene chloride layer was dried over $\mathrm{MgSO}_{4}$. Compound 77 was separated using column chromatography. ${ }^{13}$ The ester bond of 77 was hydrolyzed using $1 \mathrm{~N} \mathrm{NaOH}$ to obtain 78. The carboxylic group of $\mathbf{7 8}$ was reduced using $\mathrm{NaBH}_{3}$ and isoformyl chloroformate. ${ }^{14}$ The resulting solution was extracted with THF and the dry organic material was column chromatographed to obtain 79 (Scheme 5.7).

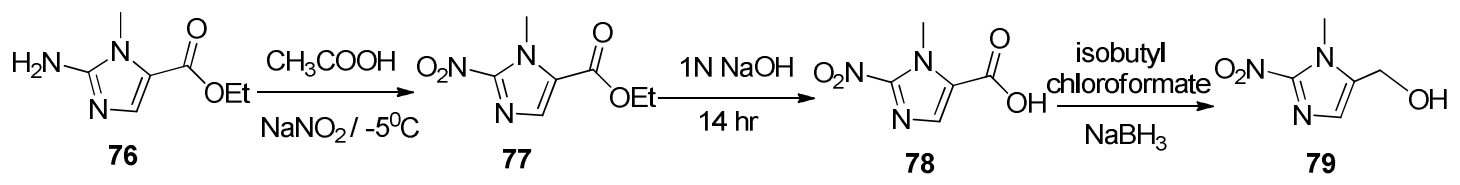

Scheme 5.7. Synthesis of 1-methyl-2-nitro-5-hydroxymethyl imidazole 79 


\subsection{Synthesis of 80 and 81}

Prodrugs 80 and $\mathbf{8 1}$ may be made employing Mitsonobu coupling reactions. The nitroaromatics 73 and 79 were reacted with the coumarin fluorophore 69 under Mitsonobu conditions. The attempts to make compounds $\mathbf{8 0}$ and $\mathbf{8 1}$ were not successful (Scheme 5.8).<smiles>Cc1cc(=O)oc2cc(OCc3cnc([N+](=O)[O-])n3C)ccc12</smiles><smiles>Cc1cc(=O)oc2cc(OC(C)(Br)c3ccc([N+](=O)[O-])s3)ccc12</smiles>

Scheme 5.8. Fluorescent probes 83 and 84 .

\subsection{Synthesis of 3-acetylquinoline-1,2,4-benzotraizine 1,4-dioxide 84}

In an separate effort to prepare a probe for hypoxia was done by coupling 3amino-1,2,4-benzotraizine 1,4-dioxide (TPZ), 33 with 6-aminoquinoline 43 , a known fluorophore. TPZ was reacted with triphosgene $\mathbf{8 2}$ to produce intermediate $\mathbf{8 3}$ and then, 43 was added in situ to obtain 84 (Scheme 5.9). ${ }^{15}$<smiles></smiles>

Scheme 5.9. Synthesis of 84 using triphosgene 82,33 and 43 


\subsection{Experimental}

\subsubsection{Synthesis of paranitrophenyl-4-methyl-coumarin ether (70)}

To a slurry of $\mathrm{NaH}(148 \mathrm{mg}, 6.16 \mathrm{mmol})$ in dry DMF $(10 \mathrm{~mL})$, at $0^{0} \mathrm{C}$ was added with 69 (542.6 mg, $3.08 \mathrm{mmol})$, in dry DMF. Then 68 (1000 mg, $4.6 \mathrm{mmol}$ ) was added to the mixture and was stirred at $0^{0} \mathrm{C}$ for $12 \mathrm{~h}$. Upon disappearance of 69 on TLC, the mixture was extracted to EtOAc, dried with brine and column chromatographed to obtain the ether $70\left(214 \mathrm{mg}, \mathrm{R}_{\mathrm{f}}\right.$ value $=0.5$ in $50 \%$ hexane in EtOAc $) .{ }^{1} \mathrm{H} \mathrm{NMR}\left(\mathrm{CDCl}_{3}, 500\right.$ $\mathrm{MHz}): \delta \operatorname{ppm} 8.27(\mathrm{~d}, \mathrm{~J}=8.5 \mathrm{~Hz}, 2 \mathrm{H}), 7.62(\mathrm{~d}, \mathrm{~J}=8.5 \mathrm{~Hz}, 2 \mathrm{H}), 7.53(\mathrm{~d}, \mathrm{~J}=8.5 \mathrm{~Hz}, 1 \mathrm{H})$ $6.94(\mathrm{~d}, \mathrm{~J}=8.5 \mathrm{~Hz}, 1 \mathrm{H}), 6.87(\mathrm{~s}, 1 \mathrm{H}), 6.16(\mathrm{~s}, 1 \mathrm{H}), 5.24(\mathrm{~s}, 1 \mathrm{H}), 2.40(\mathrm{~s}, 1 \mathrm{H}) .{ }^{13} \mathrm{C} \mathrm{NMR}$ $\left(\mathrm{CDCl}_{3}, 125.5 \mathrm{MHz}\right): \delta 160.9,155.2,152.3,143.1,127.7,125.8,123.9,114.3,112.7$ 112.5, 101.9, 69.0, 18.7. LRMS (ESI, $[\mathrm{M}+\mathrm{H}]^{+}$) $\mathrm{m} / \mathrm{z}$ calcd for $\mathrm{C}_{17} \mathrm{H}_{14} \mathrm{~N}_{1} \mathrm{O}_{5} 312.09$ calculated, found 311.95 .

\subsubsection{Synthesis of 2-thien-2-yl-propan-2-ol (72)}

Compound 71, 2-acetylthiophene (18 mL, $143 \mathrm{mmol})$ was dissolved in $300 \mathrm{~mL}$ $\mathrm{Et}_{2} \mathrm{O}$ at $0^{0} \mathrm{C}$ and stirred. Then nitrogen was purged. Methyl magnesium bromide $(65 \mathrm{~mL}$ from $3 \mathrm{M}$ in $\mathrm{Et}_{2} \mathrm{O}$ solution) was added via a syringe. Then the reaction mixture was stirred at room temperature for $4 \mathrm{hr}$. The reaction mixture was extracted into $\mathrm{CH}_{2} \mathrm{Cl}_{2}$ and dried with brine and $\mathrm{MgSO}_{4}$. Column chromatography afforded 72 (4.39 $\mathrm{g}, \mathrm{R}_{\mathrm{f}}$ value $=0.4$ in 100\% $\left.\mathrm{CH}_{2} \mathrm{Cl}_{2}\right) .{ }^{1} \mathrm{H} \mathrm{NMR}\left(\mathrm{CDCl}_{3}, 300 \mathrm{MHz}\right): \delta \mathrm{ppm} 7.17(\mathrm{~d}, \mathrm{~J}=4.5 \mathrm{~Hz}, 1 \mathrm{H}), 6.93(\mathrm{~m}$, 2H), $1.66(\mathrm{~m}, 6 \mathrm{H}) .{ }^{13} \mathrm{C} \mathrm{NMR}\left(\mathrm{CDCl}_{3}, 75.5 \mathrm{MHz}\right): \delta 154.7,126.9,124.1,122.3,71.6,32.5$. HRMS (ESI, $[\mathrm{M}+\mathrm{H}]^{+}$) m/z calcd for $\mathrm{C}_{7} \mathrm{H}_{10} \mathrm{OS} 142.0445$ calculated, found 142.0452 . 


\subsubsection{Synthesis of 2-Thien-2-yl-Propan-2-ol (73)}

The thienyl alcohol 2-thien-2-yl-Propan-2-ol 72 (2 g, $10.6 \mathrm{mmol})$ was dissolved in $30 \mathrm{~mL}$ acetic acid and cooled to $-70^{\circ} \mathrm{C}$ using $\mathrm{MeOH}$ dry ice slurry. While stirring, fuming $\mathrm{HNO}_{3}(0.7 \mathrm{~mL}, 11.6 \mathrm{mmol})$ was gradually added with vigourous stirring and reaction was run for $2 \mathrm{hr}$. Then another hour stirring was done at $-40^{\circ} \mathrm{C}$. Temperature was raised to $0^{\circ} \mathrm{C}$ and stirred for another $1 \mathrm{hr}$. Then water/ice $200 \mathrm{~g}$ was added and EtOAc $(100 \mathrm{~mL})$ was used to extract organic material. The EtOAc layer was dried using $\mathrm{Na}_{2} \mathrm{SO}_{4}$. Column chromatography performed to separate $73\left(310 \mathrm{mg}, \mathrm{R}_{\mathrm{f}}\right.$ value $=0.2$ with $20 \%$ EtOAc in hexane $){ }^{1} \mathrm{H}$ NMR $\left(\mathrm{CDCl}_{3}, 300 \mathrm{MHz}\right): \delta \mathrm{ppm} 7.78(\mathrm{~d}, \mathrm{~J}=4.5 \mathrm{~Hz}, 1 \mathrm{H}), 6.86(\mathrm{~d}, \mathrm{~J}$ $=4.5 \mathrm{~Hz}, 1 \mathrm{H}), 1.66(\mathrm{~m}, 6 \mathrm{H}) .{ }^{13} \mathrm{C} \mathrm{NMR}\left(\mathrm{CDCl}_{3}, 75.5 \mathrm{MHz}\right): \delta 163.6,128.8,121.2,71.8$, 31.9. HRMS (ESI, $[\mathrm{M}+\mathrm{H}]^{+}$) $\mathrm{m} / \mathrm{z}$ calcd for $\mathrm{C}_{7} \mathrm{H}_{9} \mathrm{O}_{3} \mathrm{NS} 187.0303$ calculated, found 187.0299.

\subsubsection{Synthesis of 1-methyl-2-amino-5-carbethoxyimidazole (76)}

Ethyl formate $(62.5 \mathrm{~mL})$ was added to sarcosine methylester hydrochloride 74 (10 $\mathrm{g}, 71 \mathrm{mmol})$ in a $500 \mathrm{~mL}$ r.b. and chilled at $0^{0} \mathrm{C}$. Sodium hydride $(60 \%$ oil suspension, $6.58 \mathrm{~g}, 0.1645 \mathrm{mmol}$ ) was added slowly over $2 \mathrm{~h}$ and stirred for $14 \mathrm{~h}$ to produce $75 .^{12 \mathrm{a}}$ Then, trituration was done twice using $50 \mathrm{ml}$ of hexane to obtain light brown slurry. The brown slurry was added to a new $500 \mathrm{~mL}$ r.b. and added with $50 \mathrm{~mL}$ EtOH and $8 \mathrm{~mL}$ of conc. $\mathrm{HCl}$. The mixture was stirred at $90^{\circ} \mathrm{C}$ for $1 \mathrm{hr}$. Then the mixture was cooled to room temperature and filtered. To the filterate, $10 \mathrm{~mL}$ of $10 \%$ aquoes HOAc, sodium acetate $(10.73 \mathrm{~g}, 0.13 \mathrm{mmol})$ and $\mathrm{CH}_{3} \mathrm{CN}(5.5 \mathrm{~g}, 0.13 \mathrm{mmol})$ were added and stirred at for 90 min. The $\mathrm{pH}$ was raised to 8-9 using $\mathrm{KHCO}_{3}$ and the organic material was extracted to 
EtOAc. Ethyl acetate layer was dried using brine and concentrated. The dry organic mixture was column chromatographed to obtain $76\left(1 \mathrm{~g}, \mathrm{R}_{\mathrm{f}}\right.$ value $=0.31$ with $2 \% \mathrm{MeOH}$ in EtOAc in hexane) ${ }^{1} \mathrm{H}$ NMR (DMSO, $\left.500 \mathrm{MHz}\right): \delta$ ppm 7.26 (s, 1H), 6.15 (s, 2H), 4.14 $(\mathrm{q}, \mathrm{J}=7.0 \mathrm{~Hz}, 2 \mathrm{H}), 3.50(\mathrm{~s}, 3 \mathrm{H}), 1.210(\mathrm{t}, \mathrm{J}=7.0 \mathrm{~Hz}, 3 \mathrm{H}) .{ }^{13} \mathrm{C}$ NMR (DMSO, 125.5 MHz): $\delta 159.0,154.3,136.1,116.86,58.9,30.2,14.4$. HRMS (ESI, $\left.[M+H]^{+}\right) \mathrm{m} / \mathrm{z}$ calcd for $\mathrm{C}_{7} \mathrm{H}_{12} \mathrm{O}_{2} \mathrm{~N}_{3} 170.0930$ calculated, found 170.0929 .

\subsubsection{Synthesis of 1-methyl-2-nitro-5-carbethoxyimidazole (77)}

Water $(20 \mathrm{ml})$ was added with $\mathrm{NaNO}_{2}(3 \mathrm{~g})$ and the solution was cooled below $5^{0} \mathrm{C}$. Then, $1.5 \mathrm{~g}$ of $\mathbf{7 6}$ in acetic acid was added drop wise to sodium nitrite solution while maintaining the temperature below $0^{0} \mathrm{C}$. Upon completion of the reaction, ethyl acetate was used to extract organic products. The EtOAc layer was dried using $\mathrm{MgSO}_{4}$. Compound 77 was separated by silica gel chromatography $\left(0.6 \mathrm{~g}, \mathrm{R}_{\mathrm{f}}\right.$ value $=0.5$ in $100 \%$ $\left.\mathrm{CH}_{2} \mathrm{Cl}_{2}\right) .{ }^{1} \mathrm{H}$ NMR $\left(\mathrm{CDCl}_{3}, 500 \mathrm{MHz}\right): \delta \mathrm{ppm} 7.73$ (s, $\left.1 \mathrm{H}\right), 4.38$ (m, 5H), 1.40 (s, 3H). ${ }^{13} \mathrm{C}$ NMR $\left(\mathrm{CDCl}_{3}, 125.5 \mathrm{MHz}\right): \delta 159.0,136.5,134.64,126.6,61.8,35.3,14.1$. HRMS $\left(\mathrm{ESI},[\mathrm{M}+\mathrm{H}]^{+}\right) \mathrm{m} / \mathrm{z}$ calcd for $\mathrm{C}_{7} \mathrm{H}_{10} \mathrm{O}_{4} \mathrm{~N}_{3} 200.0671$ calculated, found 200.0669 .

\subsubsection{Synthesis of 1-methyl-2-nitro-5-carboxylimidazole (78)}

In $10 \mathrm{~mL}$ of $1 \mathrm{~N} \mathrm{NaOH}$ compound $77(0.6 \mathrm{~g}, 3.015 \mathrm{mmol})$ was dissolved and the mixture was stirred overnight. The $\mathrm{pH}$ was adjusted to 1 using conc. $\mathrm{HCl}$. Then the product 78 was extracted to EtOAc and ethyl acetate layer was dried using $\mathrm{MgSO}_{4}(0.6 \mathrm{~g}$, $\mathrm{R}_{\mathrm{f}}$ value $=0.2$ in $100 \%$ EtOAc). ${ }^{1} \mathrm{H}$ NMR (DMSO, $500 \mathrm{MHz}$ ): $\delta \mathrm{ppm} 7.71(\mathrm{~s}, 1 \mathrm{H}), 7.56$ 
(s, acidic H), 4.17 (s, 3H). ${ }^{13} \mathrm{C}$ NMR (DMSO, $\left.125.5 \mathrm{MHz}\right): \delta$ 160.71, 147.8, 134.1, 127.3, 35.4. LRMS (ESI, $[\mathrm{M}+\mathrm{H}]^{+}$) $\mathrm{m} / \mathrm{z}$ calcd for $\mathrm{C}_{5} \mathrm{H}_{6} \mathrm{O}_{4} \mathrm{~N}_{3} 172.03$ calculated, found 172.11 .

\subsubsection{Synthesis of 1-methyl-2-nitro-5-hydroxymethylimidazole (79)}

A mixture of $78(70 \mathrm{mg}, 0.41 \mathrm{mmol})$ and triethylamine $(0.318 \mathrm{~mL}, 0.649 \mathrm{mmol})$ in anhydrous THF $(1 \mathrm{~mL})$ was cooled in dry acetonitrile bath $\left(-20^{\circ} \mathrm{C}\right)$. Isobutyl chloroformate $(100 \mu \mathrm{L}, 7.7 \mathrm{mmol})$ was added dropwise, over $10 \mathrm{~min}$. Then the reaction was stirred over $1 \mathrm{~h}$. Then sodium borohydried $(81 \mathrm{mg})$ was added to the reaction mixture. Then water was added drop wise over a period of $1 \mathrm{~h}$ and the temperature was kept below $0^{0} \mathrm{C}$. The products were extracted to ethyl acetate and dried with brine. Column chromatography separated pure $14\left(30 \mathrm{mg}, \mathrm{R}_{\mathrm{f}}\right.$ value $=0.28$ in $100 \%$ EtOAc $){ }^{1} \mathrm{H} \mathrm{NMR}$ (MeOD, $500 \mathrm{MHz}): \delta$ ppm 7.08 (s, 1H), 4.84 (s, 1H), 4.65 (s, 2H), 4.02 (s, 3H). ${ }^{13} \mathrm{C}$ NMR (MeOD, 125.5 MHz): $\delta$ 147.4, 139.5, 127.6, 54.7, 34.9, HRMS (ESI, $\left.[\mathrm{M}+\mathrm{H}]^{+}\right) \mathrm{m} / \mathrm{z}$ calcd for $\mathrm{C}_{5} \mathrm{H}_{8} \mathrm{O}_{3} \mathrm{~N}_{3} 158.0566$ calculated, found 158. 0575 .

\subsubsection{Synthesis of 3-acetylquinoline-1,2,4-benzotraizine 1,4-dioxide 84}

The compound $33(0.15 \mathrm{~g}, 0.85 \mathrm{mmol})$ was dissolved in dry toluene $(2.5 \mathrm{~mL})$ and the mixture was stirred and heated to $90^{\circ} \mathrm{C}$. Then triphosgene $82(0.086 \mathrm{~g}, 0.29 \mathrm{mmol})$ was added to the TPZ mixture and the reaction was stirred for 5-10 min. Another batch of $82(0.086 \mathrm{~g}, 0.29 \mathrm{mmol})$ was added and then the reaction was cooled to obtain crude $\mathbf{8 3}^{15}$ To the crude 83, $43(0.15 \mathrm{~g}, 0.763 \mathrm{mmol})$ in $2.5 \mathrm{~mL}$ DMF was added and stirred at room temperature for $10 \mathrm{~min}$. The yellow solid product $\mathbf{8 4}$ was separated $\left(0.02 \mathrm{~g}, \mathrm{R}_{\mathrm{f}}\right.$ value $=$

0.1 in $2 \% \mathrm{MeOH}$ in EtOAc). ${ }^{1} \mathrm{H}$ NMR (DMSO, $500 \mathrm{MHz}$ ): $\delta$ ppm 10.45 (s, 1H), 10.30 (s, 
1H), $8.79(\mathrm{~s}, 1 \mathrm{H}), 8.30(\mathrm{~m}, 4 \mathrm{H}), 8.05(\mathrm{~m}, 2 \mathrm{H}), 7.78(\mathrm{~m}, 2 \mathrm{H}), 7.51(\mathrm{~d}, \mathrm{~J}=7.0 \mathrm{~Hz}, 1 \mathrm{H}) .{ }^{13} \mathrm{C}$ NMR (DMSO, $500 \mathrm{MHz}): \delta$ 148.7, 148.3, 145.9, 138.0, 136.6, 135.8, 132.5, 129.7, 128.5, 122.9, 121.9, 121.1, 118.0, 114.0, HRMS (ESI $\left.[\mathrm{M}+\mathrm{H}]^{+}\right) \mathrm{m} / \mathrm{z}$ calcd for $\mathrm{C}_{17} \mathrm{H}_{13} \mathrm{~N}_{6} \mathrm{O}_{3}$ 349.1049 calculated, found 349.1057. 


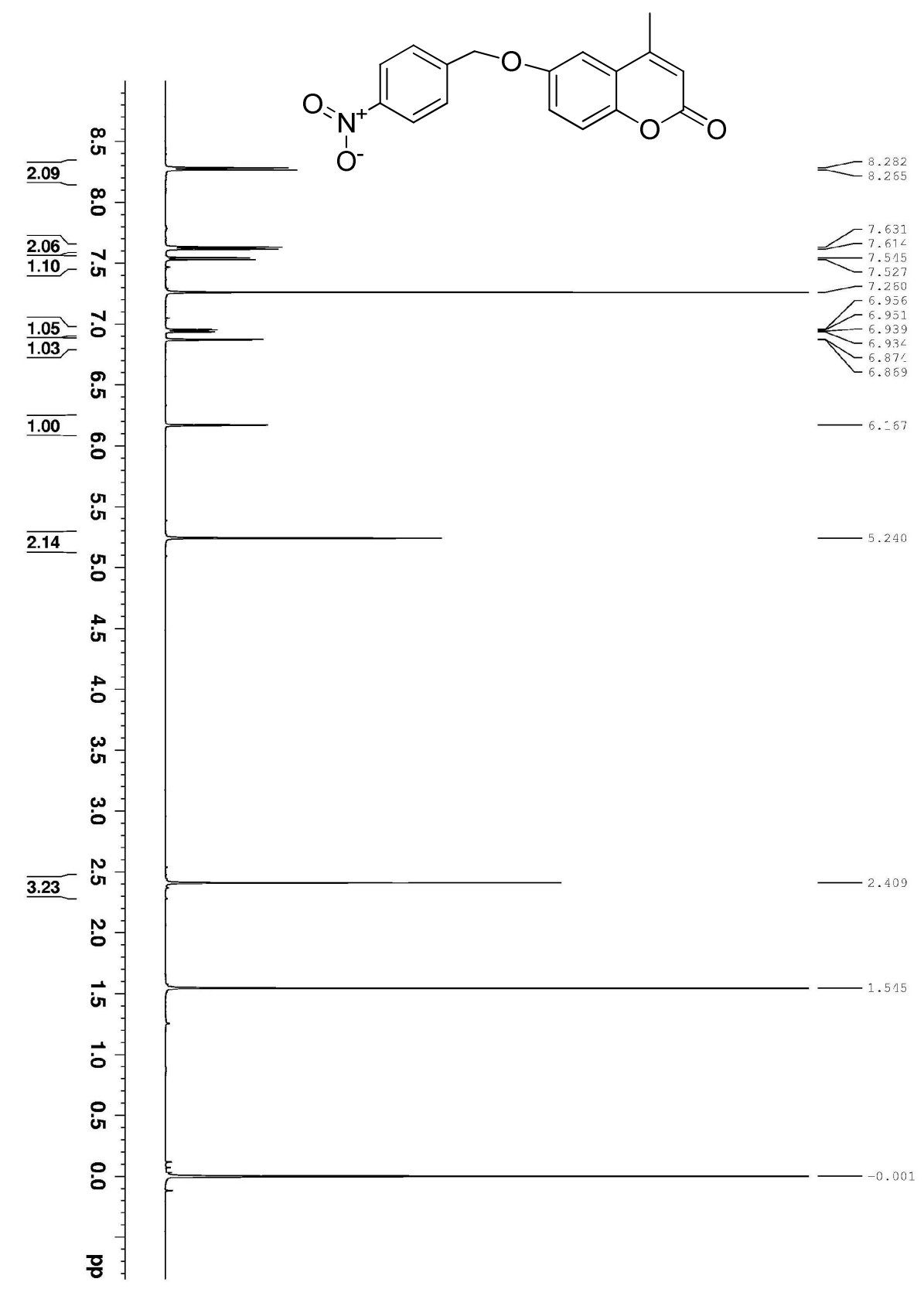

${ }^{1} \mathrm{H}$ NMR of $70\left(\mathrm{CDCl}_{3}, 500 \mathrm{MHz}\right)$ 


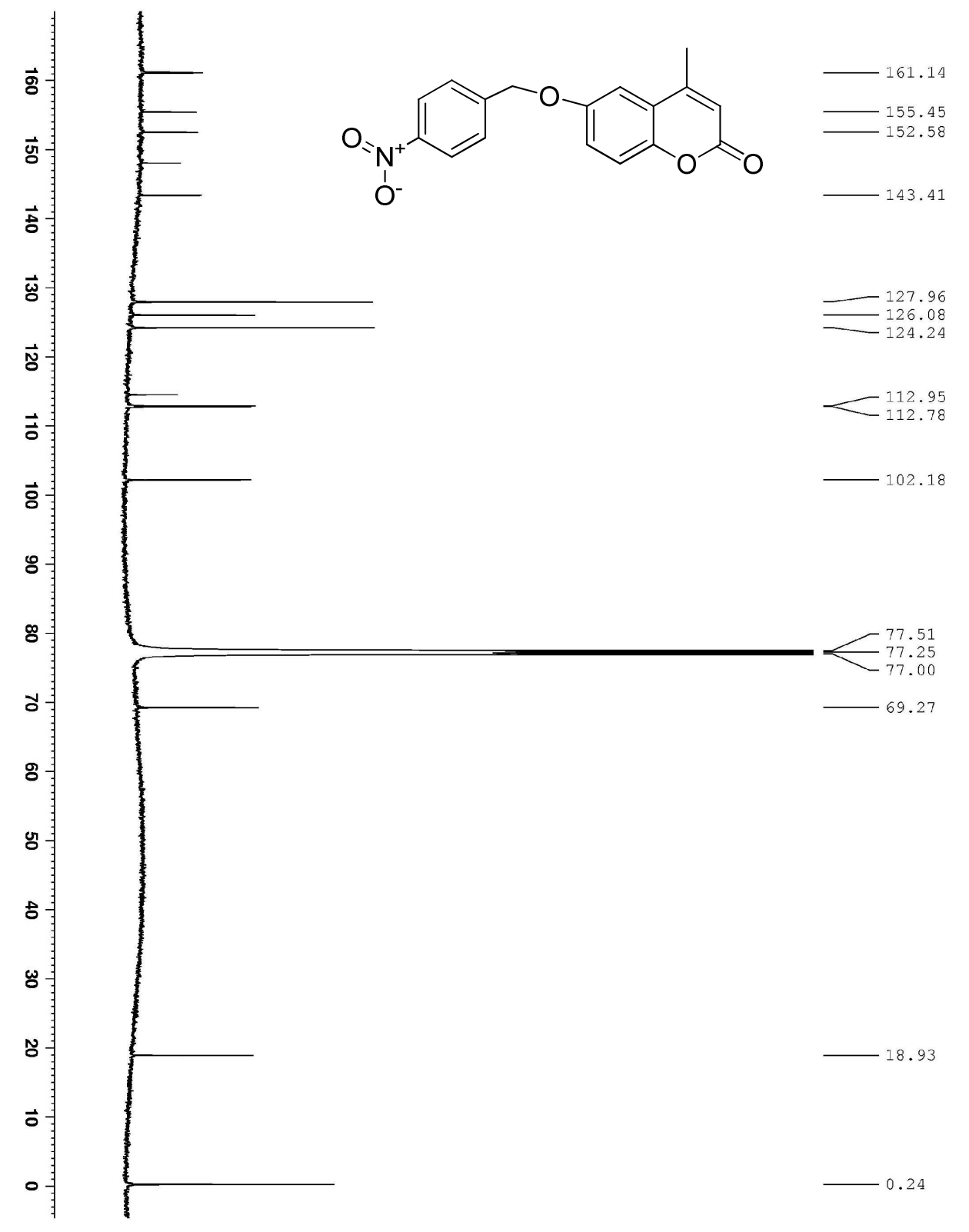

${ }^{13} \mathrm{C}$ NMR of $70\left(\mathrm{CDCl}_{3}, 125.5 \mathrm{MHz}\right)$ 


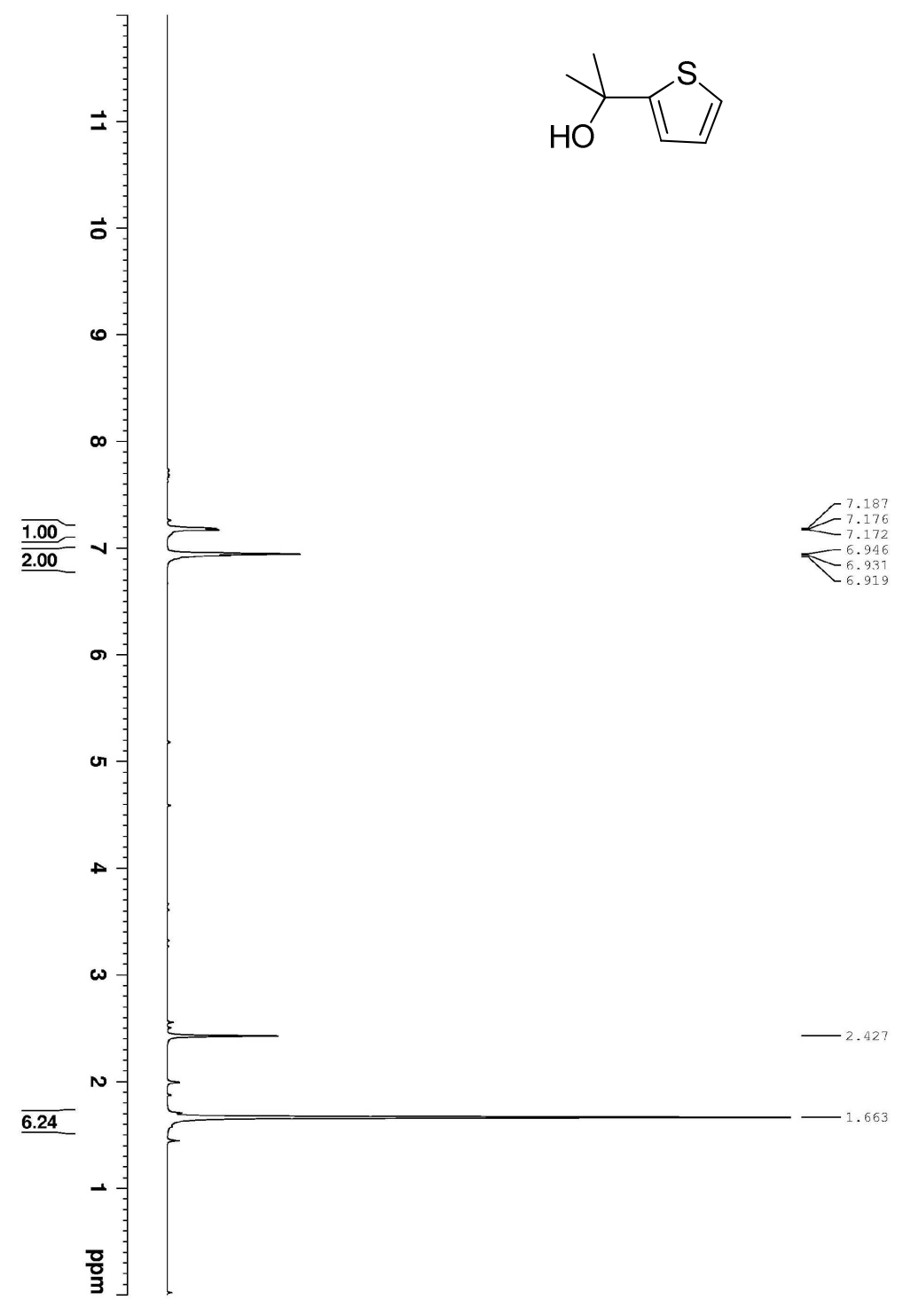

${ }^{1} \mathrm{H} \mathrm{NMR}$ of $72\left(\mathrm{CDCl}_{3}, 300 \mathrm{MHz}\right)$ 


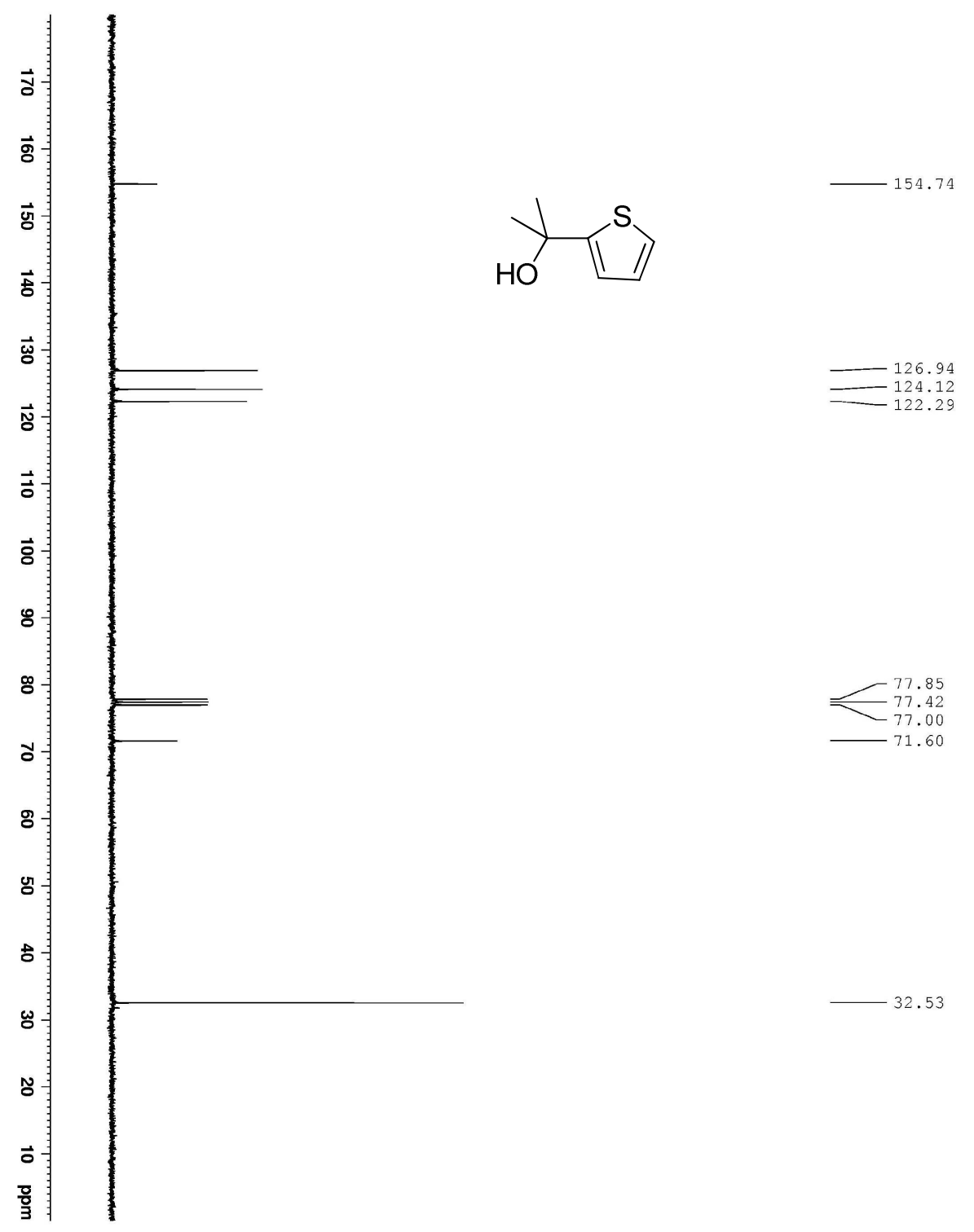

${ }^{13} \mathrm{C} \mathrm{NMR}$ of $72\left(\mathrm{CDCl}_{3}, 75.5 \mathrm{MHz}\right)$ 

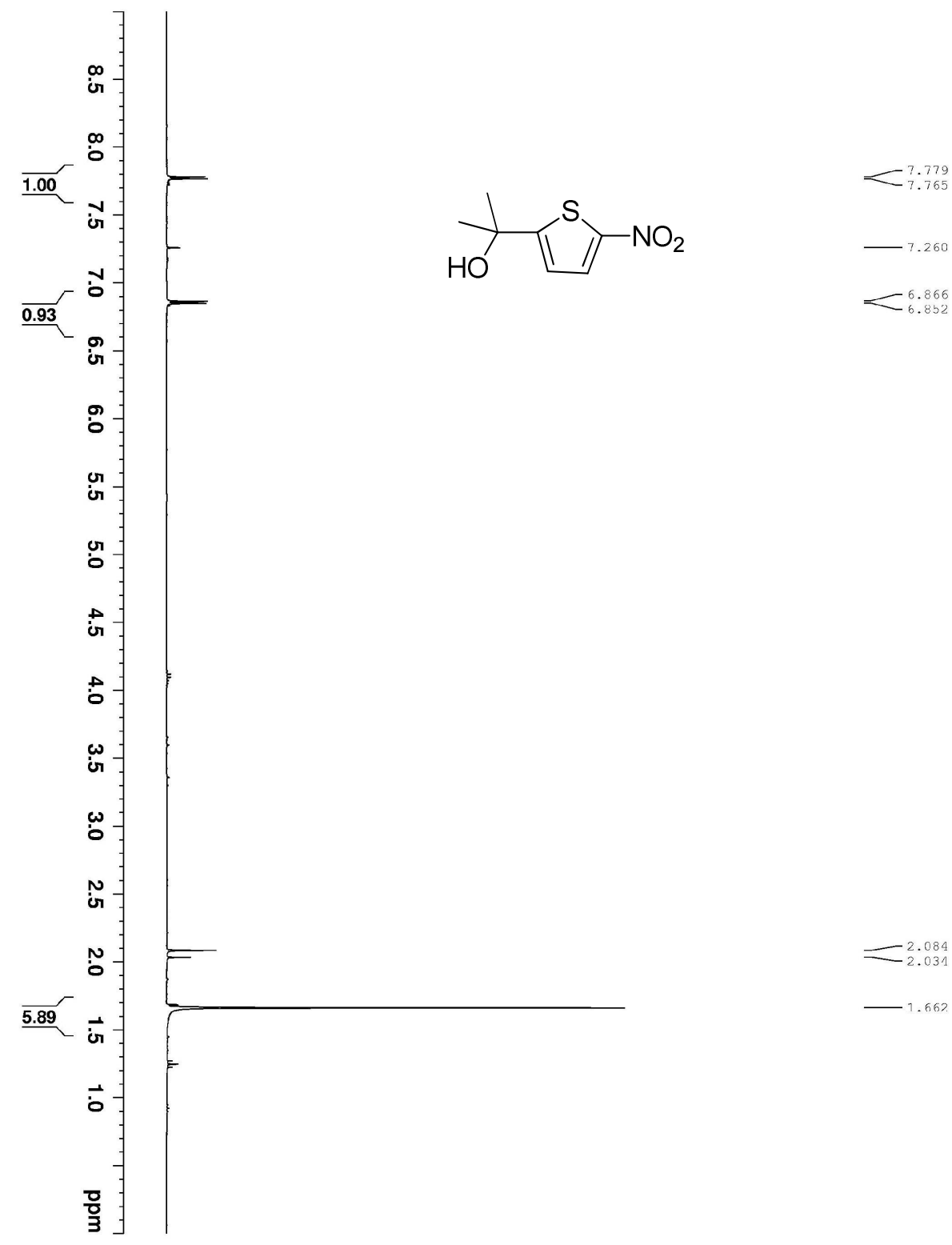

$-7.260$

$<\begin{array}{r}6.866 \\ -6.852\end{array}$

$\bar{Z}_{2.031}^{2.084}$

$-1.662$

\section{${ }^{1} \mathrm{H}$ NMR of $73\left(\mathrm{CDCl}_{3}, 300 \mathrm{MHz}\right)$}



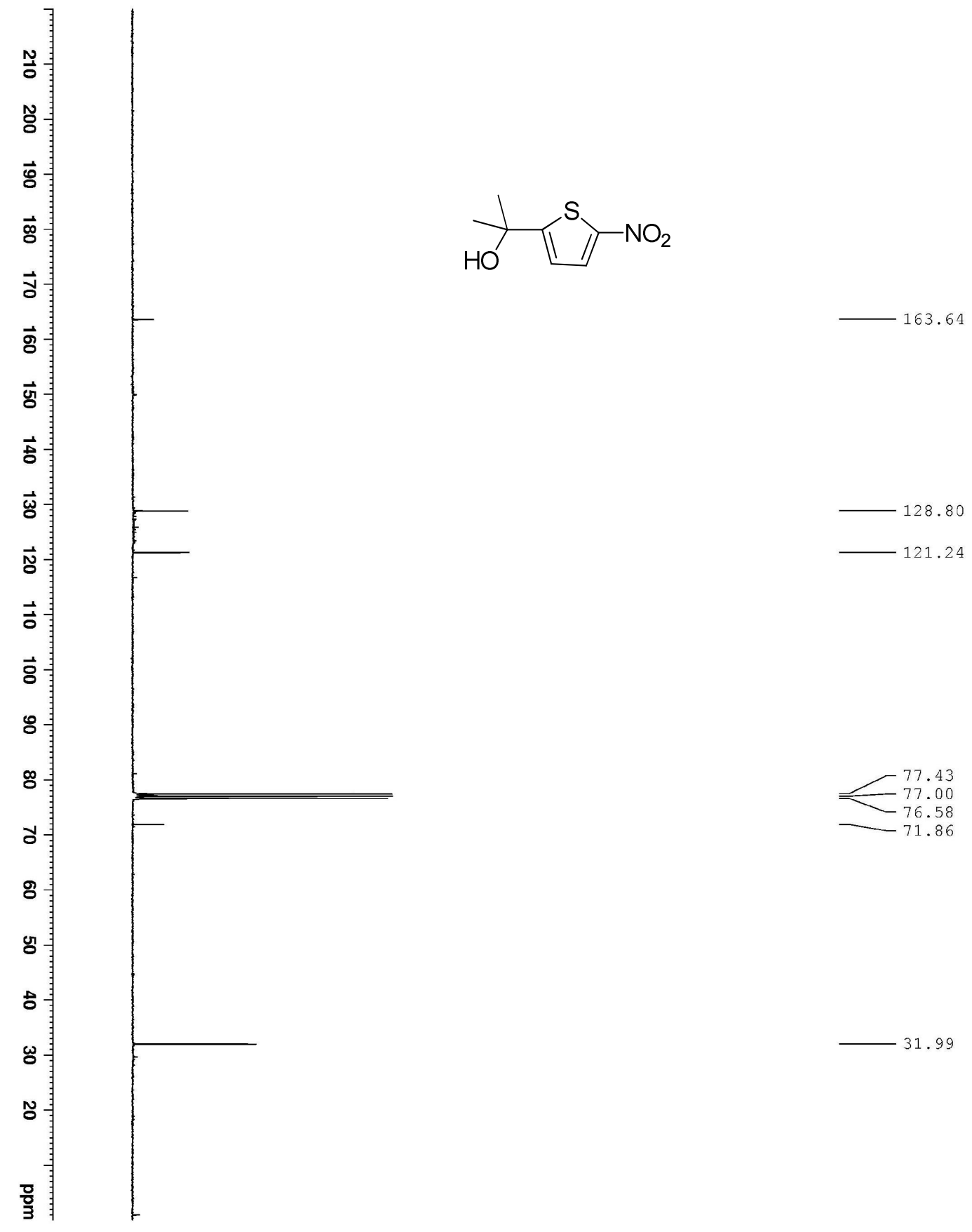

${ }^{13} \mathrm{C}$ NMR of $73\left(\mathrm{CDCl}_{3}, 75.5 \mathrm{MHz}\right)$ 


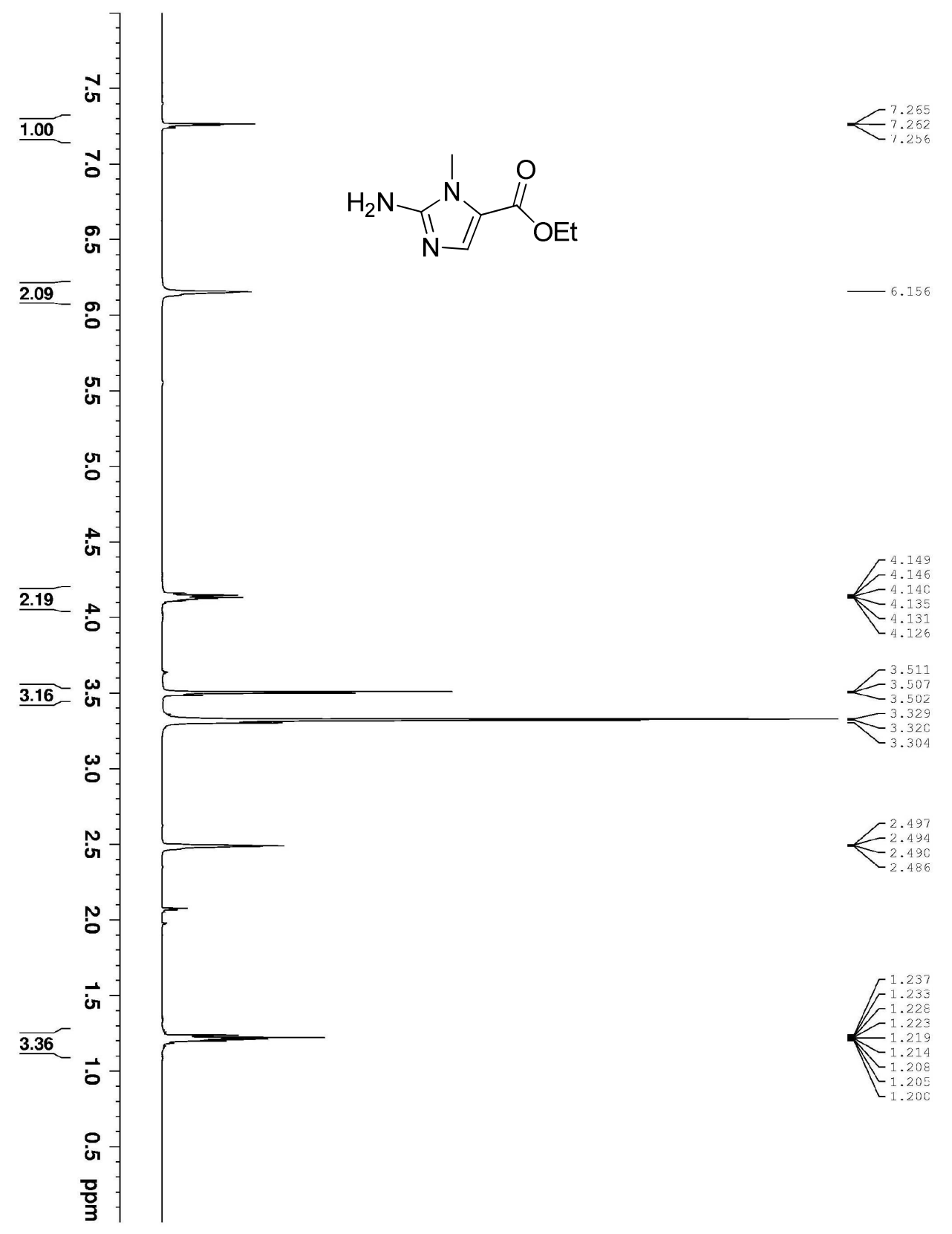

${ }^{1} \mathrm{H}$ NMR of 76 (DMSO, $500 \mathrm{MHz}$ ) 


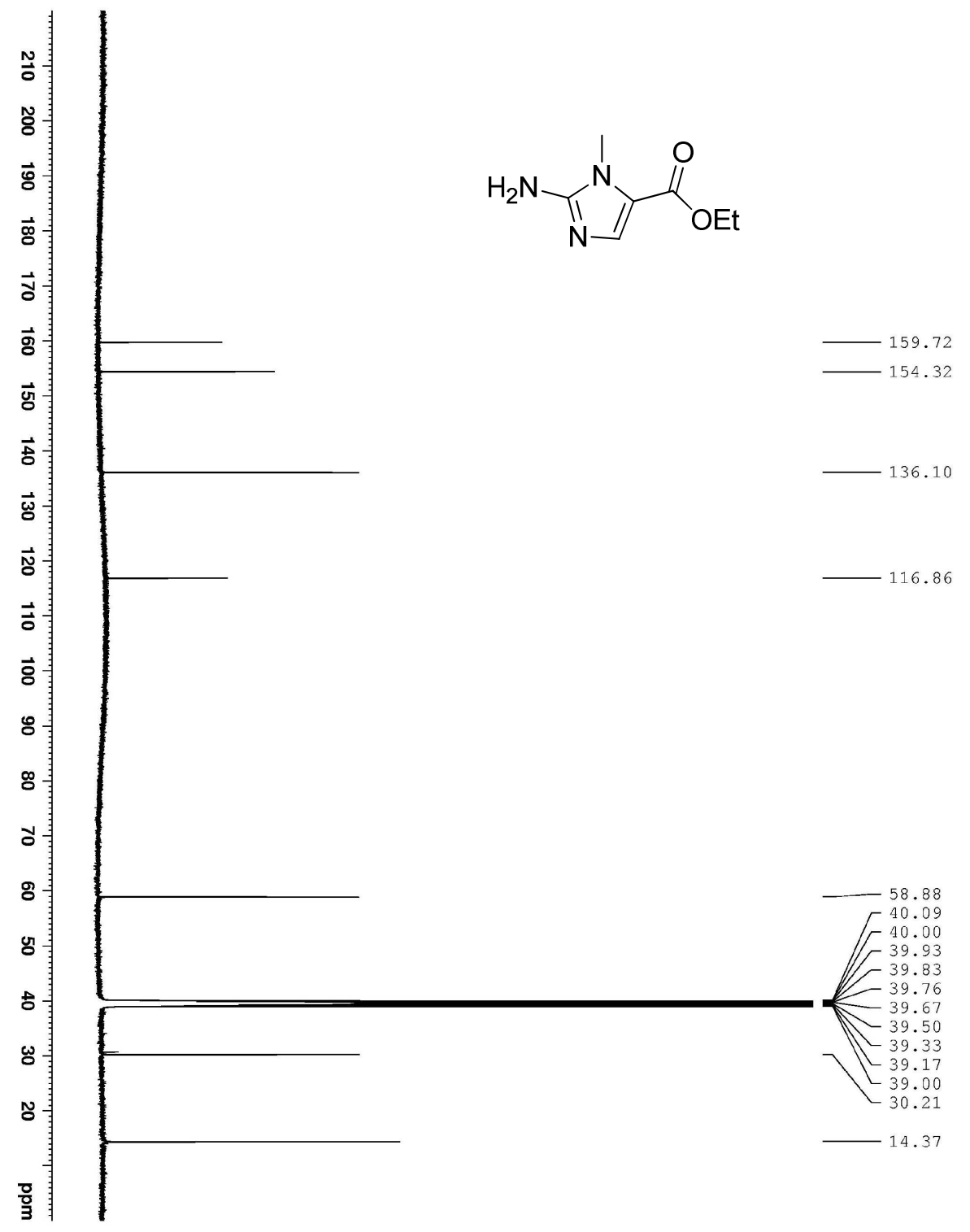

${ }^{13} \mathrm{C}$ NMR of 76 (DMSO, 125.5 MHz) 


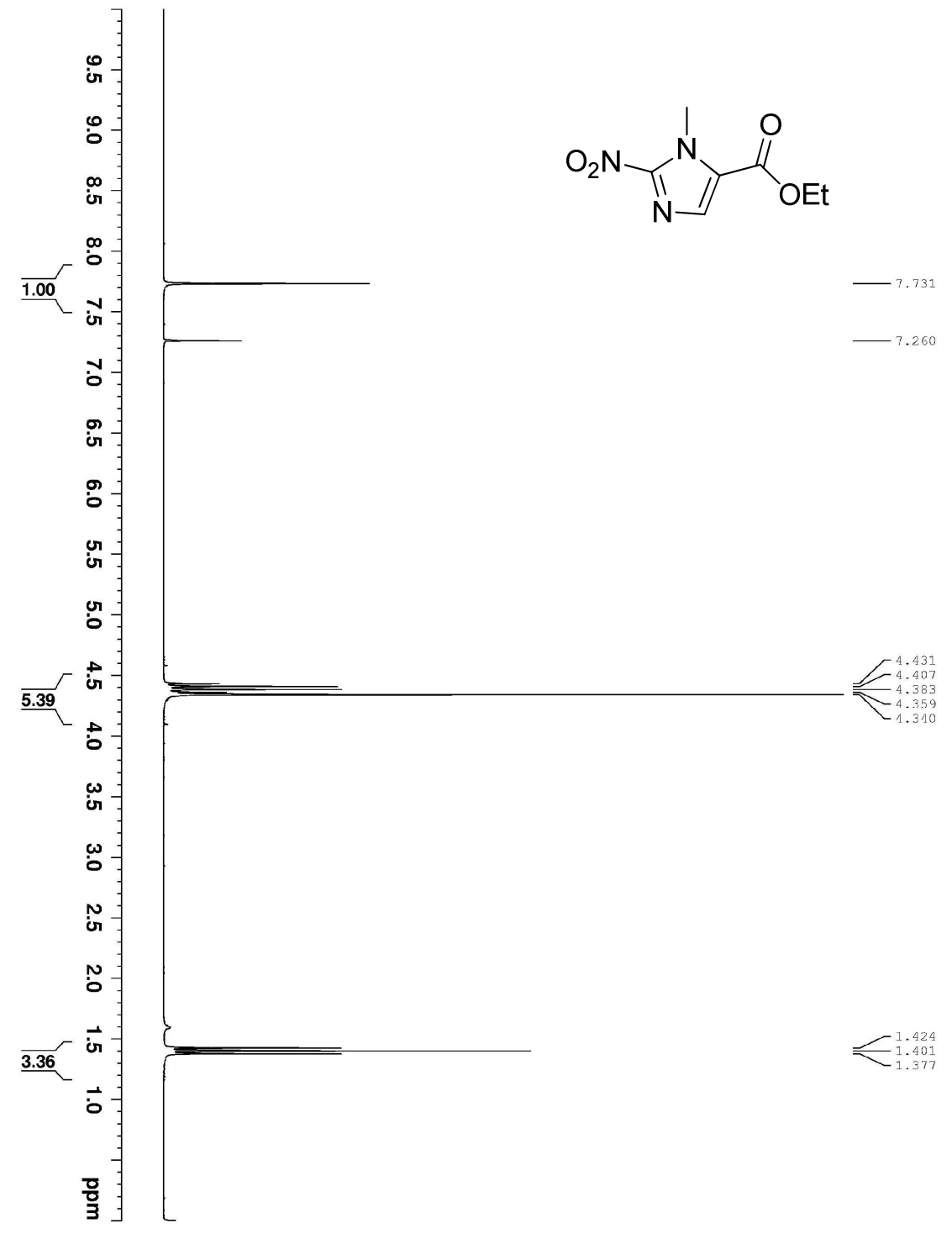

${ }^{1} \mathrm{H} \mathrm{NMR}$ of $77\left(\mathrm{CDCl}_{3}, 500 \mathrm{MHz}\right)$ 


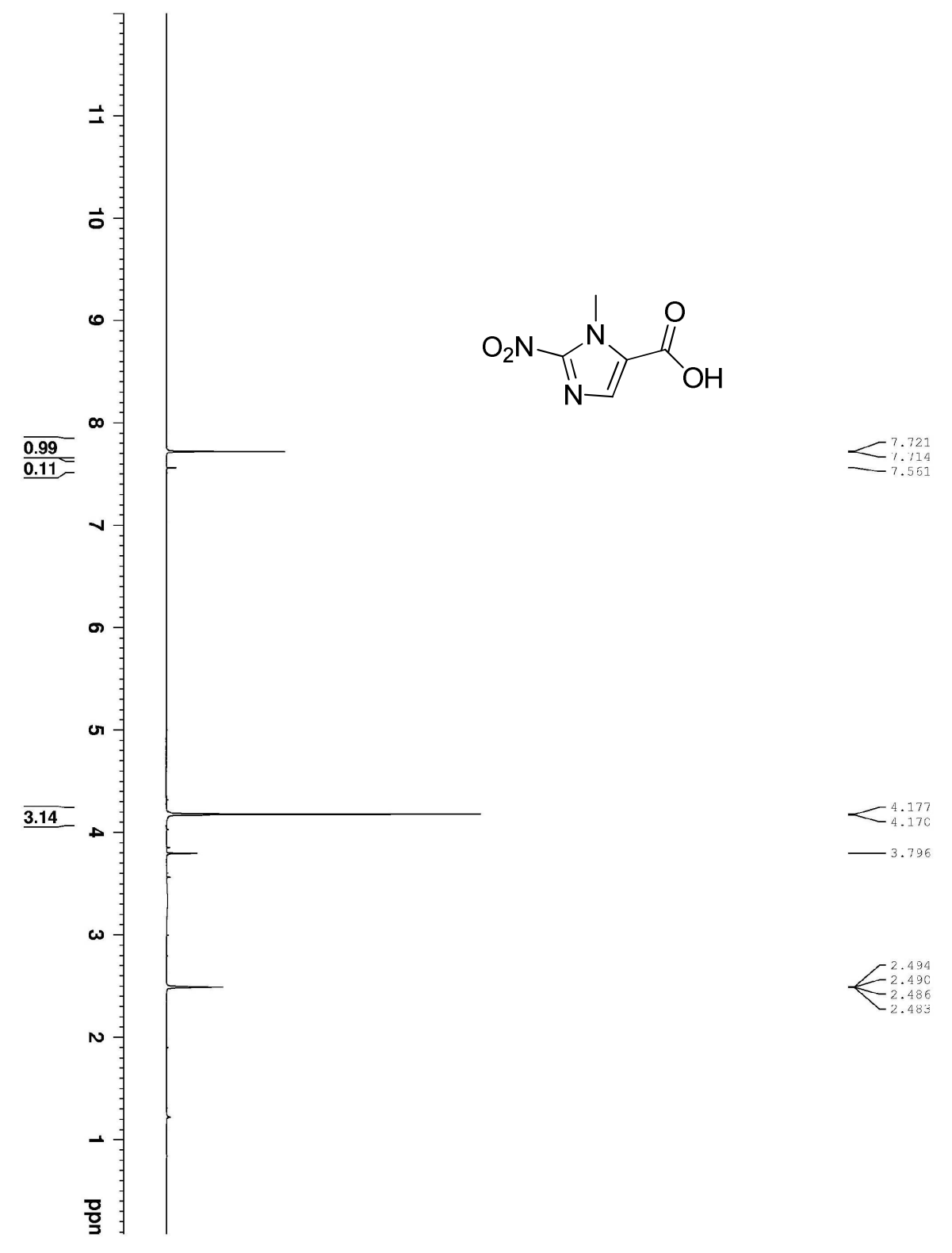

${ }^{1} \mathrm{H}$ NMR of 78 (DMSO, $500 \mathrm{MHz}$ ) 


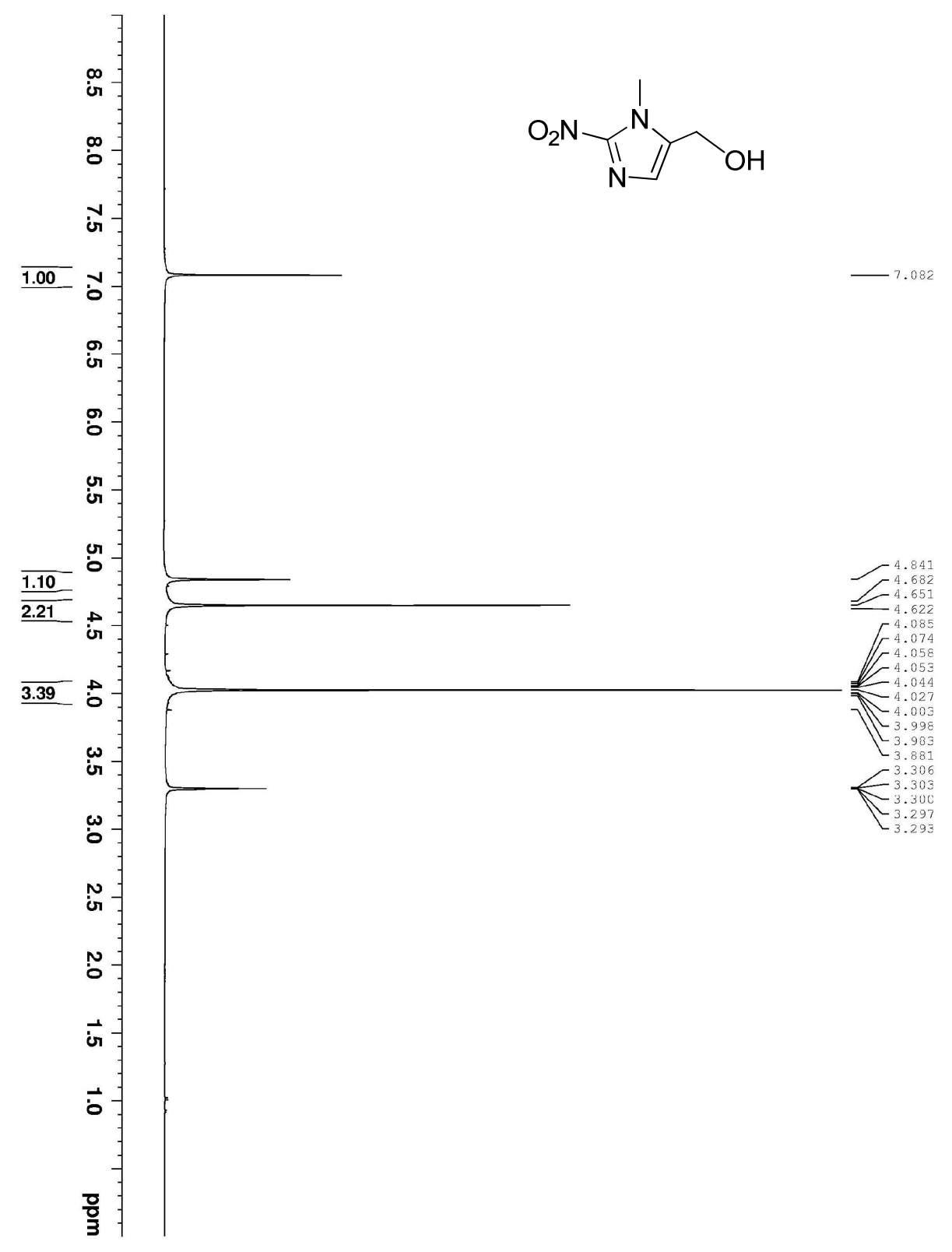

${ }^{1} \mathrm{H}$ NMR of 79 (MeOD, $500 \mathrm{MHz}$ ) 


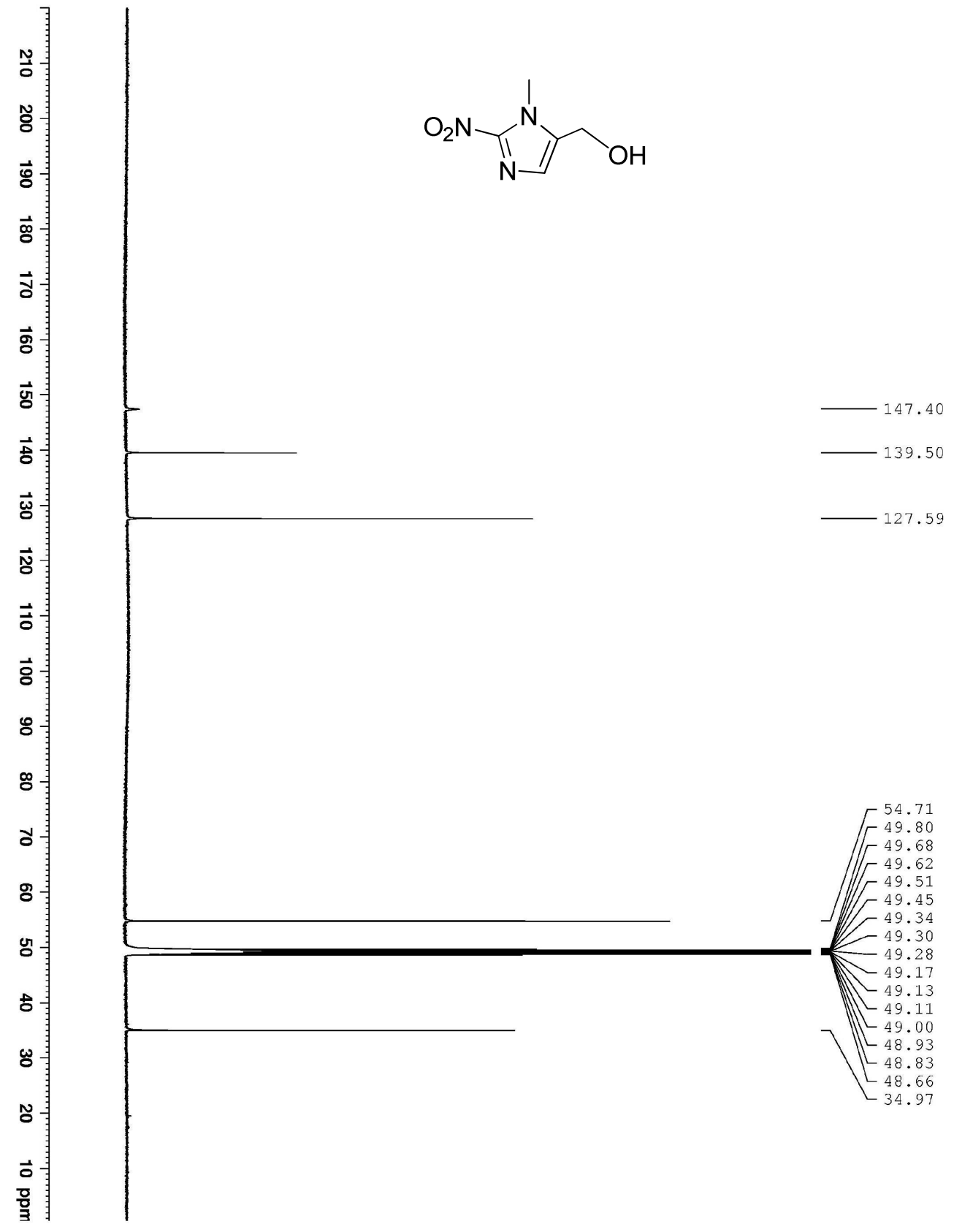

${ }^{13} \mathrm{C}$ NMR of $79(\mathrm{MeOD}, 500 \mathrm{MHz})$ 


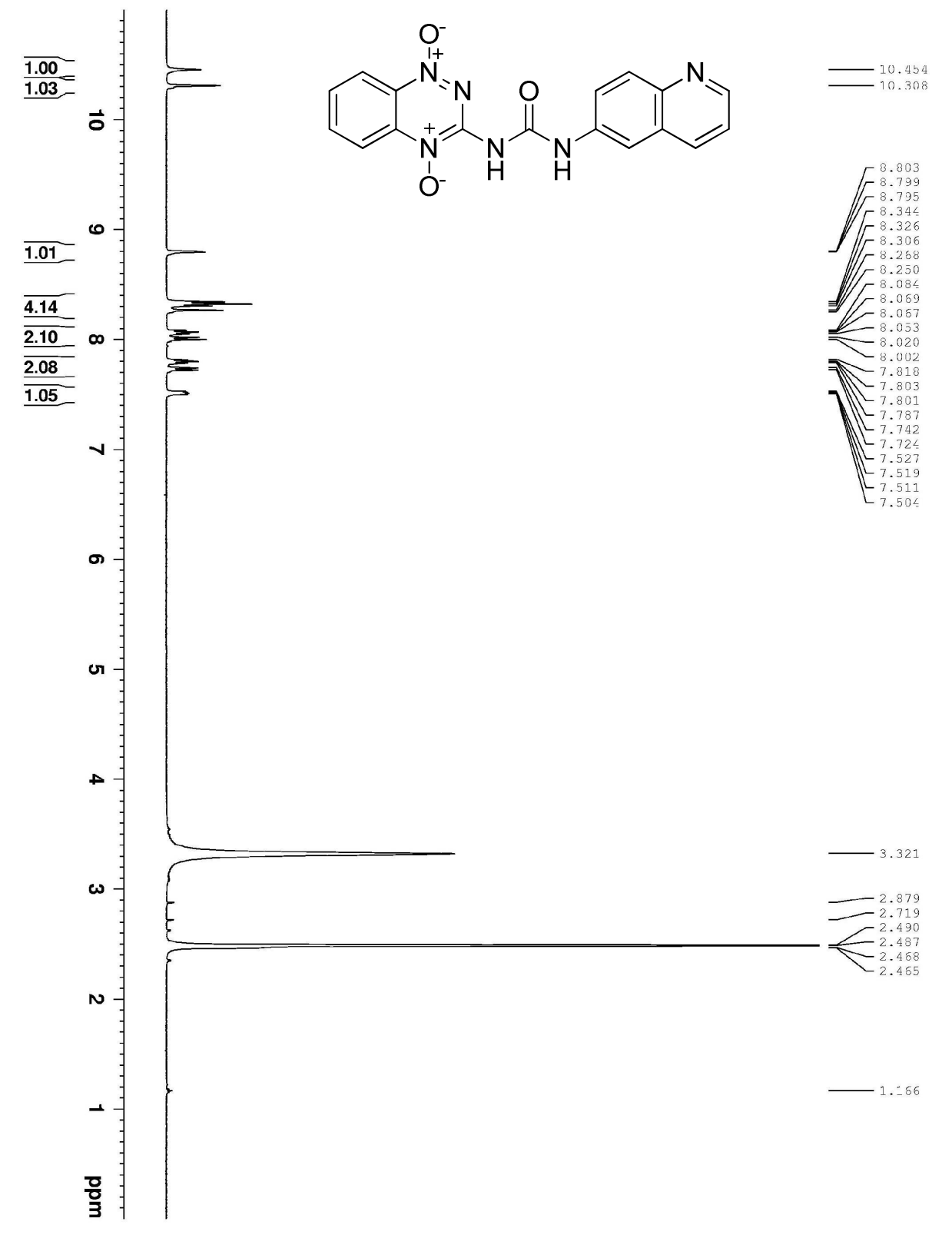

${ }^{1} \mathrm{H}$ NMR of 84 (MeOD, $\left.500 \mathrm{MHz}\right)$ 


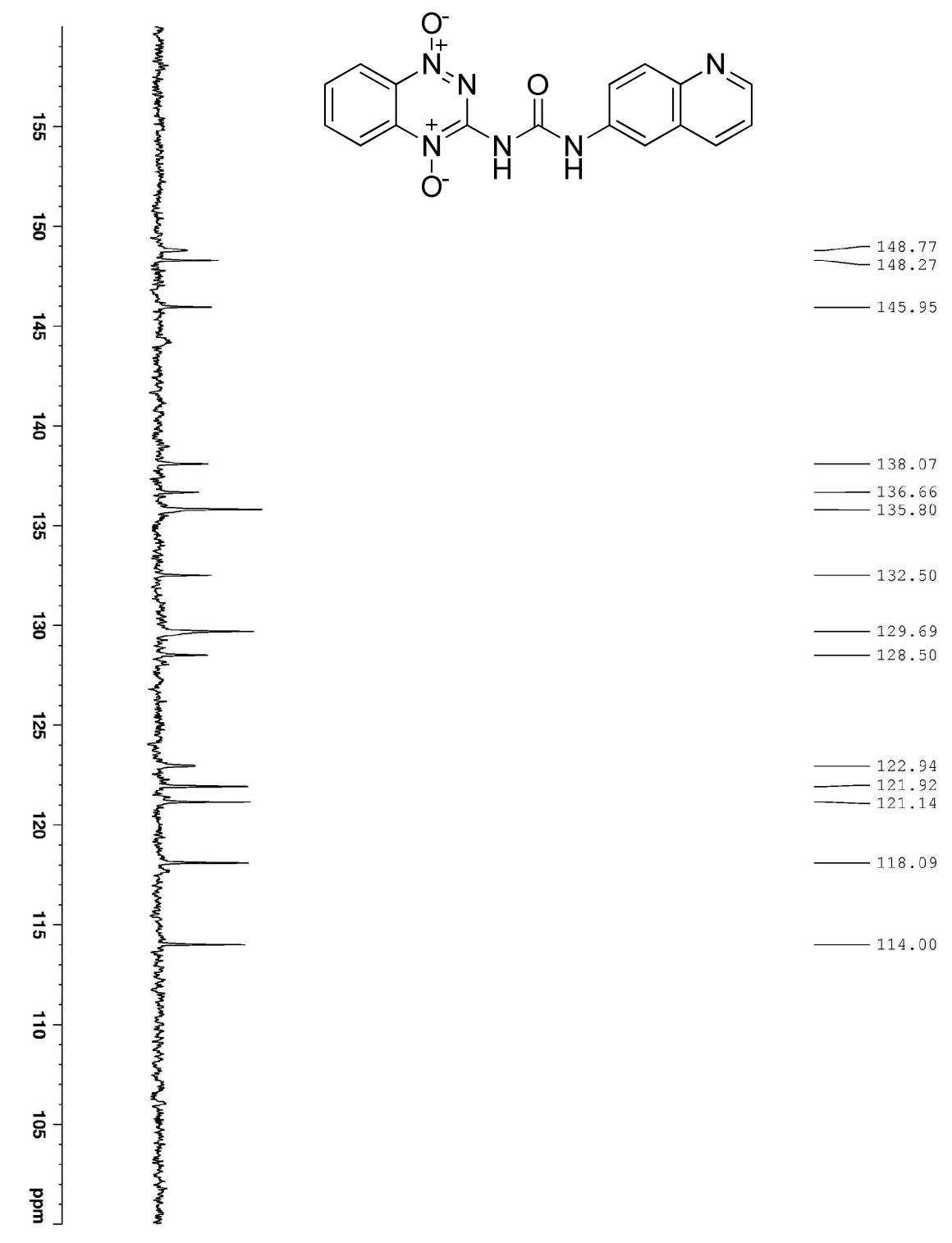

${ }^{13} \mathrm{C}$ NMR of $84(\mathrm{MeOD}, 125.7 \mathrm{MHz})$ 


\section{References for chapter 5}

1. Hay, M. P.; Pchalek, K.; Pruijn, F. B.; Hicks, K. O.; Siim, B. G.; Anderson, M. M.; Shinde, S. S.; Denny, W. A.; Wilson, W. R., Hypoxia-selective 3-alkyl 1,2,4benzotriazine 1,4-dioxides: the influences of hydrogen bond donors on extravascular transport and antitumor activity. J. Med. Chem. 2007, 50 (26), 6654-6664.

2. (a) Koch, C. J., Measurements of absolute oxygen levels in cells and tissues using oxygen sensors and 2-nitroimidazole EF5. Methods Enzymol. 2002, 352, 3-31; (b) Nordsmark, M.; Loncaster, J.; Aquino-Parsons, C.; Chou, S.-C.; Ladekarl, M.; Havsteen, H.; Lindegaard, J. C.; Davidson, S. E.; Varia, M.; West, C.; Hunter, R.; Overgaard, J.; Raleigh, J. A., Measurements of hypoxia using pimonidazole and polarographic oxygensensitive electrodes in human cervix carcinomas. Radiother. Oncol. 2003, 67, 35-44; (c) Ueda, M.; Kudo, T.; Mutou, Y.; Umeda, I. O.; Miyano, A.; Ogawa, K.; Ono, M.; Fujii, H.; Kizaka-Kondoh, S.; Hiraoka, M.; Saji, H., Evaluation of [125I]IPOS as a molecular imaging probe for hypoxia-inducible factor-1-active regions in a tumor: comparison among single-photon emission computed tomography/X-ray computed tomography imaging, autoradiography, and immunohistochemistry. Cancer Sci. 2011, 102 (Copyright (C) 2012 American Chemical Society (ACS). All Rights Reserved.), 2090-2096.

3. Dai, M.; Zhu, W.; Xu, Y.; Qian, X.; Liu, Y.; Xiao, Y.; You, Y., Versatile nitrofluorophore as highly effective sensor for hypoxic tumor cells: design, imaging, and evaluation. J. Fluoresc. 2008, 18 (2), 591-597.

4. (a) Okuda, K.; Okabe, Y.; Kadonosono, T.; Ueno, T.; Youssif, B. G. M.; KizakaKondoh, S.; Nagasawa, H., 2-Nitroimidazole-Tricarbocyanine Conjugate as a NearInfrared Fluorescent Probe for in Vivo Imaging of Tumor Hypoxia. Bioconjugate Chem. 2012, 23 (Copyright (C) 2012 American Chemical Society (ACS). All Rights Reserved.), 324-329; (b) Youssif, B. G. M.; Okuda, K.; Kadonosono, T.; Abdel, R. S. O. I.; Hayallah, A. A. M.; Hussein, M. A.; Kizaka-Kondoh, S.; Nagasawa, H., Development of a hypoxiaselective near-infrared fluorescent probe for non-invasive tumor imaging. Chem. Pharm. Bull. 2012, 60 (Copyright (C) 2012 American Chemical Society (ACS). All Rights Reserved.), 402-407.

5. Borch, R. F.; Liu, J.; Schmidt, J. P.; Marakovitz, J. T.; Joswig, C.; Gipp, J. J.; Mulcahy, R. T., Synthesis and evaluation of nitroheterocyclic phosphoramidates as hypoxia-selective alkylating agents. J. Med. Chem. 2000, 43, 2258-2265. 
6. Sun, W. C.; Gee, K. R.; Haugland, R. P., Synthesis of novel fluorinated coumarins: excellent UV-light excitable fluorescent dyes. Bioorg Med Chem Lett 1998, 8 (Copyright (C) 2012 U.S. National Library of Medicine.), 3107-10.

7. Thomson, P.; Naylor, M. A.; Stratford, M. R. L.; Lewis, G.; Hill, S.; Patal, K. B.; Wardman, P.; Davis, P. D., Hypoxia-driven elimination of thiopurines from their nitrobenzyl prodrugs. Bioorg. Med. Chem. Lett. 2007, 17, 4320-4322.

8. (a) Threadgill, M. D.; Webb, P.; O'Neill, P.; Naylor, M. A.; Stephens, M. A.; Stratford, I. J.; Cole, S.; Adams, G. E.; Fielden, E. M., Synthesis of a series of nitrothiophenes with basic or electrophilic substituents and evaluation as radiosensitizers and as bioreductively activated cytotoxins. J. Med. Chem. 1991, 34 (Copyright (C) 2012 American Chemical Society (ACS). All Rights Reserved.), 2112-20; (b) Firestone, A.; Mulcahy, R. T.; Borch, R. F., Nitro heterocycle reduction as a paradigm for intramolecular catalysis of drug delivery to hypoxic cells. J. Med. Chem. 1991, 34 (Copyright (C) 2012 American Chemical Society (ACS). All Rights Reserved.), 2933-5.

9. Naylor, M. A.; Thomson, P., Recent advances in bioreductive drug targeting. Mini-Rev. Med. Chem. 2001, 1 (Copyright (C) 2012 American Chemical Society (ACS). All Rights Reserved.), 17-29.

10. Thomson, P.; Naylor, M. A.; Everett, S. A.; Stratford, M. R. L.; Lewis, G.; Hill, S.; Patel, K. B.; Wardman, P.; Davis, P. D., Synthesis and biological properties of bioreductively targeted nitrothienyl prodrugs of combretastatin A-4. Mol. Cancer. Ther. 2006, 5 (11), 2886-2894.

11. Hay, M. P.; Sykes, B. M.; Denny, W. A.; Wilson, W. R., A 2-nitroimidazole carbamate prodrug of 5-amino-1-(chloromethyl)-3-[(5,6,7-trimethoxyindol-2yl)carbonyl]-1,2-dihydro-3H-ben[E]indole (amino-seco-CBI-TMI) for use with ADEPT and GDEPT. Bioorg. Med. Chem. Lett. 1999, 9, 2237-2242.

12. (a) Lancini, G. C.; Lazzari, E.; Arioli, V.; Bellani, P., Synthesis and relationship between structure and activity of 2-nitroimidazole derivatives. J. Med. Chem. 1969, 12 (Copyright (C) 2012 American Chemical Society (ACS). All Rights Reserved.), 775-80; (b) Cavalleri, B.; Ballotta, R.; Arioli, V.; Lancini, G., New 5-substituted 1-alkyl-2nitroimidazoles. J. Med. Chem. 1973, 16 (Copyright (C) 2012 American Chemical Society (ACS). All Rights Reserved.), 557-60.

13. Parveen, I.; Naughton, D. P.; Whish, W. J. D.; Threadgill, M. D., 2Nitroimidazol-5-ylmethyl as a potential bioreductively activated prodrug system: 
reductively triggered release of the PARP inhibitor 5-bromoisoquinolinone. Bioorg. Med. Chem. Lett. 1999, 9 (Copyright (C) 2012 American Chemical Society (ACS). All Rights Reserved.), 2031-2036.

14. Everett, S. A.; Naylor, M. A.; Patel, K. B.; Stratford, M. R. L.; Wardman, P., Bioreductively-activated prodrugs for targeting hypoxic tissues: elimination of aspirin from 2-nitroimidazole derivatives. Bioorg. Med. Chem. Lett. 1999, 9, 1267-1272.

15. Posakony, J. J.; Pratt, R. C.; Rettig, S. J.; James, B. R.; Skov, K. A., Porphyrins incorporating heterocyclic N-oxides: (oxidopyridyl)porphyrins, porphyrin-N-oxides, and a tirapazamine-porphyrin conjugate. Can. J. Chem. 1999, 77 (Copyright (C) 2012 American Chemical Society (ACS). All Rights Reserved.), 182-198. 


\section{VITA}

Anuruddha Rajapakse, the second son among three sons of Raja Rajapaksa and Sunethra Dias Weerasinghe was born July 2, 1979, in Colombo, Sri Lanka. He received primary education from St' John's College, Nugegoda and completed his secondary education at Asoka Vidyalaya, Colombo. He entered University of Peradeniya in Kandy, Sri Lanka and received a chemistry-special degree from the faculty of science. Upon completing bachelors, he entered University of Missouri-Columbia to pursue his $\mathrm{PhD}$ in Chemistry. He worked as a graduate student with Dr. Kent S. Gates and received Breckenridge/Lyons outstanding graduate research award from the department of Chemistry in 2012. 